THIS DOCUMENT CONFIRMED AS UNCLASSIFIED DIVISION OF CLASSIFICATION

BY QH Kahnlamh DATE $9 / 14170$ 


\section{DISCLAIMER}

This report was prepared as an account of work sponsored by an agency of the United States Government. Neither the United States Government nor any agency Thereof, nor any of their employees, makes any warranty, express or implied, or assumes any legal liability or responsibility for the accuracy, completeness, or usefulness of any information, apparatus, product, or process disclosed, or represents that its use would not infringe privately owned rights. Reference herein to any specific commercial product, process, or service by trade name, trademark, manufacturer, or otherwise does not necessarily constitute or imply its endorsement, recommendation, or favoring by the United States Government or any agency thereof. The views and opinions of authors expressed herein do not necessarily state or reflect those of the United States Government or any agency thereof. 


\section{DISCLAIMER}

Portions of this document may be illegible in electronic image products. Images are produced from the best available original document. 


\section{LEGAL NOTICE}

This report was prepared as an account of work sponsored by the United States Government. Neither the United States nor the United States Atomic Energy Commission, nor any of their employees, nor any of their contractors, subcontractors, or their employees, makes any warranty, express or implied, or assumes any legal liability or responsibility for the accuracy, completeness or usefulness of any information, apparatus, product or process disclosed, or represents that its use would not infringe privately owned rights.

\section{DXIDE FUEL ELEMENT DEVELOPMENT}

QUUARTERLY PROGRESS REPORT

FOR THE PERIOD ENDING MARCH 31, 1970

Approved by:

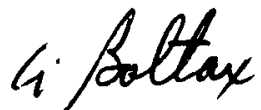

A. Boltax

Principal Investigator

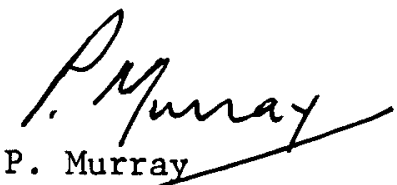

Preject Manager

Contract AT (30-1)-4135

U. S. Atomic Energy Commission

Submitted to AEC-NYOO in July 1970

\footnotetext{
Westinghouse Electric Corporation

Advanced Reactors Division

P. 0. Box 158

Madison, Pennsylvania 15663
} 


\section{LEGAL NOTICE}

This report was prepared as an account of Government sponsored work. Neither the United States, nor the Commission, nor any person acting on behalf of the Commission:

A. Makes any warranty or representation, expressed or implied, with respect to the accuracy, completeness, or usefulness of the information contained in this report, or that the use of any information, apparatus, method, or process disclosed in this report may not infringe privately owned rights; or

B. Assumes any liabilities with respect to the use of, or for damages resulting from the use of any information, apparatus, method, or process disclosed in this report.

As used in the above, "person acting on behalf of the Commission" includes any employe or contractor of the Commission, or employe of such contractor, to the extent that such employe or contractor of the Commission, or employe of such contractor prepares, disseminates, or provides access to, any information pursuant to his employment or contract with the Commission, or his employment with such contractor.

Fiented in the United states of America Avallibl, Ion

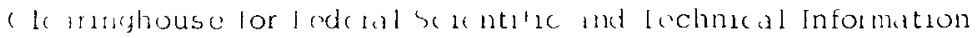

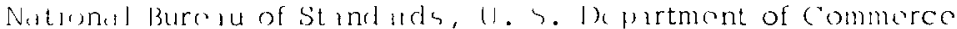

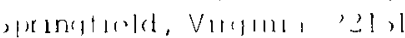

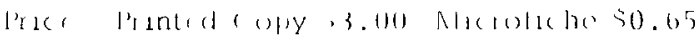


INTRODUCTION........................... 1-1

General. ................................

Summary of objectives........................

Summary of Prior Work.......................

Summary of Current Progress..................... 1-2

OFBA-210...........................

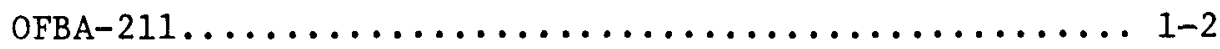

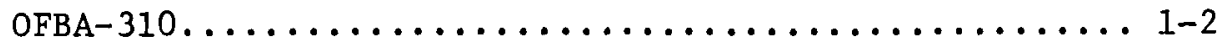

OFBA-311.............................

OFBA-312..............................

OFBA-313.............................

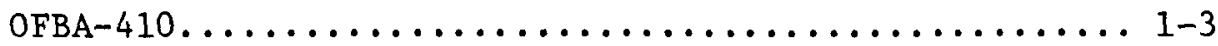

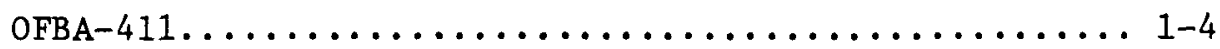

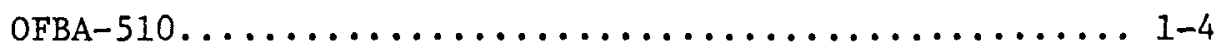

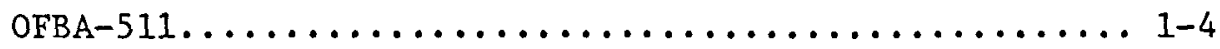

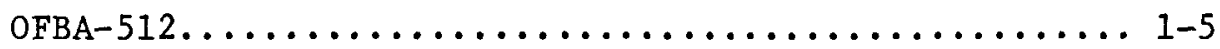

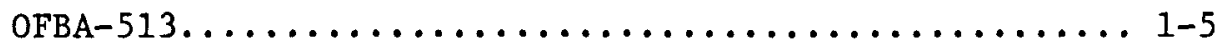

2 OFBA-110 PROJECT ADMINISTRATION................. 2-1

Objectives............................. 2-1

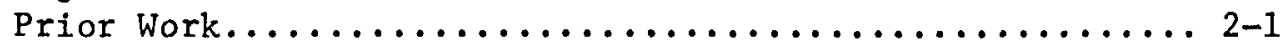

Current Progress........................... 2-2

3 OFBA-210 FUEL PERFORMANCE ANALYSIS................ $3-1$

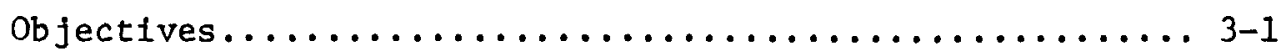

Prior Work................................

Current Progress........................... 3-1

OLYMPUS-II Development................... 3-1

Irradiation-Induced Creep................... 3-5

Initial Code Applications.................... 3-7

Stress Effects on Void Growth.................. 3-10

4 OFBA-211 DEVELOPMENT OF ANALYTICAL METHODS AND FUEL LIFETIME

CODES....................................

Objectives............................ 4-1

Prior Work. ................................ $4-1$

Current Progress.......................... 4-2

Code Improvements.......................4-2

Experimental Pin Analysis.................... 4-2 
Pin Parameter Sensitivity Study...............4-5

Axial Deformation Analysis.................. 4-9

Objectives............................

Prior Work............................. $5-1$

Current Progress..........................

Design of Fuel Motion Restrictors and Fuel Pin...... 5-1 Thermal Analysis........................ 5-1

Stress-Strain Analysis.................... 5-11

Objectives..............................6-1

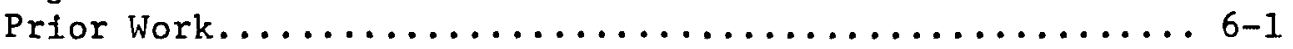

Current Progress..........................6 6-2

Fuel Pin Design....................... 6-2

Subassembly Design - Nuclear................66-2

Subassembly Design - Thermal................. 6-5

Subassembly Design - Mechanical................ 6-7

Project Activities...................... 6-12

7 OFBA-312 217 PIN GRID-TYPE FUEL ASSEMBLY DESIGN AND

DEVELOPMENT ............................. 7-1

Objectives.............................

Prior Work.............................

Current Progress.......................... 7-1

General............................. 7-1

Preliminary Grid Mechanical Analysis............. 7-1

Parameter Study for FFTF Open Loop Testing.......... 7-2

8 OFBA-313 FABRICATION, DEVELOPMENT, AND TESTING OF LMFBR FUEL ASSEMBLIES .......................... $8-1$

Subtask 1. Hexagonal Grid-Fuel Rod Fretting and Wear Test.................................. 8-1

Objectives........................... 8-1

Prior Work.......................... $8-1$

Current Progress........................ 8-1 


\section{CONTENTS (CONTINUED)}

Section

Page

Subtask 2. Sodium Corrosion of Fuel System Weldments and Brazements.......................... $8-2$

Objectives........................... $8-2$

Prior Work.......................... $8-2$

Not Charged to this Contract............... 8-2

Charged to this Contract.................. $8-2$

Current Progress......................... 8-3

\section{OFBA-410 FABRICATION DEVELOPMENT OF EBR-II GRID-TYPE}

SUBASSEMBLIES ............................ $9-1$

Objectives............................

Prior Work..............................

Current Progress........................... $9-2$

Equipment (Procurement not funded under this contract) 9-2 Materials............................ 9-2

Linear Procurement....................... 9-2

Inner and Outer Can Procurement............... 9-2

Grid Fabrication......................... 9-3

Liner Fabrication......................... $9-7$

Inner Can Fabrication..................... 9-7

Bottom Grid Fabrication................... 9-7

End Fittings....................... 9-8

Subassembly Assembly.................... 9-8

10 OFBA-411 SUBASSEMBLY DESIGN AND HARDWARE........... 10-1

Subtask 1. Subassembly Hardware............... 10-1

objectives............................ 10-1

Prior Work............................. 10-1

Current Progress........................... 10-1

Subtask 2. Flow Testing..................... 10-2

Objectives............................. 10-2

Prior Work............................. 10-2

Current Progress.......................... 10-2

General............................ 10-3

11 OFBA-510 PELLET FABRICATION..................11-1 
Objectives.............................. 11-1

Prior Work............................... 11-1

Work Charged to Contract.................... 11-1

Related Work Not Charged to Contract.............11-1

Current Progress......................... 11-2

Investigation of Process Variables.............11-2

Mixed-Oxide Fuel Fabrication.................. 11-9

12 OFBA-511 FUEL CHARACTERIZATION.................. 12-1

Objectives................................ 12-1

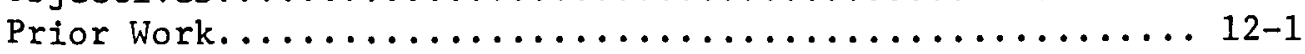

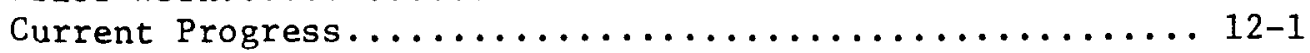

Analytical Chemistry...................... 12-1

Metallography and Audoradiography.............. 12-6

13 OFBA-512 FUEL ELEMENT FABRICATION............... 13-1

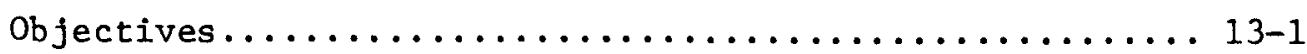

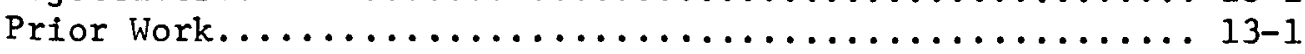

Current Progress............................ 13-1

Vold Deployment Irradiation Assemblies (WSA-1, WSA-2). 13-1

WSA-3 Assembly.......................... 13-14

14 OFBA-513 PRODUCT CONTROL AND DOCUMENTATION........... 14-1

Objectives.............................. 14-1

Prior Work................................. 14-1

Current Progress.......................... 14-1

REFERENCES ............................. 15-1 


\section{CONTENTS (CONTINUED)}

Section

Page

Subtask 2. Sodlum Corrosion of Fuel System Weldments and Brazements........................... 8-2

Objectives........................... $8-2$

Prior Work............................ $8-2$

Not Charged to this Contract.............. $8-2$

Charged to this Contract................. $8-2$

Current Progress...................... 8-3

9 OFBA-410 FABRICATION DEVELOPMENT OF EBR-II GRID-TYPE

SUBASSEMBLIES ........................... 9-1

Objectives.............................. $9-1$

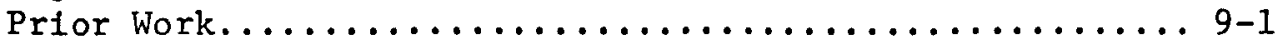

Current Progress........................... $9-2$

Equipment (Procurement not funded under this contract) 9-2

Materials............................. 9-2

Linear Procurement........................ $9-2$

Inner and Outer Can Procurement................ 9-2

Grid Fabrication........................ 9-3

Liner Fabrication.......................... $9-7$

Inner Can Fabrication........................ 9-7

Bottom Grid Fabrication................... 9-7

End Fittings............................ $9-8$

Subassembly Assembly................... 9-8

10 OFBA-411 SUBASSEMBLY DESIGN AND HARDWARE............ 10-1

Subtask 1. Subassembly Hardware................ 10-1

Objectives............................ 10-1

Prior Work.............................. 10-1

Current Progress........................... 10-1

Subtask 2. Flow Testing.................... 10-2

Objectives............................. 10-2

Prior Work............................... 10-2

Current Progress......................... 10-2

General............................. 10-3

11 OFBA-510 PELLET FABRICATION...................11-1 
Objectives..............................

Prior Work...............................

Work Charged to Contract....................11-1 Related Work Not Charged to Contract............. 11-1

Current Progress........................... 11-2

Investigation of Process Variables............ 11-2

Mixed-Oxide Fuel Fabrication.................. 11-9

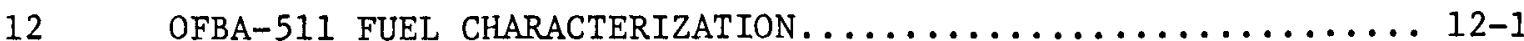

Objectives.............................. 12-1

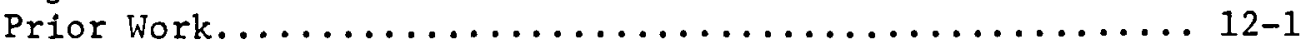

Current Progress......................... 12-1

Analytical Chemistry....................... 12-1

Metallography and Audoradiography............. 12-6

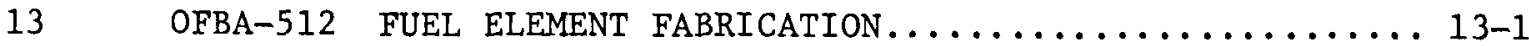

Objectives..............................13-1

Prior Work................................13-1

Current Progress............................13-1

Void Deployment Irradiation Assemblies (WSA-1, WSA-2) . 13-1

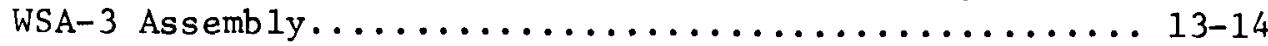

14 OFBA-513 PRODUCT CONTROL AND DOCUMENTATION............ 14-1

Objectives................................ 14-1

Prior Work.................................. 14-1

Current Progress......................... 14-1

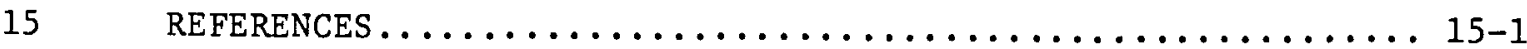


Figure

Page

3-1 OLYMPUS I Flow Diagram............................

3-2 OLYMPUS II Flow Diagram...................... 3-3

3-3 OLYMPUS II Output for FFTF Conditions (high irradiationInduced creep)............................... 3-8

3-4 OLYMPUS II Output for FFTF Conditions (1ow irradiationinduced creep) $\ldots \ldots \ldots \ldots \ldots \ldots \ldots \ldots \ldots \ldots \ldots \ldots \ldots \ldots . \ldots \ldots$

3-5 OLYMPUS II Description of an EBR-II Experimental Pin....... 3-9

3-6 Preliminary Calculation of Stress Effects on Cladding Swelling................................. 3-11

4-1 CYGRO-F Analysis of EBR-II Pin Diametral Strains......... 4-4

4-2 Effect of Pin Parameters on Cladding Diametral Strains...... 4-6

4-3 CYGRO-F Effect of Pellet Denstty on Maximum Cladding Strain.. 4-7

4-4 Effect of Smear Density on Maximum Cladding Strain......... 4-8

4-5 CYGRO-F Effect of Gap on Maximum Cladding Strain......... 4-10

4-6 CYGRO-F Effect of Gap on Maximum Cladding Strain......... 4-10

4-7 Maximum Cladding Strains..................... 4-11

4-8 Maximum Cladding Stresses........................ 4-11

4-9 Effect of Fuel-Cladding Interaction on Axlal Strain Rates... 4-12

5-1 Axial Fuel Motion Restrictor.................... 5-2

5-2 Fue1 Pin Assembly with Axial Fuel Motion Restrictors - Type 1

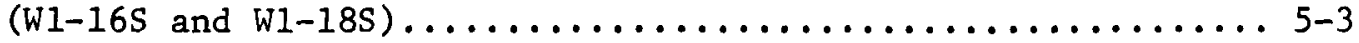

5-3 Fuel Pin Assembly with Axial Fuel Motion Restrictors - Type II

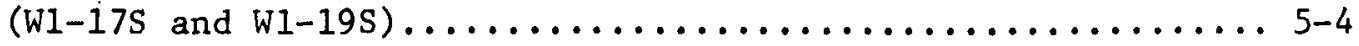

5-4 Capsule Temperature Profiles W1-19S Nominal Conditions....... 5-7

5-5 Capsule Temperature Profiles W1-19S Hot Channel Conditions... 5-8

5-6 Temperature Profiles Near Fuel Motion Restrictor - Beginning of Life Conditions.............................. 5-10

5-7 Temperature Profiles Near Fuel Motion Restrictor - End of Life Conditions.............................. 5-10

5-8 Temperature Profiles Near Fuel Motion Restrictor (Beginning

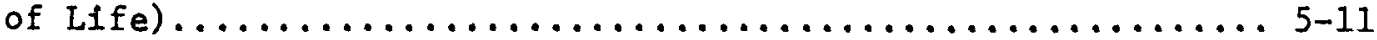

5-9 Difference in Mean Temperature Between Cladding and Restrictor

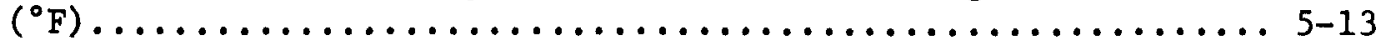

5-10 Axlal straln Profiles - w1-16s.................... 5-14 


\section{LIST OF FIGURES (CONTINUED)}

Figure

Page

5-11 Axial Strain Profiles - W1-17s.................... 5-15

5-12 Axial strain Profiles - w1-18s.................... 5-16

5-13 Axial Strain Profiles - w1-19s..................... 5-16

$6-1 \quad$ Zero Power Ramp Incident.........................6-3

$6-2$ Full Power Ramp Incident........................6-3

$6-3$ Loss of Flow Incident............................ $6-4$

6-4 Coolant Outlet Temperature Distribution for 37-Pin Subassembly with Pitch Distortion...........................6-8

6-5 37-Pin S/A Flow Induced Vibration...................6-9

6-6 EBR-II 37-Pin Subassembly-Allowable Temperature Drop Through Liner Can Wall Vs. Inner Can Mean Temperature.............. 6-10

6-7 Grid Support Strap Deflection Vs. Inner Can Mean Temperature for Grid at Core Outlet...........................6-11

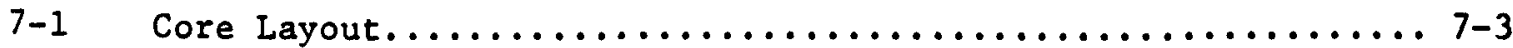

7-2 Spacer Grid Types............................ 7-6

7-3 Effect of Pin Diameter on $\Delta P$ with "Line of S1ght" Grid Design 7-7

7-4 Effect of Pin Diameter on Temperature Distribution......... 7-11

7-5 Effect of Fuel Length, Outlet Temperature and Number of Grids on Pressure Drop............................... 7-15

7-6 Effect of Fuel Length, Outlet Temperature and Grid Number on Pressure Drop............................... 7-16

7-7 Effect of Outlet Temperature on Pressure Drop $(6 \mathrm{kw} / \mathrm{ft}) \ldots \ldots 7-17$

7-8 Effect of Outlet Temperature on Pressure Drop $(8 \mathrm{kw} / \mathrm{ft}) \ldots \ldots 7-18$

7-9 Effect of Outlet Temperature on Pressure Drop (10 kw/ft).... 7-19

7-10 Effect of Number of Grids on Assembly Pressure Drop $\left(1000^{\circ} \mathrm{F}\right.$

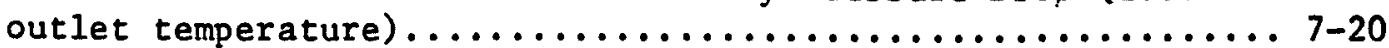

7-11 Effect of Number of Grids on Assembly Pressure Drop $\left(900^{\circ} \mathrm{F}\right.$ outlet temperature).............................. 7-21

7-12 Effect of Grid Strap Thickness on Assembly Pressure Drop $\left(1000^{\circ} \mathrm{F}\right.$ outlet temperature, 16 Honeycomb gr1ds).......... 7-22

7-13 Effect of Grid Strap Thickness on Pressure Drop $\left(900^{\circ} \mathrm{F}\right.$ outlet

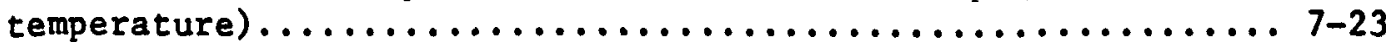

7-14 Effect of Grid Strap Thickness on Assembly Pressure Drop $\left(950^{\circ} \mathrm{F}\right.$ outlet temperature)....................... 7-24 


\section{LIST OF FIGURES (CONTINUED)}

7-15 Effect of Grid Strap Thickness on Pressure Drop (1000 $\mathrm{F}$ outlet temperature, 14 Honeycomb grids)............... 7-25

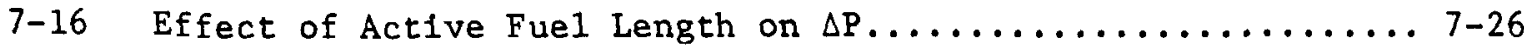

7-17 Effect of Linear Power on Pressure Drop.............. 7-27

7-18 Effect of Fuel Length, Outlet Temperature and Number of Grids

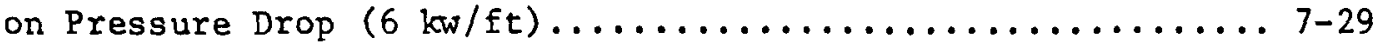

7-19 Effect of Fuel Length, Outlet Temperature and Number of Grids

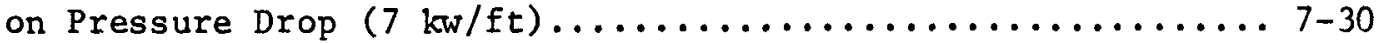

7-20 Effect of Fuel Length, Outlet Temperature and Number of Grids

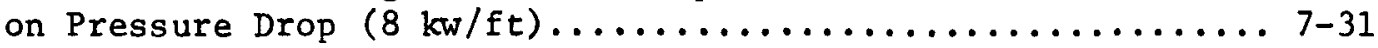

7-21 Effect of Fuel Length, Outlet Temperature and Number of Grids on Pressure Drop $(9 \mathrm{kw} / \mathrm{ft}) \ldots \ldots \ldots \ldots \ldots \ldots \ldots \ldots \ldots \ldots \ldots \ldots$ 7 32

7-22 Effect of Fuel Length, Outlet Temperature and Number of Grids

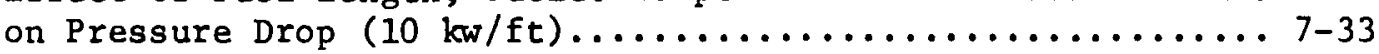

7-23 Maximum Internal Fuel Rod Pressure vs. Burnup for $90.9 \%$ Theoretical Density Fuel 14.7 psia Hellum Fill (simplified calculation).

Grid Welding Fixture.

Subassembly Components; Grids, Liners and Cans.

9-3 Inner Can: Showing Bottom Grid, Liner, and Grid Postions.... 9-9

9-4 Subassembly Cross Section Without Fuel Pins. 3X Magn....... 9-10

10-1 Flow Test Housing Diagram...................... 10-3

11-1 Material Flow for Design $1 \ldots \ldots \ldots \ldots \ldots \ldots \ldots \ldots \ldots \ldots \ldots$

11-2 Material Flow for Wet Milling Trials................ 11-8

12-1 The Particle Size Distribution for Natural and Enriched $\mathrm{UO}_{2}$ Powders................................... 12-5

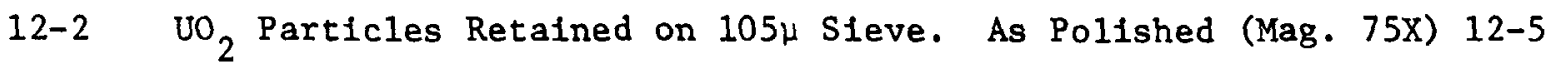

12-3 Autoradiograph of a $95 \%$ Dense, $43 \%$ Enriched (U, Pu) $\mathrm{O}_{2}$ Pellet

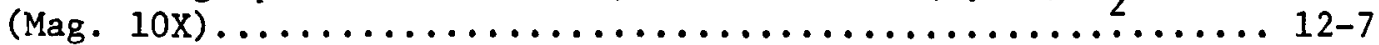

12-4 Autoradiograph of a $91 \%$ Dense, $43 \%$ Enriched (U, Pu) $\mathrm{O}_{2}$ Pellet

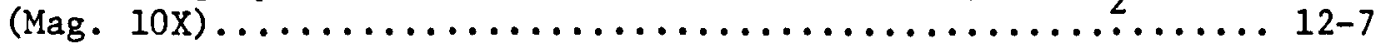

12-5 Autoradiographs of Sintered (U, Pu) $\mathrm{O}_{2}$ Pellets. Illustrating the Effects of Different Material/Vold Ratios Employed During Powder M1lling (Mag. 10x) ........................ 12-9

12-6 (a) is an Autoradiograph, and (b) is a Photomicrograph of the Same Green (U, Pu) $\mathrm{O}_{2}$ Pellet Surface (Mag. 10X)........... 12-10 
12-7 (a) is an Autoradiograph and (b) is a Photomicrograph of the Same Sintered (U, $\mathrm{Pu}) \mathrm{O}_{2}$ Pellet Surface (Mag. 10X)......... 12-11

13-1 Overall Program Process Flow Diagram for WSA-1 and WSA-2... 13-2

13-2 Final Fuel-Motion Restrictor Disc Configuration.......... 13-5

13-3 Percent Available Heat Transfer Area and Centerhole Deformation Obtained at Various Crimping Pressures........ 13-6

13-4 Average Applied Axial Stress to Cause Crimp Displacement.... 13-7

13-5 Crimping Press with Fuel Tube Connected to Loading-Tube Extension of Udder Bag....................... 13-8

13-6 Bottom Half of Crimping Die Block Showing Slot Filled with Urethane Compression Medium and with a Crimped Tube in Posi-

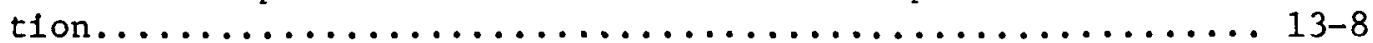

13-7 Void Deployment Irradiation Test Fuel Pin.-............ 13-9

13-8 Summary of Welding Study Performed on Bottom End Plug to Fuel Tube (1).................................. 13-10

13-9 Summary of Welding Study Performed on Top End Plug (2) and Connector Plug (3) to Plenum Tube....................13-11

13-10 Summary of Welding Study Performed on Fuel Tube to Connector

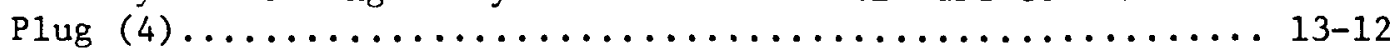

13-11 Fina1 Closure Weld Nugget (4) Illustrating Mixing of Austenite + Delta Ferrite Phases (Mag. 65X)................... 13-13

13-12 Apparatus for Xenon Tagging Unencapsulated Irradiation Test Fuel Pins................................. 13-16 


\section{LIST OF TABLES}

Table

Page

4-1 Principle Experimental EBR-II PIn Parameters Used in CYGRO Studies....................................4-3

5-1 Fuel Pin Details--Design....................... 5-5

5-2 Fuel Pin and Capsule Data--Design................... 5-5

5-3 Operating Conditions............................ 5-9

5-4 Summary of Fuel Pin Capsule Stress--Strain Analysis......... 5-12

6-1 WSA-3 Mockup Geometry for Nuclear Calculations.............. 6-5

6-2 The Effect of Channel Closing on Coolant Temperature and Temperature Gradients........................... 6-6

6-3 Coolant Temperature Gradients Across Selected Fuel Rods for Variations in Grid Pitch...........................6-6

7-1 Sumary of Design Parameters for Assemblies with 14 Honeycomb Grids................................... 7-5

7-2 217-Pin Layouts Inside Hexagonal Duct................. 7-8

7-3 Dimensions................................ 7-9

7-4 Nominal Design Parameters.......................... 7-10

7-5 Linear Power in Open Loops With Fuel of the Same Enrichment and Adjacent Assemblies.......................... 7-12

7-6 Tabulation of Cladding and Fuel Temperatures for $1000^{\circ} \mathrm{F}$ Nominal Outlet Temperature and $10 \mathrm{kw} / \mathrm{ft}$ Linear Power.............. 7-13

7-7 Range of Parameters Studied....................... 7-14

11-1 Experimental Investigation Details....................11-3

11-2 Designs of Current Powder Preparation Investigations......... 11-5

12-1 Nitrogen Contents (ppm) of (U, Pu) $\mathrm{O}_{2}$ Pellet Batches for WSA-1 and WSA-2 Irradiation Experiments................ 12-2

12-2 Pellet Drylng Trials Data........................ 12-3

12-3 Comparison of Certain Impurity Contents in the Overall $\mathrm{UO}_{2}$ Powder Versus Those in the Coarse Fraction................. 12-6

12-4 Physical Characterization Data on Various (U, $\mathrm{Pu}$ ) $\mathrm{O}_{2}$ Pellet Batches........................................ 12-8

13-1 Fabrication Process Steps for WSA-2.................. 13-3 
SECTION 1

INTRODUCTION

\section{GENERAL}

This is the seventh quarterly progress report and covers the work performed during the third quarter of FY-1970.

\section{SUMMARY OF OBJECTIVES}

The overall program approach is to conduct parallel analytical and experimental studies on mixed-oxide fuel pins with close liaison and feedback between the two activities. In the analytical work, the initial efforts will be directed to compiling all pertinent data on the irradiation behavior of austenitic stainless steel cladding, mixed-oxide fuel pins. A similar effort will be directed toward compiling data on the behavior of Type 316 austenitic stainless steel cladding - in particular on high-burnup fuel pins. These data will be analyzed by current theoretical models, and where required, new models and computer codes will be devised. These analytical techniques will be used to provide the technical basis for the experimental irradiation programs. This procedure, in turn, will permit rellable parametric studies of design variables of interest to FFTF and LMFBR.

\section{SUMMARY OF PRIOR WORK}

All work related to the present investigations and performed prior to the present period has been fully reported in:

\footnotetext{
WARD-3791-28 "Oxide Fuel Element Development Quarterly Progress Report for the Period Ending September 30, 1968."

WARD-3791-32 "Oxide Fuel Element Development Quarterly Progress Report for the Period Ending December 31, 1968."

WARD-3791-37 "Oxide Fuel Element Development Quarterly Progress Report for the Perlod Ending March 31, 1969."

WARD-3791-39 "Oxide Fuel Element Development Quarterly Progress Report for the Period Ending June 30, 1969."

WARD-4135-1 "Oxide Fuel Element Development Quarterly Progress Report for the Perlod Ending September 30, 1969."

WARD-4135-4 "Oxide Fuel Element Development Quarterly Progress Report for the Period Ending December 31, 1969."
} 
A summary of current progress for the tasks in this program is presented in this section. A description of progress is given in the individual task sections of this document.

OFBA-210

Preparation of the OLYMPUS-II fuel-pin behavior code was completed and correlation of the code with experimental data was initiated. The code incorporates a number of sub-routines describing various cladding and fuel behavior models. Those sub-routines now include calculation of strains due to fission gas pressure and also the latest revision of irradiation-induced creep of the cladding. The revision is based on a detailed analysis of the mechanical behavior of the cladding under a stress field, and is presently being used as a design basis for FFTF fuel elements. A preliminary model for assessing the effects of stress on void growth and thus overall cladding swelling has been developed. The model shows that stress-induced void growth can give rise to large dimensional growth; therefore, further studies are indicated.

OFBA-211

Development of the CYGRO-F code continued. The fuel cracking model originally in the code was modified to permit radial movement of the fuel, thus reducing the calculated hot fuel-cladding gap. Further revision is planned. The code was applied to selected DFR and EBR-II experimental pins and to selected FFTF pin operating conditions. Results of the experimental pins showed good agreement in some cases and revealed several possible experimental uncertainties which must be resolved to make the available data more useful. Those uncertainties will form the basis of the next set of conditions to be used for the continuing sensitivity studies. The FFTF pin studies clearly demonstrated the utility and detailed analytical capability of the CYGRO-F code. Several critical aspects of fuel pln performance were identified from these studies. Two of these were: the maximum plastic strain within the cladding is a more sensitive index for assessing cladding behavior than either total strain or total mechanical strain; and for the pin operating conditions studied, a minimum stress level of $\sim 30,000$ psi is required before significant mechanical strain begins. Code studies of axial strain rates of fuel and cladding were conducted and showed that once the fractional factor between the two exceeds 0.1 , the cladding restrains axial fuel growth.

OFBA -310

Subassembly WSA-2 was shipped to EBR-II and inserted in the reactor on March 27, 1970 at the start of run 41B. Design of the fuel motion restrictors, which are being incorporated in four of the WSA-1 fuel pins, was completed. Thermal, hydraulic, and mechanical analyses of these four pins were also completed, and the addendum to the data package, to be submitted to EBR-II early in the next report period, was nearly completed. The subassembly is scheduled for shipment to EBR-II by the end of April 1970. 
Fuel pin safety analyses for off-normal transient conditions in EBR-II were completed. Preliminary nuclear analysis of the subassembly, WSA-3, in a water-flooded condition was performed and indicated a $k_{\text {eff }}$ significantly less than the EBR-II requirement of 0.6. Channel closing analyses were conducted to determine the effect of rod displacements and variations in pitch on channel coolant temperatures and temperature gradients across fuel pins. Flow induced vibration studies concluded that the maximum allowable vibration limit of 0.001 inch is not exceeded in WSA-3 for 4-inch spans between grids and end-of-life conditions. Stress analyses were performed on the inner and outer cans, liners, and grid support straps. Previously calculated bowing determinations were revised to include the effects of triaxial straining on the bow amplification factor. Subassembly design drawings were completed. Standard subassembly hardware components have been recelved and fuel pin hardware was ordered. The outer drum of the shtpping container was received. Final fabrication requirements for fuel pellets were established.

OFBA- 312

A tentative design basis for a grid-type LMFBR/FFTF fuel assembly was specified. Studies of several candidate grid types were conducted to arrive at the design. The grid types examined were DFR type honeycomb and singleplanar and triplanar line of sight grids. Preliminary drawings and stress analyses were made. Analyses were initiated to determine corrosion wastage and flow induced vibration of rod bundles. Parametric studies were performed to evaluate the thermal and hydraulic limits imposed on the fuel assembly design by the reactor environment. Data prepared to form a basis for design selections covered significant ranges of pin diameters, coolant outlet temperature, number of grids, grid strap thickness, active fuel length, and linear power rating of the pins.

OFBA- 313

Subassembly and test capsule design drawings were completed for the fretting test in Subtask 1. Initial operation of the driver fuel assembly test (DFAT) rig experienced problems with the by-pass sodium cooler, requiring subsequent design and fabrication of a new heat exchanger. Operational problems related to a heater failure and faulty instrumentation were also experienced in the sodium loop systems used for Subtask 2. The braze test loop (WBTL-2) continued to accumulate operating time after deviations in the oxygen content of the sodium were corrected.

OFBA-410

An ample supply of acceptable grid strap material was received from the supplier. Fabrication of liners and inner and outer cans was completed by the vendor. Corrections and modifications to grid fabrication fixtures and processes continued to be made during the period. Fifteen developmental inner grid assemblies were welded and inspected. Improved inspection 
techniques, which incorporate a computerized printout of a grid cell pitch and dimple circle diameter measurements, were developed for grids. Five developmental support strap assemblies were welded and inspected to identify required modifications in fixtures and processes. Electra-discharge machining (EDM) electrodes have been made and tried for final shaping of the slots and flow tabs in the support strap assemblies. A design change was successfully effected for the spacers on the liners and inner cans to circumvent distortions experienced during welding of the spacers. A purchase order was placed for EDM of liner flanges for final sizing. Two inner cans were machined to length, drilled, slotted, and the ends chamfered. Three bottom support grids have been machined, one of which has been fitted with key stock received from ANL. End fittings were received for the flow test and fretting test assemblies.

\section{OFBA-411}

The grid strap forming tool was continuously modified to improve the quality of the grid straps. The corrugated straps are now being produced with the proper length and angle tolerances. Further modifications were made to dimple configurations in order to produce the proper dimple circle diameters within a welded inner grid assembly. The grid support strap froming tool was set up and, after several modifications, successfully operated to produce acceptable straps. EDM operations on tabs and slots were established and the work initiated. All other tooling was completed except for grid and liner loading fixtures, for which purchase orders were placed. Design modifications were made to fuel pin top end plugs, bottom grid support, and sodium drainage areas to facilitate recommendations of the EBR-II Project noted in other tasks (OFBA-311 and -410). Flow test housing design was completed and fabrication initiated. Test plans and instrumentation requirements were established.

OFBA -510

A systematic study of the effect of process variables on pellet fabrication was conducted. Emphasis is on simultaneously achieving acceptable homogeneity and pellet density control. The effects of various powder treatments on sieving, blending, and melting processes and on pressing and sintering characteristics were investigated. Present results suggest that dry milling, the preferred method, will be satisfactory for low density pellets, but wet milling will be required for high densities ( $95 \% \mathrm{TD}$ ). Based on those results, preliminary batches of fuel pellets for the WSA-3 subassembly have been prepared.

\section{OFBA- 511}

All characterization work on the $(\mathrm{U}, \mathrm{Pu}) \mathrm{O}_{2}$ pellet batches for use in the WSA-1 and -2 subassemblies was completed with the exception of total gas release. The homogeneity of all fuel pellet batches was examined by autoradiography and found to be acceptable. Moisture adsorption studies were conducted and sources leading to high values identified. Methods for 
avolding excessive adsorption or satisfactorily removing water have also been identifled and verification trials are in progress. Detalled homogeneity studies of pellets prepared by various process trials conducted by WARD indicated that acceptable pellets can be fabricated by dry or wet milling techniques when proper controls are used. Both miling methods will be needed to achieve the range of densitles required for the irradiation test program. Further work is in progress to verify that homogeneity as well as all other specifications can be met by the present process methods.

OFBA-512

Fabrication of the 19-encapsulated irradiation test rods for subassembly WSA-2 was completed. Fabrication of the 19-fuel rods for WSA-1 has been completed and encapsulation is scheduled for completion by Apri1 20. Four of these latter rods included axial fuel motion restrictors. The in-box crimping method developed during this report period was successfully employed in fabricating these pins. Development of xenon tagging procedures and welding methods to meet the more stringent requirements of the WSA-3 subassembly were infitiated.

OFBA-513

A complete data package was compiled for the WSA-2 assembly. Routine accumulation of data for the WSA-1 assembly is proceeding. 


\section{OBJECTIVES}

The objectives of this task are to assure that the project is successfully completed, on schedule, within budget, and to the satisfaction of the Atomic Energy Commission; to assure compliance with contracted obligations; and to coordinate this profect with other AEC-sponsored and Westinghouse-sponsored LMFBR development projects.

Overall project direction and day-to-day administration will be provided under this task. Plans and controls will be established and maintained; periodic reviews will be held with the Commission; correspondences and reports will be coordinated; and day-to-day technical and administrative liaison with the Commission will be provided.

PRIOR WORK

Revised work programs for FY-1970 were submitted to the Commission in December 1969. Technical work has continued on the basis of those work programs.

For FY-1970 administrative control, the project is divided into the following tasks:
OFBA -110
Project Administration
OFBA-210
Fuel Performance Analysis
OFBA-211
Development of Analytical Methods and. Lifetime Codes
OFBA-212 (a)
Design Limit and Transient Survival Testing of Fuel Element
OFBA -310
Encapsulated Mixed-0xide Fuel Pin Irradiation Tests
OFBA -311
Mixed-Oxide Irradiation Tests in Grid-Type Subassemblies
OFBA -312
217 Pin Grid-Type Fuel Assembly Design and Development

\footnotetext{
(a) A final report for Task OFBA-212 is in reproduction and is, therefore, not contained in this progress report.
} 
OFBA-313 Fabrication, Development, and Testing of LMFBR Fue1 Assemblies

OFBA-410 Fabrication, Development of EBR-II Grid-Type Subassemblies

OFBA-411 Subassemb1y Design and Hardware

OFBA-510 Pellet Fabrication

OFBA-511 Fue1 Characterization

OFBA-512 Fuel Element Fabrication

OFBA-513 Product Control and Documentation

This breakdown is more detailed than that used in FY-1969 and reflects increased effort in FY-1970. Much of that increased effort is associated with fuel pin fabrication each of which is controlled and reported separately. OFBA-211, 212, 312 , and 313 are new tasks as of FY-1970. In addition, separate tasks have been established for the design of encapsulated and unencapsulated fuel pin tests.

\section{CURRENT PROGRESS}

The quarterly progress report (WARD-4135-4) for the period ending December 31, 1969 was prepared and distributed.

Contract Modification No. 3 was received and executed to cover funding through June 30, 1970 . 


\section{SECTION 3 \\ OFBA-210 FUEL PERFORMANCE ANALYSIS}

W. K. Appleby, A. Blancheria, A. Boltax, and T. P. Soffa

\section{OBJECTIVES}

The maximum utilization of expensive and limited irradiation test data is achieved by continuing theoretical analysis of the data. The objectives of this task are to provide analyses of the effects of irradiation on the properties and structure of cladding materials, and the interrelationship of these processes with the stresses imposed by fuel swelling. The technical approach involves the development of theoretical models and appropriate computer codes. The basic objective is to provide an understanding of the behavior of stainless steel cladding oxide fuel elements exposed to fast neutron flux.

\section{PRIOR WORK}

Re-writing of the OLYMPUS code as OLYMPUS-II was initiated and new and improved models to describe fuel-cladding gap closure and fuel swelling were prepared and incorporated into the model. Calculation of a complete set of confidence intervals for the cladding swelling correlations was completed; these included global intervals about the predicted mean and intervals for the next experimental observation. Analysis of in-reactor creep continued and correlations for $20 \%$ cold worked and solution treated Type 316 stainless steel were established.

\section{CURRENT PROGRESS}

\section{OLYMPUS-II Development}

Development of the OLYMPUS-II fuel pin behavior code has been completed. The code will be correlated with experimental pins during the next report period.

Figures 3-1 and 3-2 show a flow diagram of the OLYMPUS-I and OLYMPUS-II models. The OLYMPUS-II has been written in a form utilizing a number of sub-routines to calculate parameters, such as fission gas pressure, irradiation-induced creep, etc. In this way any subsequent changes in the procedures for the calculation of these parameters can easily be incorporated into the code.

The code computes diametral deformation of the fuel pin at any given axial location. The required data input includes a description of the cladding and fuel geometry, the cladding material, the fuel density, the power rating, and the cladding temperature at the axial location under consideration. 
$w$
ve
1
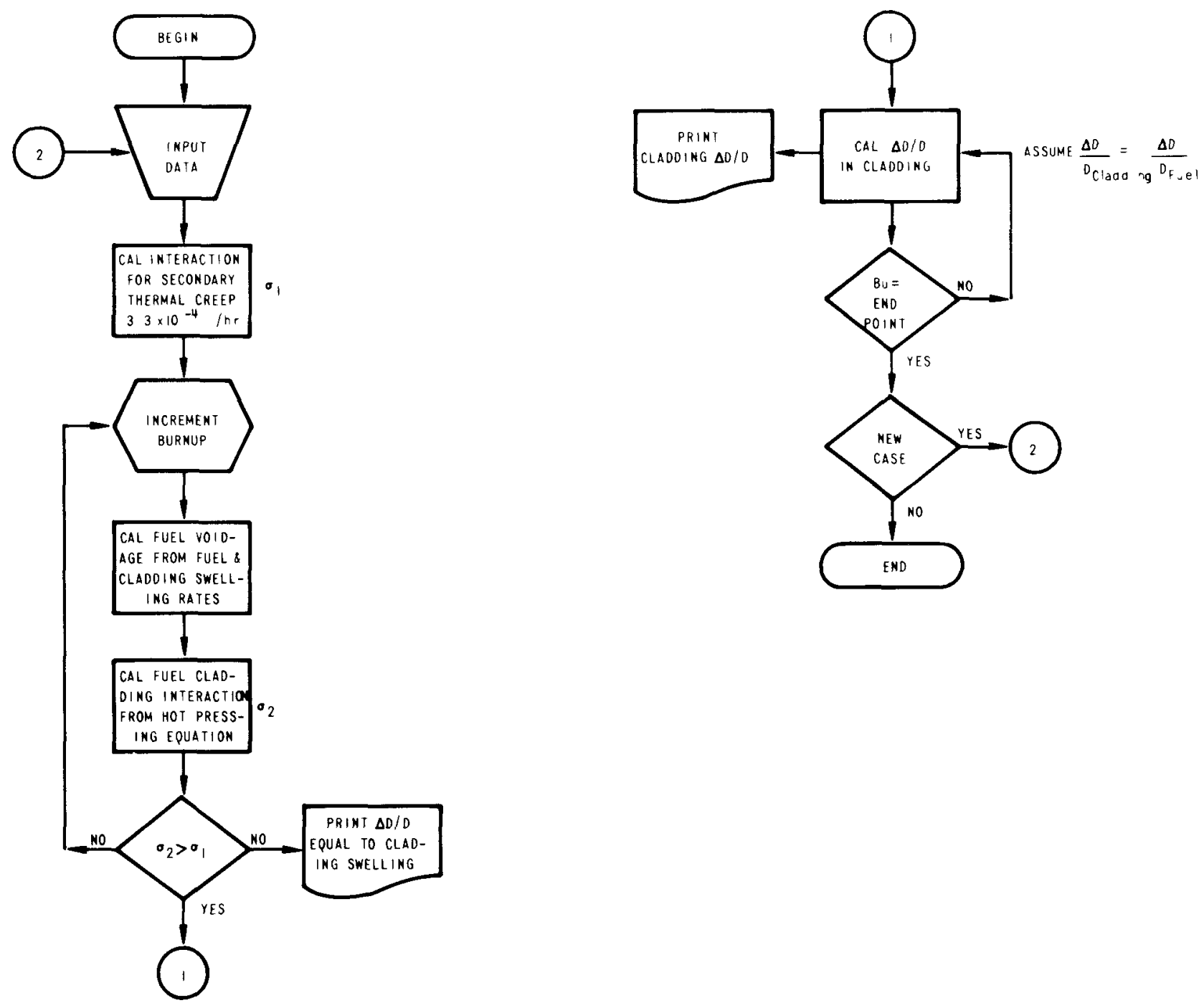

Figuie 3-1. Olympus I Flon Diaglam 

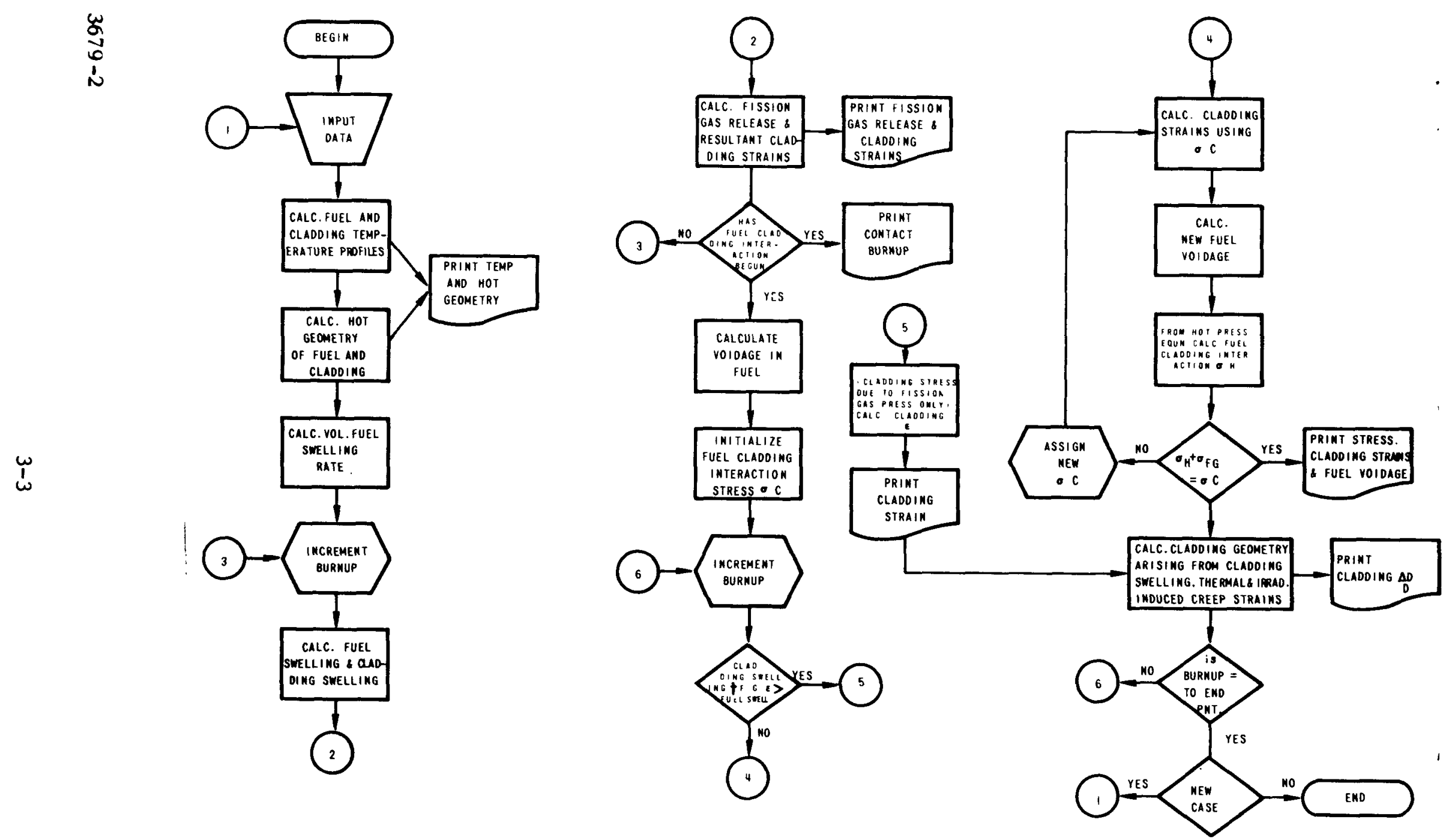

Figure 3-2. Olympus II Flow Diagram 
The first sub-routine to be called calculates the fuel and cladding radialtemperature profile (OXIDE-II). The model assumes that restructuring of the fuel gives rise to three discrete density rings in the fuel plus a central void. The temperatures of the boundaries between these regions are input variables, although constant values have been assumed to date. The temperatures of the equiaxed grain boundary and the columnar grain boundary are assumed 1600 and $2000^{\circ} \mathrm{C}$, respectively.

Using the values of fuel center and surface temperature calculated in OXIDE-II, the next sub-routine (OLYGAP) calculates the hot geometry of the fuel and cladding and then proceeds to calculate the burnup at which fuel cladding mechanical interaction begins. The burnup at which this mechanical interaction begins is dependent upon the size of the hot fuel-cladding gap. However, the extent of this gap that is useful for the accommodation of fuel swelling is largely unknown. It is probable that during startup the fuel will crack giving thermal fuel-cladding contact and redistributing the hot fuel-cladding gap. It is likely (at least for high power levels) that some of the redistributed gap will be lost to the central void. Because of this uncertainty, the "useful" hot fuel-cladding gap is treated as a further variable parameter, and fuel pin performance studies are made for a range of possibilities.

Calculation of the onset of fuel-cladding mechanical interaction requires knowledge of cladding swelling, fuel swelling, fission-gas release and the strains (irradiation-induced and thermal) arising from fission gas pressure. Descriptions of these parameters are stored in further sub-routines and used as necessary.

The fuel swelling model used in the code is based upon the Greenwood-Speight analysis and is input in the form of a table giving volumetric fuel swelling rates as a function of the local fuel temperature. A volumetric average fuel swelling rate is obtained by calculating the mean rate over fifty equal volume increments between the fuel center and surface.

Cladding swelling correlations for $20 \%$ cold-worked and solution treated Type 316 stainless steel giving the percentage swelling as a function of fluence and temperature are contained in a further sub-routine. The correlations are those described in the last quarterly report of this series (WARD-4135-4).

Fission gas release is calculated using a correlation currently being developed at WARD. Knowing the average/point burnup and the plenum volume, the gas release is converted into an average release, and then into a pressure. The cladding radial, axial, and hoop stresses are calculated from a knowledge of the pin geometry, and these stresses are in turn used to calculate the cladding strain from irradiation-induced creep and thermal deformation.

The strains arising from irradiation-induced creep are calculated using the correlations described below. Thermal deformation is assessed from a combination of correlations describing the secondary creep of $20 \%$ cold worked and solution treated Type 316 stainless steel plus a description of stressstrain relationships from tensile test data. 
After fuel-cladding mechanical interaction occurs, the stress experienced by the cladding is computed using an iteration procedure which arrives at a value of stress that is self-consistent with the thermal and Irradiationinduced creep strains, fuel hot pressing stress, and the fission gas pressure. An iteration procedure allows the stress on the cladding to decrease with time if cladding swelling and irradiation-induced creep are large enough to reduce the fuel-cladding interaction.

\section{Irradiation-Induced Creep}

Calculation of cladding strain in the OLYMPUS-II Code is additionally complicated by the need to compute irradiation-induced creep from hydrostatic and shear stresses, and thermal creep from the equivalent stress which is in turn used to calculate the additional strain due to the deviatoric stress.

For the case where fuel-cladding mechanical interaction occurs, the cladding stresses are calculated in the following manner.

$$
\begin{aligned}
& \sigma_{\theta}=\frac{\sigma_{c}{ }^{r} o}{t} \\
& \sigma_{a}=\frac{\sigma_{f g} r_{0}}{2 t} \\
& \sigma_{r}=\frac{-\sigma_{c}}{2}
\end{aligned}
$$

where $\sigma_{\theta}, \sigma_{a}, \sigma_{r}$ are the principal stresses in the hoop, axial, and radial directions, respectively. $\sigma_{c}$ is the total interaction pressure on the cladding, and $\sigma_{\mathrm{fg}}$ is the fission gas pressure.

Then the hydrostatic stress is given by

$$
\sigma_{H}=\frac{\sigma_{\theta}+\sigma_{a}+\sigma_{r}}{3}
$$

and the deviatoric stress in the hoop direction is

$$
S_{\theta}=\sigma_{\theta}-\sigma_{H}
$$

To compute the thermal deformation; the equivalent stress, $\bar{\sigma}$, is calculated using the Von Mise's criteria:

$$
\left.\bar{\sigma}=\frac{1}{2}\left(\sigma_{\theta}-\sigma_{a}\right)^{2}+\left(\sigma_{a}-\sigma_{r}\right)^{2}+\left(\sigma_{r}-\sigma_{\theta}\right)^{2}\right]^{1 / 2}
$$


The associated equivalent thermal strain, $\bar{\varepsilon}$, is calculated using this stress and the time interval. The additional strain in the hoop direction is calculated from the deviatoric stress and ratio of equivalent strain to equivalent stress.

$$
\varepsilon_{S}=\frac{3}{2} \frac{\bar{\varepsilon}}{\bar{\sigma}} S_{\theta}
$$

Irradiation-induced creep is due to two components, hydrostatic strain $\left(\varepsilon_{H}\right)$ and shear strain $\left(\varepsilon_{S}\right)$, so that total irradiation-induced creep $\left(\varepsilon_{T}\right)$ is given by

$$
\varepsilon_{\mathrm{T}}=\varepsilon_{\mathrm{H}}+\varepsilon_{\mathrm{S}}
$$

The dominant mechanism of irradiation-induced creep is considered to be vacancy diffusion so that both the shear and hydrostatic components are assumed to be superplastic in character and consequently not strain limiting.

The hydrostatic strain (in fact a volume increase) is the much larger component. Having computed the hydrostatic stress (Equation 4), $\varepsilon_{H}$ is calculated.

$$
\varepsilon_{\mathrm{H}}=\left(\frac{\varepsilon_{\mathrm{H}}}{\sigma_{\mathrm{H}}}\right) \sigma_{\mathrm{H}}
$$

The WARD-PNL correlation for $\varepsilon_{\mathrm{H}} / \sigma_{\mathrm{H}}$ is

$$
\frac{\varepsilon_{H}}{\sigma_{H}}=11.73 \times 10^{-8} \alpha\left[1-\exp \left(-\phi t / 6.37 \times 10^{20}\right)\right]+27.9 \times 10^{-30} \alpha \phi t
$$

for $20 \%$ cold worked Type 316 stainless steel. The correlation for solution treated Type 316 stainless steel is

$$
\frac{\varepsilon_{H}}{\sigma_{H}}=2.7 \times 10^{-8} \alpha\left[1-\exp \left(-\phi t / 1.47 \times 10^{21}\right)\right]+28.05 \times 10^{-30} \alpha \phi t
$$

Where $\alpha=\exp \left(1.405-0.027 \mathrm{~T}\left({ }^{\circ} \mathrm{K}\right)\right.$ 
Using the deviatoric stress, $S_{\theta}$, the shear component of irradiation-1nduced creep is calculated from Equation (7) and the WARD-PNL $\bar{\varepsilon} / \bar{\sigma}$ correlations:

$$
\frac{\bar{\varepsilon}}{\bar{\sigma}}=0.78 \times 10^{-8} \alpha\left[1-\exp \left(-\phi t / 6.37 \times 10^{20}\right)\right]+1.86 \times 10^{-30} \alpha \phi t
$$

for $20 \%$ cold worked Type 316 stainless steel of

$$
\frac{\bar{\varepsilon}}{\bar{\sigma}}=0.18 \times 10^{-8} \alpha\left[1-\exp \left(-\phi t / 1.47 \times 10^{21}\right)\right]+1.87 \times 10^{-30} \alpha \phi t
$$

for solution treated Type 316 stainless steel.

Equations 9-12 supersede earlier 1rradiation-induced creep recommendations. In order to calculate the increment of strain, $d \varepsilon$, over the time interval, $\mathrm{dt}$, the differential forms of the above equations are used in the code.

\section{Initial Code Applications}

The code was applied to selected FFTF fuel pin conditions and experimental fuel pins to verify the logic of the code and to initiate normalization with experimental data. Figure 3-3 shows an OLYMPUS-II output for FFTF high fluence/burnup conditions. Fuel-cladding interaction started at $0.5 \%$ burnup causing the cladding hoop stress to increase sharply. The initial thermal deformation and irradiation-induced creep then rapidly relax the fuel-cladding interaction stress. Thereafter interaction continuously falls as the cladding swelling rate increases and eventually exceeds the fuel swelling rate. At this point, the cladding stress is again only due to fission gas pressure. The role of irradiation-induced creep as a means of relaxing the fuel-cladding interaction stress is illustrated from a comparison of Figures 3-3 and 3-4. Figure 3-4 is similar to 3-3 except that the irradiation-induced creep is one-fifth that in Figure 3-3. Although the interaction stress is much larger, little effect on the thermal deformation is observed because of the high creep strength of $20 \%$ cold worked Type 316 stainless steel at $445^{\circ} \mathrm{C}$.

Figure 3-5 shows an OLYMPUS-II description of an EBR-II experimental pin tested with a high fuel density, a high linear power, and cladding with solution treated Type 316 stainless steel. The fuel-cladding diametral gap was only $1.9 \mathrm{mils}$, and thus fuel-cladding mechanical interaction occurred immediately following start-up.

Because of the burnup dependences of cladding swelling and fuel swelling, the onset of fuel-cladding mechanical interaction is very sensitive to the size of the calculated Initlal hot gap. A large gap tends to persist for a long time, because cladding swelling increases exponentlally with burnup 


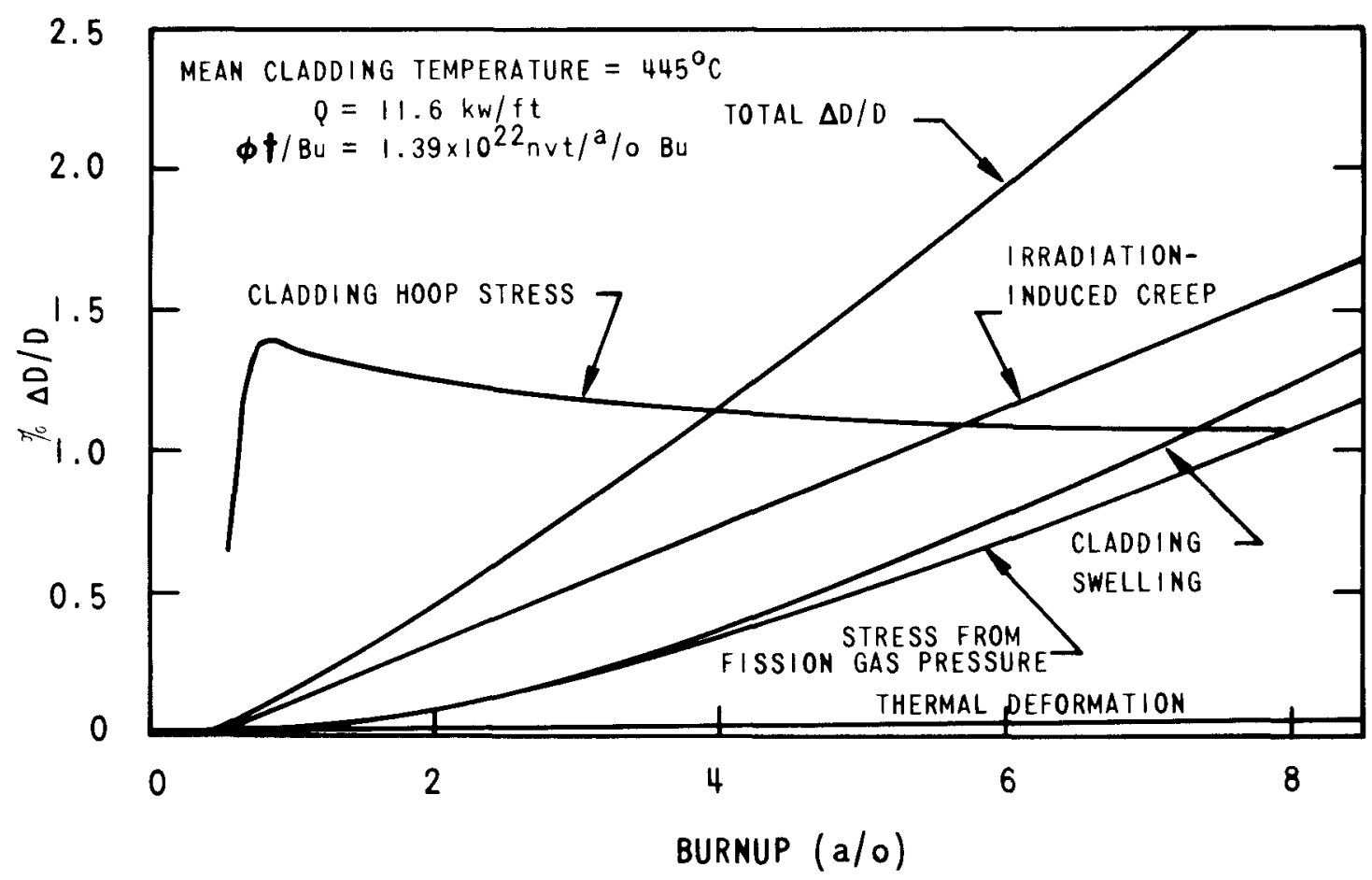

$16 \mathrm{~K}=$ a

$12 K \stackrel{2}{a}$ 岕

cs

8k 옹

$4 K$ 竞

Figura 3-3. OLYMPUS II Output for FFTF Conditions (high irradiationnudue ed cicep)

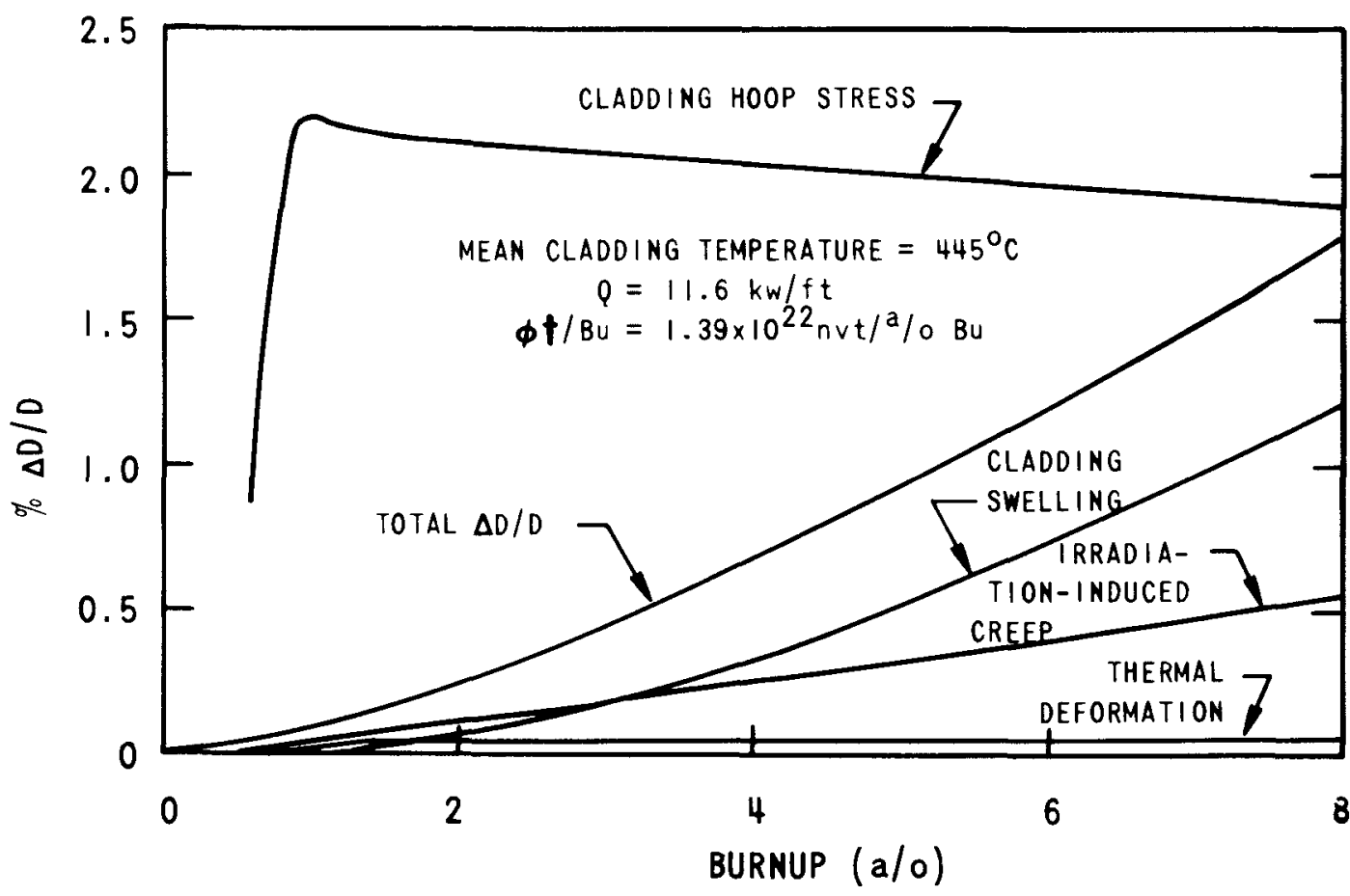

$20 K$

$16 K$

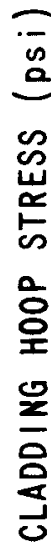

Figure 3-4. OLYMPUS II Output for FFTF Conditions (low 1 rradiationinduced creep)

$3679-10-11$ 


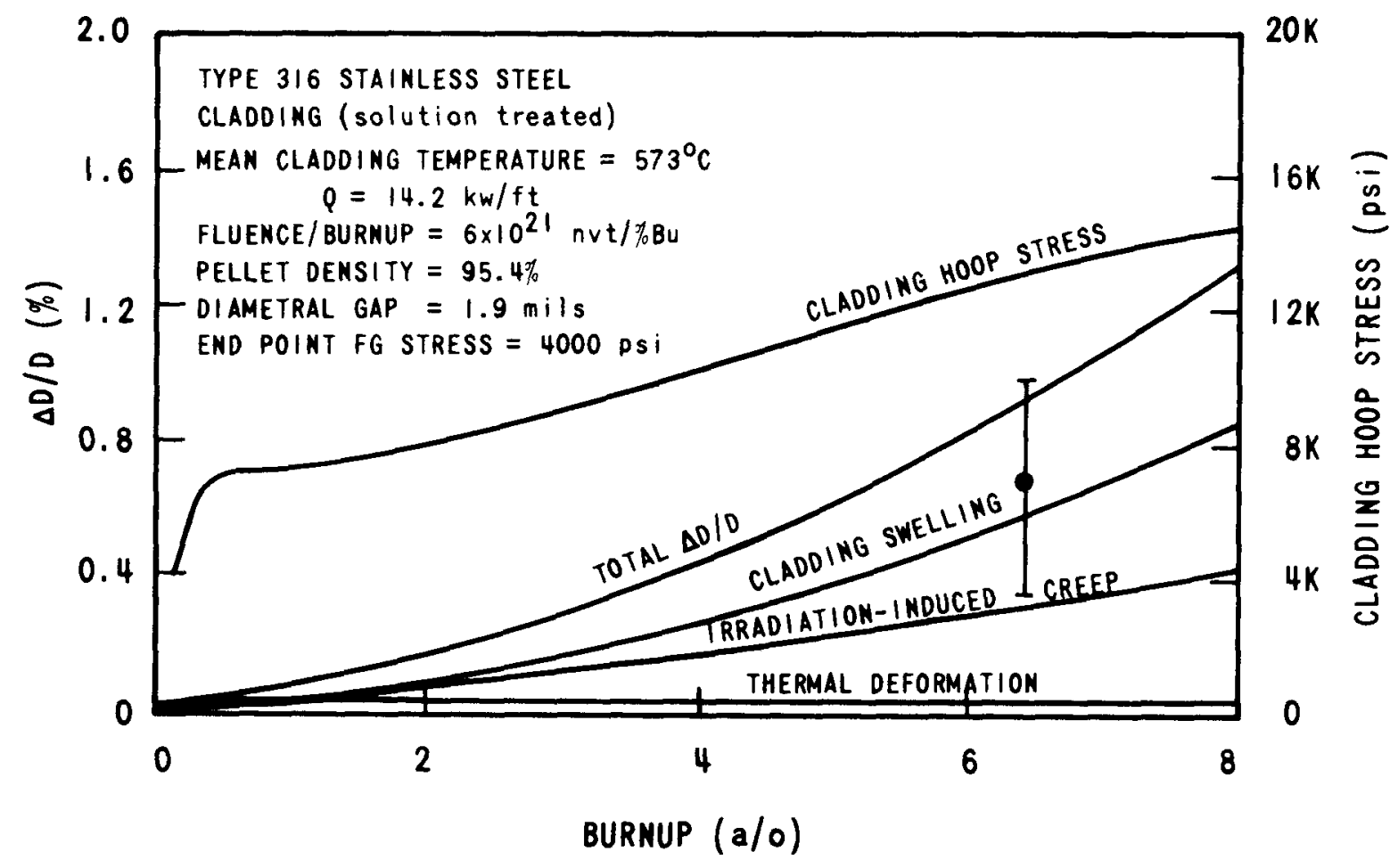

Figure 3-5. OLYMPUS II Description of an EBR-II Experimental Pin $3679-12$ 
whereas fuel swelling is assumed to be 11near. At the high fluence/burnup ratios typical of FFTF, a large hot gap may not close (thermal contact may occur) so that no fuel-cladding interaction results, and the stress on the cladding is due solely to fisston gas pressure. Smaller hot gaps, however, close rapidly. The calculated hot gap of $0.3 \mathrm{mils}$ closed in $0.5 \% \mathrm{BU}$ in Figures 3-3 and 3-4 despite the high fluence/burnup ratio.

\section{Stress Effects on Void Growth}

A model has recently been developed to describe the effects of hydrostatic stress on the growth of voids in stainless steel. The model is based on the theoretical work of Gulden et al.[1] and experimental data obtained in DFR and EBR-II. The model is based on the effective vacancy supersaturation and indicates that the growth rate of voids is given by:

$$
\frac{\mathrm{dr}}{\mathrm{dt}}=\frac{\mathrm{d}_{\mathrm{v}} \Omega \sigma_{\mathrm{H}}}{\mathrm{rkT}}
$$

Where

$$
\begin{aligned}
& \mathrm{r}=\text { void radius } \\
& D_{v}=\text { vacancy diffusion coefficient (taken as } D_{v}=0.58 \exp (-66,900 / R T \text { ) } \\
& \Omega=\text { atomic volume } \\
& \sigma_{H}=\text { hydrostatic stress } \\
& k=\text { Boltzmann's constant } \\
& \mathrm{T}=\text { absolute temperature }
\end{aligned}
$$

Evaluation of Equation 13 indicates that stress induced void-growth effects are significant at temperatures greater than $550^{\circ} \mathrm{C}$. For example, at $600^{\circ} \mathrm{C}$ with $\sigma_{\mathrm{H}}=1000 \mathrm{psi}$ and a void radius of $200 \mathrm{~A}$, the void growth rate is $\sim 20 \AA / 1000$ hours. A simflar calculation at $500^{\circ} \mathrm{C}$ indicates a void growth rate two orders of magnitude lower.

Figure 3-6 shows the results of preliminary application of this model to an FFTF hot channel pin ( $20 \%$ cold worked Type 316 stainless steel cladding) with a maximum mid-wall temperature of $620^{\circ} \mathrm{C}$. In Figure 3-6 only fission gas pressure effects are considered. Note that stress induced void growth occurs only above the core mid-plane $\left(\mathrm{T}>550^{\circ} \mathrm{C}\right.$ ) and becomes significant at 60,000 and $80,000 \mathrm{MWD} / \mathrm{Te}$ when the fluence and hydrostatic stress due to fission gas pressure are large.

The preliminary analysis shown in Figure 3-6 reveals that stress induced void growth can give rise to large dimensional growth of the cladding from fission gas pressure alone. These studies point out the need for experimental fuel pin irradiation data at cladding temperatures above $550^{\circ} \mathrm{C}$. 


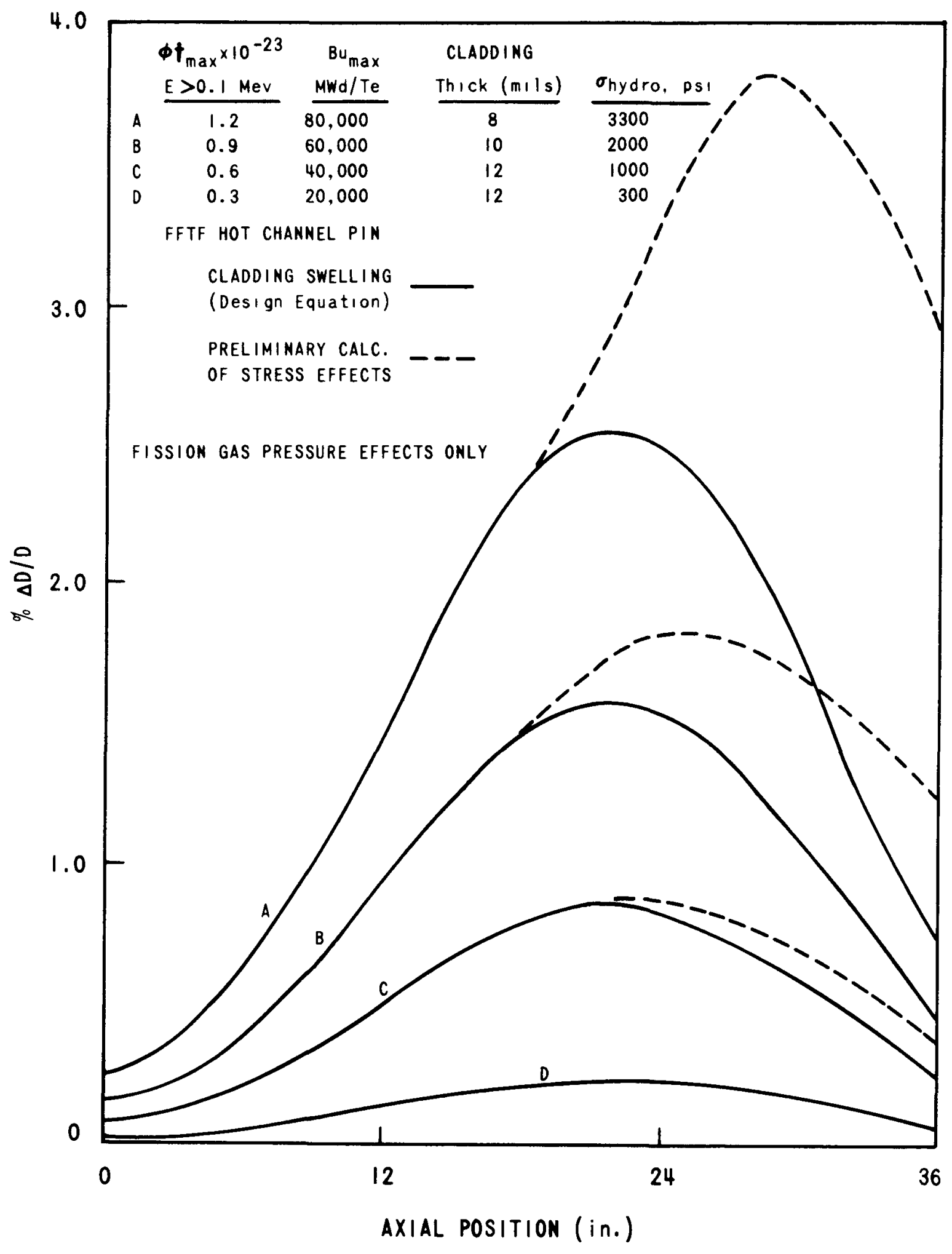

Figure 3-6. Preliminary Calculation of Stress Effects on Cladding Suelling $3679-9$ 


\section{OBJECTIVES}

The overall objective of this task is to develop detalled design codes for performance of mlxed-oxide fuel rods over the range of parameters characteristic of the LMFBR. This task is closely related to Task OFBA-210. The major emphasis of Task OFBA-211 is the development of the CYGRO code for fast reactor applications.

The activities of Task OFBA-211 can be divided into four areas, with initial emphasis on the first three areas:

1. Development of analytical methods to predict steady state behavior of the fuel rod system.

2. Identification of information needed to improve the models.

3. Development of integrated design codes.

4. Development of design models to predict off-normal transient behavior of the fuel system.

The starting point for this program is the CYGRO-2 code developed at Bettis Atomic Power Laboratory. The modifications of CYGRO-2 for application to fast reactor fuel pin studies are called the CYGRO-F series codes.

\section{PRIOR WORK}

The performance analysis of "standard" fuel pins with CYGRO-F demonstrated certain operational deficiencies in the code. The systematic elimination of these problems was initiated.

Experimantal data on fuel creep properties showed that power law used in the code inadequate. An approximation to the two-part experimental creep law showed that variations in fuel mechanlcal properties had small but significant effects on pin performance predictions.

Simulation of representative FFTF fuel pins with CYGRO showed that large ( $~ 6 \mathrm{mt1}$ ) fuel-cladding gaps were not closed because of the high rate of cladding swelling. This effect could lead to fuel center melting at moderate ratings if physical redistribution of the fuel by cracking did not reduce the effective gap size. 


\section{CURRENT PROGRESS}

\section{Code Improvements}

The vold migration model in CYGRO limfted the migration distance of a void to less than a ring width during any time step. Consequently, with the very steep temperature gradients present in highly-rated fuel, time steps were very short. This not only made the code running times excessively long, but affected the precision of the stress-strain analysis. The calculational procedure for void migration was completely changed to allow unlimited migration distances during each time step. The physical model of void migration was not changed. Time steps are now controlled by limits on stress and strain increments. The new void migration model allows a more continuous stress-strain analysis and has eliminated some of the artifacts which occurred previously.

Fuel cracking behavior is expected to significantly influence gap closure, but the anticipated effects were not reproduced in the original code. Startup behavior has been improved by revising the fuel cracking model. A temperature dependent cracking criterion was introduced to prevent cracking in the hot, central portions of the fuel. When cracking occurs, the elastic modulus is relaxed by a factor of 10 , as in the original model. In addition, if cracking occurs in both the axial and circumferential components of an annulus, it is assumed that the radial thermal strain of that annulus is the same as that of the outermost, uncracked annulus. Thus, when cracking occurs upon startup, the fuel pellet will expand more rapidly and reduce the initial hot gap size. Further development of this model is planned to allow free swelling of the hotter fuel when the outer annuli are cracked.

\section{Experimental Pin Analysis}

Comparison of experimental data with CYGRO-F predictions may be used as a measure of the validity of the analytical results. This approach must be used with caution because discrepancies between analysis and experiment may result from factors other than deficiencies in the code. The principle experimental uncertainties are:

\section{Nominal pin operating conditions}

2. Frequent fluctuations in experimental conditions

3. Very limited measurements (usually only diametral strain measurements)

4. Detailed pin parameters and materials properties

Two regions (one near to the maximum rating location and one near to the maximum cladding temperature region) from each of two EBR-II experimental pins were examined. The details of the EBR-II pin parameters and operating conditions shown in Table 4-1 represent an overall judgement of published 
data. The effects of uncertainties in these data will form the basis of a sensitivity analysis to be performed during the next period.

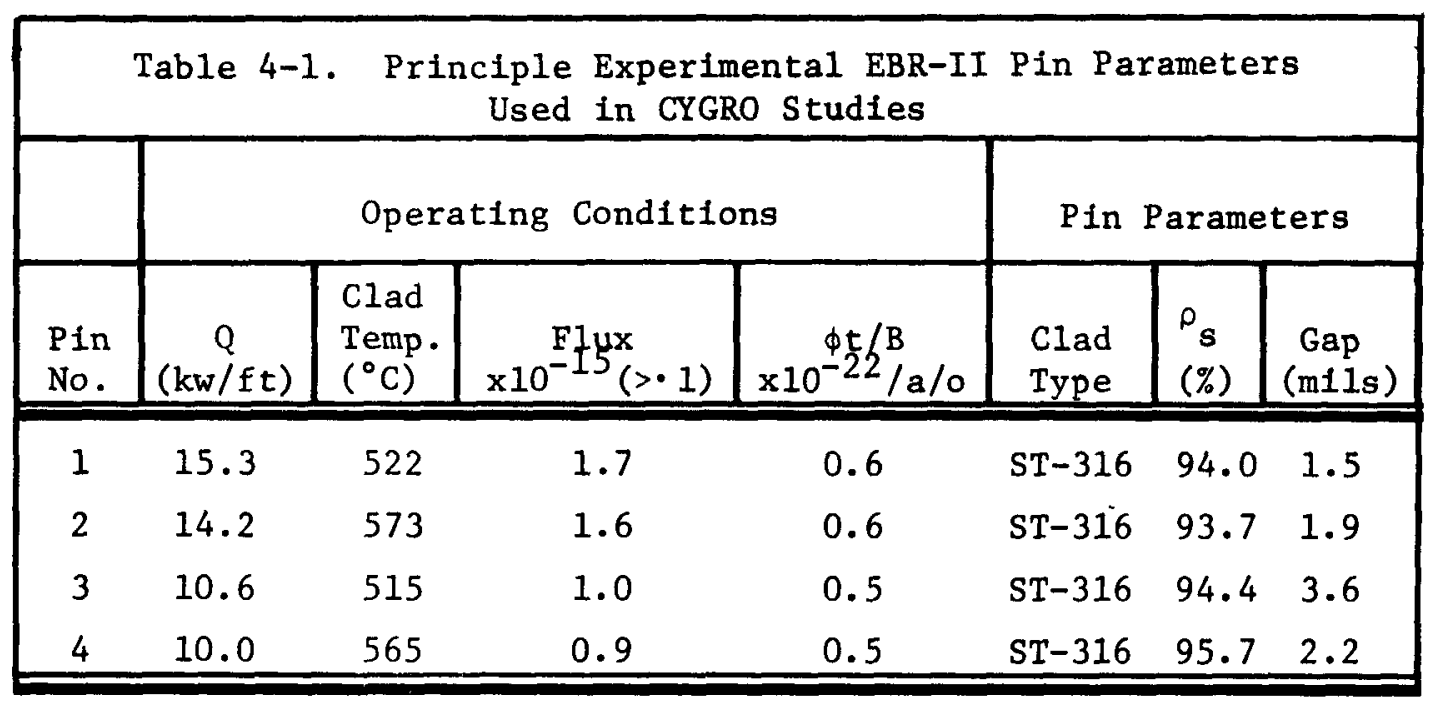

The results from analysis of the experimental EBR-II data showed substantial overprediction of $\triangle D / D$ for the solution treated-cladding pins (Figure 4-1). The reasons for this pattern of results have not yet been established, but the following aspects of the model and the data and the data are being investigated as possible sources of uncertainty.

1. Fuel swelling rates predicted by the emplrical swelling models may be too high. With strong cladding, the magnitude of the diametral strain is less sensitive to the fuel swelling rate than with weak cladding.

2. The fuel creep model used predicts too low a plasticity at low stresses by neglecting diffusion creep.

3. With small (< 3 mils) fuel cladding gaps, there is a significant amount of thermal interference between fuel and cladding on startup.

4. Internal cladding stresses due to differential swelling are less in cold-worked than in solution-treated cladding so that the latter is less able to support fuel-cladding mechanical interaction loads (Further comments on this point will be made in the next section).

5. Stress-relaxation by irradiation-induced creep may have substanially reduced the internal stresses of the solutiontreated cladding, and thus strain due to fuel-cladding interaction would be reduced. (Irradiation-induced creep has not been incorporated in the code at this time.) 


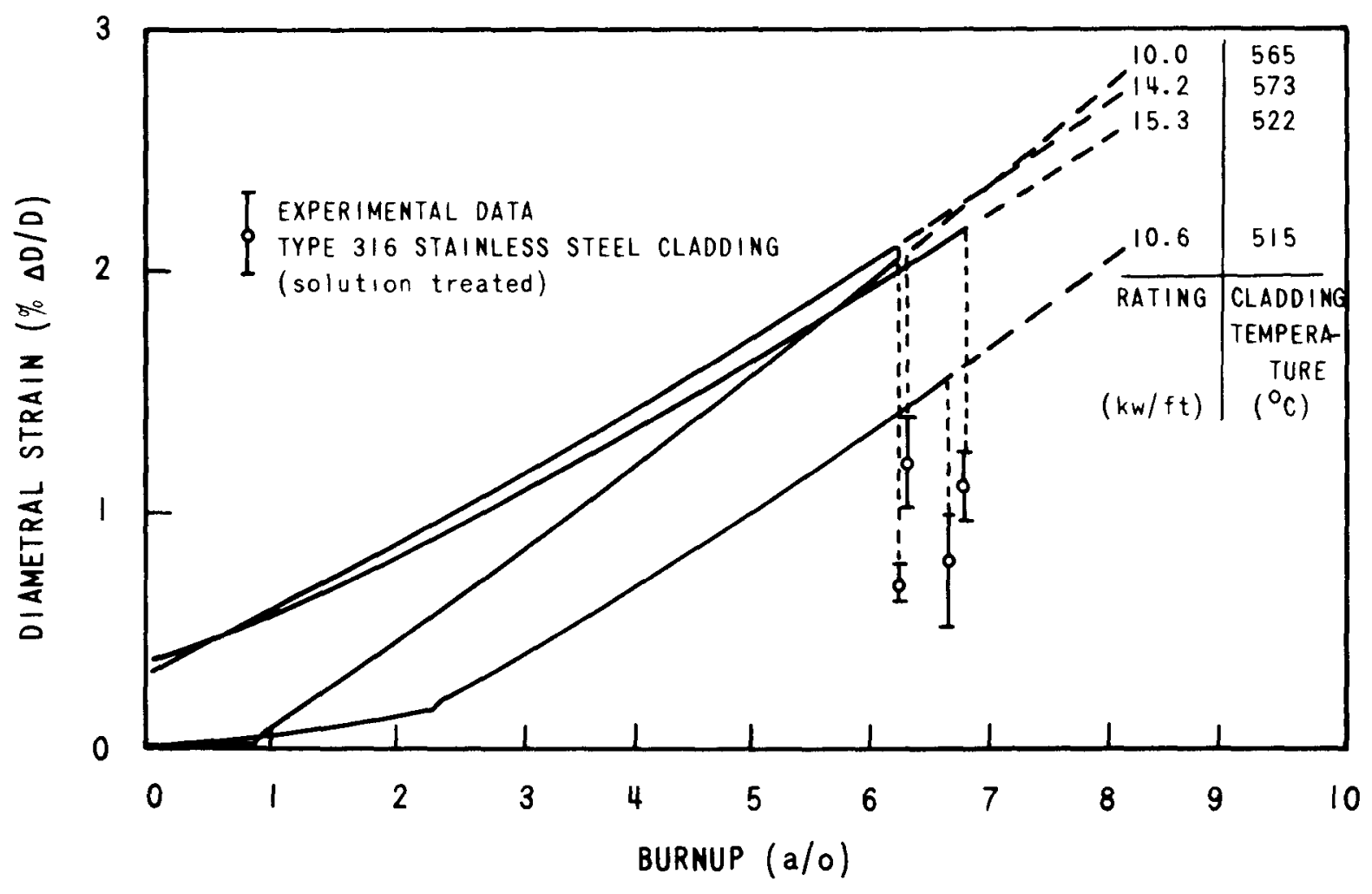

Figure 4-1. CYGRO-F Analysis of EBR II Pin Diametral Strans $3679-27$ 
6. The solution-treated property data used in the analysis may not be appropriate for the cladding used for the experimental pins; e.g., in fabrication of the EBR-II pins, a moderate amount of cold work (2-5\%CW estimated) was introduced. The level of cold work may have significant effects on the cladding swelling.

7. Frequent major fluctuations in operating conditions which are known to occur in EBR-II may significantly effect fuel behavior.

\section{Pin Parameter Sensitivity Study}

The sensitivity of pin behavior to a limited range of pin design parameters was studied using the average, peak, and hot FFTF pin operating conditions as a basis. Emphasis was placed on the peak pin.

The parameters studied included:

1. Fuel-cladding gap - 2.5 to $5.5 \mathrm{mils}$ diametral

2. Smeared density - 86 to $92 \%$

3. Pellet density -89.5 to $95.8 \%$

4. Cladding mechanical properties

Although the present version of the code does not include irradiation-induced creep of the cladding, most of the results provide relative effects of changing pin parameters. The studies demonstrated the detailed analytical capabilities of the CYGRO-F code and provide a basis for further revisions. The mafor results extracted from these studies to date are summarized below:

1. Although total diametral strain is important for core design and for comparison with experimental data, it is not the most sensitive Index for assessing cladding performance. Figure 4-2 shows the relative insensitivity of total strain to smear density for the peak FFTF pin. A small density effect is apparent; but it is relatively Insignificant compared to the total strain resulting from cladding swelling.

2. The maximum plastic strain within the cladding is a more sensitive parameter than total diametral strain, or the diametral mechanical strain (for small values). These latter two strains represent averages across the cladding crosssection. Plastic deformation is not uniform throughout the cladding cross-section or in the three princlpal directions. Also, the maximum plastlc strain is probably the most significant parameter of the three since it is expected to control initiation of cracking. The sensitivity of maximum plastic strain to pellet and smear densities is shown in Figure 4-3 and 4-4. Although these strains are small, it 


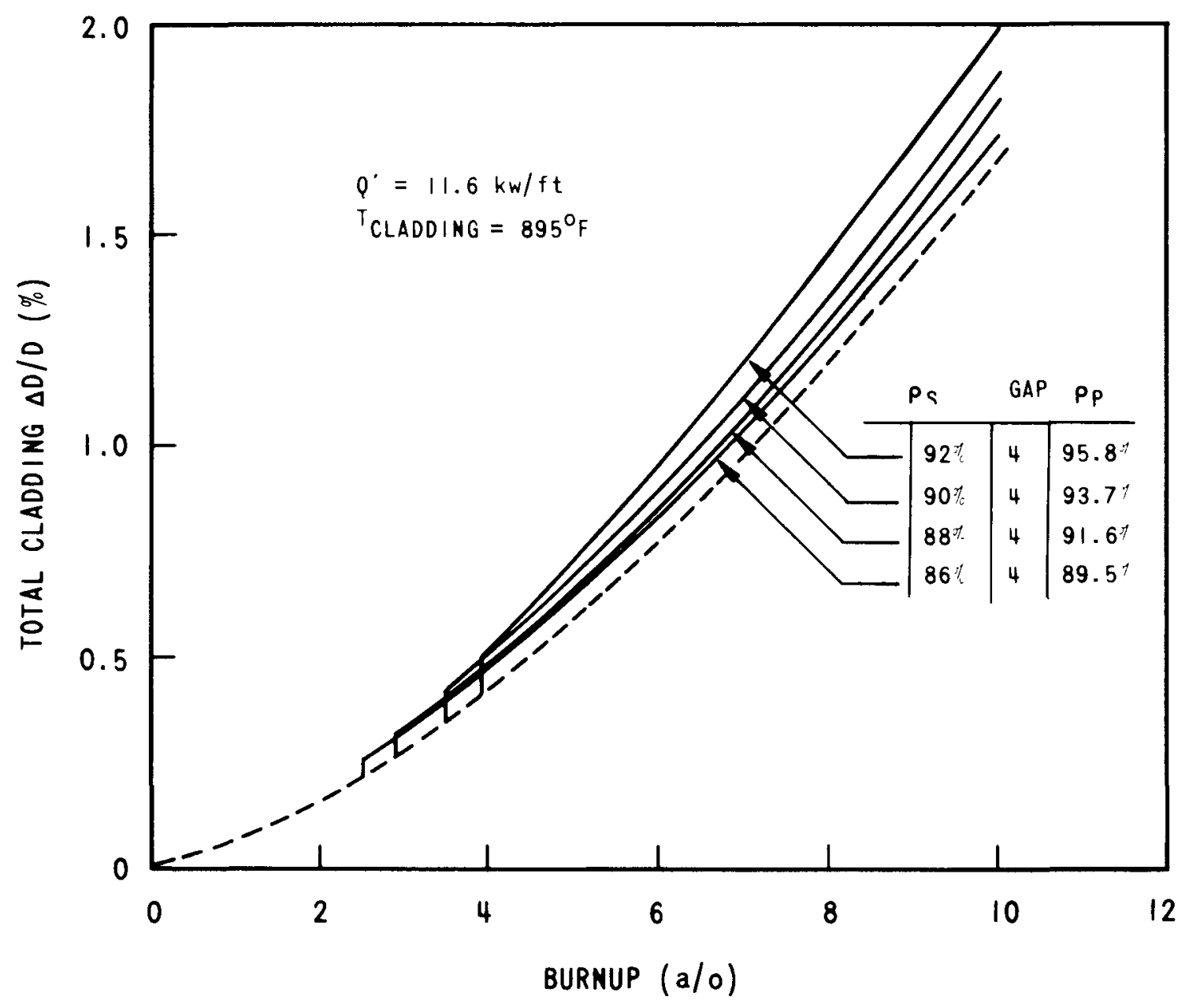

Figure 4-2. Effect of Pin Parameters on Cladding Diametral Strains $3679-28$ 


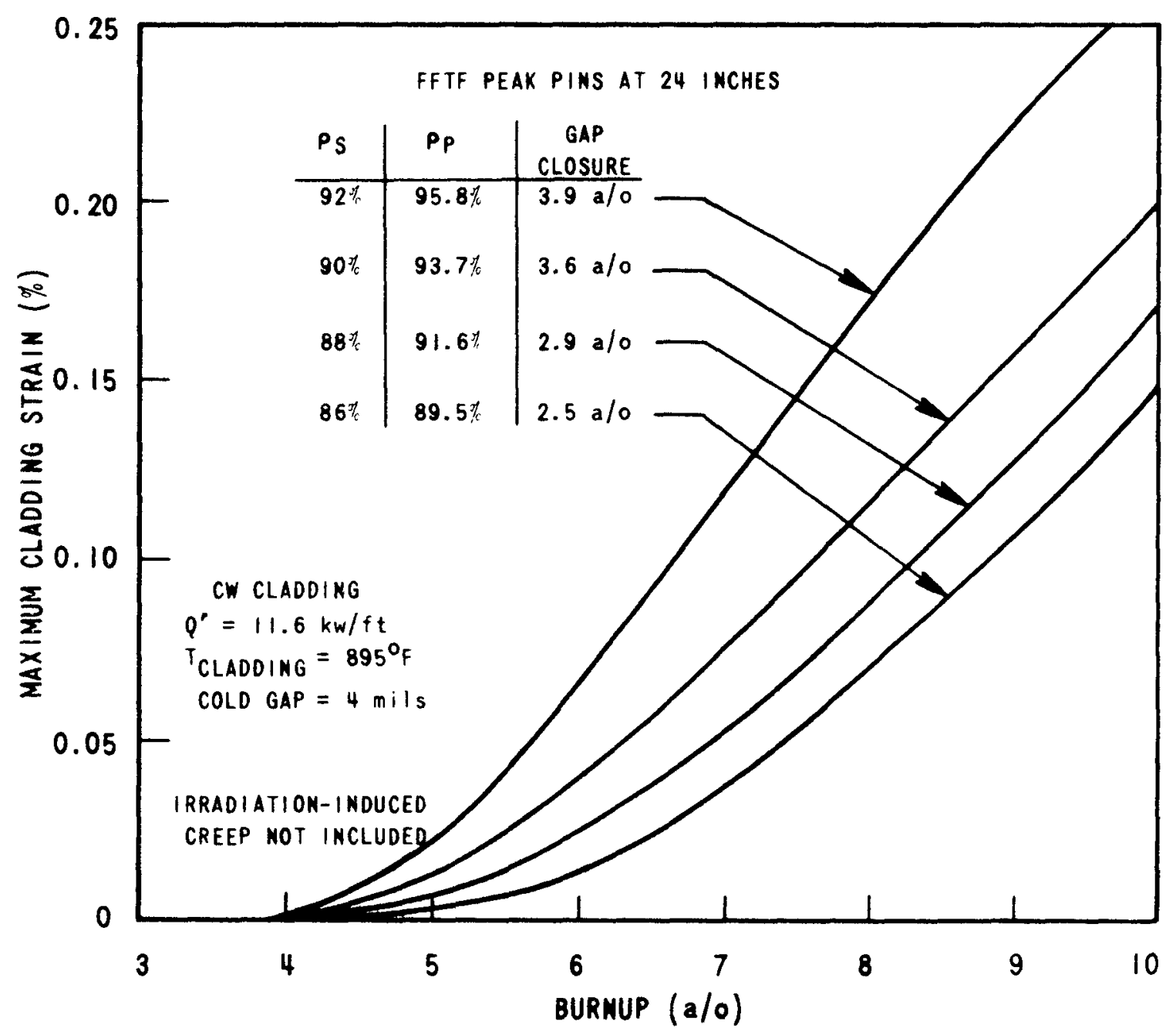

Figure 4-3. CYGRO F-Effect of Pellet Density on Maximum Cladding Stran $3679-29$ 


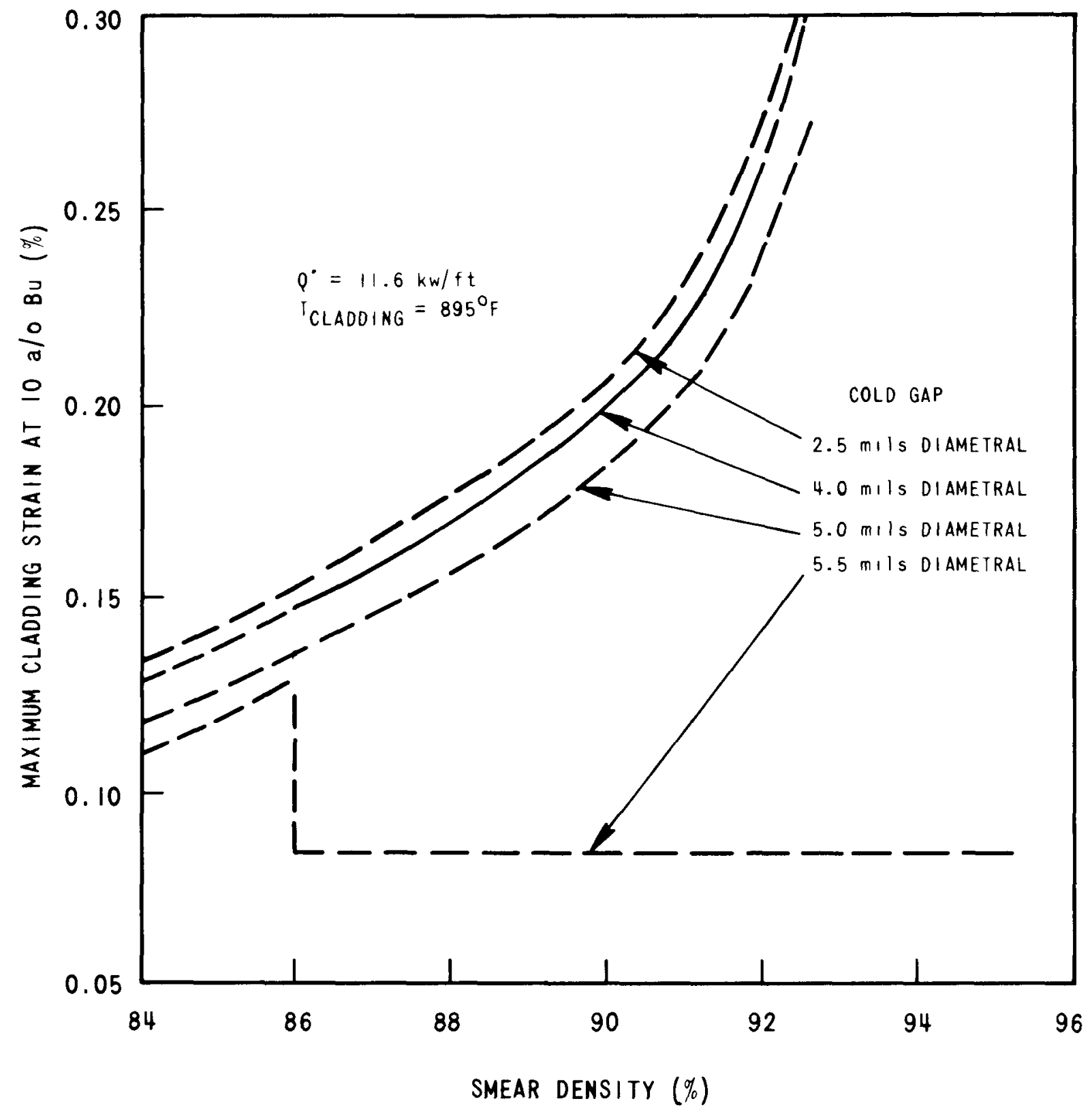

Figura 4-4. Effect of Smedr Density on Maximum Cladding Stian 3679-8 
must be noted that the present FFTF design criterion is a maximum total mechanical strain of $0.2 \%$.

3. For the cladding temperatures studied, a minimum stress level of $\sim 30,000$ psi must be attained before any significant mechanical strain occurs. This effect can be seen by examining Figures 4-5 and 4-6. In some cases this stress is not attained unt1I an appreciable time after fuel-cladding contact has occurred. Fue1-cladding contact loads do not increase significantly during this strain-1ncubation perlod. Fission gas pressure stresses are also small (2000-3000 psi) compared to the total stress during this period. Thus, the internal stresses in the cladding are the only ones that are increasing significantly with time. The mafor source of internal stresses is the differential cladding swelling which results from the temperature gradient in the cladding. Although the internal stresses may cause localized plastic deformation, the persistance of an elastic zone minimizes external dimensional changes. However, it appears that once the minimum stress level is reached, the addition of a small external force (fuel swelling, gas pressure, etc.) causes the elastic region to "yleld" and significant deformation then begins to occur. The tendency towards constant stress-constant strain rate conditions shown in Figures 4-5 and 4-6 is consistent with this explanation. It must be emphasized, however, that irradiation-induced creep (in an actual pin or when incorporated in the code) is expected to significantly relax the internal stress. Thus, the code results (requirement of a minimum stress level) suggest that very little mechanical strain will occur due to fuel-cladding interaction in an actual pin for the operating conditions studied.

4. Use of solution-treated creep properties with cold-worked swelling significantly relaxes the maximum stresses but at the expense of some additional maximum plastic strain. These results are shown in Figures $4-7$ and 4-8. This combination of properties was used to examine the effects of designing the fuel pin with solution treated mechanical properties. The results also indicate the trend to be expected when irradiation-induced creep is included in the code.

Additional analysis of these results is in progress to identify the direction of further development of the code.

\section{Axial Deformation Analysis}

A study was made of the axial strain rates in CYGRO-F. As the fuel and cladding swell and expand radlally, they also deform axlally, but under the condition that the radial coordinates remain plane and normal to the $z$-axis. Thus, all the annull of the fuel strain axially an equal amount, as do the cladding annuli; the amounts or rates of each belng dependent upon the internal conditions of each. 


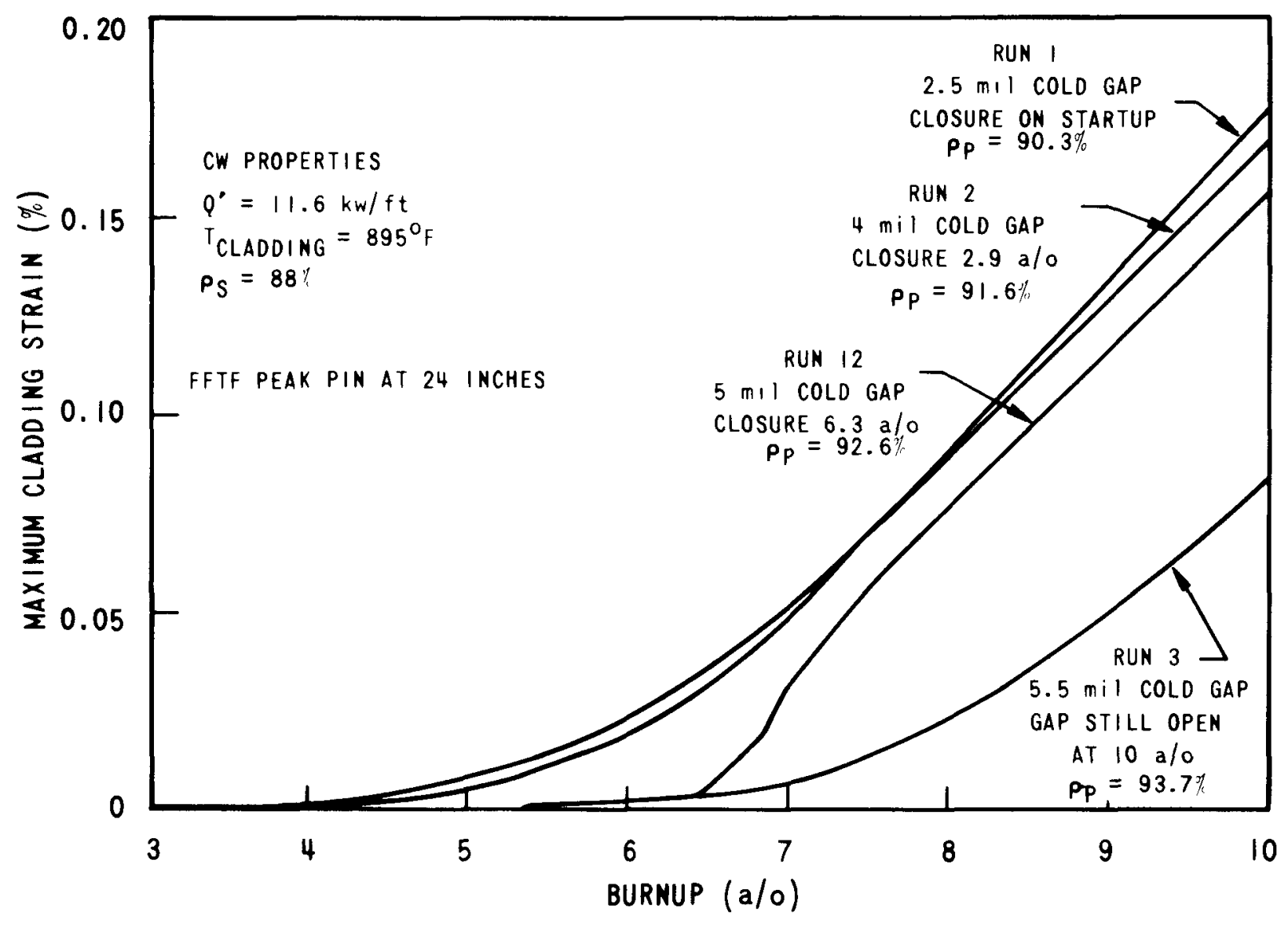

Figure 4-5. CYGRO-F Effect of Gap on Maximum Cladding Strain

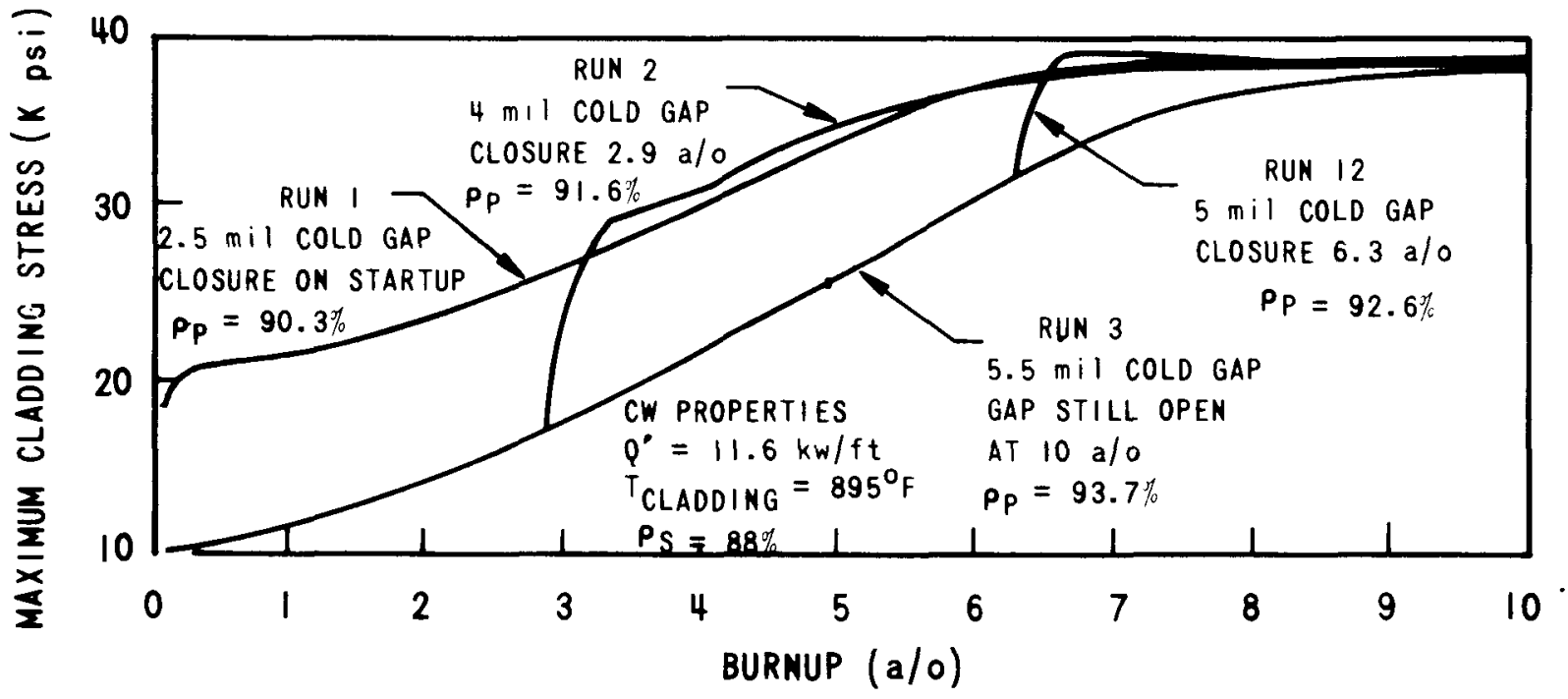

Figure 4-6. CYGRO-F Effect of Gap on Maximum Cladding Strain $3679-6-7$ 


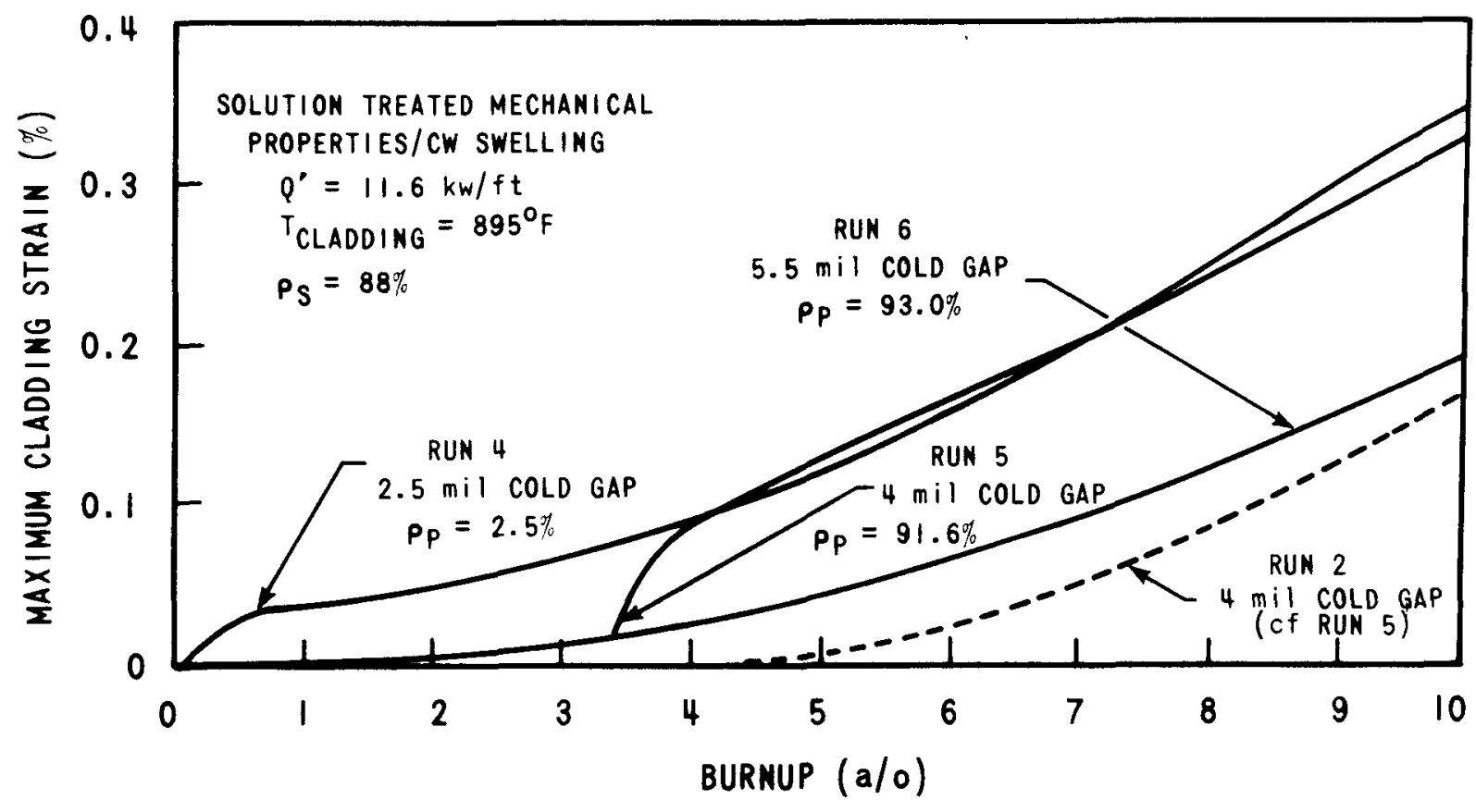

Figure 4-7. Maximum Cladding Strains

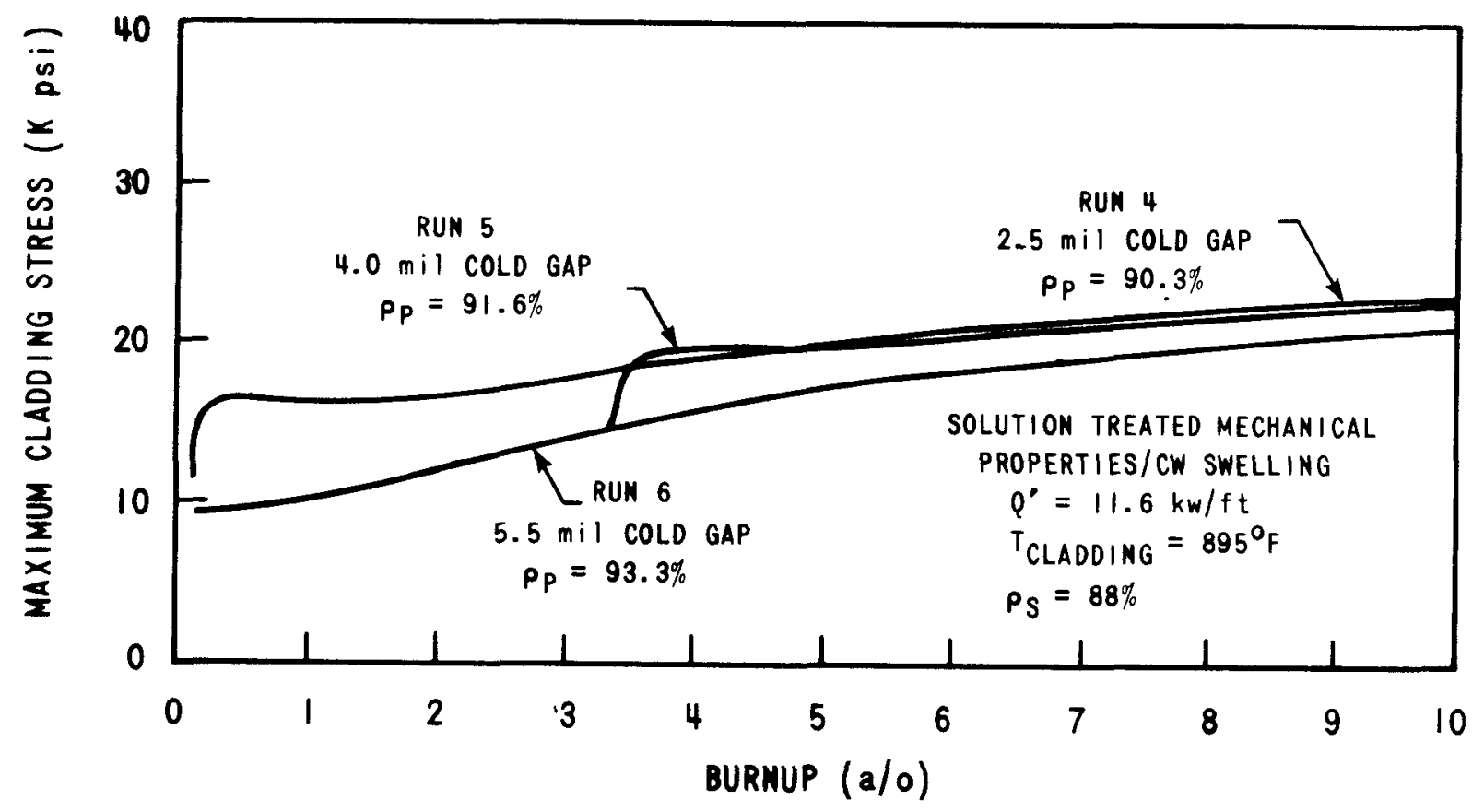

Figure 4-8. Maximum Cladding Stresses 
As long as the fuel-cladding gap is open, the fuel and cladding strain independently; but once the gap closes, interaction forces begin to build up and a frictional force is introduced to make the fuel and cladding axial strain rates equal. The effect of varlous values of this friction, which is defined as the ratio of axial force to radial force, is shown in Figure 4-9. Before contact, all results show that the fuel axial strain rates decrease throughout life while the cladding axial strain rates continually increase slightly. After contact, the fuel axial strain rate is nearly identical to that of the cladding alone when the friction factor exceeds 0.1 , suggesting substantial restraint of axial fuel swelling.

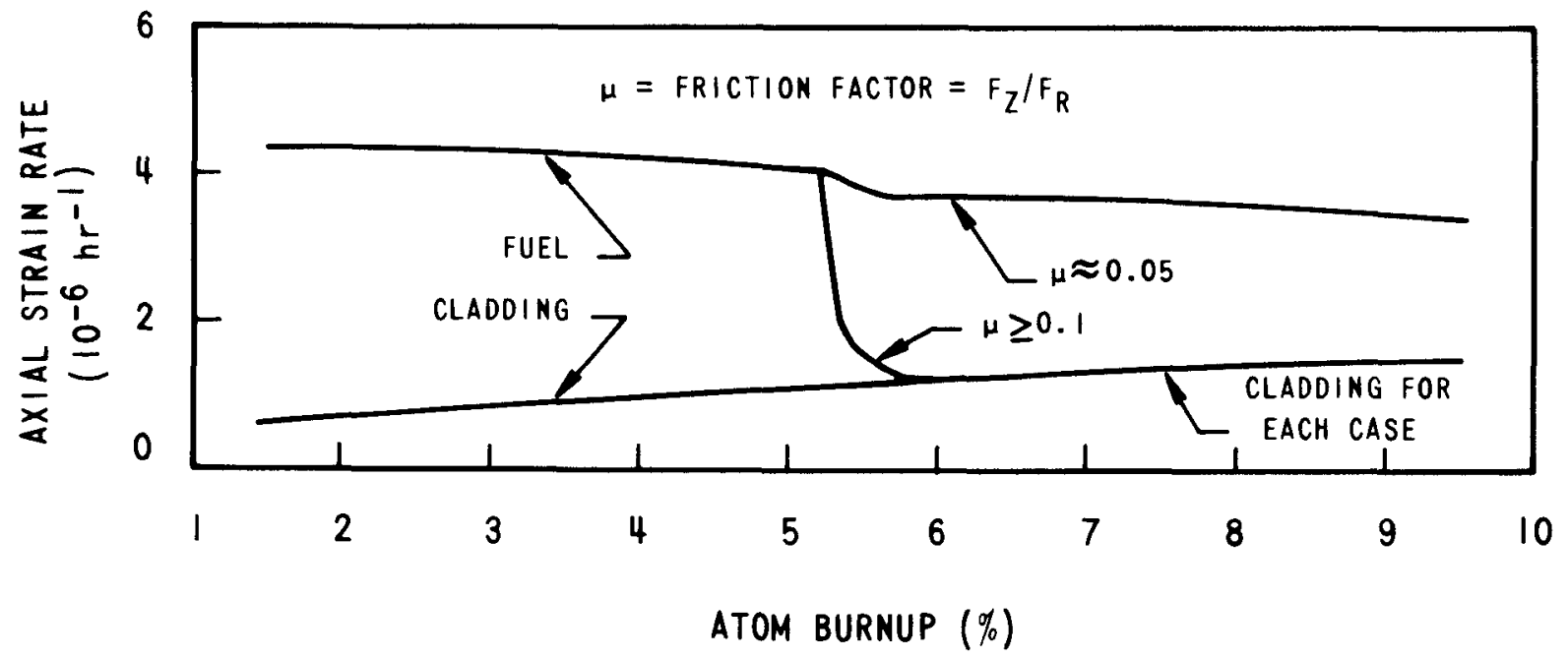

Figure 4-9. Effect of Fuel-Cladding Interaction on Axial Strain Rates $3679-5$ 


\section{SECTION 5 \\ OFBA-310 ENCAPSULATED MIXED-OXIDE FUEL PIN IRRADIATION TESTS}

A. Blancherla, R. Borst, T. Damico, R. K. Dawless, P. J. Levine, R. A. Markely, U. P. Nayak, J. F. Patterson

\section{OBJECTIVES}

The objectives of this work are to plan, conduct, and evaluate in-reactor experiments of critical areas of spectal sensitivity to fuel-pin behavior analysis.

\section{PRIOR WORK}

Design, performance, and safety analysis of the WSA-1 and WSA-2 subassemblies were completed except for the four fuel pins containing axial fuel motion restrictors. Analysis of these four pins was conducted with emphasis on thermal behavior of the restrictors.

\section{CURRENT PROGRESS}

The data package for WSA-1 and WSA-2 (except for the four fuel pins with fuel motion restrictors) was submitted to the EBR-II Project. Subassembly WSA-2 was shipped to EBR-II and Inserted in the reactor at the start of run 41B on March 27, 1970.

\section{Design of Fuel Motion Restrictors and Fuel Pin}

The design of the fuel motion restrictor was completed. A schematic of the restrictor is shown in Figure 5-1. The restrictor is attached to the cladding by isostatically compressing the cladding into the "V" groove shown in the Figure. Each fuel pin contains four restrictors including one coincident with the top of the core. Two types of restrictor arrangements are used in the fuel-pin assembly as shown in Figures 5-2 and 5-3. Fuel pin and capsule data are given in Tables 5-1 and 5-2.

\section{Thermal Analysis}

The arrangement of restrictors divides the fuel stack into four separate columns. The CAPSULE code was modifled to perform incremental temperature calculations along the pin contalning these four separate columns. Heat transfer to the coolant at the axial gaps and along the stainless steel restrictors was neglected in these calculations. With this assumption the mean coolant, capsule outer surface, capsule inner surface, cladding outer surface, cladding Inner surface, and fuel surface temperatures were calculated at selected axtal positions in each column. The FREUD code was used 


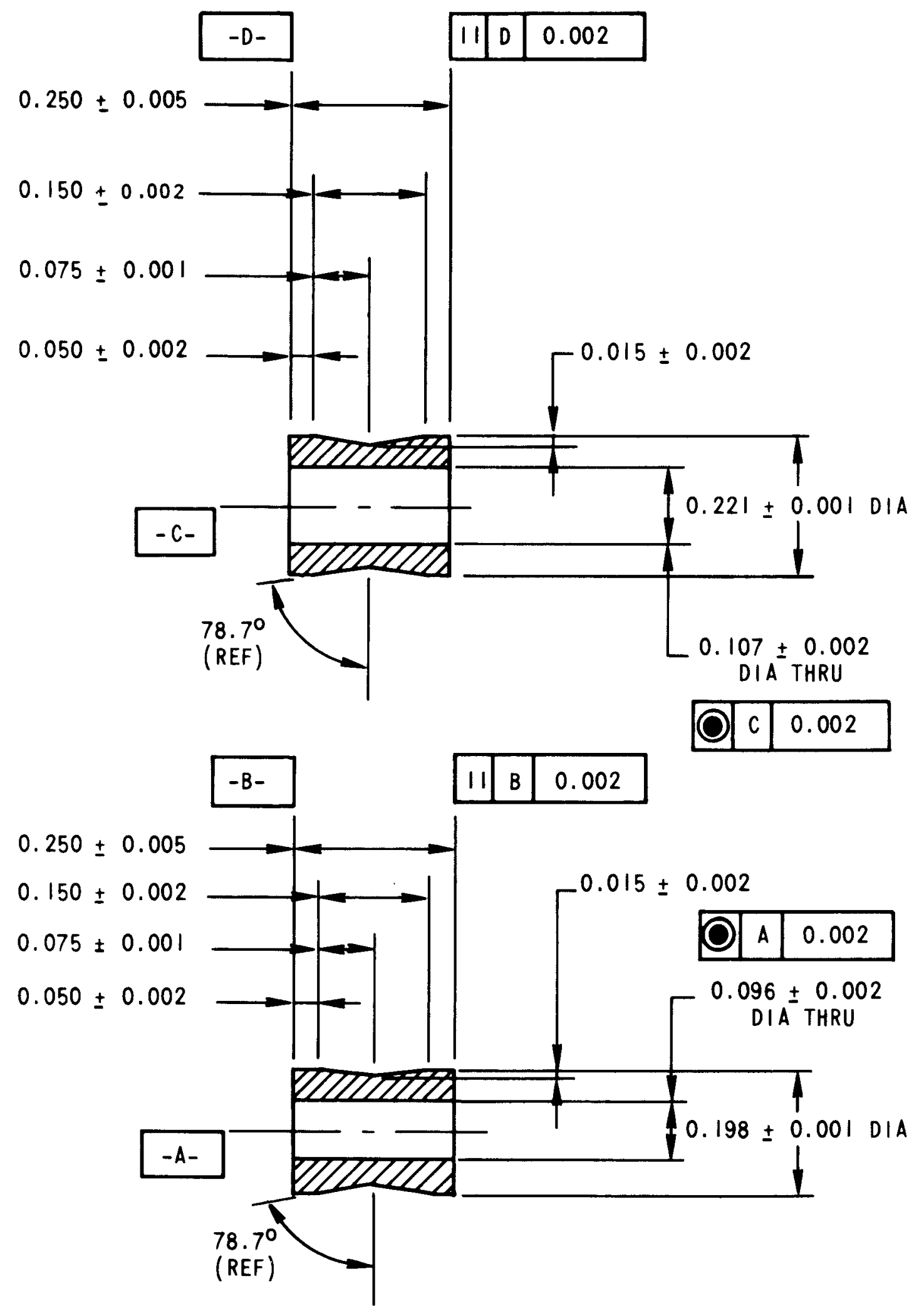

Figure 5-1. Axial Fuel Motion Restrictor

$3679-14$ 


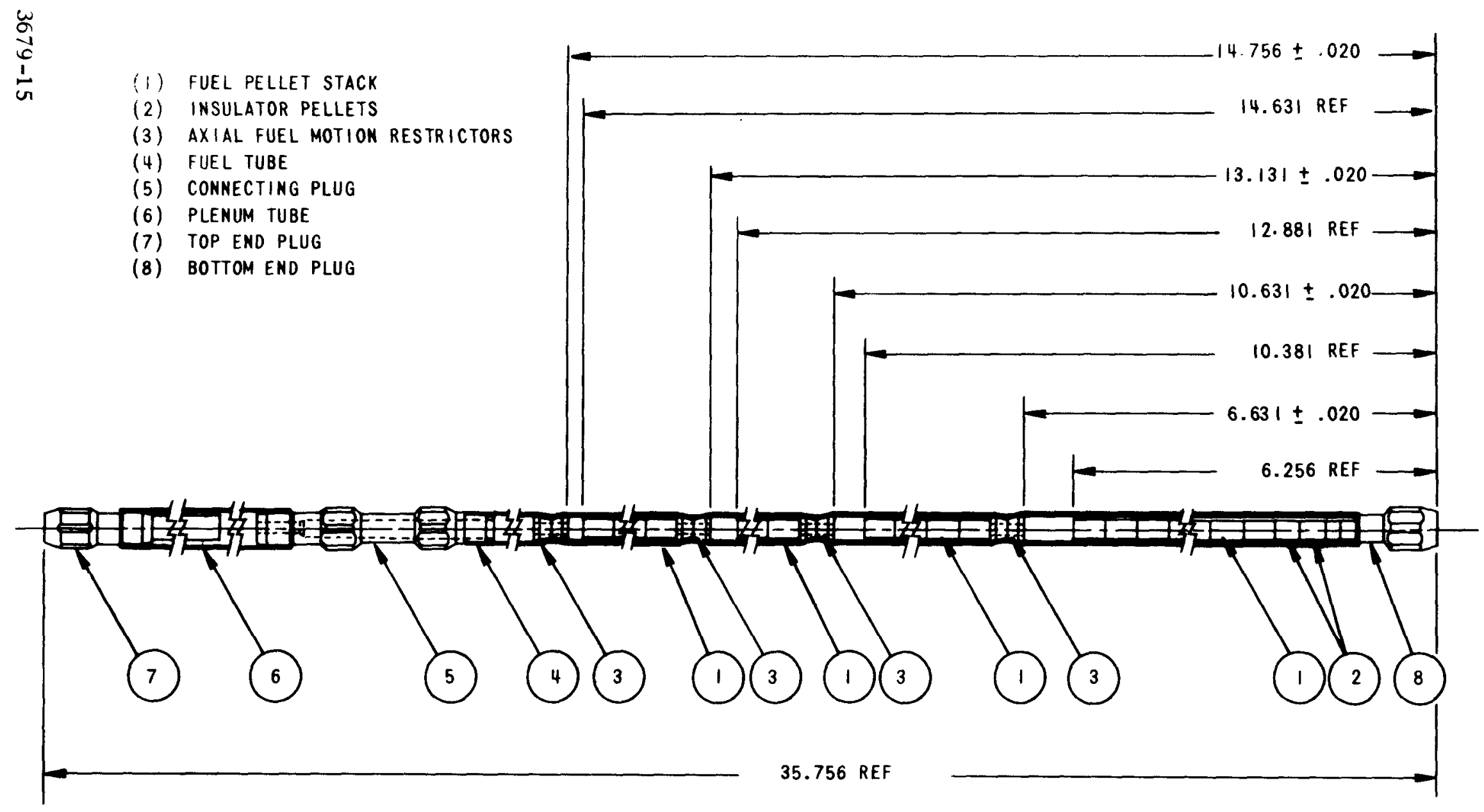

Figure 5-2. Fuel Pin Assembly with Axial Fuel Motion Restrictors - Type 1 (W1-16S and W1-18S) 
\& (1) FUEL PELLET STACK

(ै) (2) INSULATOR PELLETS

(1) AXIAL FUEL MOTION RESTRICTORS

(4) FUEL TUBE

(5) CONNECTING PLUG

(6) PLENUM TUBE

(7) TOP END PLUG

(8) BOTTOM END PLUG

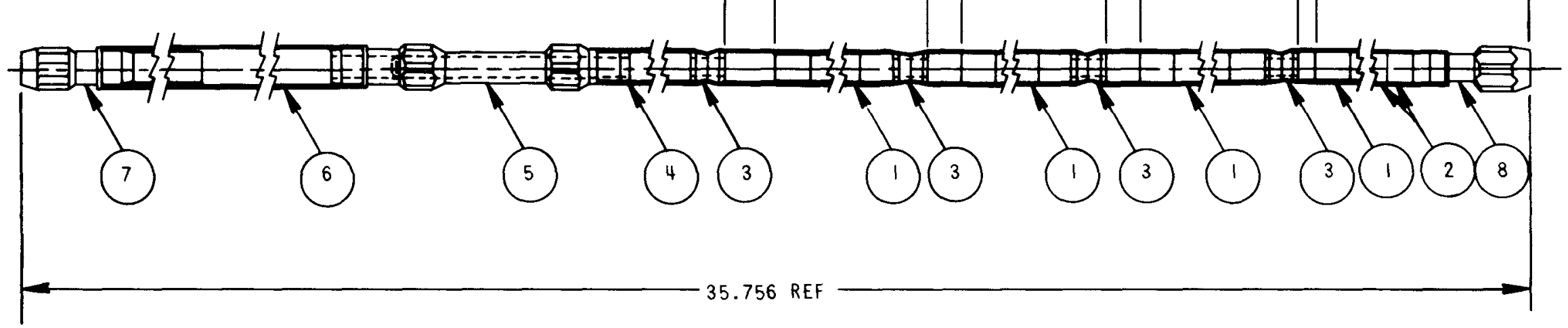

Fizure 5-3. Fuel Pin Assembly with Axial Fuel lot ion Restrictors Type 11 (W1 17S an W1 195) 


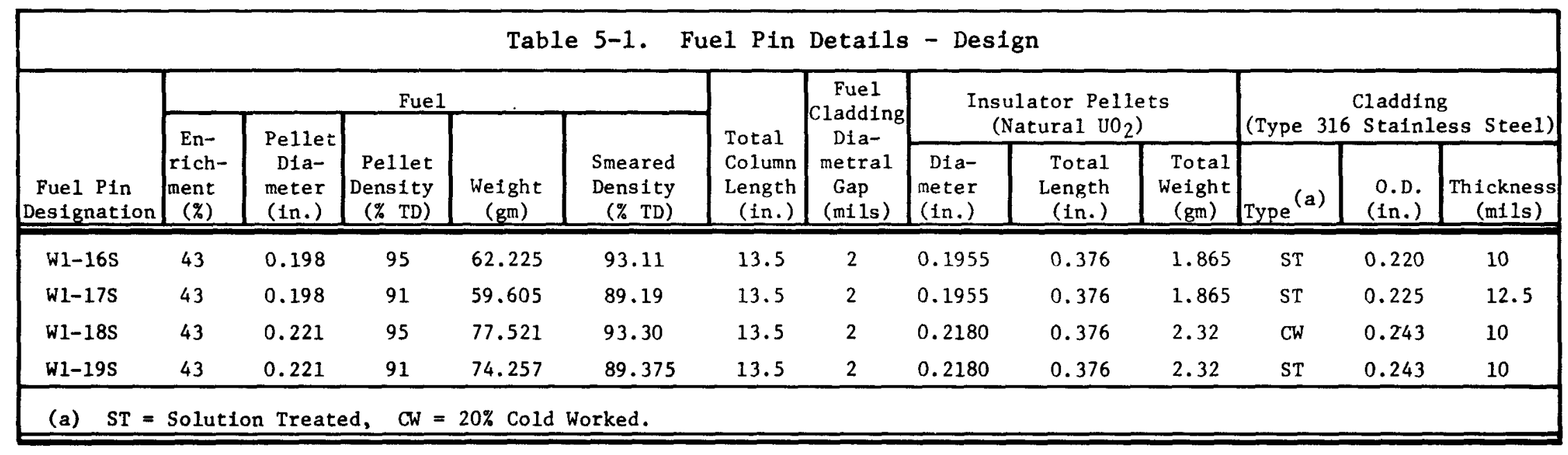

\begin{tabular}{|c|c|c|c|c|c|c|c|}
\hline $\begin{array}{c}\text { Pin } \\
\text { Number }\end{array}$ & $\begin{array}{l}\text { Fuel Pin } \\
\text { Fill Gas } \\
\end{array}$ & $\begin{array}{l}\text { Fuel Pin } \\
\text { Gas Plenum } \\
\left.\text { Vo1. (1n. }{ }^{3}\right) \\
\end{array}$ & $\begin{array}{r}\text { Sodium } \\
\text { Level in } \\
\text { Capsule (in.) }\end{array}$ & $\begin{array}{c}\text { Sodium } \\
\text { Volume in } \\
\text { Capsule (in. }{ }^{3} \text { ) }\end{array}$ & \begin{tabular}{|c} 
Sodium \\
Weights in \\
Capsule (g) \\
\end{tabular} & $\begin{array}{r}\text { Capsule } \\
\text { Fill Gas } \\
\end{array}$ & $\begin{array}{c}\text { Capsule } \\
\text { Gas Plenum } \\
\text { Vol. (in. }{ }^{3} \text { ) } \\
\end{array}$ \\
\hline W1-16S & Helium & 0.895 & 26.01 & 0.9981 & 15.84 & Helium & 0.3189 \\
\hline W1-17S & Helium & 0.895 & 26.01 & 0.9708 & 15.41 & Helium & 0.3189 \\
\hline W1-18S & Helium & 0.895 & 25.90 & 0.8637 & 13.71 & Helium & 0.3208 \\
\hline W1-19S & Helium & 0.895 & 25.90 & 0.8637 & 13.71 & Helium & 0.3208 \\
\hline
\end{tabular}


calculate fuel centerline temperatures.

W1-19S is one of the highest rated fuel pins (with restrictors) and has the highest fuel temperatures. Complete temperature profiles are shown for this fuel pin in Figure 5-4 for nominal conditions and Figure 5-5 for hot channel conditions. The discontinuities in the profiles indicate the positions of the restrictors.

A summary of the maximum power ratings, peak operating temperatures, and burnups for both nominal and hot channel conditions is presented in Table 5-3.

The fuel motion restrictor located about 1.25 inch above the core midplane in pin w1-19S was selected for detailed thermal analysis, since this restrictor is exposed to highest fuel temperatures.

The TOSS code was used to perform a two dimensional heat transfer analysis. This code uses a finite difference technique. The physical problem is analyzed by dividing the specific region into nodes of various types which are used to model the heat transfer processes. For this analysis, it was assumed that both conduction and radiation occur between the restrictor and the fuel which is directly above and in contact with it. The fuel below the restrictor is separated by a substantial gap and hence only radiative heat transfer is effective.

Parametric studies performed with the TOSS Code showed that conductance between restrictor and cladding was the important factor in determining restrictor temperatures. Results indicated that good thermal contact in this region was desirable to minimize the restrictor temperature. The crimping process that was developed does provide an excellent restrictor-cladding contact.

The TOSS studies also showed that increasing the conductance between fuel and cladding reduces the restrictor temperatures as well as the fuel temperatures. The effects of the contact conductance between the fuel and restrictor was small over the range studied ( 1000 to $\left.4000 \mathrm{Btu} / \mathrm{hr}-\mathrm{ft}^{2} \mathrm{I}^{\circ} \mathrm{F}\right)$. The axial gradient produced in the fuel was of much greater importance and for this reason, more fuel nodes were used in the region of the fuel restrictor interface.

For the analysis of the restrictor in Pin W1-19S, a beginning-of-life case and an end-of-life case were considered. In order to calculate the beginning of life restrictor to cladding conductance, a maximum cold radial gap of $1.5 \mathrm{mils}$ was assumed to exist along the full length of the restrictor. This is quite conservative in that the crimping process produces intimate contact in the crimp region. The end-of-life conductance was calculated assuming the gap contains fission gas rather than helium. The end-of-life gap size was calculated by allowing the cladding to swell at the appropriate rate while swelling of the restrictor was neglected. This approach produces the maximum gap opening. The effect of differential thermal expansion on the gap size was included in both cases.

Fuel and restrictor axial temperature profiles at selected radil are shown in Figures 5-6 and 5-7 for the beginning-of-life and end-of-life cases, respectively. The calculated values of the conductances are given in these 


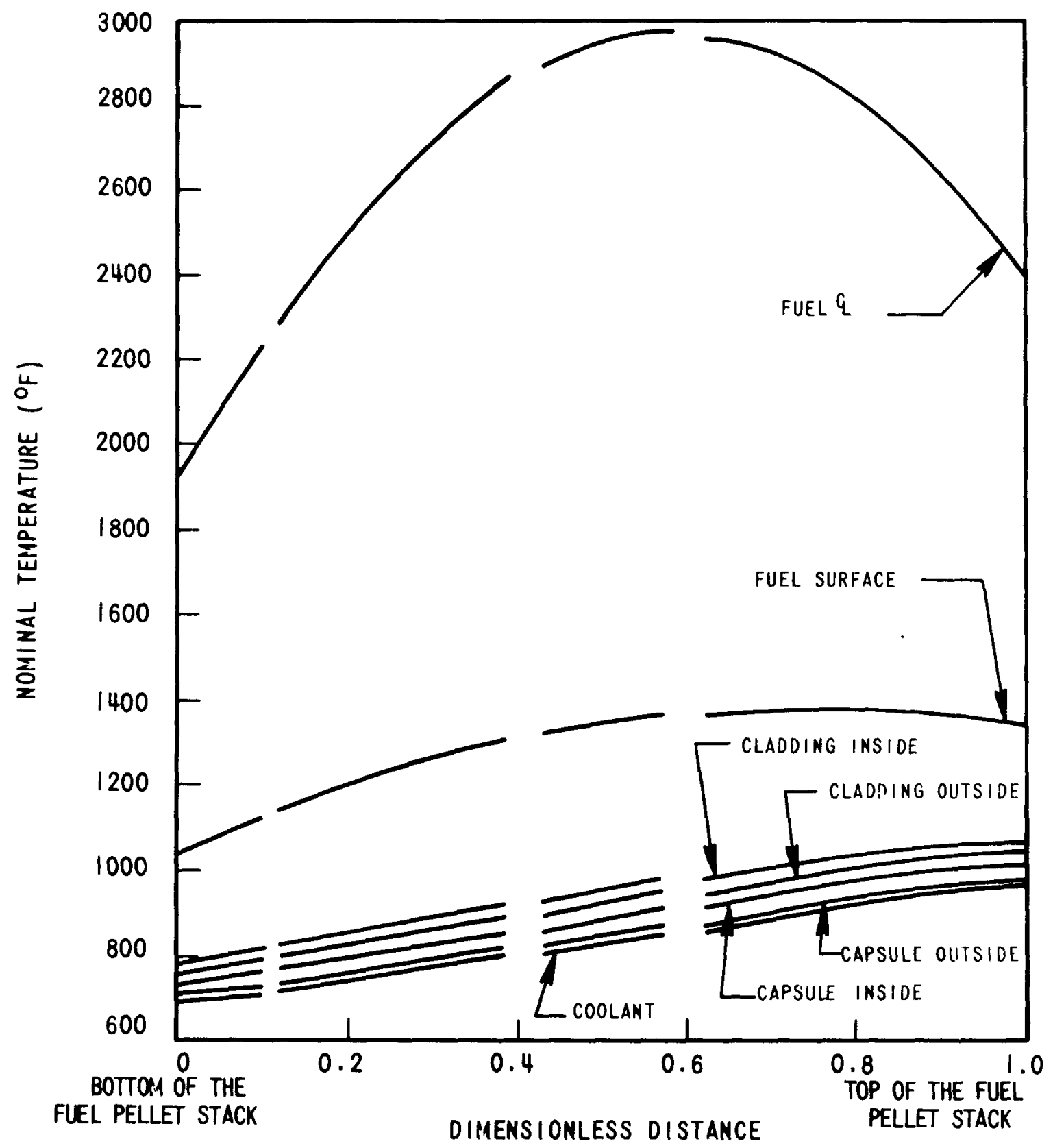

Figure 5-4. Capule Temperature Profiles W1 - 19S Nominal Concition $3679-17$ 


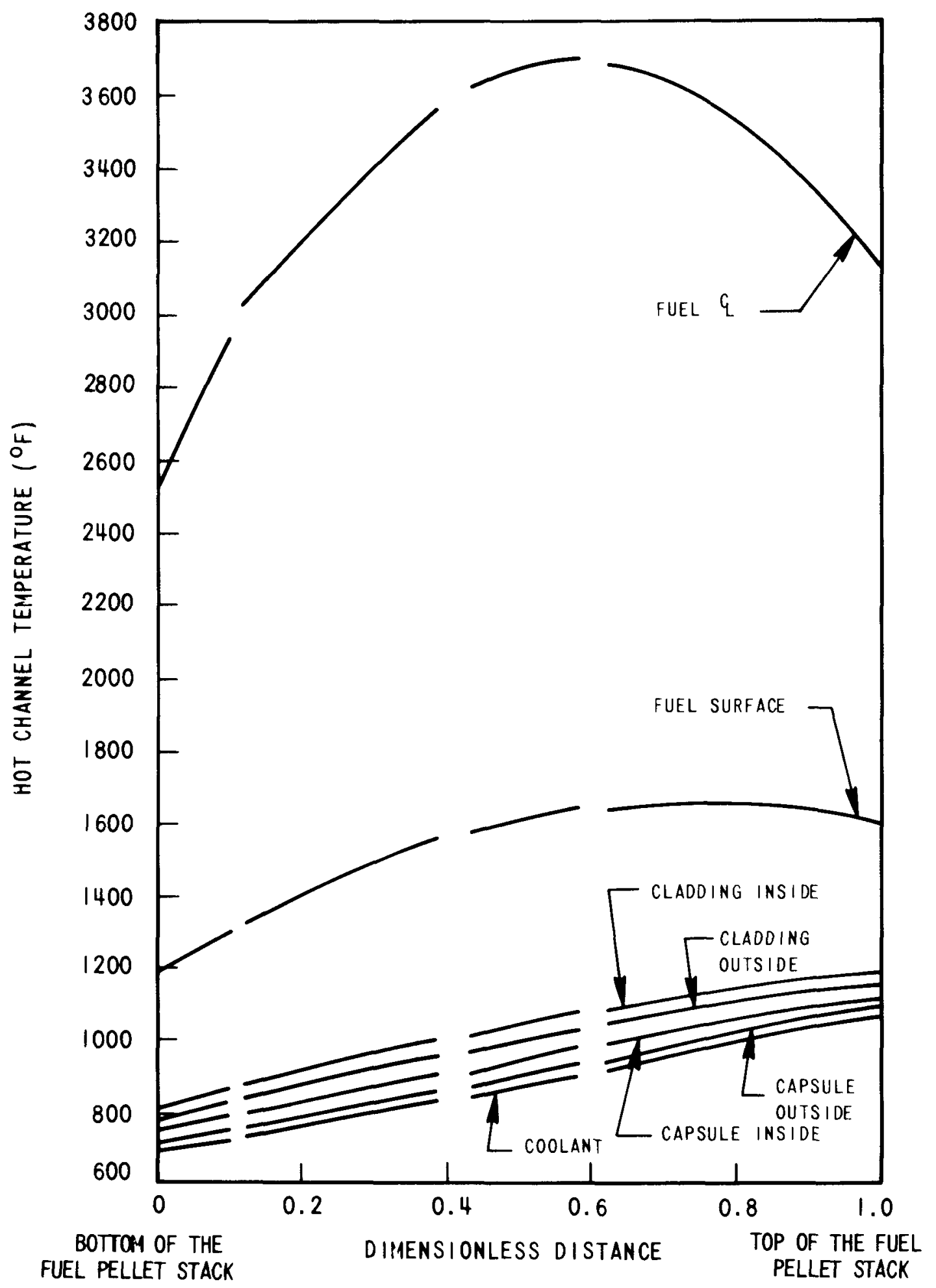

Figure 5-5. Capsule Temperature Profiles 1.1 19S loot Chanel Conclitions

$3679-18$ 


\begin{tabular}{|c|c|c|c|c|c|c|c|c|c|c|c|}
\hline \multicolumn{12}{|c|}{ Table 5-3. Operating Conditions } \\
\hline \multicolumn{12}{|c|}{ Nomina1 Peak Operating Conditions } \\
\hline \multirow{2}{*}{$\begin{array}{c}\text { Pin } \\
\text { Number }\end{array}$} & \multirow{2}{*}{$\begin{array}{l}\text { Linear } \\
\text { Rating } \\
(\mathrm{kw} / \mathrm{ft})\end{array}$} & \multirow{2}{*}{$\begin{array}{c}\text { Total } \\
\text { Pin Heat } \\
\text { Gener- } \\
\text { ation } \\
(\mathrm{kw})\end{array}$} & \multirow{2}{*}{$\begin{array}{l}\text { Coolant } \\
\text { Outlet } \\
\text { Temp. } \\
\left({ }^{\circ} \mathrm{F}\right)\end{array}$} & \multirow{2}{*}{$\begin{array}{c}\text { Capsule } \\
\text { Outer } \\
\text { Surface } \\
\text { Temp. } \\
\left({ }^{\circ} \mathrm{F}\right)\end{array}$} & \multirow{2}{*}{$\begin{array}{c}\text { Capsule } \\
\text { Inner } \\
\text { Surface } \\
\text { Temp. } \\
\left({ }^{\circ} \mathrm{F}\right)\end{array}$} & \multirow{2}{*}{$\begin{array}{c}\text { Cladding } \\
\text { Outer } \\
\text { Surface } \\
\text { Temp. } \\
\left({ }^{\circ} \mathrm{F}\right)\end{array}$} & \multirow{2}{*}{$\begin{array}{l}\text { Cladding } \\
\text { Inner } \\
\text { Surface } \\
\text { Temp. } \\
\left({ }^{\circ} \mathrm{F}\right)\end{array}$} & \multirow{2}{*}{$\begin{array}{c}\text { Fuel } \\
\text { Surface } \\
\text { Temp. } \\
\left({ }^{\circ} \mathrm{F}\right)\end{array}$} & \multirow{2}{*}{$\begin{array}{l}\text { Fue1 } \\
\text { Center- } \\
\text { line } \\
\text { Temp. } \\
\left({ }^{\circ} \mathrm{F}\right)\end{array}$} & \multicolumn{2}{|c|}{ Burnup } \\
\hline & & & & & & & & & & $(a / 0)$ & $\mathrm{Mwd} / \mathrm{Te}$ \\
\hline W1-16S & 5.8 & 5.1 & 902 & 910 & 928 & 951 & 969 & 1247 & 2150 & 2.9 & 23,800 \\
\hline W1-17S & 5.9 & 5.1 & 905 & 913 & 932 & 955 & 978 & 1245 & 2294 & 4.9 & 40,200 \\
\hline W1-18S & 8.1 & 7.0 & 981 & 992 & 1015 & 1041 & 1063 & 1390 & 2803 & 5.0 & 41,000 \\
\hline W1-19S & 8.0 & 6.9 & 979 & 990 & 1014 & 1041 & 1062 & 1378 & 2958 & 5.0 & 41,000 \\
\hline \multicolumn{12}{|c|}{ Peak Hot Channel Operating Conditions } \\
\hline $\begin{array}{c}\text { Pin } \\
\text { Number }\end{array}$ & \multicolumn{3}{|c|}{$\begin{array}{c}\text { Tota1 } \\
\text { Pin Heat } \\
\text { Gener- } \\
\text { ation } \\
(\mathrm{kw}) \\
\end{array}$} & $\begin{array}{l}\text { Coolant } \\
\text { Out let } \\
\text { Temp. } \\
\left({ }^{\circ} \mathrm{F}\right)\end{array}$ & $\begin{array}{c}\text { Capsule } \\
\text { Outer } \\
\text { Surface } \\
\text { Temp. } \\
\left({ }^{\circ} \mathrm{F}\right) \\
\end{array}$ & $\begin{array}{c}\text { Capsul } \\
\text { Inner } \\
\text { Surface } \\
\text { Temp. } \\
\left({ }^{\circ} \mathrm{F}\right) \\
\end{array}$ & $\begin{array}{r}\text { Clad } \\
\text { Out } \\
\text { Surf } \\
\text { Tem } \\
\left(^{\circ} \mathrm{F}\right.\end{array}$ & $\begin{array}{l}\text { ding } \\
\text { er } \\
\text { ace } \\
\text { ap. } \\
\text { ? }\end{array}$ & $\begin{array}{l}\text { Cladding } \\
\text { Inner } \\
\text { Surface } \\
\text { Temp. } \\
\left({ }^{\circ} \mathrm{F}\right) \\
\end{array}$ & $\begin{array}{l}\text { Fuel } \\
\text { Surface } \\
\text { Temp. } \\
\left({ }^{\circ} \mathrm{F}\right)\end{array}$ & $\begin{array}{c}\text { Fuel } \\
\text { Center- } \\
\text { line } \\
\text { Temp. } \\
\left({ }^{\circ} \mathrm{F}\right)\end{array}$ \\
\hline$W 1-16 S$ & 7.0 & 5 . & & 969 & 982 & 1006 & 103 & & 1062 & 1470 & 2849 \\
\hline W1-17S & 7.1 & 6 . & & 973 & 986 & 1011 & 104 & & 1074 & 1467 & 3018 \\
\hline W1-18S & 9.7 & 8. & & 1073 & 1091 & 1123 & 115 & & 1188 & 1668 & 3682 \\
\hline W1-19S & 9.6 & 8. & & 1071 & 1089 & . 1122 & 115 & & 1188 & 1652 & 3693 \\
\hline $\begin{array}{l}\text { Peak co } \\
\text { Burnup }\end{array}$ & $\begin{array}{l}\text { itions are } \\
\text { its: a/o } \\
\text { MWd/ }\end{array}$ & $\begin{array}{l}\text { not nec } \\
/ \mathrm{Te} \text { Heav } \\
\text { (fue }\end{array}$ & $\begin{array}{l}\text { cessarily } \\
\text { y atoms } \\
\text { 1) }\end{array}$ & coincid & & & & & & & \\
\hline
\end{tabular}




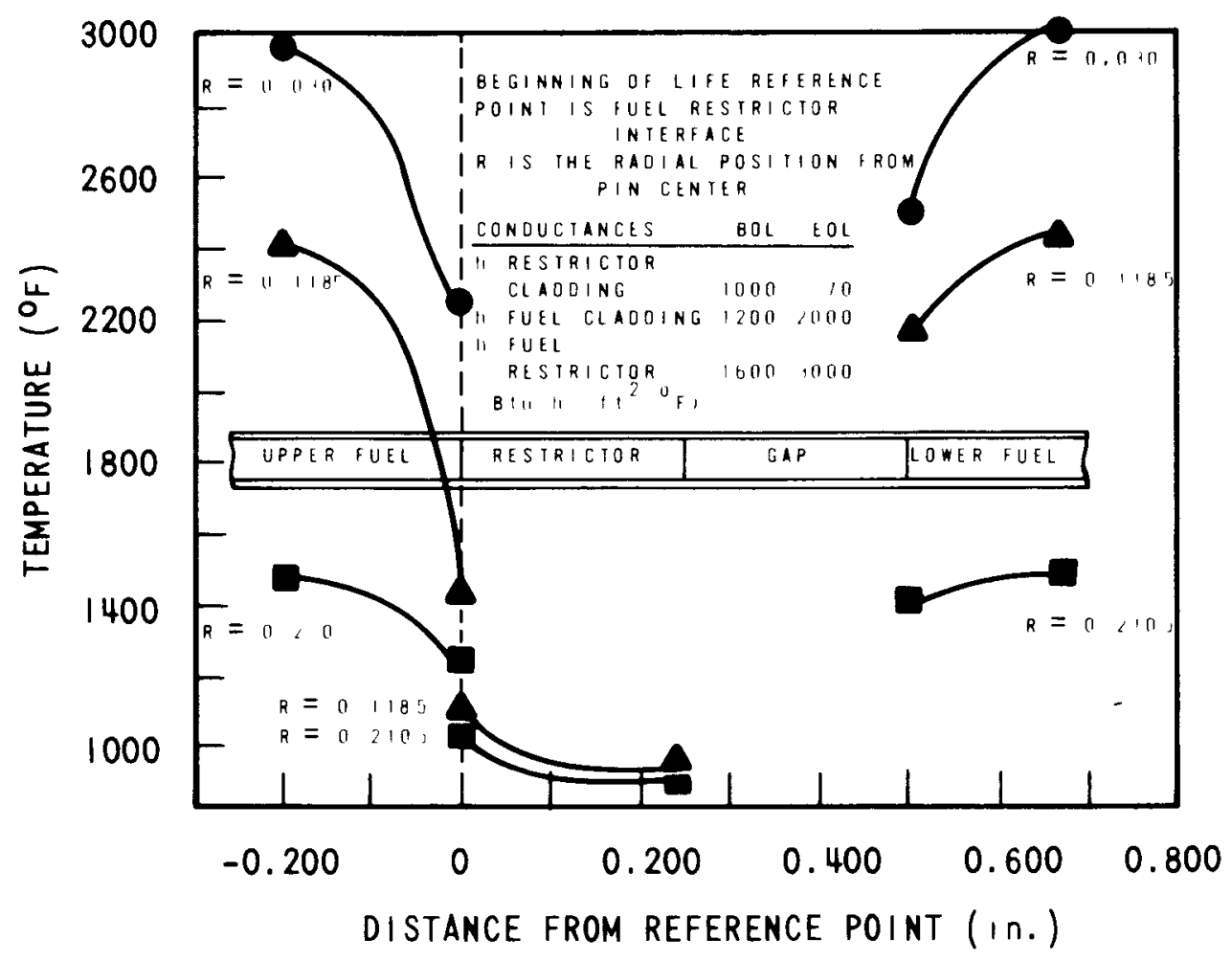

Figure 5-6. Temperature Profiles Nedi Fuel Motion RestistorBeginning of Life Conditions

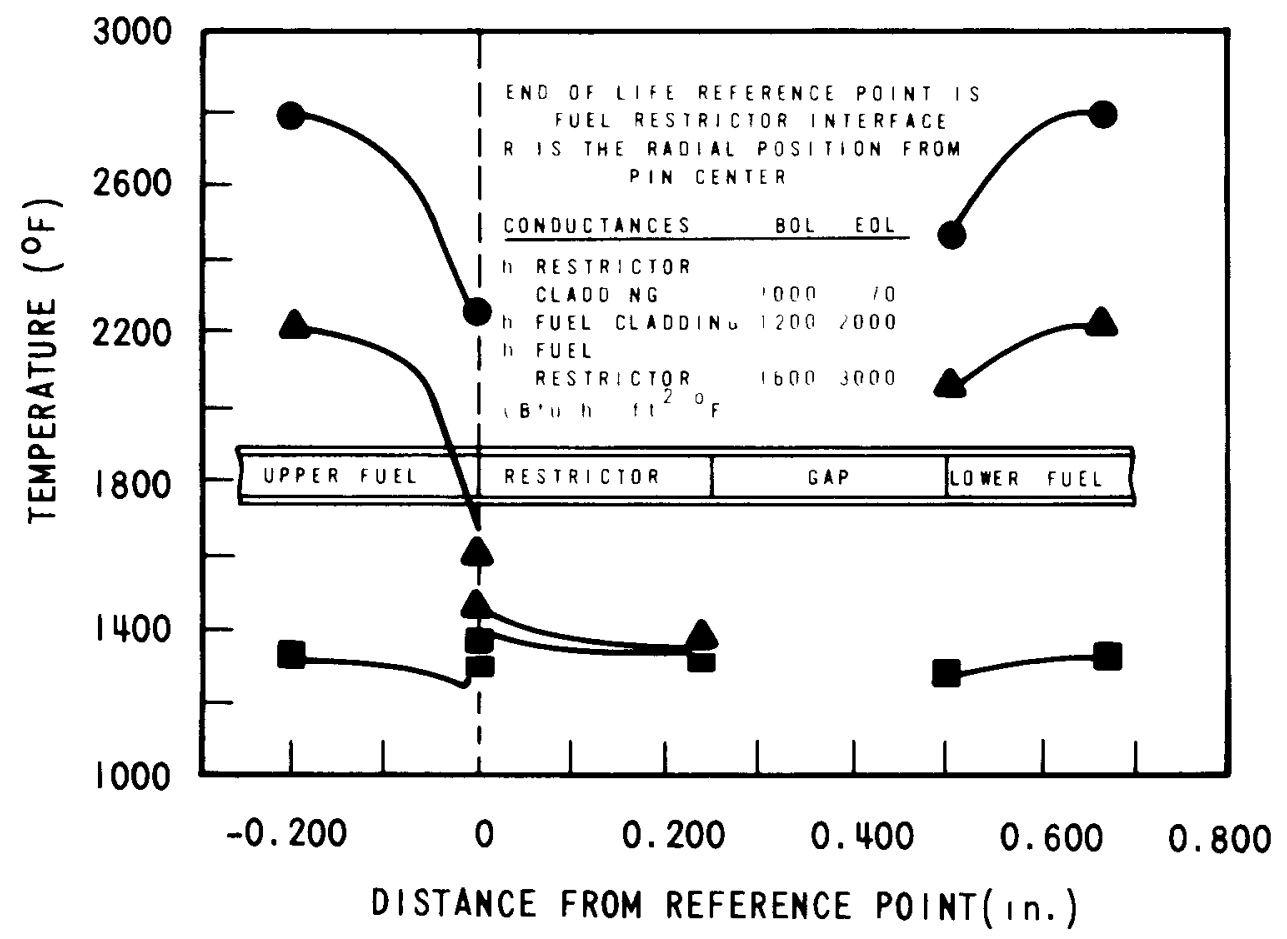

Figure 5-7. Temperatuie Profiles Near Fucl Motion RestinctorEnd of $L_{1} f($ Cond 1 t 1 ons 
figures. The maximum restrictor temperature at the beginning-of-1ife was conservatively calculated to be $1121^{\circ} \mathrm{F}$ while at the end-of-life this temperature is $1454^{\circ} \mathrm{F}$. Figure $5-8$ shows axlal temperature profiles for the capsule and cladding in the vicinity of the restrictor.

亩

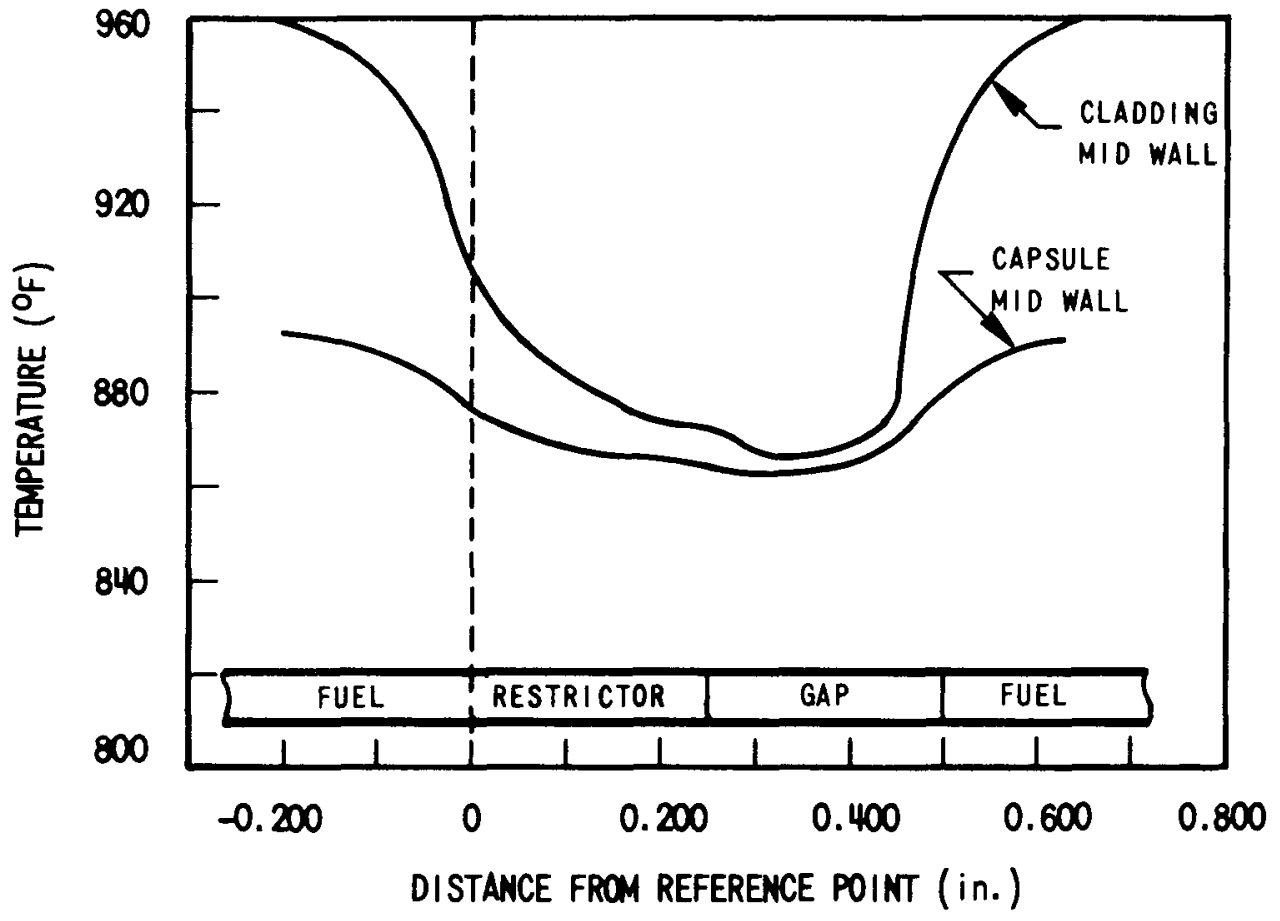

Figure 5-8. Temperature Profiles Near Fuel Motion Restrictor (Beginning of $l_{1} \mathrm{fe}$ )

Stress-Strain Analysis

The techniques and assumptions for this analysis were presented in previous quarterlies and in WARD-111. A summary of the results for pins W1-16S, $-17 \mathrm{~S}$, $-18 \mathrm{~S}$, and $-19 \mathrm{~S}$ is given in Table 5-4. Pertinent data for the capsules and pins are given in this table.

An estimate of the strains in the cladding due to differential thermal expansion between the cladding and the restrictor has been made based on the following assumptions:

1. At the beginning-of-life there is zero radial gap between the cladding and the restrictor.

2. The cladding and the restrictor are both hollow circular cylinders of uniform thickness.

3. The restrictor is a rigid body since it is four to six times as thick as the cladding for any pin.

4. The cladding undergoes creep straining to relieve the contact pressure to zero over the life of the pin. The temperature difference which produces this contact pressure should also cause a differential swelling. 


\begin{tabular}{|c|c|c|c|c|c|c|c|c|}
\hline \multicolumn{9}{|c|}{ Fuel Pin Stress-Strain Analysis } \\
\hline $\begin{array}{c}\text { Pin } \\
\text { Number }\end{array}$ & $\begin{array}{c}\text { Fractional } \\
\text { Fission } \\
\text { Gas Release } \\
\end{array}$ & $\begin{array}{l}\text { Initial } \\
\text { Fuel Pin } \\
\text { Plenum } \\
\text { Pressure } \\
\text { (psi) } \\
\end{array}$ & \multicolumn{2}{|c|}{$\begin{array}{l}\text { End of Life } \\
\text { Fuel Pin } \\
\text { Plenum } \\
\text { Pressure } \\
\text { (psi) } \\
\end{array}$} & $\begin{array}{l}\text { Cladding } \\
\text { Effective } \\
\text { Thickness } \\
\text { End of Life } \\
\text { (in.) } \\
\end{array}$ & $\begin{array}{c}\text { Fuel Pin } \\
\text { Equivalent } \\
\text { Pressure } \\
\text { Stress } \\
\text { End of Life } \\
\text { (psi) }\end{array}$ & $\begin{array}{c}\text { Fuel Pin } \\
\text { Thermal } \\
\text { Stress } \\
\text { (psi) } \\
\end{array}$ & $\begin{array}{c}\text { Fuel Pin } \\
\text { Strain } \\
(\%)\end{array}$ \\
\hline W1-16S & 0.30 & 83 & \multicolumn{2}{|c|}{124} & 0.0063 & 700 & 3770 & 0.0096 \\
\hline W1-17S & 0.50 & 82 & \multicolumn{2}{|c|}{193} & 0.0070 & 1890 & 4820 & 0.0170 \\
\hline W1-18S & 0.40 & 101 & \multicolumn{2}{|c|}{227} & 0.0065 & 2700 & 4420 & 0.0232 \\
\hline W1-19S & 0.60 & 98 & \multicolumn{2}{|c|}{279} & 0.0065 & 3760 & 4570 & 0.0297 \\
\hline \multicolumn{9}{|c|}{ Capsule Stress-Strain Analysis } \\
\hline $\begin{array}{c}\text { Pin } \\
\text { Number } \\
\end{array}$ & $\begin{array}{c}\text { Capsule } \\
\text { Plenum } \\
\text { Pressure } \\
\text { Beginning } \\
\text { of Life } \\
\text { (psi) }\end{array}$ & \multicolumn{2}{|c|}{$\begin{array}{c}\text { Capsule } \\
\text { Plenum } \\
\text { Pressure } \\
\text { End of Life } \\
\text { (psi) } \\
\end{array}$} & \multicolumn{2}{|c|}{$\begin{array}{c}\text { Capsule } \\
\text { Effective } \\
\text { Thickness } \\
\text { End of Life } \\
\text { (in.) }\end{array}$} & $\begin{array}{l}\text { Capsule } \\
\text { Equivalent } \\
\text { Pressure } \\
\text { Stress } \\
\text { End of Life } \\
\text { (psi) }\end{array}$ & $\begin{array}{c}\text { Capsule } \\
\text { Thermal } \\
\text { Stress } \\
\text { (psi) } \\
\end{array}$ & $\begin{array}{c}\text { Capsule } \\
\text { Strain } \\
(\%)\end{array}$ \\
\hline W1-16S & 81 & \multicolumn{2}{|c|}{91} & \multicolumn{2}{|c|}{0.0158} & 570 & 3760 & 0.014 \\
\hline W1-17S & 79 & \multicolumn{2}{|c|}{83} & \multicolumn{2}{|c|}{0.0158} & 540 & 3920 & 0.015 \\
\hline W1-18S & 82 & \multicolumn{2}{|c|}{105} & \multicolumn{2}{|c|}{0.0155} & 720 & 4910 & 0.020 \\
\hline W1-19S & 82 & \multicolumn{2}{|c|}{104} & \multicolumn{2}{|c|}{0.0155} & 710 & 5070 & 0.020 \\
\hline
\end{tabular}

(a) Excluding cladding swelling and fuel-cladding interaction strains, but includes strains due to different cladding swelling. 
Calculations indicate this w1ll cause the cladding to swell away from the restrictor and reduce the amount of forced straining. For conservatism, the effect of swelling was neglected in this particular analysis.

A plot of maximum cladding strain as a function of the differences of the mean temperatures of the cladding and the restrictor is given in Figure 5-9. As discussed in the previous section, $\Delta T$ mean is very dependent on the conductance between the restrictor and the cladding. The worst case for strain arises when the restrictor and cladding are in contact at low pressures. Under these conditions, the value of the conductance would be approximately $1000 \mathrm{Btu} / \mathrm{hr}-\mathrm{ft}^{2}{ }^{\circ} \mathrm{F}$; and the maximum $\Delta \mathrm{T}$ mean is thus estimated to be approximately $200^{\circ} \mathrm{F}$. From Figure 5-9, this would give a forced strain of $0.25 \%$. Differential swelling will substantially decrease this value.

Cladding strains due to swelling and fuel-cladding interactions were calculated using the OLYMPUS II Code. A detailed description of the code is presented under OFBA-210. Strain proftles for W1-16S, -17S, -18S, and $-19 \mathrm{~S}$ are shown in Figures 5-10 through 5-13.

Design and safety analysis reports for these four fuel pins containing axial fuel motion restrictors have been prepared and will be submitted to the EBR-II Project early in the next quarter.

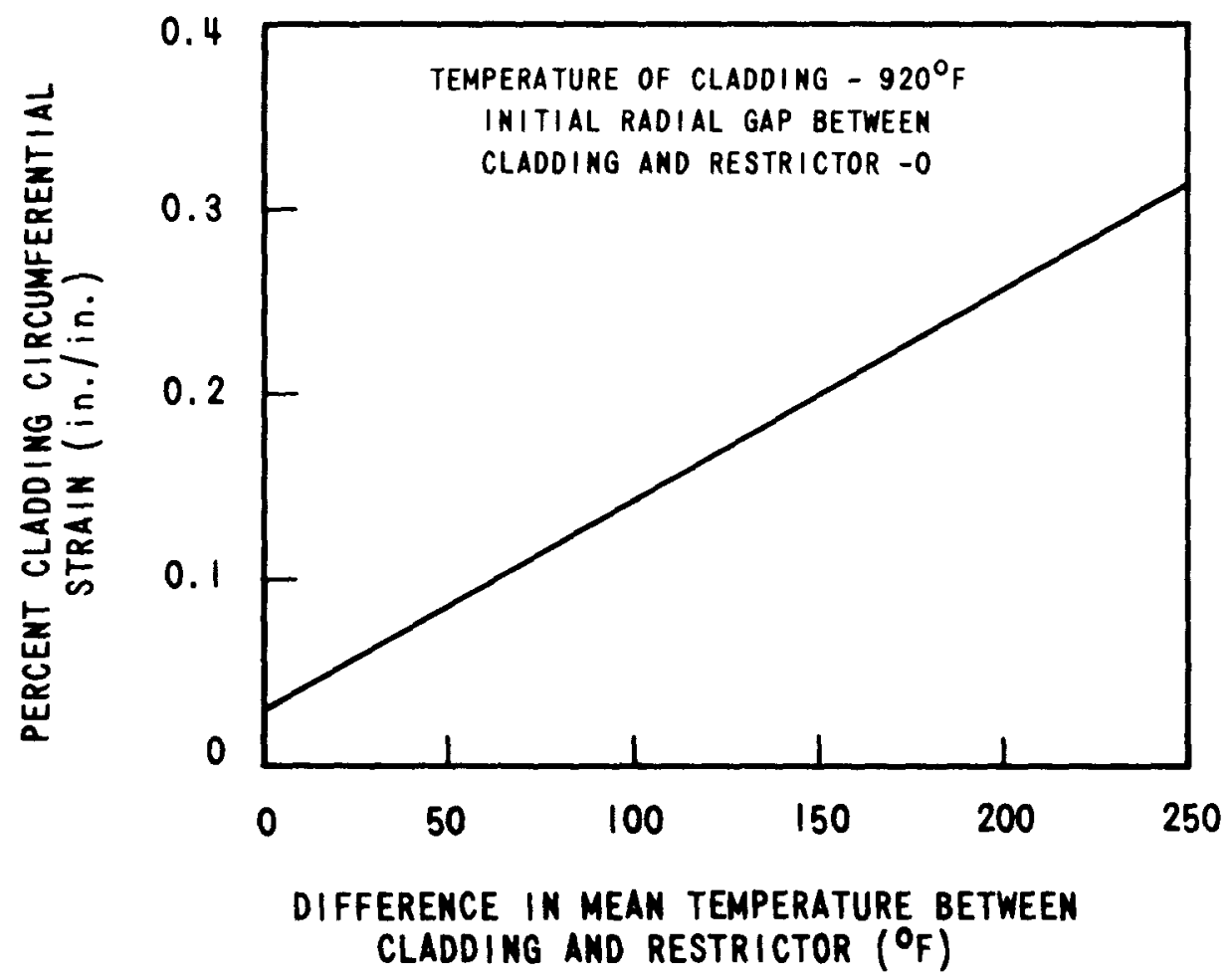

Figure 5-9. Percent Cladding Circumferential Strain vs. Difference in Mean Temperature Between Cladding and Fuel Motion Restrictor

$3679-22$ 


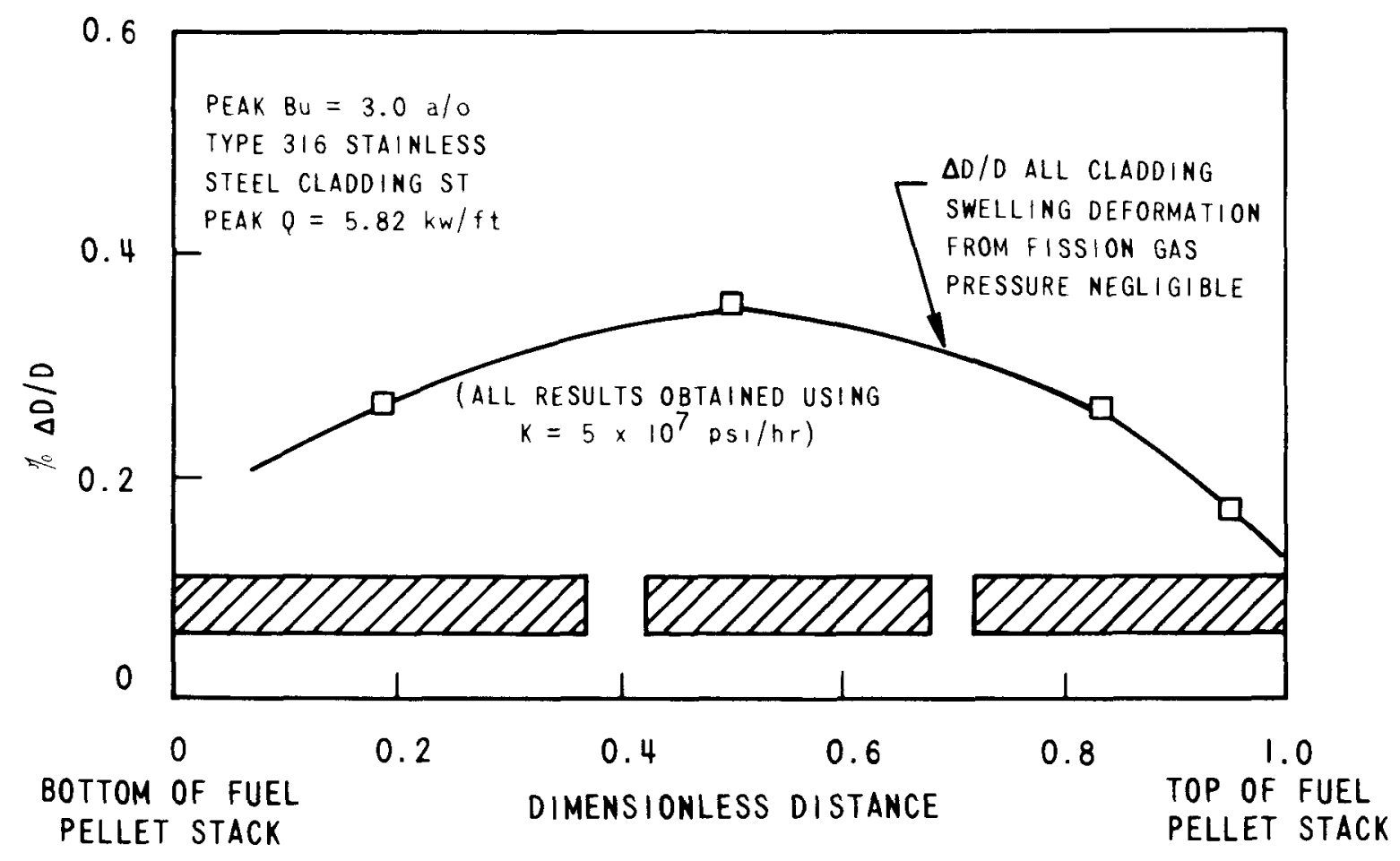

Figur, 5-10. Axial Stidin Protalas-W1-16S

$3679-23$ 


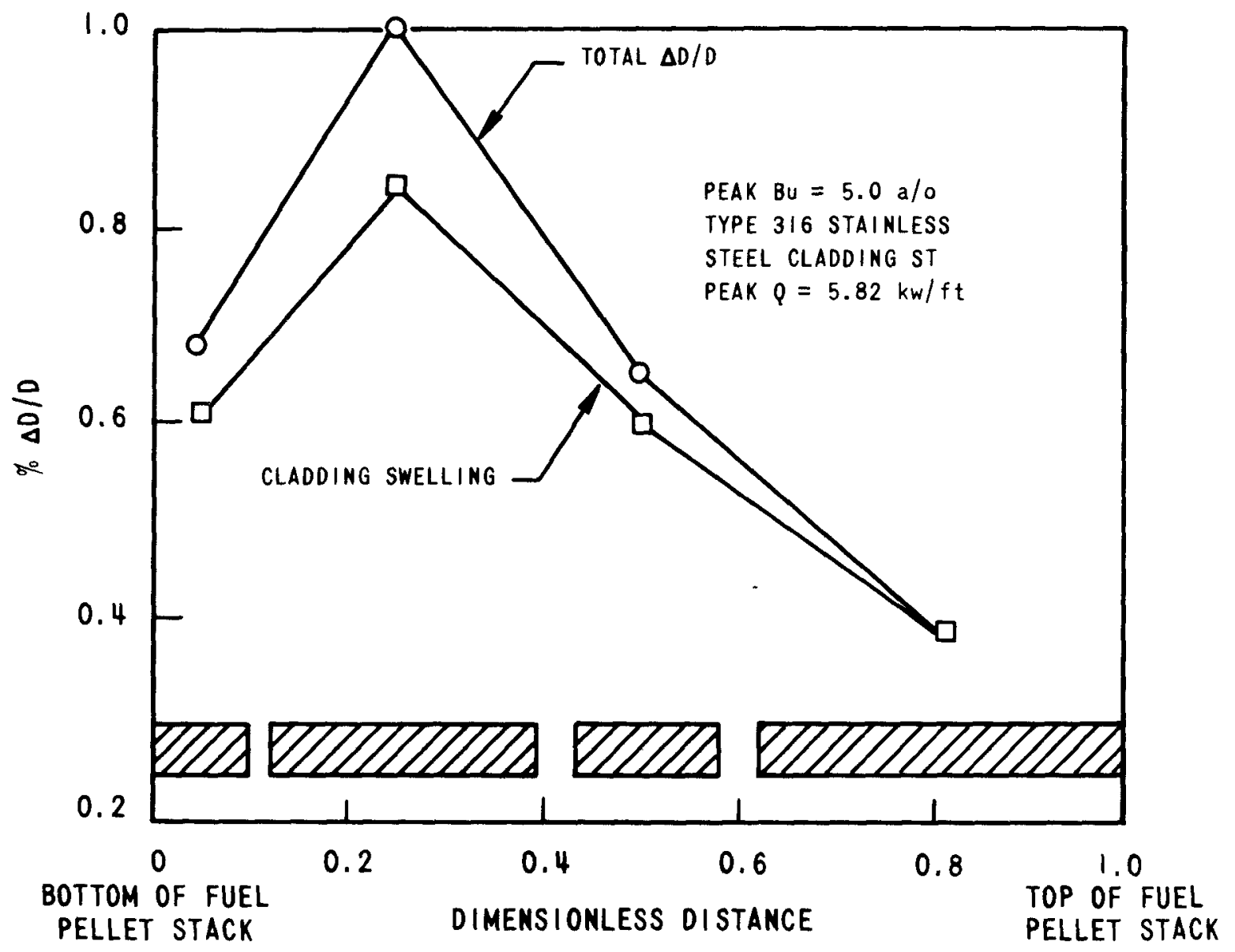

Figure 5-11. Axial Strain Profiles-W1-17S

$3679-24$ 


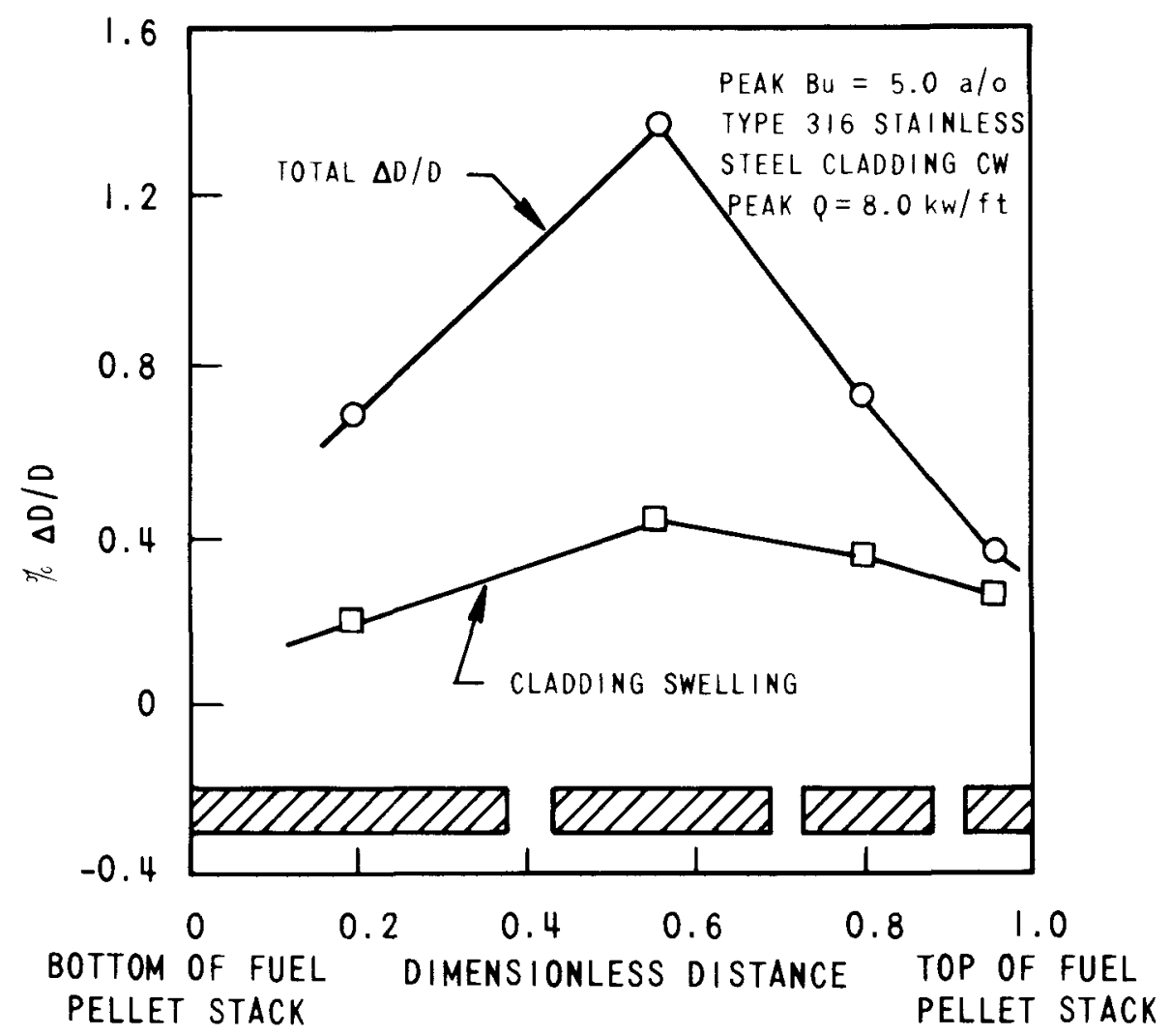

Figuie 5-12. Axial Stian Protiles-W1-18S

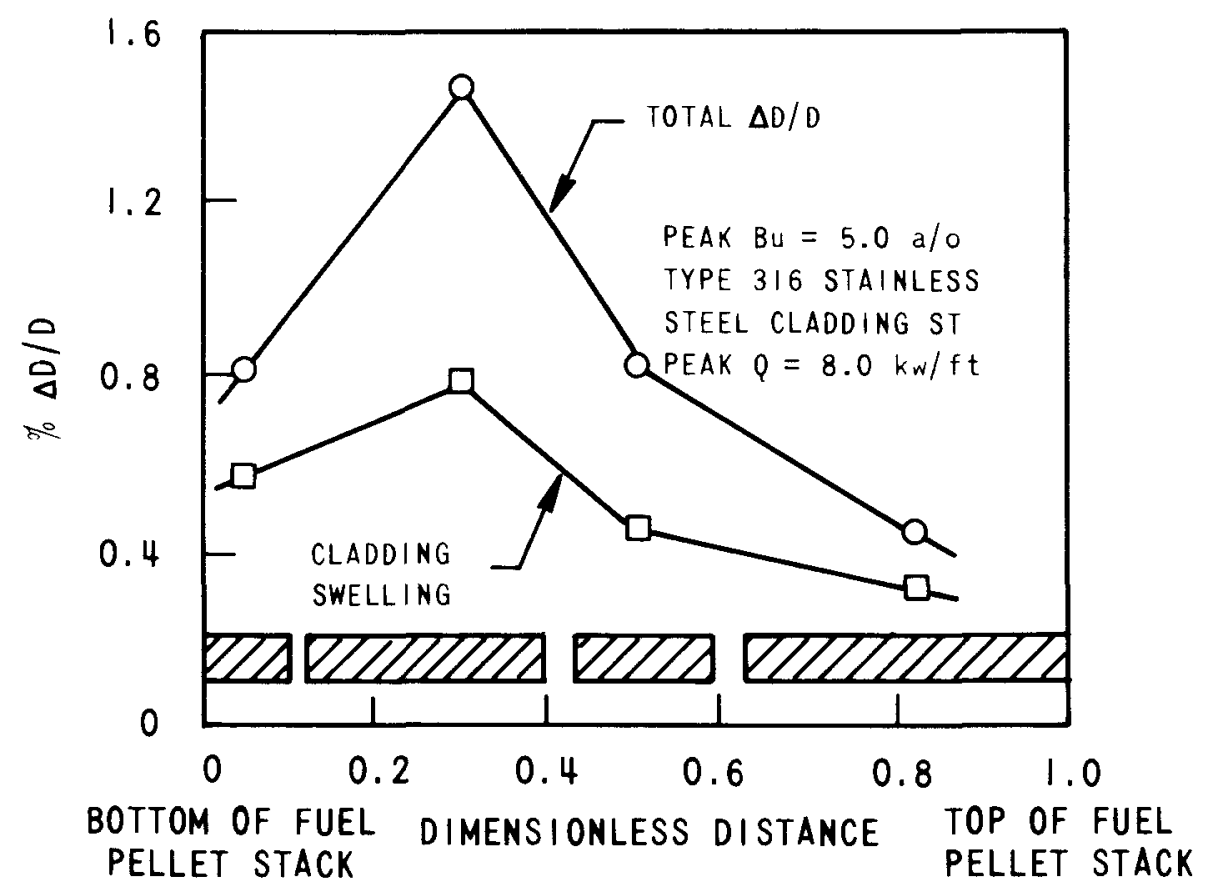

Figure 5-13. Axial Stran Prof les-W1-19S

$3679-25-26$ 
A. Biancheria, T. A. Damico, R. K. Dawless, F. C. Engel, D. E. Kusner, P. J. Levine, R. A. Markley, J. Olhoeft, J. F. Patterson, and R. W. Tilbrook

\section{OBJECTIVES}

This task is part of the overall irradiation program on mixed-oxide fuel to study special areas of fuel-rod behavior and assembly performance. The specific objectives are to design, irradiate, and evaluate grid-type subassemblies with unencapsulated mixed-oxide fuel pins for the following purposes.

1. Demonstrating satisfactory performance of 316 stainless steel grid-type subassemblies in a fast reactor environment.

2. Investigating the combined effects of radiation, flowing sodium, stress, and temperature on the mechanical and corrosion properties of grid material and on pin-grid interaction.

3. Developing statistically significant design information on mixedoxide fuel pin performance.

The grid-type subassembly is further intended to provide an irradiation vehicle which will minimize the interaction between individual pins.

PRIOR WORK

Detailed thermal, mechanical, and nuclear analyses were performed to establish the design and operating conditions of the fuel pins and overall subassembly.

Parametric studies were completed to determine the effect of design variables and tolerances on operating conditions. Axial grid spacing and the start-oflife fuel pin-grid dimple spacing were set. Stress and fatigue analysis on the grid was performed.

The approval-in-principle was recelved for a Row 5 position in EBR-II operating at $50 \mathrm{MWt}$. The design and analysis has since been modified for Row 6 to accommodate the proposed power increase to $62.5 \mathrm{MWt}$. Fuel pin design drawings were completed and required hardware was ordered. The tubing for cladding was recelved. A fuel pin shlpping container was designed and ordered. 


\section{CURRENT PROGRESS}

Fuel Pin Design

The safety analyses for off-normal transient conditions specified in the EBR-II guide[2] were performed and completed during the quarter. Fue1 pin number W3-1, which has the highest power rating and cladding temperature of the 37 pins, was analyzed for each of the cases using a version of the transient code FORE 2. The first case assumed the reactor was at delayed critical and zero power conditions ( 10 watts, $700^{\circ} \mathrm{F}$ and no coolant flow) and that a single control rod was driven into the reactor at 5 inches per minute. The resulting temperatures are shown as a function of time in Figure 6-1. After completion of this analysis, the case requirements were changed to full coolant flow, which is a less critical situation. For the no coolant flow situation the stagnant sodium reaches its boiling temperature corresponding to one atmosphere pressure $\left(1618^{\circ} \mathrm{F}\right)$ in 138 seconds and the cladding reaches its melting point $\left(2600^{\circ} \mathrm{F}\right)$ in 142 seconds. Fuel melting temperature, $4910^{\circ} \mathrm{F}$, is reached at the fuel center line in 145 seconds and the fuel surface is molten before 150 seconds over approximately the full length of the pin.

The second case assumes the reactor is at nominal operating conditions and that a single control rod is driven into the core at 5 inches per minute. Figure 6-2 shows the temperature variations with time at the positions of maximum value. The fuel center reaches melting temperature in 45 seconds. The cladding and coolant are below $1280^{\circ} \mathrm{F}$ at 50 seconds.

In addition to the above, a case was analyzed for loss of coolant flow during normal operating conditions. An immediate reactor scram results in the changes in maximum temperatures with time as shown in Figure 6-3. Al1 temperatures decrease from the steady state values and reach minima in the 9 to 23 seconds interval. All temperatures reach a maximum in the range $1230-1290^{\circ} \mathrm{F}$ at approximately 90 seconds. Thereafter all temperatures reduce continuously. All temperature gradients during this part of the transient are small and will not cause failure.

Subassembly Design - Nuclear

A nuclear analysis is being performed to determine whether WSA-3 is subcritical when flooded and surrounded with an infinite water reflector. The hexagonal array of fuel pins surrounded by the cans and water are mocked up in a cylindrical geometry. This is done for an individual, typical hexagonal cell and for the full test assembly for spatial considerations. Mockup geometry data are tabulated in Table 6-1. A water thickness of one foot is assumed to represent an infinite reflector, as suggested by the data in TID-7028.[3] Survey calculations in one dimension are employed to test the sensitivity of results to spatial mesh size, group constants and axial buckling prior to making the more-involved 3-dimensional calculations.

Preliminary results indicate for this 37 pin subassembly (WSA-3) in a flooded condition in an infinite sea of water that $k_{\text {eff }}$ is substantially less than the 0.6 maximum criteria. 


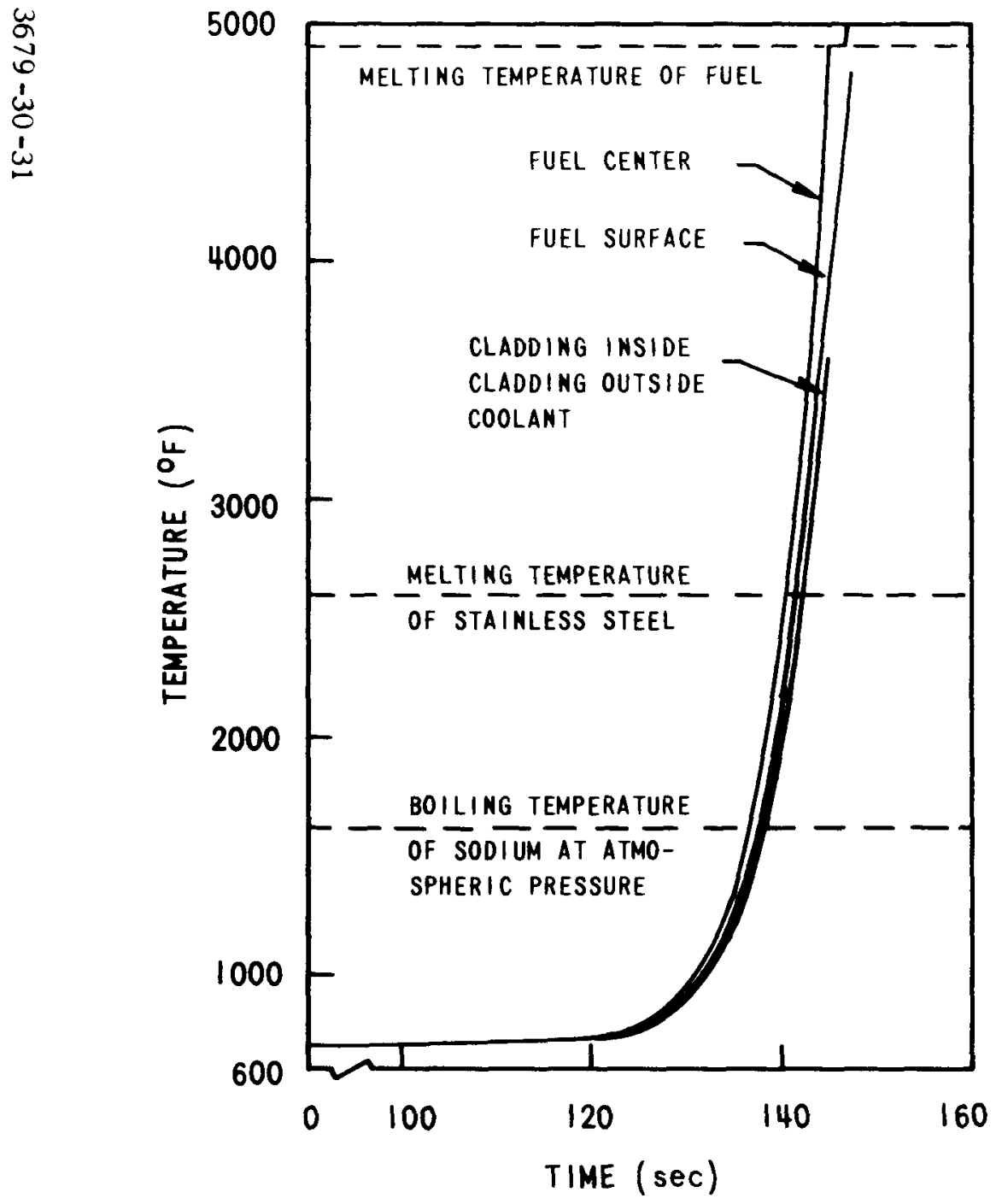

Figure 6-1. Zero Power Ramp Incident

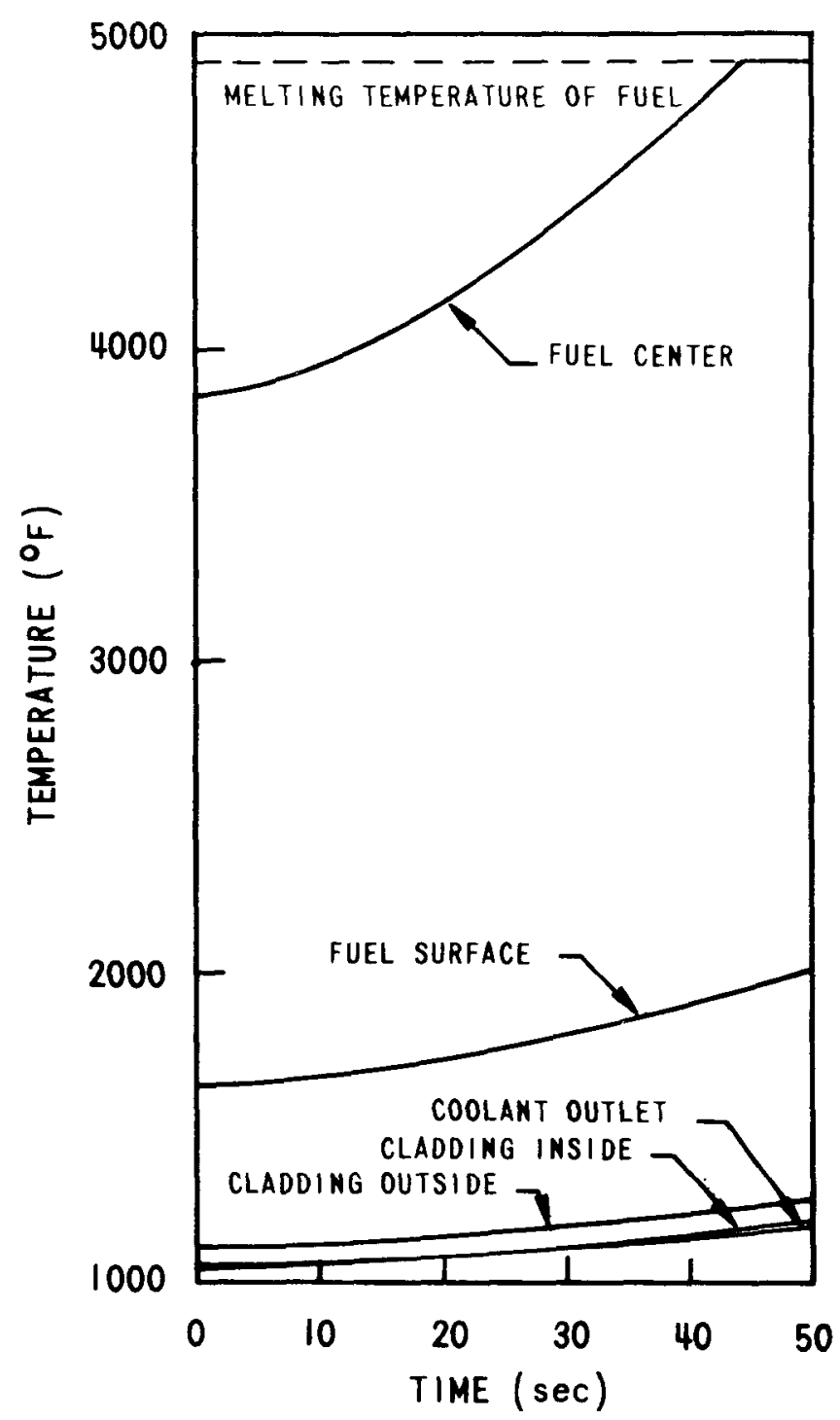

Figure 6-2. Full Power Ramp Incident 


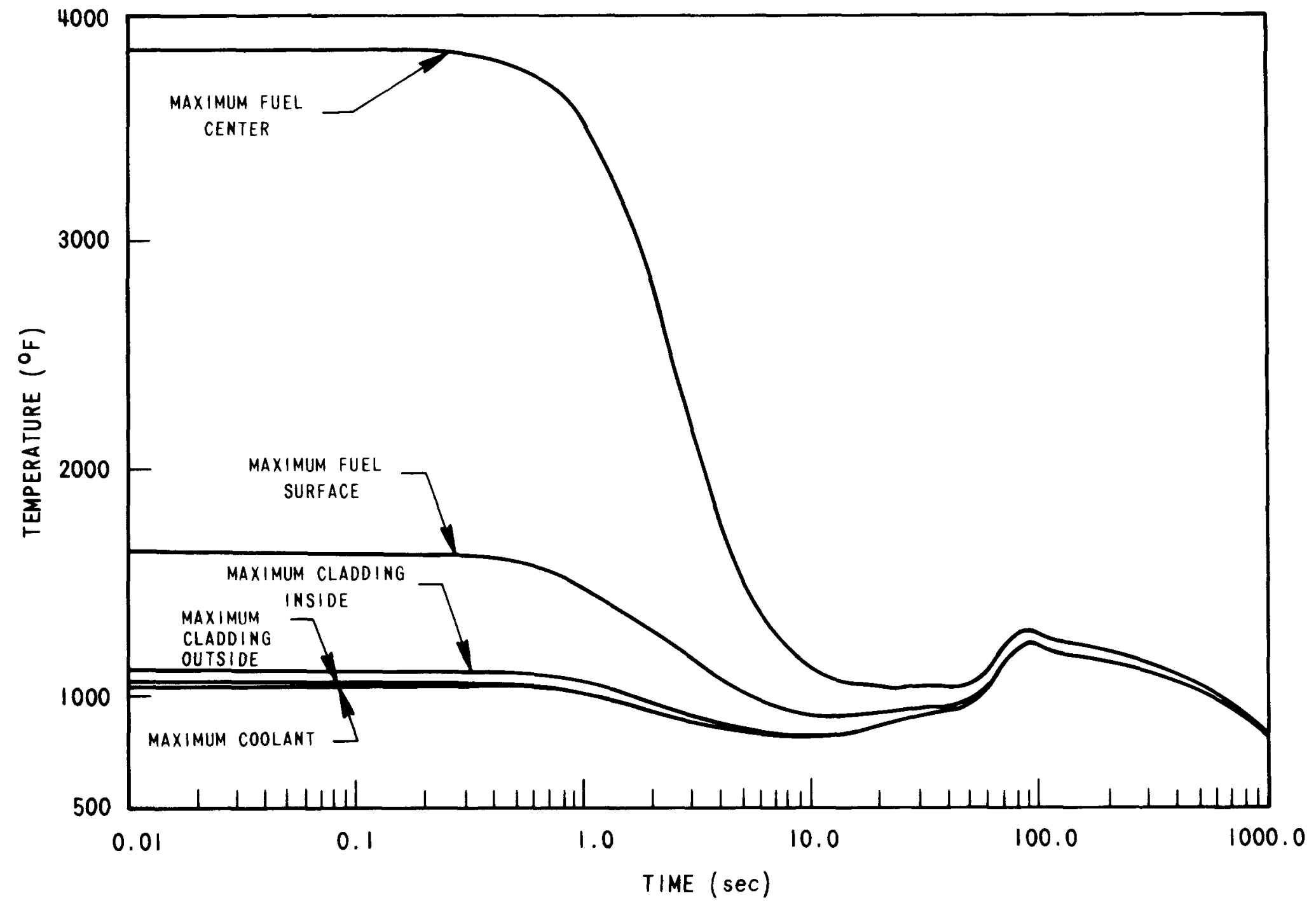

Figure 6-3. Loss of Flon Ine 1dent 
Table 6-1. WSA-3 Mockup Geometry for Nuclear Calculations

Pellet Dlameter (max. smear densfty)

$$
0.195 \mathrm{in.}
$$

Cladding $O D$

$0.230 \mathrm{ln}$.

Cladding Thickness

$0.015 \mathrm{in}$.

Pitch (hexagonal)

0.285 in.

Effective Cell Diameter

0.299 in.

$0.760 \mathrm{~cm}$

Active Core Height

$13.5 \mathrm{In}$.

Effective Core Radius

0.9102 in.

$34.29 \mathrm{~cm}$

$2.312 \mathrm{~cm}$

Radial Reflector Thickness ( $\mathrm{SS}+\mathrm{H}_{2} \mathrm{O}$ )

$0.730 \mathrm{~cm}$

Axial Reflector Thtckness ( $\mathrm{SS}+\mathrm{H}_{2}$ )

$30.0 \mathrm{~cm}$

Pure Water Thickness

$30.0 \mathrm{~cm}$

Core Area (perpendicular to axis)

$16.79 \mathrm{~cm}^{2}$

Core Volume

Cell Area (perpendicular to axis)

0.5788 1iter

$0.4538 \mathrm{~cm}^{2}$

Cell Volume

Cladding Vo1. Fraction in Cell

$15.56 \mathrm{~cm}^{3}$

0.1440

Moderator Vol. Fraction in Cell

0.4093

Subassembly Design - Thermal

The orifice size for WSA-3 was redesigned for operation at $62.5 \mathrm{MWt}$ in a Row 6 position. In contrast to the tpo orifices positioned in series as noted in a previous quarterly report, [4] only a single orifice will be required for conditions of pressure and flow in the inner blanket region (Rows 6 and 7). Final sizing and analysis of the appropriate orffice will be determined on the basis of the planned hydraulic flow test discussed in Task OFBA-411 (Section 10).

Thermal analysis of the subassembly continued during the quarter to examine the effect of rod displacements (channel closing) in a normal flow cell on coolant temperatures and temperature gradients across fuel pins. The closing of an equivalent channel was studied by simultaneously and equally displacing three adjacent rods towards the center of the channel. This produces reduced flow in the channel in question whtle surrounding channels experfence increased flow. The result is an increase in central channel coolant temperatures and coolant temperature gradients across fuel pins, as shown in Table 6-2 for various degrees of displacement. Two percent turbulent mixing was assumed for these calculations. These results will be used to analyze the effects of channel closing on overall performance of the assembly.

In the manufacture of grid assemblies for WSA-2, potentlal varlations in pitch may occur which would result in temperature varfations across the fuel pins. To determine the magnitude of such changes, two representative cases 


\begin{tabular}{|c|c|c|c|}
\hline \multicolumn{4}{|c|}{$\begin{array}{c}\text { Table 6-2. } \\
\text { On Coolant Temperature and Temperature Gradients }\end{array}$} \\
\hline $\begin{array}{c}\text { Pin } \\
\text { Clearance } \\
\text { (in.) }\end{array}$ & $\begin{array}{c}\text { Simultaneous } \\
\text { Displacement } \\
\text { of 3 Pins }\end{array}$ & $\begin{array}{c}\text { Change in Coolant } \\
\text { Outlet Temperature } \\
\text { of Central Channel } \\
\left({ }^{\circ} \mathrm{F}\right)\end{array}$ & $\begin{array}{c}\text { Maximum } \Delta \text { T Coolant } \\
\text { Across Displaced Rod }\end{array}$ \\
\hline \hline 0.055 & 0.000 & - & 13 \\
0.045 & 0.005 & +17 & 36 \\
0.035 & 0.010 & +34 & 79 \\
0.025 & 0.015 & +50 & 102 \\
0.015 & 0.020 & +69 & 129 \\
0.005 & 0.025 & +93 & 79 \\
\hline \hline
\end{tabular}

\begin{tabular}{|c|c|c|c|c|}
\hline $\begin{array}{l}\text { Pin } \\
\text { No. }\end{array}$ & $\begin{array}{l}\text { Case } 1 \\
P=0.285 \\
\text { Nominal } \\
\left({ }^{\circ} \mathrm{F}\right)\end{array}$ & $\begin{array}{l}\text { Case } 2 \\
P=0.283 \\
\left({ }^{\circ} \mathrm{F}\right)\end{array}$ & $\begin{array}{c}\text { Case } 3 \\
P=0.283,0.283 \\
0.286 \text { toward } \mathrm{P} \text { in } 1 \\
\left({ }^{\circ} \mathrm{F}\right)\end{array}$ & $\begin{array}{c}\text { Case } 4 \\
P=0.283,0.283 \\
0.286 \text { toward Pin } 16 \\
\left({ }^{\circ} \mathrm{F}\right)\end{array}$ \\
\hline 1 & 19 & 12 & 28 & 14 \\
\hline 2 & 11 & 11 & 13 & 27 \\
\hline 3 & 13 & 18 & 25 & 26 \\
\hline 4 & 14 & 13 & 33 & 26 \\
\hline 9 & 6 & 12 & 28 & 18 \\
\hline 15 & 9 & 19 & 33 & 10 \\
\hline 16 & 19 & 21 & 45 & 28 \\
\hline 17 & 18 & 11 & 28 & 20 \\
\hline 22 & 8 & 14 & 39 & 16 \\
\hline 23 & 5 & 13 & 33 & 8 \\
\hline 37 & 10 & 14 & 16 & 27 \\
\hline
\end{tabular}


were analyzed. The first of these assumed a $2-m 11$ reduction in pitch in al1 directions, or an overall value of 0.283 inches instead of the designed 0.285 inches. This tended to increase peripheral flow rates and reverse the direction of thermal gradients across peripheral rods. The magnitude of the $\Delta T^{\prime}$ 's were essentially unchanged. The second case assumed a reduction in pitch to 0.283 inches in two directions and an increase to 0.286 inches In the third direction. Two separate orfentations of the larger pitch were analyzed--orlented toward pin $\|_{1} 1$, as shown in Figure 6-4, and orlented toward pin \#16. The subassembly temperature distribution for the former is shown in the figure. A comparison of all three analyses for pitch variation to the nominal case is made in Table 6-3. The resultant temperature gradients all appear tolerable, with Case 3 producing the highest (most undesirable) gradients.

\section{Subassembly Design - Mechanical}

Flow induced vibration amplitudes of the WSA-3 fuel rods have been estimated using a modified form of Brugreen's correlation. [5] This includes the effect of an axial compressive load (produced by friction forces between fuel rods and grids) on the fuel rod vibration frequency and amplitude. Figure 6-5 is a plot of beginning-of-1ife vibration amplitudes for the range of span lengths present in WSA-3 for various values of $P / P_{C R}$, where $P$ is the axial load and $\mathrm{P}_{\mathrm{CR}}$ is the critical buckling load of the fuel rod span. Since the maximum allowable vibration amplitude has been set at 0.001 inches based on PWR experlence, beginning-of-11fe amplitudes for WSA-3 pins are well below the limit. During life vibration amplitudes can increase due to 1) creep strains induced by the axial load, which reduce the effective elastic modulus of the fuel rod; 2) straining of the cladding by fission gas pressure, fuel forced strain, and thermal plus irradiation effects, thus reducing the effective elastic modulus of the fuel rod; and 3 ) corrosion of the cladding material by the sodium coolant and fuel interaction, which reduces the effective moment of inertia of the fuel rod.

Using the appropriate analyses and WARD design data, it is also concluded that for end-of-life conditions existing in WSA-3, the maximum allowable vibration amplitude limit is not exceeded for the 4-inch spans in the core. Calculations indicate the maximum allowable vibration amplitude would be reached for core span length of 9 inches and the maximum possible axial load of 18 pounds. However, channel closing analysis shows the fuel rods reach thermal instability for 6 -inch spans in the core region. The 6.7inch spans outside the core present no problem, since the temperatures are lower than in the core region. A stress analysis was performed on the inner and outer cans and liners to determine if the primary membrane stress, $\mathrm{S}_{\mathrm{M}}$, exceeds a maximum allowable $1 \mathrm{imlt}$ based on ASME Boller and Pressure Vessel Code criteria. The maximum limit is that stress which produces a secondary creep rate of $10-5 \% \mathrm{In} / \mathrm{fn} / \mathrm{hr}$. Since actual operating temperatures could not be accurately determined at this time, a range form 850 to $1050^{\circ} \mathrm{F}$ was investigated for the inner and outer cans and liners. In the analysis, the following points were considered to contribute to the stress: 


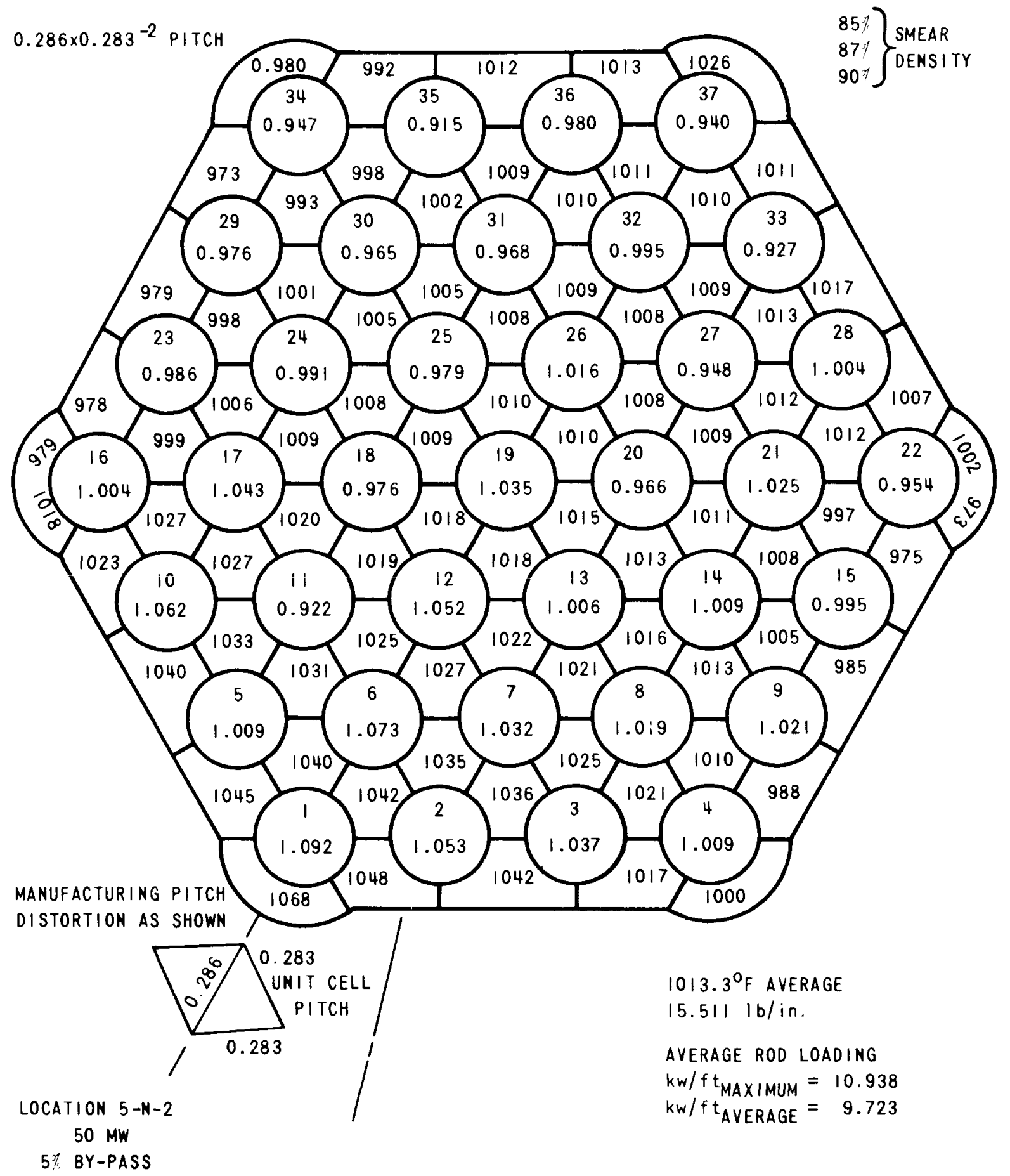

$2 \%$ TURBULENT MIXING

Figure 6-4. Coolant Outlet Temperature Distribution for 37-Pin Subassembly with Pitch Distortion

$3679-33$ 


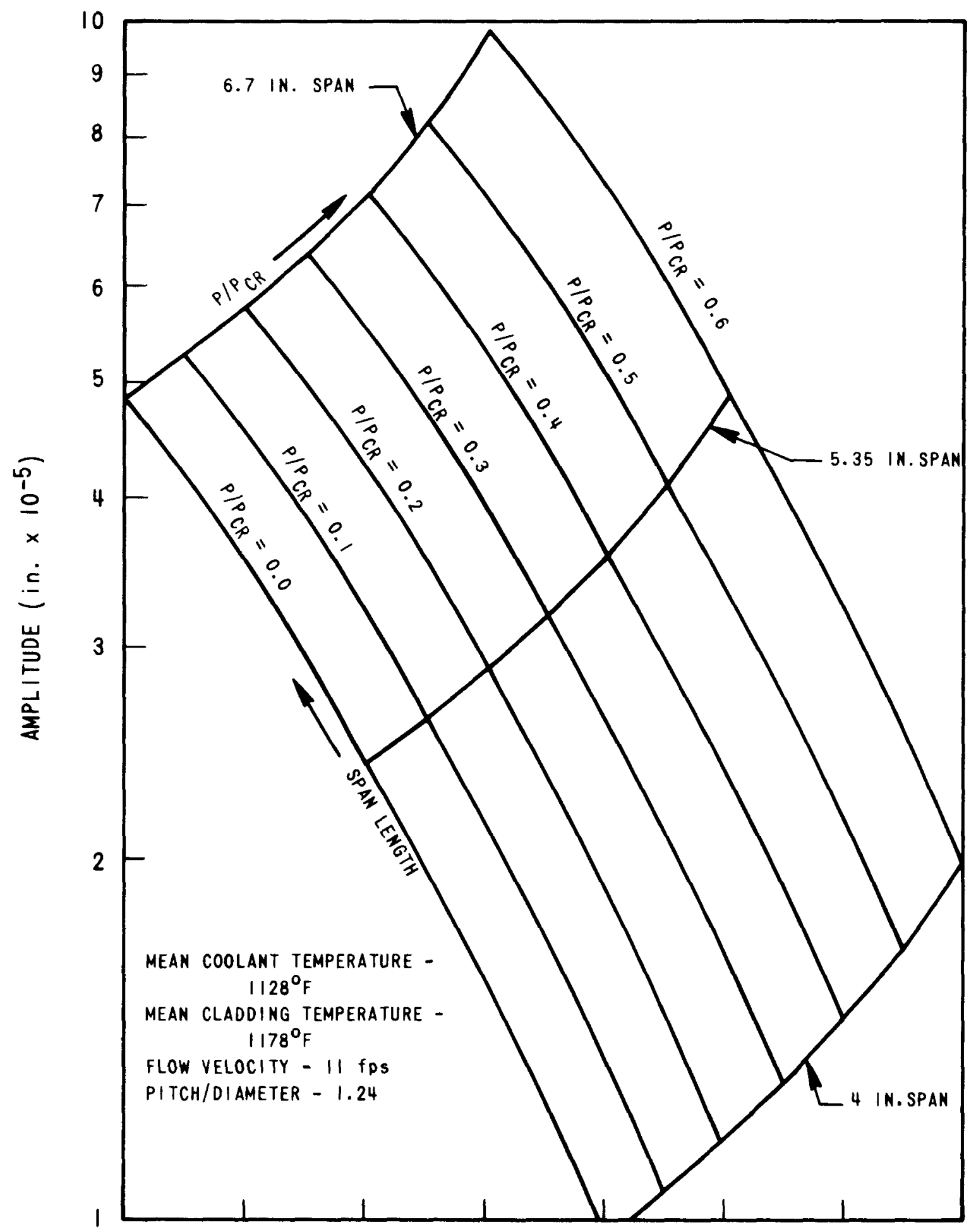

Figure 6-5. 37-Pin S/A Flow Induced Vibration

$3679-34$ 
1. Pressure drop across the can wall

2. Pressure drop axially through subassembly

3. Axial grid loads produced by friction forces between fuel rods and grid cells

4. Temperature gradient through can wall

5. Differential irradiation swelling through can wall

6. Temperature gradient across subassembly

7. Differential irradiation swelling across subassembly

8. Differential "radial" growth between cans

The results of the analysis indicate that the stresses produced in the inner and outer cans are well below maximum limits using values less than $100^{\circ} \mathrm{F}$ for the temperature drop across the can wall. Liner stresses are acceptable for a temperature drop through the wall less than $224^{\circ} \mathrm{F}$ and an inner can and a liner mean wall temperature of 850 and $1025^{\circ} \mathrm{F}$, respectively. This analysis assumed no pressure drop across can walls and the use of annealed material for conservatism. Figure 6-6 shows the allowable temperature drop across liner walls as a function of the inner can mean wall temperature.

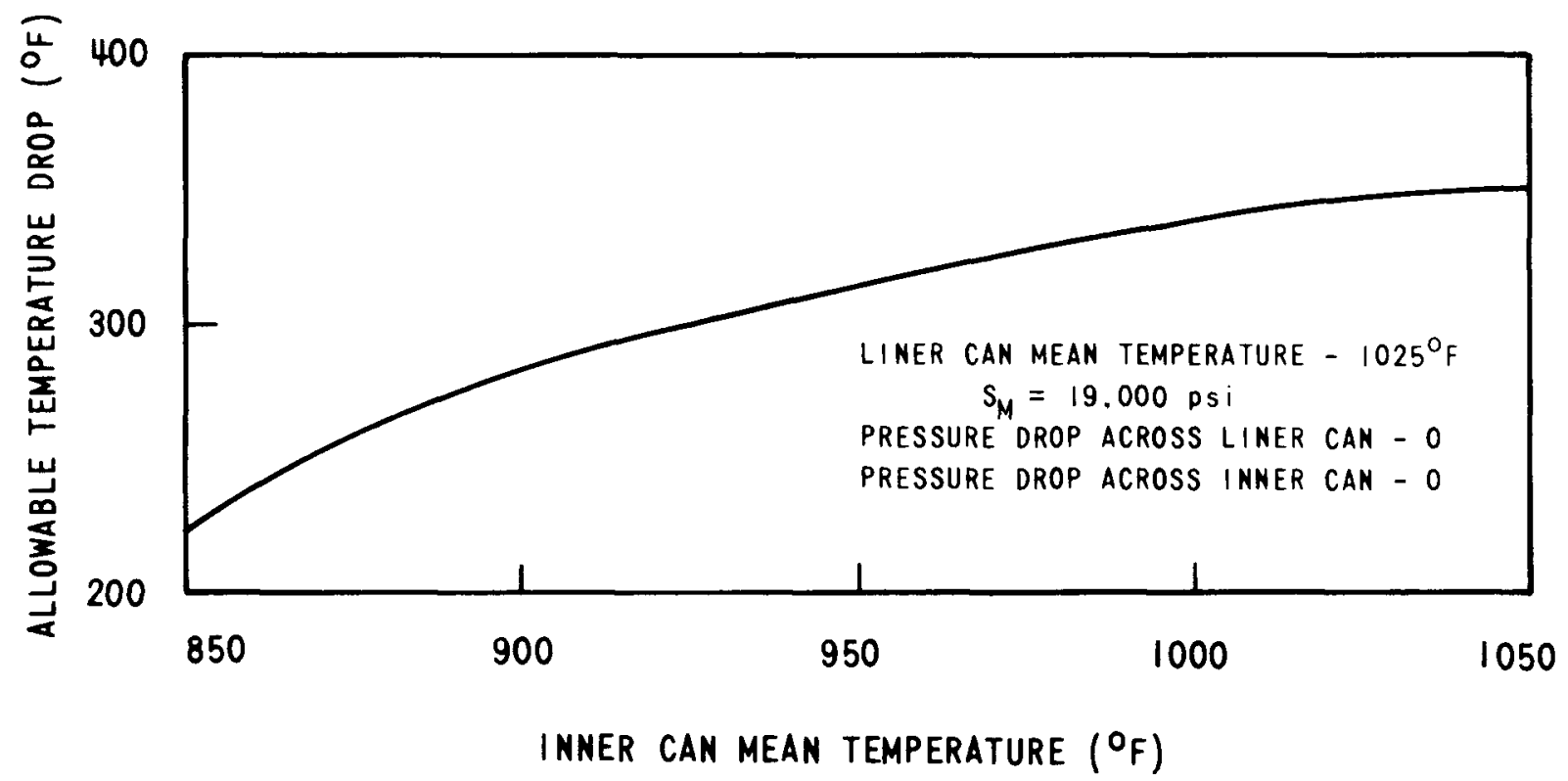

Figure 6-6. EBR-II 37-Pin Subassembly-Al lowable Temperature Drop Through Liner Can Wall Vs. Inner Can Mean Temperature

$3679-35$ 
An analysis on the grid support strap was performed during the current report period in addition to the stress analysis reported last quarter for the grid strap. The purpose of the analysis was to determine if the maximum possible stresses in the support strap tab exceed the maximum allowable stress (that which produces a secondary creep rate of $10^{-5} \% \mathrm{in} / \mathrm{in} / \mathrm{hr}$ ). The value is approximately 23,000 psi for a support strap mean temperature of $1000^{\circ} \mathrm{F}$. The analysis 1nvolved the determination of an interaction deflection of the tab caused by interactions between the inner can and grid due to differential growth (thermal expansion and irradiation-induced swelling). Figure 6-7 shows results of deflection calculations as a function of the inner can mean wall temperature. The calculated maximum allowable deflections are +2.94 and $-1.07 \mathrm{mils}$, both of which fall outside the curves in the figure. Thus, the support strap tabs meet the design criteria.

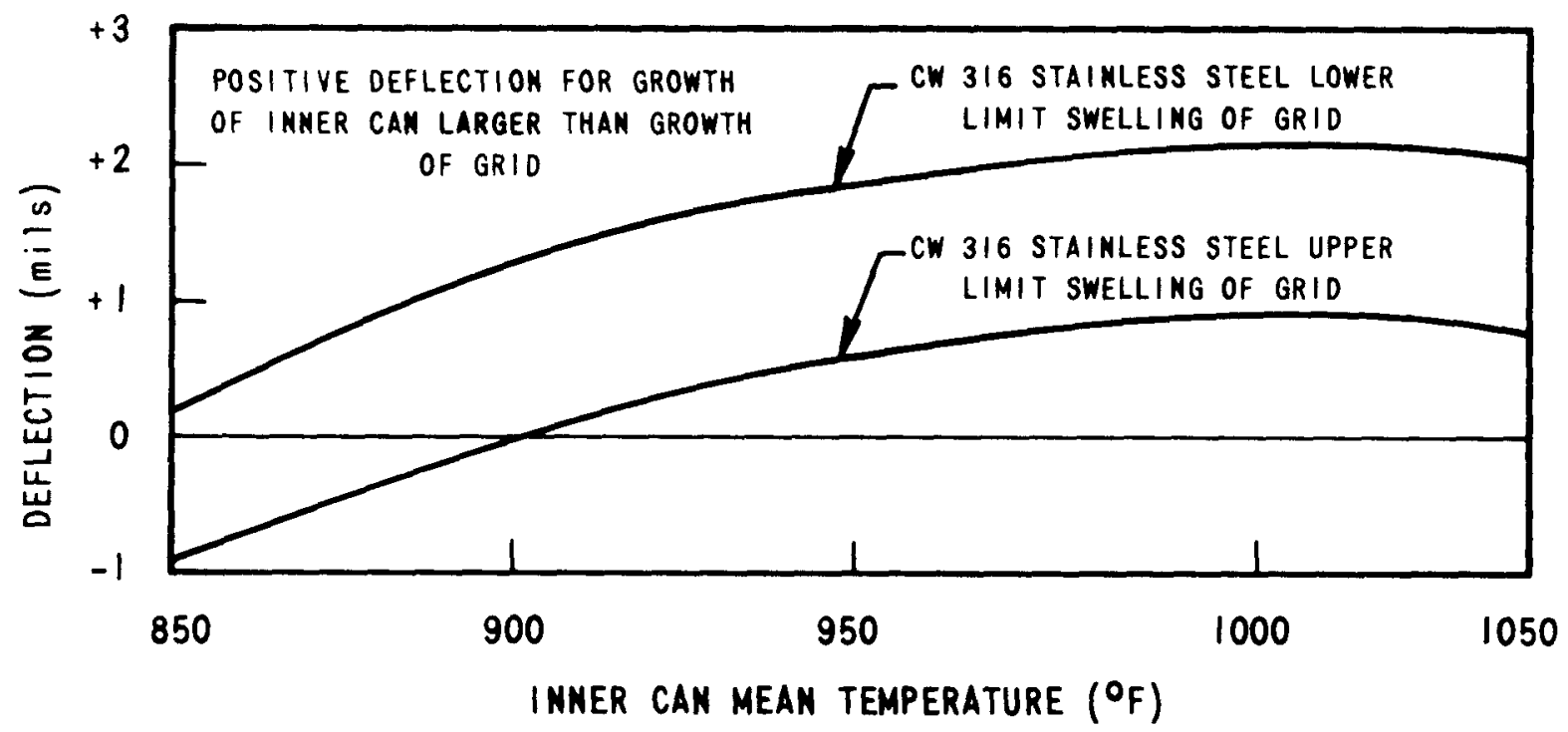

Figure 6-7. Grid Support Strap Deflection Vs. Inner Can Mean Temperature for Grid at Core Outlet

$3679-36$

Mechanical analysis was performed to determine the effect of triaxial straining on bow amplification and the resultant effects on maximum allowable temperature drop across a fuel rod. Previous thermal stability analyses did not include this aspect. The calculations resulted in an amplification factor on initial bow (prior to all channel closing effects) of 1.250 for 4-1nch spans. Comparing this factor to that calculated previously for beginning-of-life conditions of 1.215, tri-axial stralning effects increased the amplification by the factor 0.010 or $1 \%$. This very small change is the result of the allowable cladding hoop strain of only $0.2 \%$. The analyses also indicated that fuel rod deflection is quite insensitive to the temperature gradient for a 4-1nch span. Therefore, a maximum allowable, $\Delta \mathrm{T}$ for this case cannot be estimated on the basis of channel closing alone. 


\section{Project Activities}

During the quarter all subassembly design drawings were completed, incorporating the changes noted last period during the trip to the EBR-II. The changes and drawings are being prepared for submittal to the EBR-II Project for review and comment. Standard subassembly hardware components (1.e., grid bars and end fittings) have been recelved from ANL. Fuel pin end plugs and other required fuel pin hardware have been ordered. The tungsten carbide pellets to be used for simulating the mixed-oxide pellet mass in the flow test pins were recelved.

The outer container (Spec 17C drum) for the Spec 6M fuel pin shipping container has been recelved. The inner $S p e c 2 R$ can and associated fuel pin holder will now be ordered.

Specifications for fuel pellets have been discussed with fabrication personnel (OFBA-510), and final pellet requirements have been established. Preparation of suitable visual standards for the production pellets remains to be accomplished. 
OFBA-312 217 PIN GRID-TYPE FUEL ASSEMBLY DESIGN AND DEVELOPMENT

B. A. Bishop, F. C. Enge1, R. A. Markley, and J. F. Patterson

\section{OBJECTIVES}

The objective of this program is to develop a grid type fuel assembly for the LMFBR program and to provide a backup design for the FFTF reactor. This program will include the design, development, and evaluation of the grid and grid-type assembly.

\section{PRIOR WORK}

The work program was specifled; a preliminary scoping parameter study was performed; and grid manufacturability studies were initlated.

\section{CURRENT PROGRESS}

Genera1

The fuel element development program proposal, work program, and cost estimates were revised and submitted.

The tentative design basis for a grid-type LMFBR/FFTF Fuel Assembly was specified.

Completion of preliminary analysis of four candidate grid types was delayed until additional studies are completed to determine how the program might be reoriented to focus more on the development of backup core for FFTF while obtaining the maximum amount of information for an LMFBR design. This study will initially assume the use of an FFTF fuel pin and then, if necessary, recommend design modifications needed for LMFBR goals.

\section{Preliminary Grid Mechanical Analysis}

Honeycomb DFR Type Grids

1. The bending stress analysis was performed using the perforated plate correlation. A tentative grid height of one inch gives satisfactory stress levels for three dimple fuel rod contact for $1000^{\circ} \mathrm{F}$ grid temperatures.

2. Grid dimple dimensions were determined on the basis of an elastic plastic analysis.

3. Engineering drawings of the honeycomb grid concepts (double strap, and single-strap interlocking) were completed. Draw1ngs are being revised to include: 

a. manufacturing tolerances based upon 37-pin grid fabrication experience
b. a new dimple concept that should reduce grid cell distortion during fabrication

\section{Line of Sight Grids}

1. Two types of line of sight grids were sketched and preliminary dimensions determined. A single plane grid and triplanar grid were considered.

2. An elastic stress analysis of both grid straps was performed. For very small grid-fuel rod interference the elastic limit of the grid material was exceeded. An elastic-plastic analysis was then performed. Results indicated very high fuel rod-grid interaction forces at expected values of interference. On this basis a load limiting dimple will be incorporated into the triplanar design. A new concept will be required to make the stiffer monoplanar line-of-sight grid feasible.

\section{General Grid Design}

1. Mean corrosion wastage allowances and the corresponding 1,2 , and 3 standard deviation limits were determined for all expected grid operating conditions.

2. A fuel rod vibration analysis was performed at end-of-1ife conditions using the Burgreen correlation as modifled by Westinghouse to account for fuel rod axial loading. Results gave the required grid spacing such that the vibration amplitude for a given axial load would not exceed 0.001 inch. The core, axial reflector, and gas plenum regions were analyzed.

\section{Parameter Study for FFTF Open Loop Testing}

A parameter study was performed to define the thermal and hydraulic limits imposed on the grid-type fuel assembly design by conditions in the FFTF core.

\section{Summary}

The fuel assembly with grid type spacers planned for irradiation testing in one of the "open loop" positions of the FFTF will utflize the same space and end fittings as the adjacent wire wrap "driver" assemblies. It has to be adequately cooled by the sodium flow rate produced by the avallable head. To obtain significant performance data the pin size should be in the range planned for future cores for the FFTF and for the Demonstration Plant reactor 
cores, 0.230 to 0.250 -inch OD. The difference in design between grid and wire wrap spacers for an assembly of 217 pins affects the range of power and operating temperatures of pins of a given size and enrichment.

The parameter study was made to find the design limits. Rod diameter, coolant outlet temperature, number of grids, grid strap thickness, $\mathrm{kw} / \mathrm{ft}$, and active fuel length were varied. Two types of grids were examined, honeycomb and line-of-sight grids. A burnup goal of 110,000 MWD/Tonne was assumed. The results of the study show that pins of the same size $(0.230-$ inch OD) as those of the driver FFTF assemblies have to be operated with higher outlet temperature because of the 1 lmit in available coolant head. The same pressure drop limitation eliminated from consideration assemblies with pins larger than 0.240 -inch OD. The most suitable design depends on the choice of assembly location, nearly central or peripheral, see Figure 7-1.

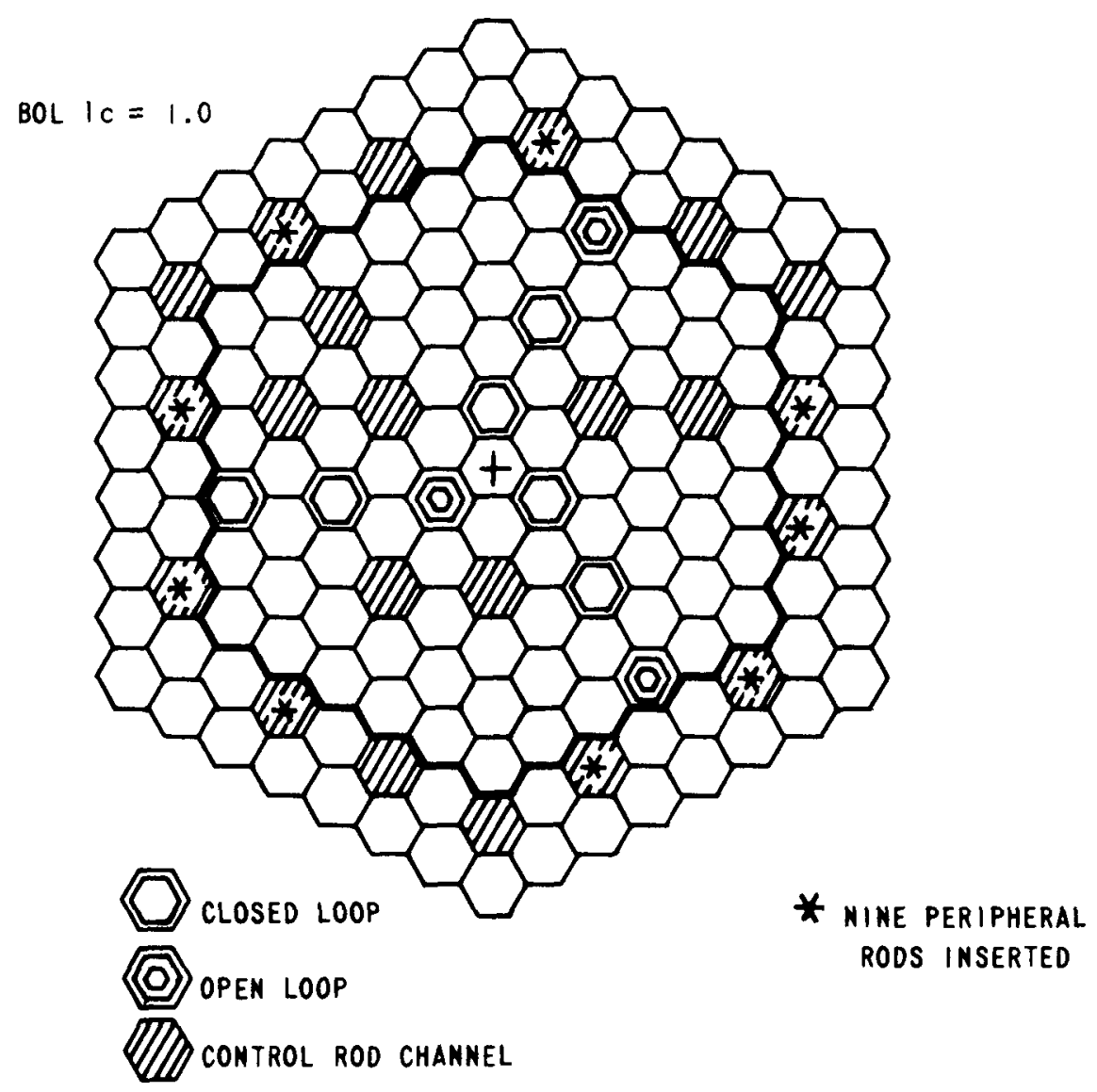

Figure 7-1. Core Layout

$3679-37$ 
In the near-central location, a grid-type assembly of $217,0.230$-inch diameter rods requires an outlet temperature near $1000^{\circ} \mathrm{F}$. The peripheral assembly is sufficiently cooled when the outlet temperature is near $950^{\circ} \mathrm{F}$. This assumes a core length of 36 inches. Trade-offs can be made to reach lower outlet temperature by reducing active fuel length, number of grids, or grid design. A combination of honeycomb grids in the active fuel region and the line-of-sight grids above may be favorable. Such refinements will have to be covered in future investigations. Table 7-1 summarizes the parameters of possible design choices.

\section{Geometry}

The available space and environment, compatability with adjacent assemblies, and convenience suggest use of the same inlet and outlet hardware configurations as employed in the FFTF driver fuel assemblies. The FFTF hexagonal duct can was dimensioned for 80,000 MWD/Tonne average fuel burnup. The inside dimension is 4.335 inches across flats. Table 7-2 shows the pin layouts for two different hexagonal ducts, 4.335 inches for $80,000 \mathrm{MWD} / \mathrm{Tonne}$ and 4.277 inches for 110,000 MWD/Tonne. For the 80,000 MWD/Tonne duct size, and $0.230-i n c h$ pin diameter pins, and 1.24 pitch to diameter ratio (P/D), the edge distances would be large, producing excessive cooling and temperature gradients across the outer row of pins. Reduction of the edge distance to the 0.75 pitch minus rod diameter $(P-D)$ required for sufficient cooling of the corner pins produced a larger triangular pitch. Operation of the grid-type fuel assembly up to $110,000 \mathrm{MWD} / \mathrm{Tonne}$ maximum burnup requires accommodation of an additional dimension increase caused by swelling. The distance across flats inside the hexagonal duct was reduced to 4.277 inches. For that distance and an edge distance of 0.75 times the pin clearance, 0.75 $(P-D)$, the triangular pitch was calculated for all pin diameters in the range of interest. Table 7-3 shows the resultant pitch, unit cell flow areas and other geometrical values for pin diameters from 0.220 to 0.250 inch. These were determined for two types of grid design, the "honeycomb" and the "lineof-sight", see Figure 7-2. The grid strap thickness of the honeycomb grids can be based on strength criteria, since the locating of the pins is performed by raised projections. The geometry determines the thickness of the line-of-sight grid straps. These may be on inadequate strength for the larger pin sizes and present excessive flow blockage for the smaller ones. However, for one pin size, 0.230 inch, the line-of-sight grid strap thickness of $16 \mathrm{mils}$ is equal to that considered for the honeycomb grid for the same pin diameter. Sixteen-mil grid straps can be used for pins near 0.220inch diameter with projections for locating the pins. Their pressure drop is shown in Figure 7-3. The following study assumes all grids in each assembly to be of one type. However, mixed designs are feasible; (e.g., honeycomb grids in the core region and line-of-sight grids in the reflector and gas space regions. Monoplanar line-of-sight grids are assumed in this study, and triplanar grids may be more favorable for local cooling of the pins.

\section{Thermal Limits and Results}

A preliminary choice of hot channel factors was made on a basis of statistic combination of most design uncertainties. A more detailed analysis may 


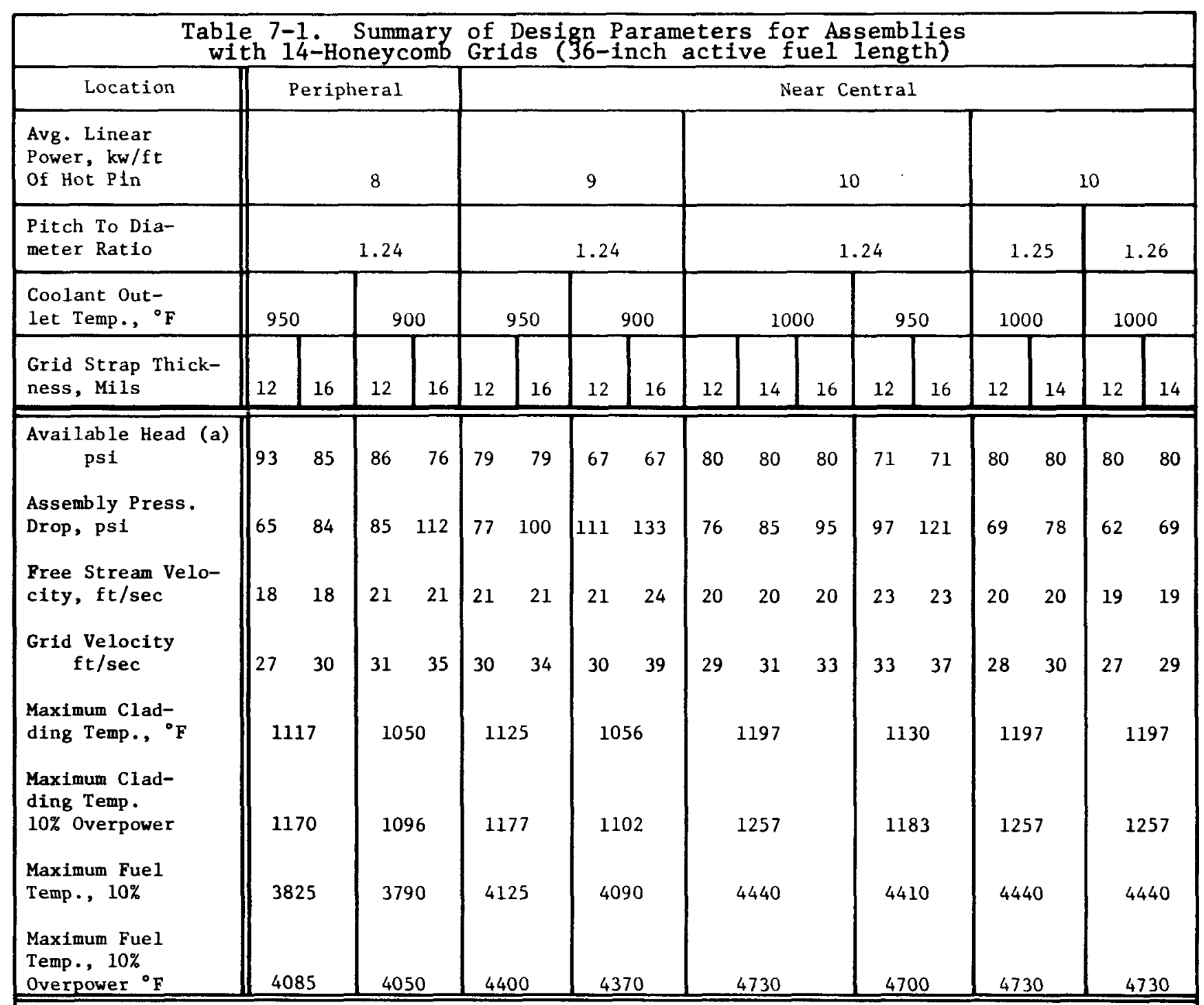

(a) Plenum to plenum $\Delta p$ minus end fitting and instrumentation loss. 

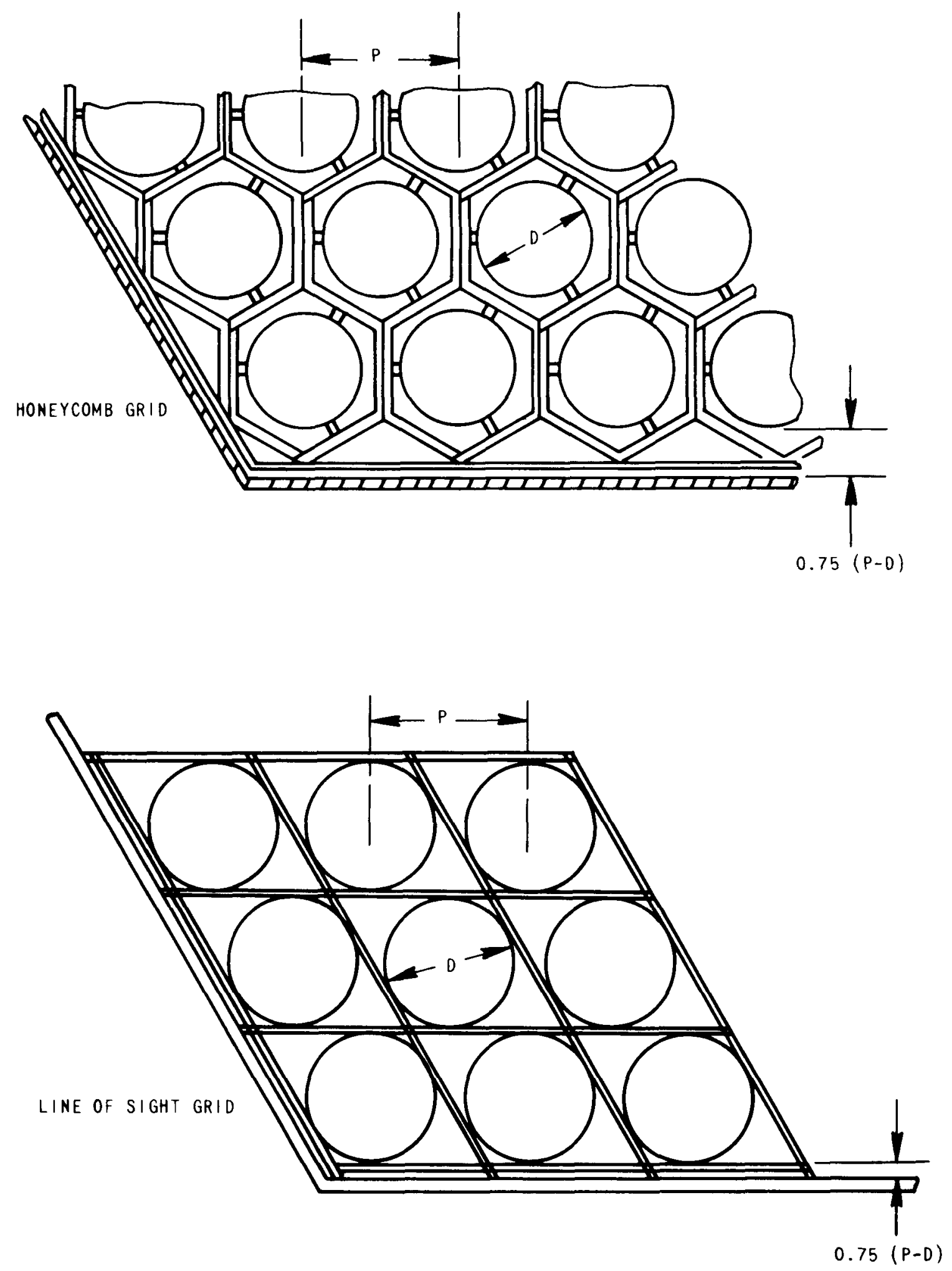

Figure 7-2. Spared Grad Typers 


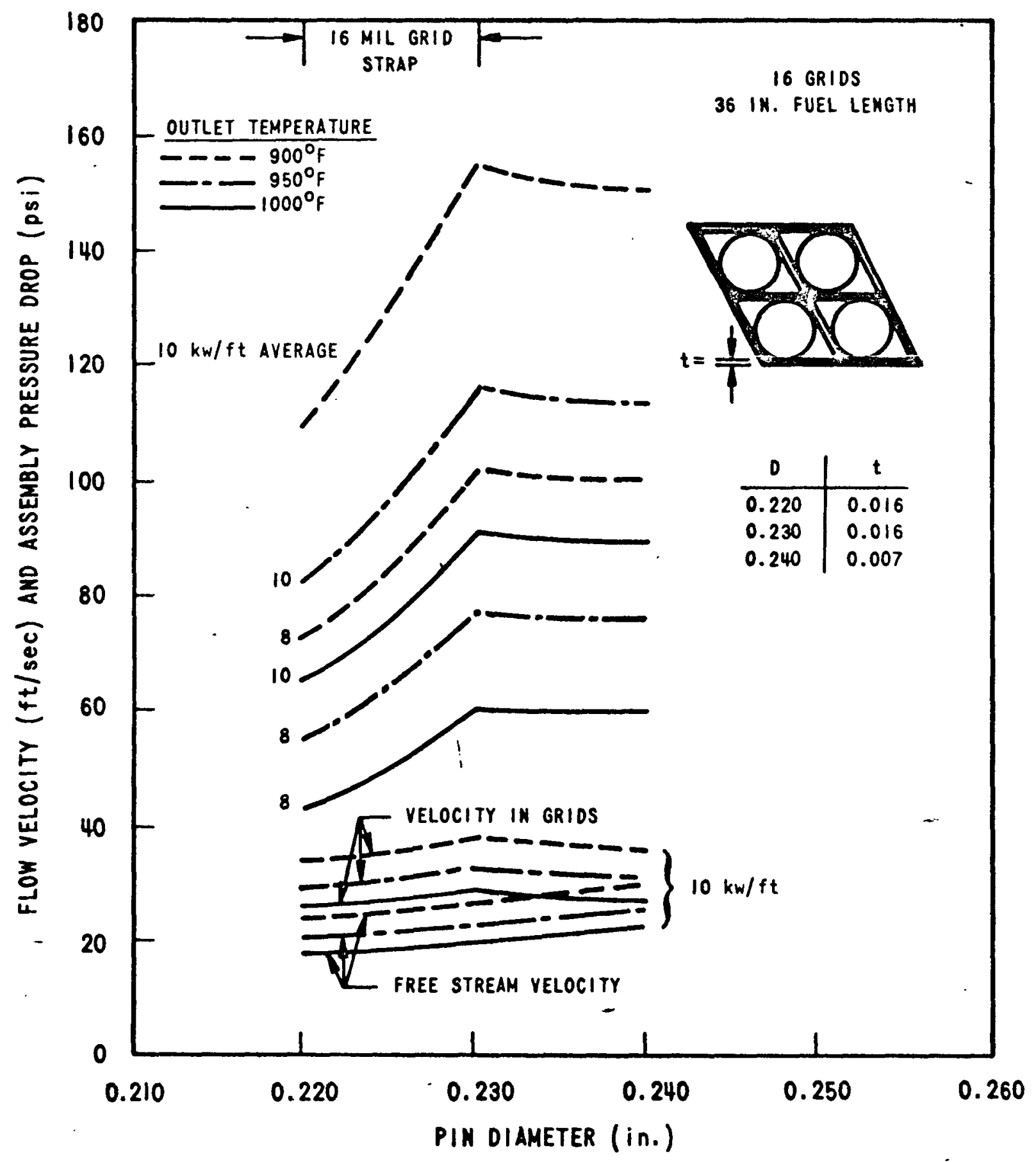

Figure 7-3. Effect of Pin Diameter on $\Delta P$ with "Line of Sight" Grid Design

$-3679-39$ 


\begin{tabular}{|c|c|c|c|c|c|}
\hline $\begin{array}{l}\text { Inside Hex } \\
\text { Across Flats } \\
\quad \text { (in.) }\end{array}$ & $\begin{array}{l}\text { Pin } \\
\text { Diameter } \\
\text { D } \\
\text { (in.) }\end{array}$ & $\begin{array}{l}\text { Edge } \\
\text { Distance } \\
\text { (in.) }\end{array}$ & $\begin{array}{l}\text { Triangular } \\
\text { Pitch } \\
\text { P } \\
\text { (in.) }\end{array}$ & $P / D$ & Remarks \\
\hline \multicolumn{6}{|c|}{$1.27(\mathrm{P}-\mathrm{D})$} \\
\hline \multirow[t]{2}{*}{4.335} & $\begin{array}{l}0.220 \\
0.230 \\
0.240 \\
0.250\end{array}$ & $\begin{array}{l}0.0826 \\
0.0711 \\
0.0596 \\
0.0483\end{array}$ & $\begin{array}{l}0.285 \\
0.286 \\
0.287 \\
0.288\end{array}$ & $\begin{array}{l}1.295 \\
1.243 \\
1.196 \\
1.152\end{array}$ & \multirow[t]{2}{*}{$\begin{array}{l}\text { FFTF and Duct. Dim. } \\
\text { Corner and Side } \\
\text { channels over-cooled } \\
\text { for } 80,000 \mathrm{MWD} / \text { Tonne }\end{array}$} \\
\hline & & & $.75(P-D)$ & & \\
\hline \multirow[t]{2}{*}{4.335} & $\begin{array}{l}0.220 \\
0.230 \\
0.240 \\
0.250\end{array}$ & $\begin{array}{l}0.0521 \\
0.0449 \\
0.0376 \\
0.0304\end{array}$ & $\begin{array}{l}0.2895 \\
0.2898 \\
0.2901 \\
0.2905\end{array}$ & $\begin{array}{l}1.316 \\
1.260 \\
1.209 \\
1.162\end{array}$ & \multirow[t]{2}{*}{$\begin{array}{l}\text { Better temperature } \\
\text { distribution - for } \\
80,000 \mathrm{MWD} / \text { Tonne }\end{array}$} \\
\hline & & & $.75(\mathrm{P}-\mathrm{D})$ & & \\
\hline 4.277 & $\begin{array}{l}0.220 \\
0.230 \\
0.240 \\
0.250\end{array}$ & $\begin{array}{l}0.0488 \\
0.0420 \\
0.0348 \\
0.0275\end{array}$ & $\begin{array}{l}0.285 \\
0.286 \\
0.28634 \\
0.2867\end{array}$ & $\begin{array}{l}1.295 \\
1.2435 \\
1.193 \\
1.147\end{array}$ & $\begin{array}{l}\text { Better temperature } \\
\text { distribution for } \\
110,000 \mathrm{MWD} / \text { Tonne }\end{array}$ \\
\hline
\end{tabular}

produce a considerable revision of the values listed in Table 7-4. This table also summarizes other design choices for the 217-pin assembly, as well as a comparison with current FFTF data.

There has not been any choice made between the peripheral and the nearly central open loop locations for the grid-type subassembly. A peripheral location is favored, because the steeper flux gradient will produce greater stresses in the grids. However, flux level, swelling, and burnup will be somewhat higher in the more central location. Table 7-5 shows that for a fuel enrichment equalling that of the surrounding subassemblies, the maximum linear pin loading in the more central location is close to $10 \mathrm{kw} / \mathrm{ft}$. For the peripheral locations, it approaches $8 \mathrm{kw} / \mathrm{ft}$. The parameter studies were made at power levels of 8 and $10 \mathrm{kw} / \mathrm{ft}$ and with an overpower factor of 1.10. The latter affects temperature levels but not flow rates and pressure drop. Figure $7-4$ shows the highest temperatures of coolant, cladding, and fuel for the range of fuel pin diameters studied. There are no problems at $8 \mathrm{kw} / \mathrm{ft}$, and even at $10 \mathrm{kw} / \mathrm{ft}$ and $0.220-i n c h$ pin diameter, the highest fuel temperature at $10 \%$ overpower is below the melting point. The inside cladding temperature reaches $1264^{\circ} \mathrm{F}$, at 1.10 overpower, while the cladding surface temperature does not exceed $1215^{\circ} \mathrm{F}$ in the range studied. These results are for the $1000^{\circ} \mathrm{F}$ coolant outlet temperature and 36 -inch active fuel length. They will be lower for the other outlet temperatures and fuel lengths examined below. Table 7-6 gives a comparison of maximum temperatures with and without hot channel factors for the case of a nominal linear power of $10 \mathrm{kw} / \mathrm{ft}$ and $1000^{\circ} \mathrm{F}$ outlet temperature. 


\begin{tabular}{|c|c|c|c|c|c|c|c|c|c|c|c|c|c|}
\hline \multicolumn{14}{|c|}{ Honeycomb Grid } \\
\hline \multirow[b]{2}{*}{$\begin{array}{l}\text { Pin } \\
\text { OD } \\
\text { (in.) }\end{array}$} & \multirow[b]{2}{*}{$\begin{array}{l}\text { Pitch } \\
\text { (in.) }\end{array}$} & \multirow{2}{*}{\multicolumn{2}{|c|}{$\mathrm{P} / \mathrm{D}$}} & \multirow{2}{*}{\multicolumn{2}{|c|}{$\begin{array}{c}\text { Clearance } \\
\text { P-D } \\
\text { (In.) }\end{array}$}} & \multicolumn{4}{|c|}{ Unit Cell } & \multicolumn{3}{|c|}{ Grid Flow Area } & $\begin{array}{l}\text { Total Grid } \\
\text { Loss Coefficient }\end{array}$ \\
\hline & & & & & & $\begin{array}{l}\text { Flow } \\
\text { Area } \\
\text { (in.2) }\end{array}$ & \multicolumn{2}{|c|}{$\begin{array}{l}\text { Wetted } \\
\text { Perimeter } \\
\text { (in.) }\end{array}$} & $\begin{array}{l}\text { Eq. } \\
\text { Dia. } \\
\text { (in.) }\end{array}$ & $\begin{array}{l}20 \mathrm{Mil} \\
(\mathrm{in.2})\end{array}$ & $\begin{array}{l}16 \mathrm{Mi1} \\
(\mathrm{in} .2)\end{array}$ & $\begin{array}{l}12 \mathrm{MII} \\
(\mathrm{in} .2)\end{array}$ & \begin{tabular}{l|l|l}
\multicolumn{3}{|c|}{ Outlet Temp. ${ }^{\circ} \mathrm{F}$} \\
1000 & 950 & 900
\end{tabular} \\
\hline 0.220 & 0.285 & \multicolumn{2}{|c|}{1.295} & \multicolumn{2}{|c|}{0.065} & 0.01616 & \multicolumn{2}{|c|}{0.3456} & 0.1871 & 0.01038 & 0.01141 & 0.0125 & $1.47 \quad 1.45$ \\
\hline 0.230 & 0.286 & \multicolumn{2}{|c|}{1.2435} & \multicolumn{2}{|c|}{0.056} & 0.01464 & \multicolumn{2}{|c|}{0.3613} & 0.1621 & 0.00880 & 0.00987 & 0.0109 & 1.851 .83 \\
\hline 0.240 & 0.28635 & \multicolumn{2}{|c|}{1.193} & \multicolumn{2}{|c|}{0.04635} & 0.01288 & \multicolumn{2}{|c|}{0.3770} & 0.1367 & 0.00707 & 0.00810 & 0.0092 & 2.22 \\
\hline 0.250 & 0.2867 & 1.1 & & 0.0 & 67 & 0.01105 & 0.39 & & 0.1130 & 0.00523 & 0.00626 & 0.0073 & $3.91 \quad 3.87$ \\
\hline & & & & & & & Line & f $\mathrm{S1}$ & ght Grid & & & & \\
\hline & & & & & & learance & & Gri & Flow & Area & F1ow & & Total Grid \\
\hline Pin & & & & & & Lin & le of & Str & Un & & Area & Los & is Coefficient \\
\hline OD & Pitc & & & & $P-D$ & Sig & & Thi & & & Grid & Outle & t Temp. ${ }^{\circ} \mathrm{F}$ \\
\hline (in.) & (in. & & P/ & & (in.) & (in & & (in & (in & & $(\ln .2)$ & 1000 & \begin{tabular}{l|l}
950 & 900
\end{tabular} \\
\hline 0.22 & 0.28 & & 1.2 & 95 & 0.065 & 0.0 & 268 & 0.0 & 0.0 & 1616 & 0.01173 & 1.36 & 1.24 \\
\hline 0.230 & 0.28 & & 1.2 & 435 & 0.056 & 0.0 & 177 & 0.0 & 0.0 & 1464 & 0.01020 & 1.56 & 1.54 \\
\hline $0.24 C$ & 0.28 & 3635 & 1.1 & & 0.046 & 0.0 & 080 & 0.0 & 0.0 & 1288 & 0.01030 & 0.91 & 0.89 \\
\hline
\end{tabular}




\begin{tabular}{|c|c|c|}
\hline & FFTF & $\begin{array}{c}217 \text { Pin } \\
\text { Grid-Type Assembly } \\
\text { Preliminary }\end{array}$ \\
\hline $\mathrm{F}_{\mathrm{R}}^{\mathrm{N}}$ & 1.40 & $1.00^{(\mathrm{a})}$ \\
\hline $\mathrm{F}_{\mathrm{A}}^{\mathrm{N}}$ & 1.24 & 1.24 \\
\hline$F_{\Delta H}^{E}$ & 1.336 & 1.336 \\
\hline$F_{\theta}^{E}$ & 2.965 & 1.857 \\
\hline $\mathrm{F}_{\mathrm{CLAD}}^{\mathrm{E}}$ & 1.177 & 1.216 \\
\hline$F_{\mathrm{GAP}}^{\mathrm{E}}$ & 1.44 & 1.19 \\
\hline $\mathrm{F}_{\text {FUEL }}^{\mathrm{E}}$ & 1.162 & 1.1975 \\
\hline $\begin{array}{l}\text { GAP conductance } \\
\left(\mathrm{Btu} / \mathrm{hr}-\mathrm{ft} \mathrm{t}^{2}-{ }^{\circ} \mathrm{F}\right)\end{array}$ & 1700 & 1200 \\
\hline $\begin{array}{l}\text { Avg. Linear Power in } \\
\text { Hot Pin, }(\mathrm{kw} / \mathrm{ft})\end{array}$ & 10 & 8,9 , or 10 \\
\hline Assembly Outlet Temperature, $\left({ }^{\circ} \mathrm{F}\right)$ & 900 & \\
\hline Active Fuel Length, (in.) & 36 & \\
\hline No. of Grids & - & \\
\hline Free Stream Velocity, (ft/sec) & 21 & \\
\hline Assemb1y Pressure Drop, (psi) & 110 & \\
\hline Fuel Pin Assembly Length, (in.) & 93 & 93 \\
\hline Maximum Burnup (MWD/Tonne) & 80,000 & \\
\hline Gas Plenum Length, (in.) & 42 & \\
\hline Grid Length, (in.) & & 1.0 \\
\hline
\end{tabular}

(a) Power distribution map utilized in subchannel analysis replaces $F_{R}^{N}$ 


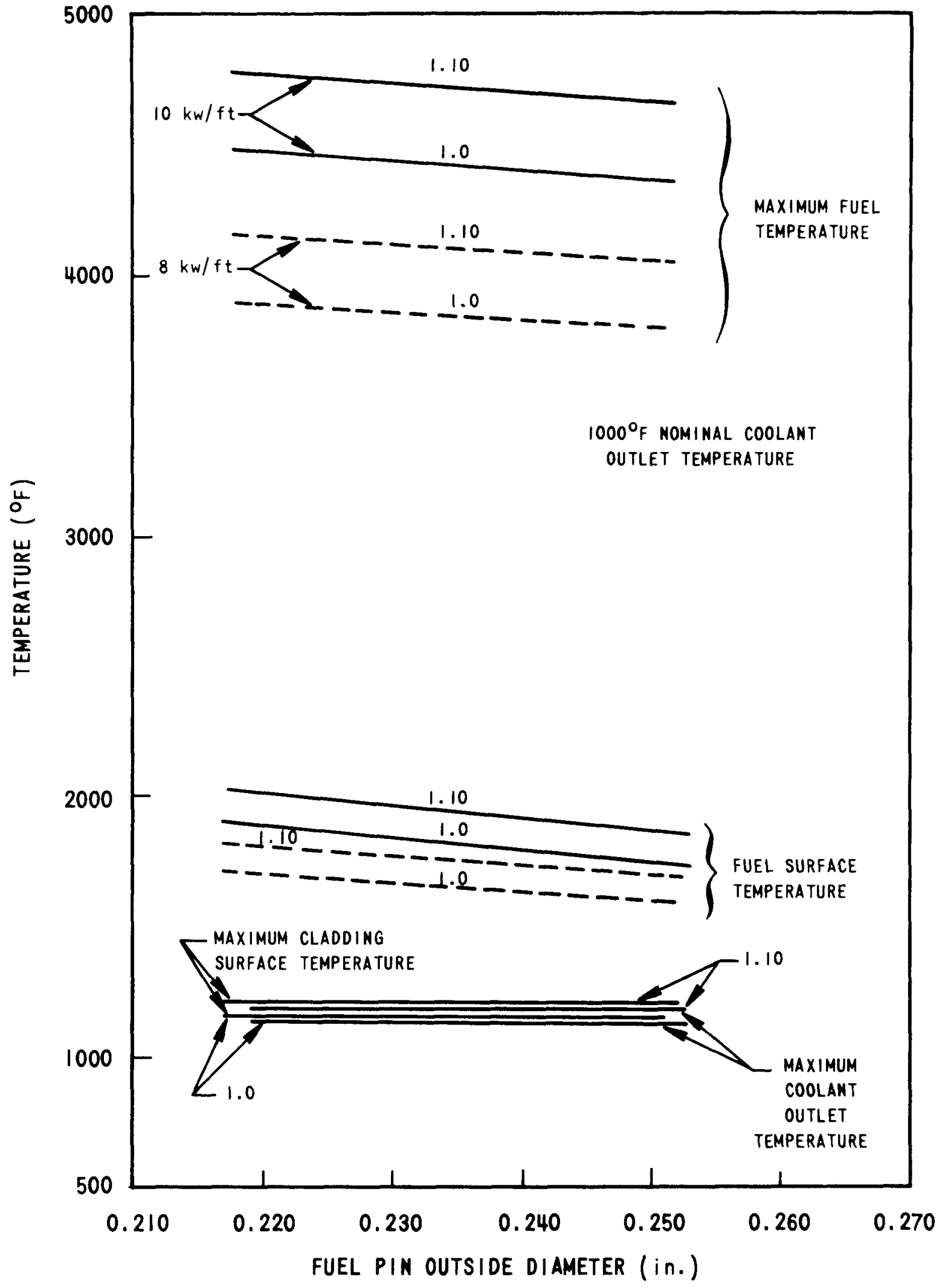

Figure 7-4. Effect of Pin Diameter on Temperature Distribution 


\begin{tabular}{|c|c|c|c|}
\hline \multirow{3}{*}{ Pin } & \multicolumn{3}{|c|}{$\begin{array}{c}\text { Axial Average Linear Power } \mathrm{kw} / \mathrm{ft} \\
\text { Open Loop Location }\end{array}$} \\
\hline & \multirow{2}{*}{$\begin{array}{c}\text { Near } \\
\text { Center } \\
\mathrm{BOL}^{(\mathrm{a})} \\
\end{array}$} & \multicolumn{2}{|c|}{ Peripheral } \\
\hline & & 1.0 & 2.0 \\
\hline Maximum & 10.0 & 8.0 & 7.5 \\
\hline Average & 9.6 & 6.0 & 5.9 \\
\hline
\end{tabular}

\section{Hydraulic Limits}

The available coolant flow head across the complete fuel assembly is approximately $110 \mathrm{psi}$. The pressure loss in the inlet and outlet fittings is estimated as follows:

\begin{tabular}{|c|c|c|c|c|c|c|}
\hline \multirow{2}{*}{$\begin{array}{c}\text { Outlet Temp. } \\
\left({ }^{\circ} \mathrm{F}\right)\end{array}$} & \multicolumn{3}{|c|}{ End Fitting $\Delta \mathrm{p}$ (psi) } & \multicolumn{2}{c|}{ Available Assembly $\Delta \mathrm{p}$ (psi) } \\
\cline { 2 - 7 } & $6 \mathrm{kw} / \mathrm{ft}$ & $8 \mathrm{kw} / \mathrm{ft}$ & $10 \mathrm{kw} / \mathrm{ft}$ & $6 \mathrm{kw} / \mathrm{ft}$ & $8 \mathrm{kw} / \mathrm{ft}$ & $10 \mathrm{kw} / \mathrm{ft}$ \\
\hline 1000 & 11 & 19 & 30 & 99 & 91 & 80 \\
950 & 14 & 25 & 39 & 96 & 85 & 71 \\
900 & 19 & 34 & 53 & 91 & 76 & 57 \\
\hline
\end{tabular}

The pressure drop and the maximum allowable sodium velocity are the principal design limitations. The free stream sodium velocity must be kept below $\sim 30 \mathrm{ft} / \mathrm{sec}$ and the velocity in the grids below $\sim 40 \mathrm{ft} / \mathrm{sec}$ to avoid excessive erosion and the chance of cavitation. In order not to exceed the available pressure drop, a trade-off of fuel length, number of grids, or fuel enrichment can be made to obtain desired levels of outlet temperatures, fuel pin size, or grid strap thickness. Table 7-7 shows the range of parameters examined in this parameter study.

\section{Line-of-Sight Grids}

The "line-of-sight" grid normally has a lower pressure drop than the honeycomb grid. However, its suitability is in question until the local cooling in the small grid flow channels can be studied in detall. Figure 7-3 shows the overall pressure drop of an assembly with sixteen line-ofsight grids. At $8 \mathrm{kw} / \mathrm{ft}$ the pressure drop limft is exceeded when the outlet 


\begin{tabular}{|c|c|c|c|c|c|c|c|c|c|c|c|}
\hline \multirow{3}{*}{$\begin{array}{l}\text { Pin } \\
\text { Dia. } \\
\text { (in.) } \\
\end{array}$} & \multicolumn{2}{|c|}{$\begin{array}{l}\text { Avg. } \\
\text { Linear } \\
\text { Power } \\
(\mathrm{kw} / \mathrm{ft})\end{array}$} & \multirow{2}{*}{\multicolumn{2}{|c|}{$\begin{array}{c}\begin{array}{c}\text { Coolant } \\
\text { Outlet } \\
\text { Temp. } \\
\left({ }^{\circ} \mathrm{F}\right)\end{array} \\
\left(600^{\circ} \mathrm{F} \text { Inlet }\right)\end{array}$}} & \multicolumn{2}{|c|}{$\begin{array}{c}\text { Maximum } \\
\text { Cladding } \\
\text { Temp. } \\
\left({ }^{\circ} \mathrm{F}\right)\end{array}$} & \multicolumn{2}{|c|}{$\begin{array}{l}\text { Fuel } \\
\text { Temp. } \\
\left({ }^{\circ} \mathrm{F}\right)\end{array}$} & \multirow{3}{*}{$\begin{array}{l}\text { Void } \\
\text { Dia. } \\
\text { (in.) } \\
\end{array}$} & \multirow{3}{*}{$\begin{array}{l}\text { Over- } \\
\text { Power } \\
\text { Factor } \\
\end{array}$} & \multirow{3}{*}{$\begin{array}{c}\text { Hot } \\
\text { Channe1 } \\
\text { Factors }\end{array}$} \\
\hline & \multirow{2}{*}{ Nominal } & \multirow[b]{2}{*}{ Max. } & & & \multirow[b]{2}{*}{ Surface } & \multirow{2}{*}{ Inside } & \multirow{2}{*}{ Surface } & \multirow{2}{*}{ Max. } & & & \\
\hline & & & Nominal & Max. & & & & & & & \\
\hline 0.220 & 10 & 13.4 & 1000 & 1040 & 1052 & 1091 & 1735 & 4200 & 0.043 & 1.1 & 1.0 \\
\hline 0.220 & 10 & 12.2 & 1000 & 1000 & 1010 & 1046 & 1630 & 3930 & 0.037 & 1.0 & 1.0 \\
\hline 0.230 & 10 & 13.4 & 1000 & 1040 & 1050 & 1088 & 1690 & 4160 & 0.042 & 1.1 & 1.0 \\
\hline 0.230 & 10 & 12.2 & 1000 & 1000 & 1008 & 1043 & 1590 & 3895 & 0.038 & 1.0 & 1.0 \\
\hline 0.240 & 10 & 13.4 & 1000 & 1040 & 1048 & 1085 & 1650 & 4130 & 0.044 & 1.1 & 1.0 \\
\hline 0.240 & 10 & 12.2 & 1000 & 1000 & 1007 & 1040 & 1555 & 3860 & 0.039 & 1.0 & 1.0 \\
\hline 0.250 & 10 & 13.4 & 1000 & 1040 & 1049 & 1083 & 1620 & 4100 & 0.045 & 1.1 & 1.0 \\
\hline 0.250 & 10 & 12.2 & 1000 & 1000 & 1007 & 1039 & 1525 & 3835 & 0.041 & 1.0 & 1.0 \\
\hline 0.220 & 10 & 13.4 & 1000 & 1190 & 1214 & 1263 & 2015 & 4770 & 0.047 & 1.1 & Fu11 \\
\hline 0.220 & 10 & 12.2 & 1000 & 1136 & 1157 & 1201 & 1885 & 4475 & 0.044 & 1.0 & Full \\
\hline 0.230 & 10 & 13.4 & 1000 & 1190 & 1212 & 1257 & 1960 & 4730 & 0.049 & 1.1 & Fu11 \\
\hline 0.230 & 10 & 12.2 & 1000 & 1136 & 1154 & 1197 & 1835 & 4440 & 0.046 & 1.0 & Ful1 \\
\hline 0.240 & 10 & 13.4 & 1000 & 1190 & 1208 & 1252 & 1910 & 4700 & 0.050 & 1.1 & Fu11 \\
\hline 0.240 & 10 & 12.2 & 1000 & 1136 & 1151 & 1192 & 1790 & 4400 & 0.048 & 1.0 & Ful1 \\
\hline 0.250 & 10 & 13.4 & 1000 & 1190 & 1208 & 1250 & 1870 & 4665 & 0.052 & 1.1 & Ful1 \\
\hline 0.250 & 10 & 12.2 & 1000 & 1136 & 1151 & 1190 & 1750 & 4365 & 0.050 & 1.0 & $\mathrm{Fu} 11$ \\
\hline
\end{tabular}


Table 7-7. Range of Parameters Studied

\begin{tabular}{ll} 
Pin Diameter, (in.) & $0.220,0.230,0.240,0.250$ \\
Coolant Outlet Temperature, $\left({ }^{\circ} \mathrm{F}\right)$ & $900,950,1000$ \\
Number of Grids & $12,14,16$ \\
Grid Strap Thickness, (mils) & $12,16,20$ \\
Active Fuel Length, (1n.) & $30,33,36$ \\
Linear Loading, Average, (kw/ft) & 6 to 10 \\
Overpower Factor & $1.0,1.10$ \\
Grid Type & Line-of-Sight, Honeycomb \\
\hline
\end{tabular}

temperature is dropped below $1000^{\circ} \mathrm{F}$. At pin diameters above 0.235 inch, the grid straps will become too thin to locate the fuel pins positively.

A study of the effect of varying the number of grids, the fuel length and the outlet temperature is summarized in Figure 7-5 for an average linear power of $8 \mathrm{kw} / \mathrm{ft}$ and in Figure $7-6$ for $10 \mathrm{kw} / \mathrm{ft}$.

\section{$\underline{\text { Honeycomb Grids }}$}

Because honeycomb grids can be built for a wider range of pin sizes, a more extensive parameter study was made of subassemblies incorporating this design. The effect of fuel pin size on pressure drop and flow velocity with a constant 36-inch active fuel length, sixteen grids, and sixteen mil grid straps is shown in Figures $7-7,7-8$, and $7-9$ for 6,8 , and $10 \mathrm{kw} / \mathrm{ft}$ average linear power, respectively. Employing the criteria contained under the subheading "Thermal Limits and Results," the figures show that at $8 \mathrm{kw} / \mathrm{ft}$ and $1000^{\circ} \mathrm{F}$ outlet temperature, assemblies of pins larger than 0.236 -inch diameter require excessive pressure drop and flow velocities for adequate cooling. At $950^{\circ} \mathrm{F}$ outlet temperature the maximum size is 0.230 -inch diameter; at $900^{\circ} \mathrm{F}, 0.220-$ inch diameter. At $10 \mathrm{kw} / \mathrm{ft}$ the maximum pin size at $1000^{\circ} \mathrm{F}$ outlet is $0.224-1$ nch; at $950^{\circ} \mathrm{F}$ outlet, $0.215-$ inch diameter; and at $900^{\circ} \mathrm{F}$ outlet, less than 0.210 -inch diameter. This shows that even with $1000^{\circ} \mathrm{F}$ outlet temperature, 36-inch active fuel length, and 16 grids, the largest pin diameter is 0.224 inch for $10 \mathrm{kw} / \mathrm{ft}$ and 0.236 inch for $8 \mathrm{kw} / \mathrm{ft}$.

The reference geometry has to be changed if larger pin diameters at lower outlet temperatures are desired. The effect of such changes is shown in Figures 7-10 and 7-11 where the number of grids is varied at $1000^{\circ} \mathrm{F}$ and $900^{\circ} \mathrm{F}$ outlet temperature; in Figures 7-12 through 7-15, where the effect of different grid strap thickness is shown for assemblies with 16 and 14 honeycomb grids; and in Figure 7-16 which shows the effect of changing the active fuel length. Figure 7-17 summarizes the effect of varying the linear power and pin diameter on pressure drop.

Assuming a choice of 0.230 -inch pin diameter, a study was made showing the effect of outlet temperature number of grids and active fuel length. Grid 


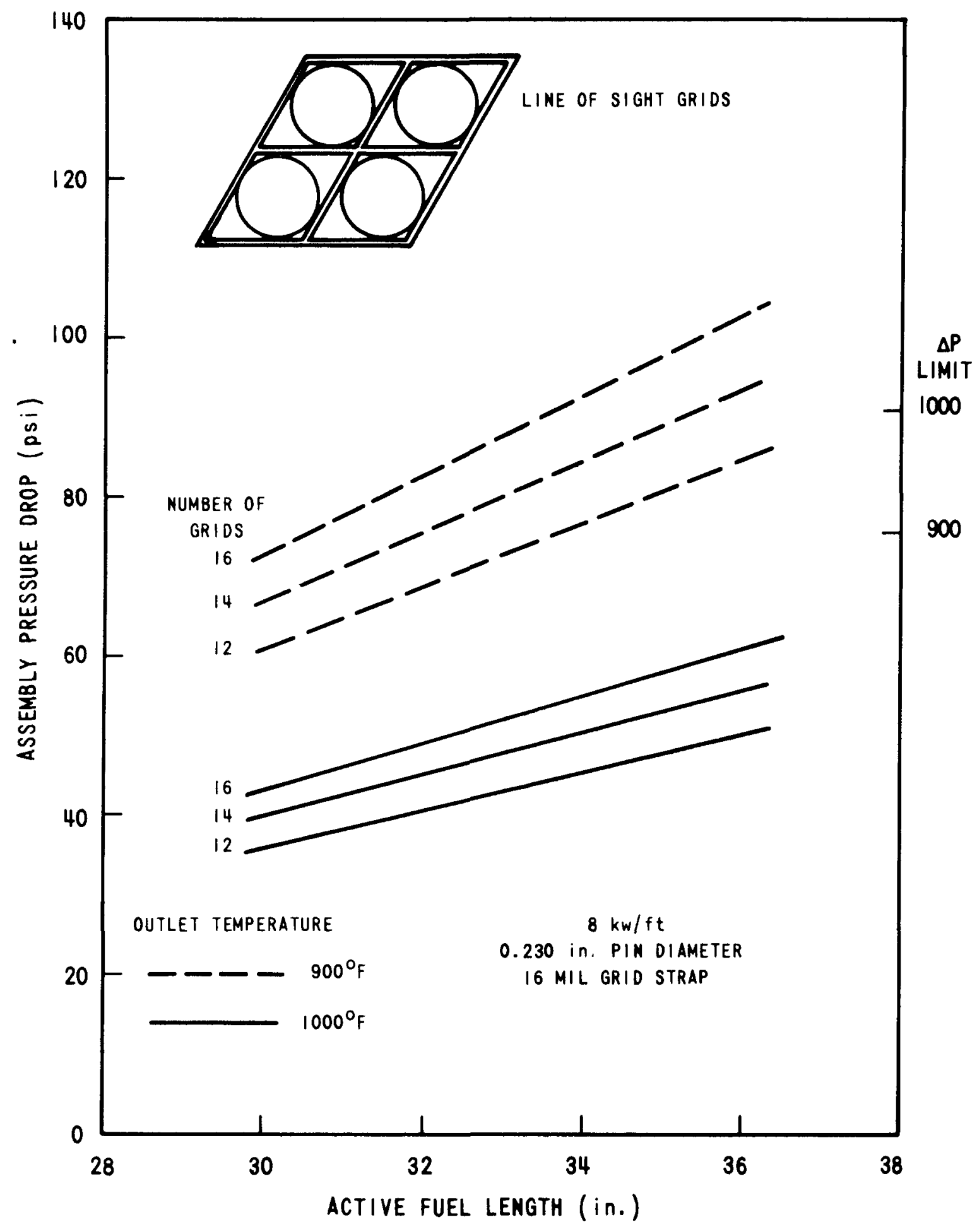

Figure 7-5. Effect of Fuel Length. Outlet Temperature and Number of Grids on Pressure Drop 


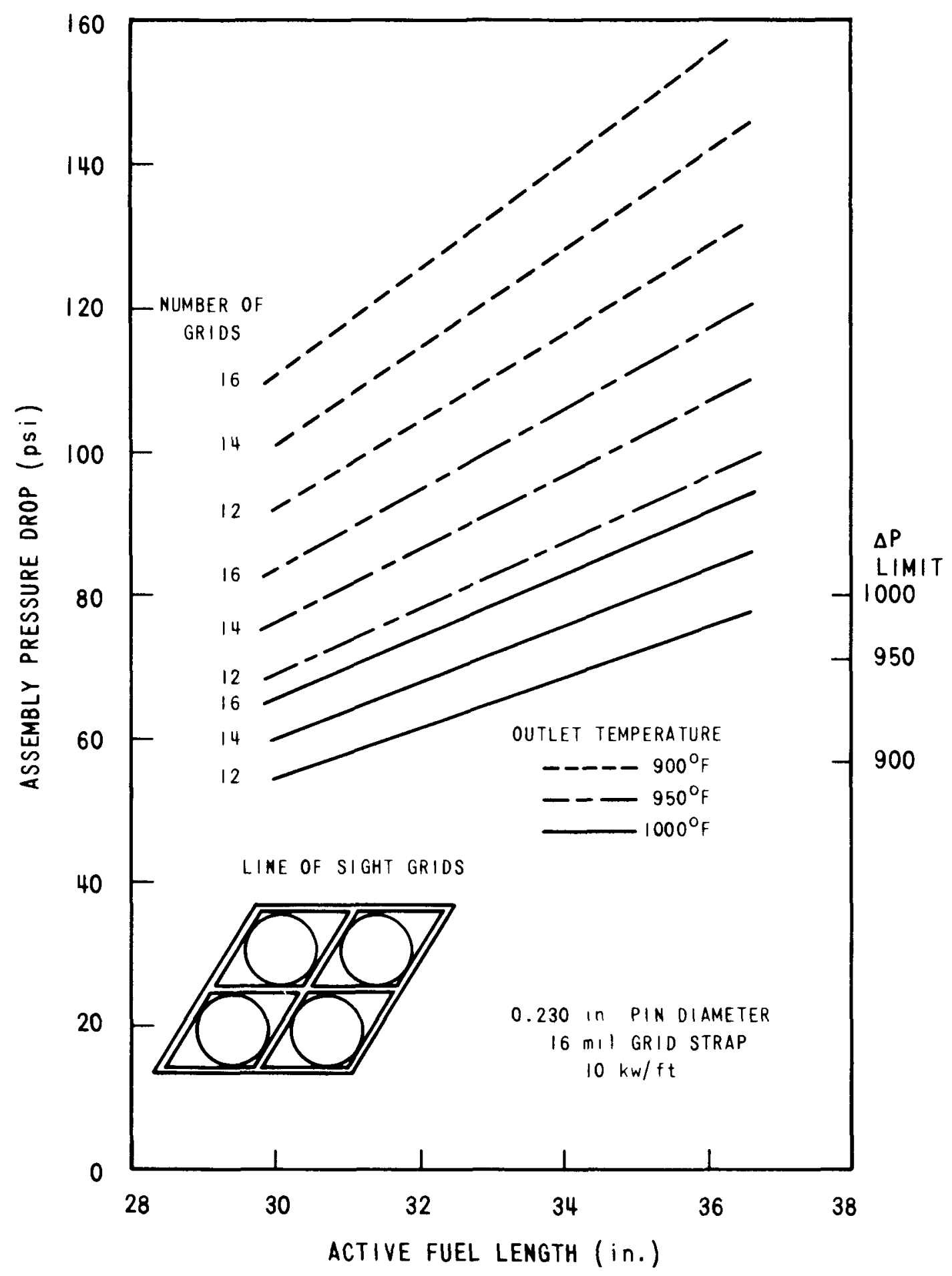

Figure 7-6. Eflect of Fuel Length, Outlet Temperature and Giad Number on Pressure Diop

$3679-42$ 


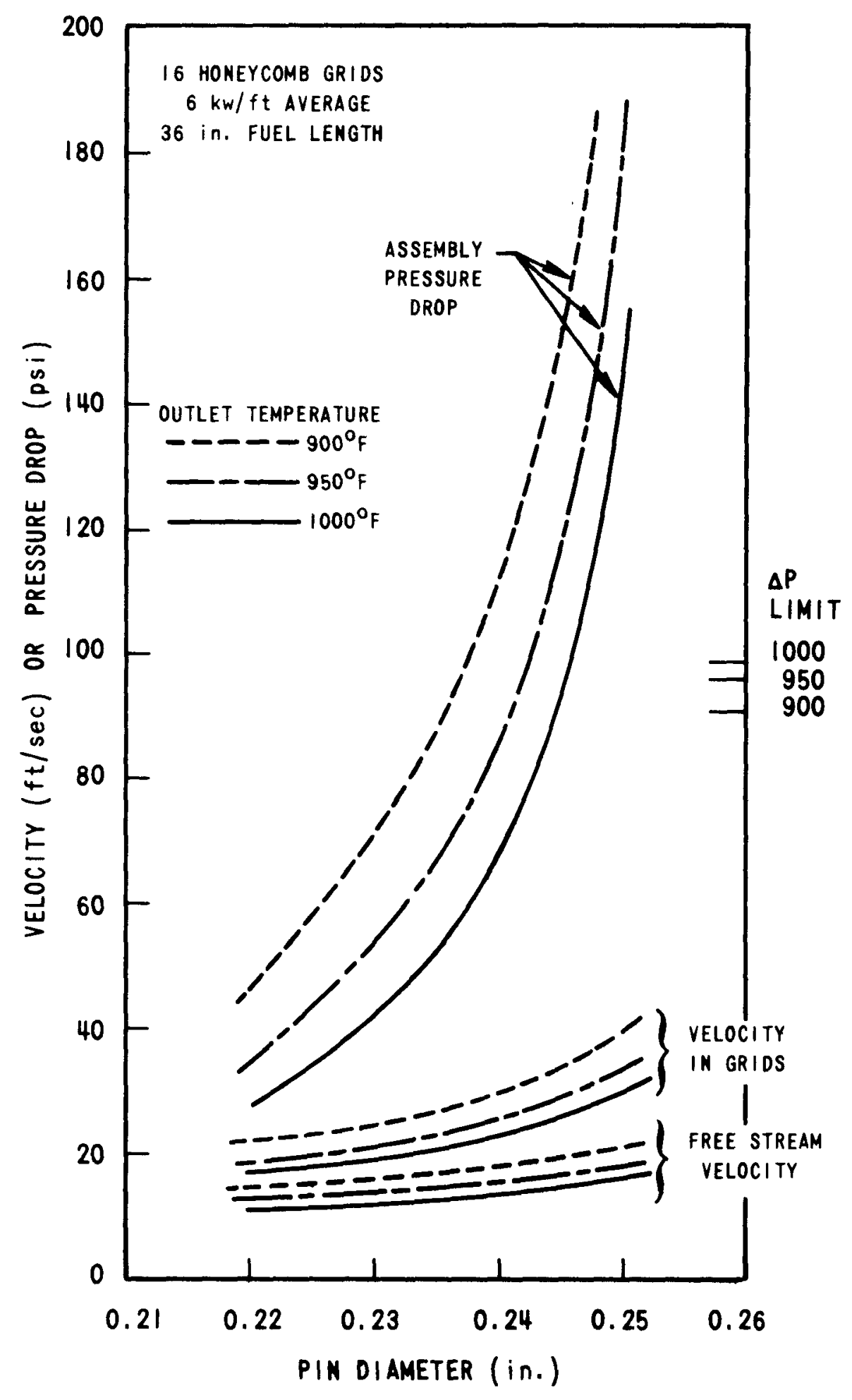

Figure 7-7. Effect of Outlet Temperature on Pressure Drop (6 kw/ft) $3679-43$ 


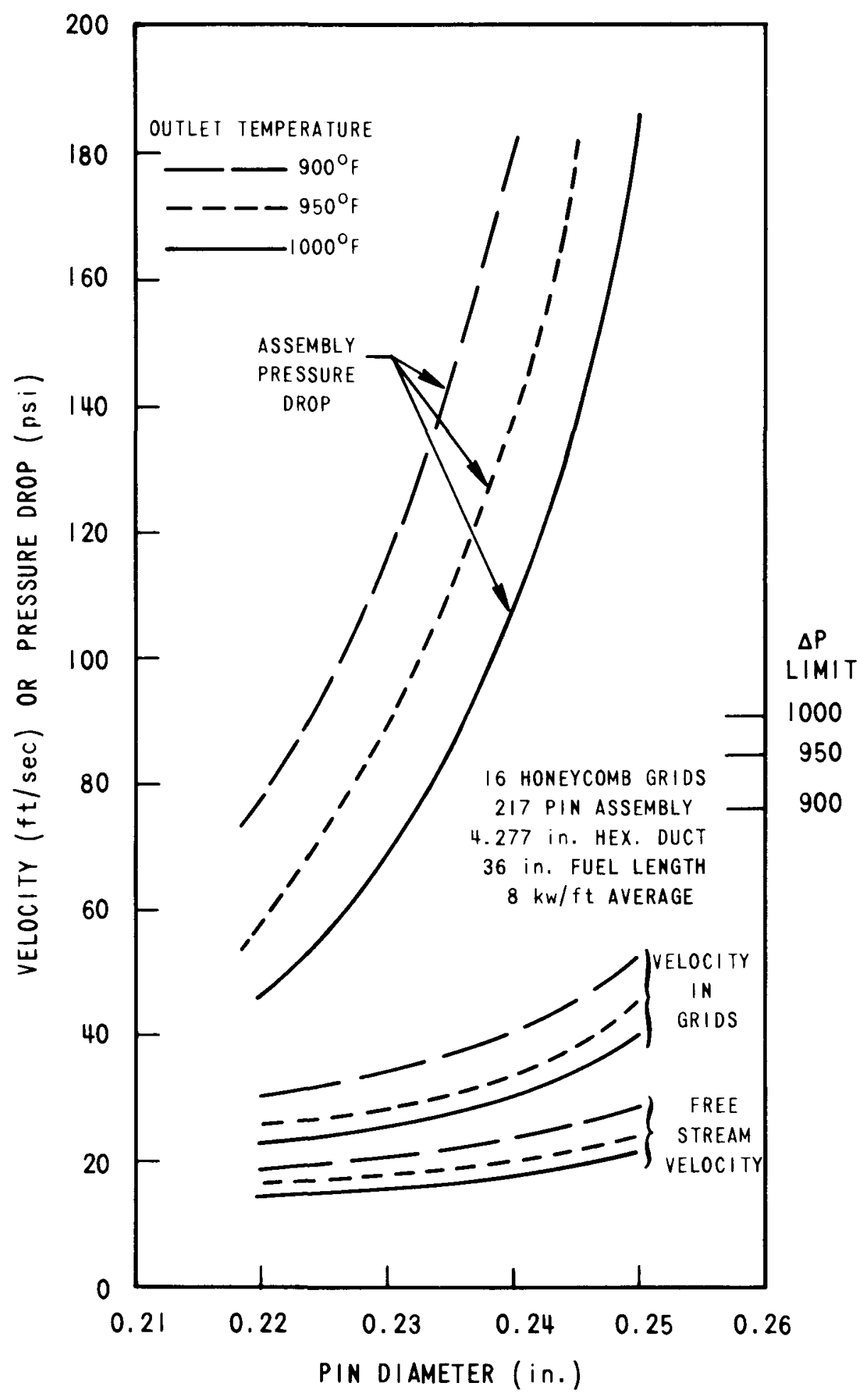

Figure 7 -8. Effect of Outlet Temperature on Pressure Drop $(8 \mathrm{kw} / \mathrm{ft})$ $3679-44$ 


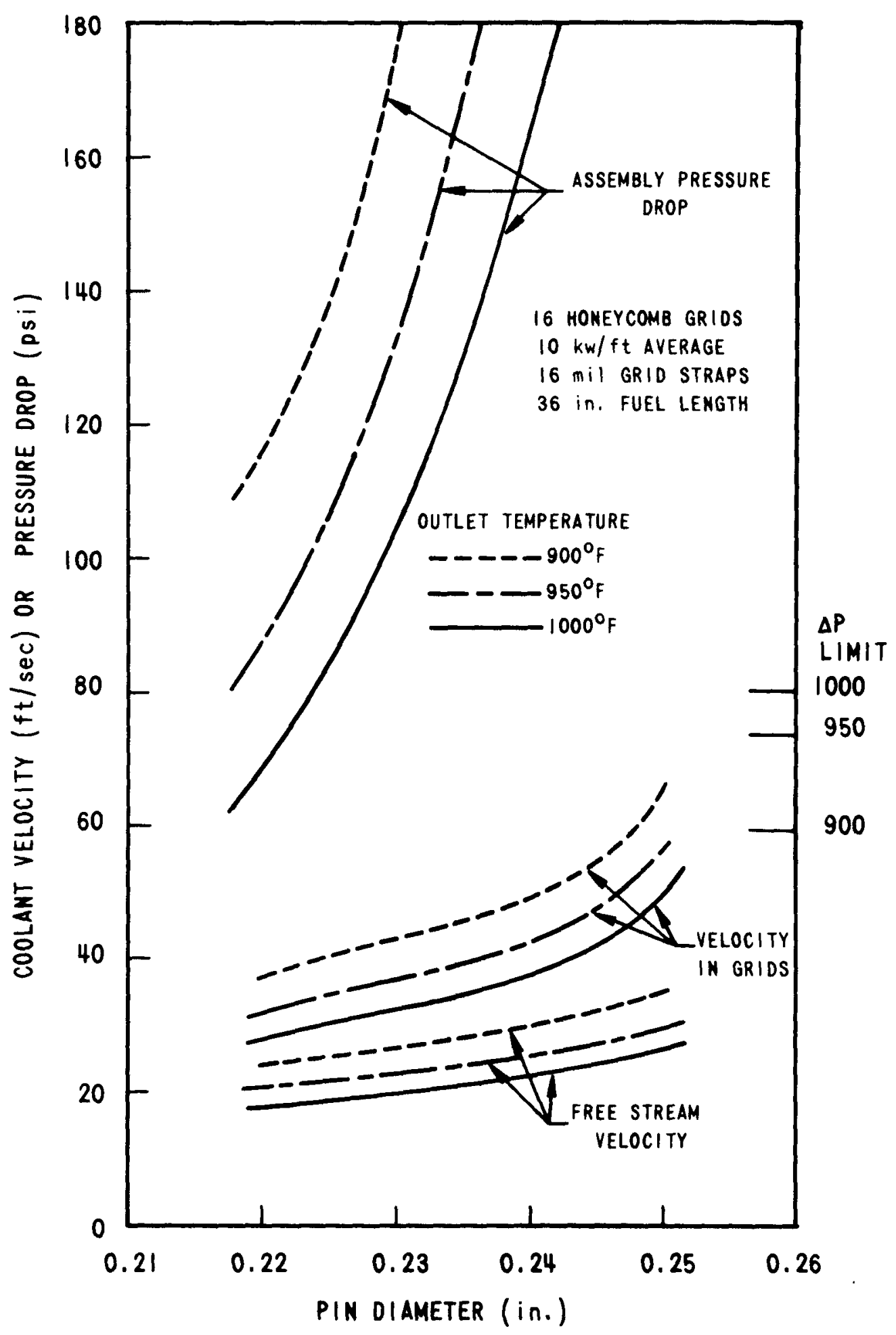

Figure 7-9. Effect of Outlet Temperature on Pressure Drop (10 kw/ ft) $3679-45$ 


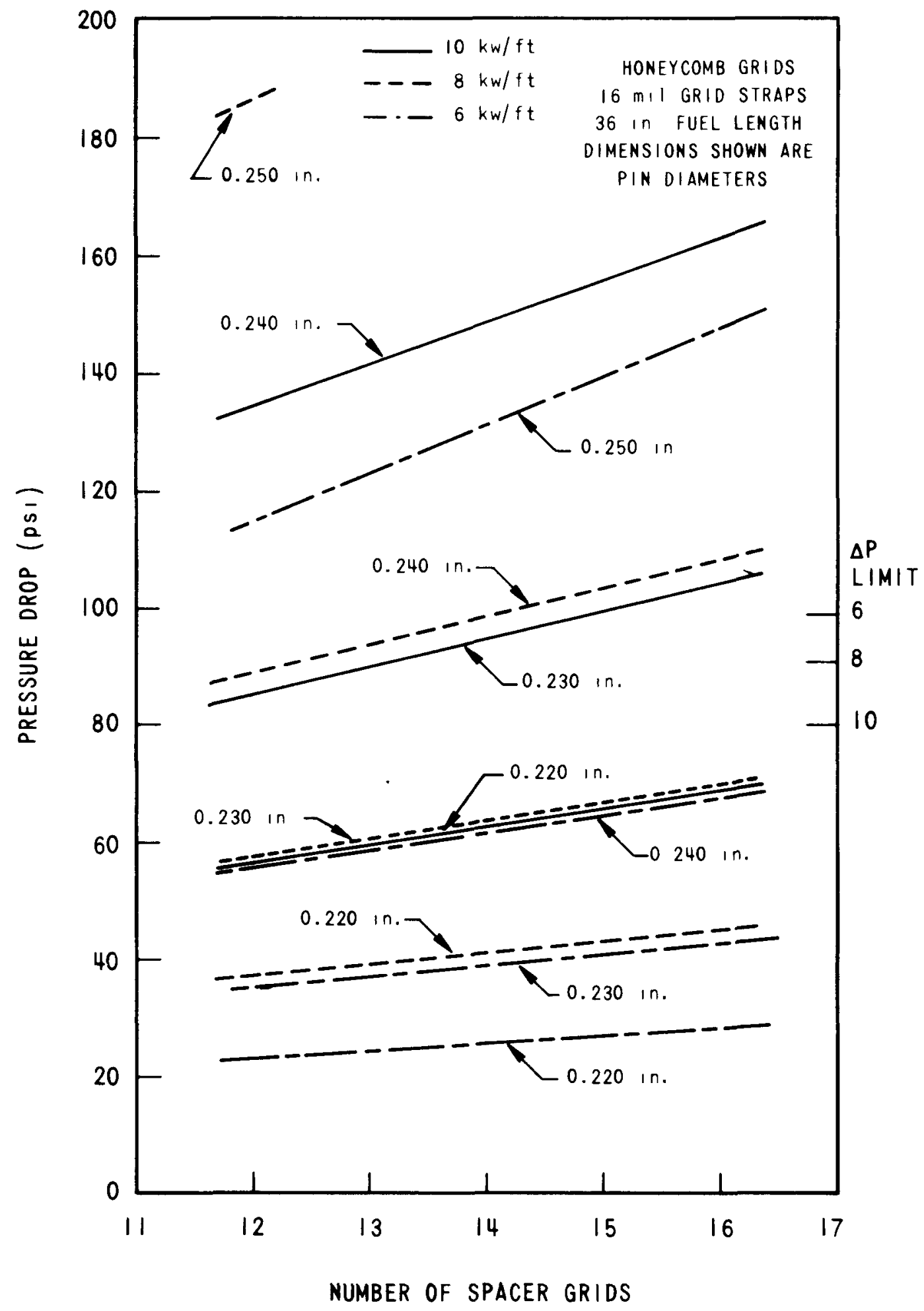

Figure 7-10. Eftert of Number of Giads on Assembly Picesure Drop $3679-46$ ( $1000^{\circ} \mathrm{F}$ outlet temperature) 


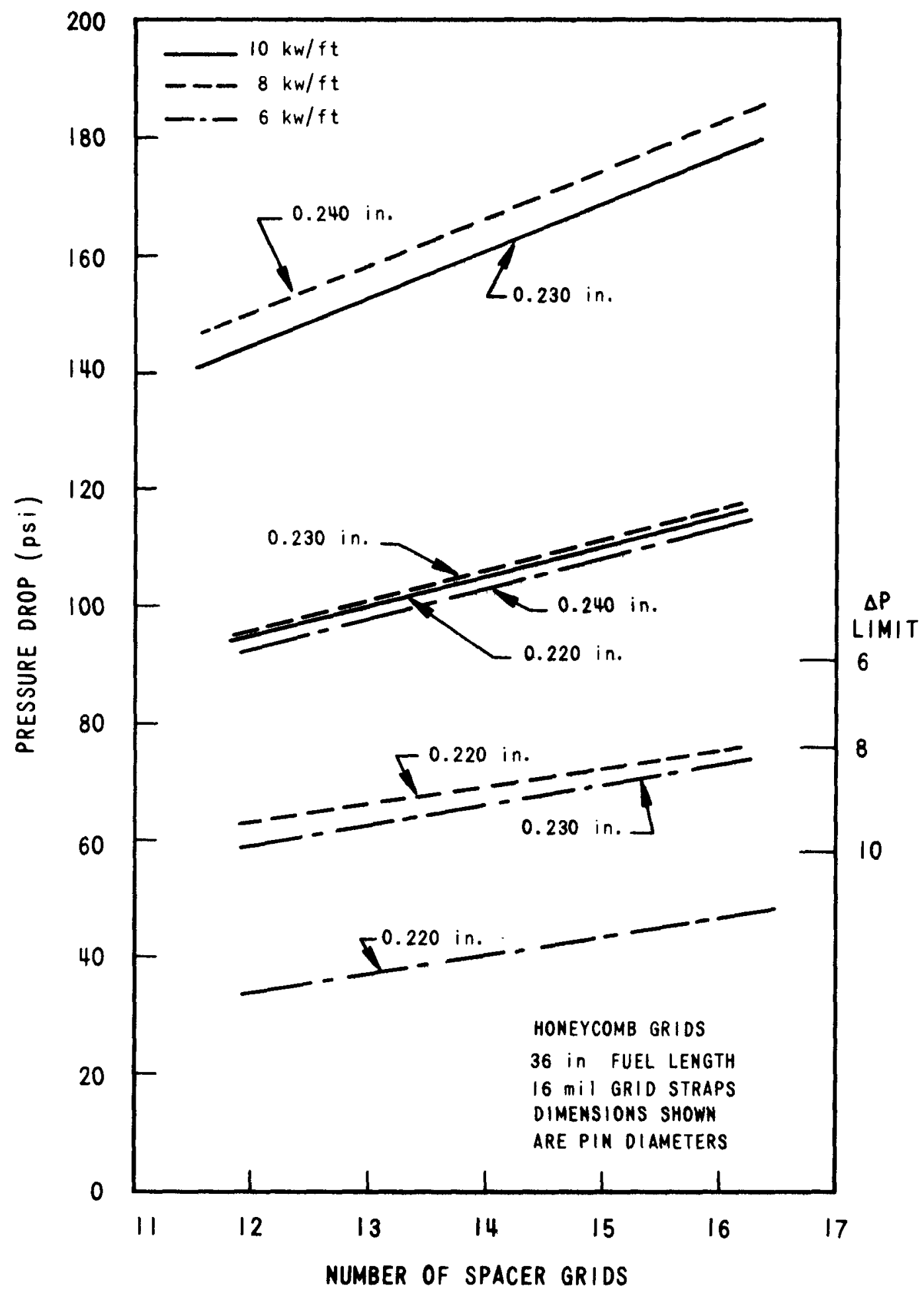

Figure 7-11. Effect of Number of Grids on Assembly Pressure Drop $\left(900^{\circ} \mathrm{F}\right.$ out let temperature) 


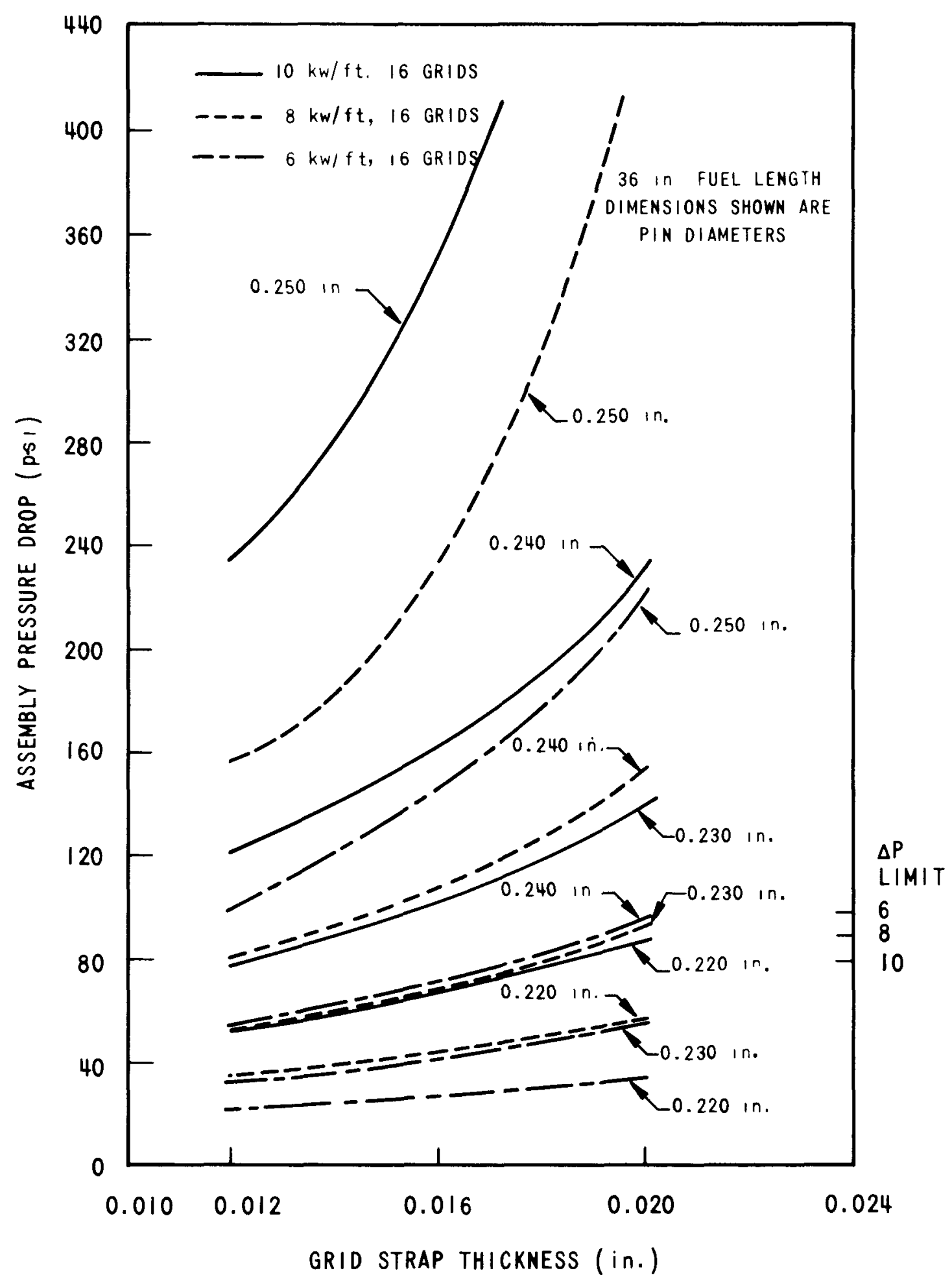

Figure 7-12. Effect of Grid Strap Thickness on Assembly Pressure Drop ( $1000^{\circ} \mathrm{F}$ outlet temperature, 16 Honeycomb grids) $3679-48$ 


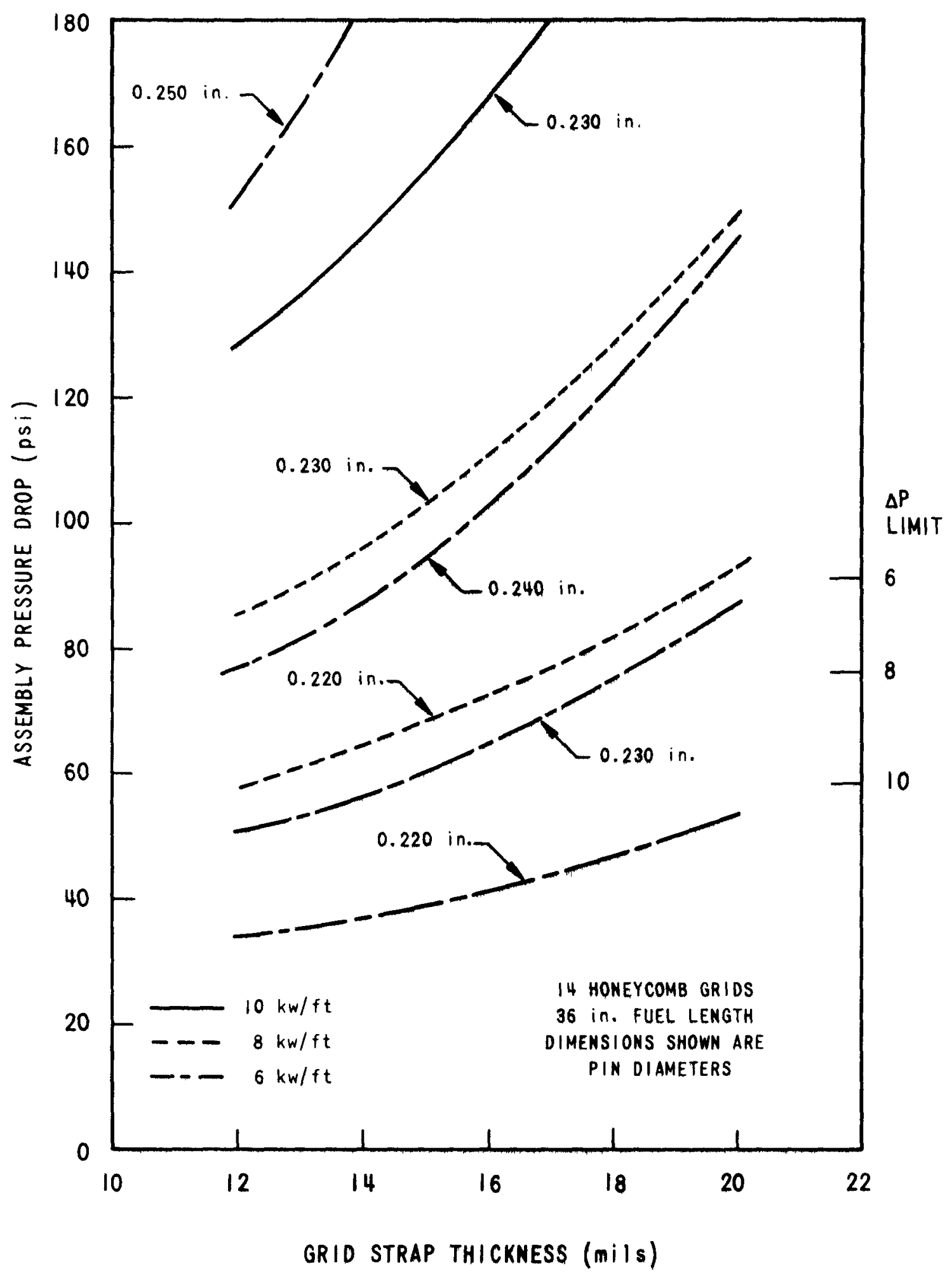

Figure 7-13. Effect of Grid Strap Thickness on Pressure Drop $\left(900^{\circ} \mathrm{F}\right.$ outlet temperature) 


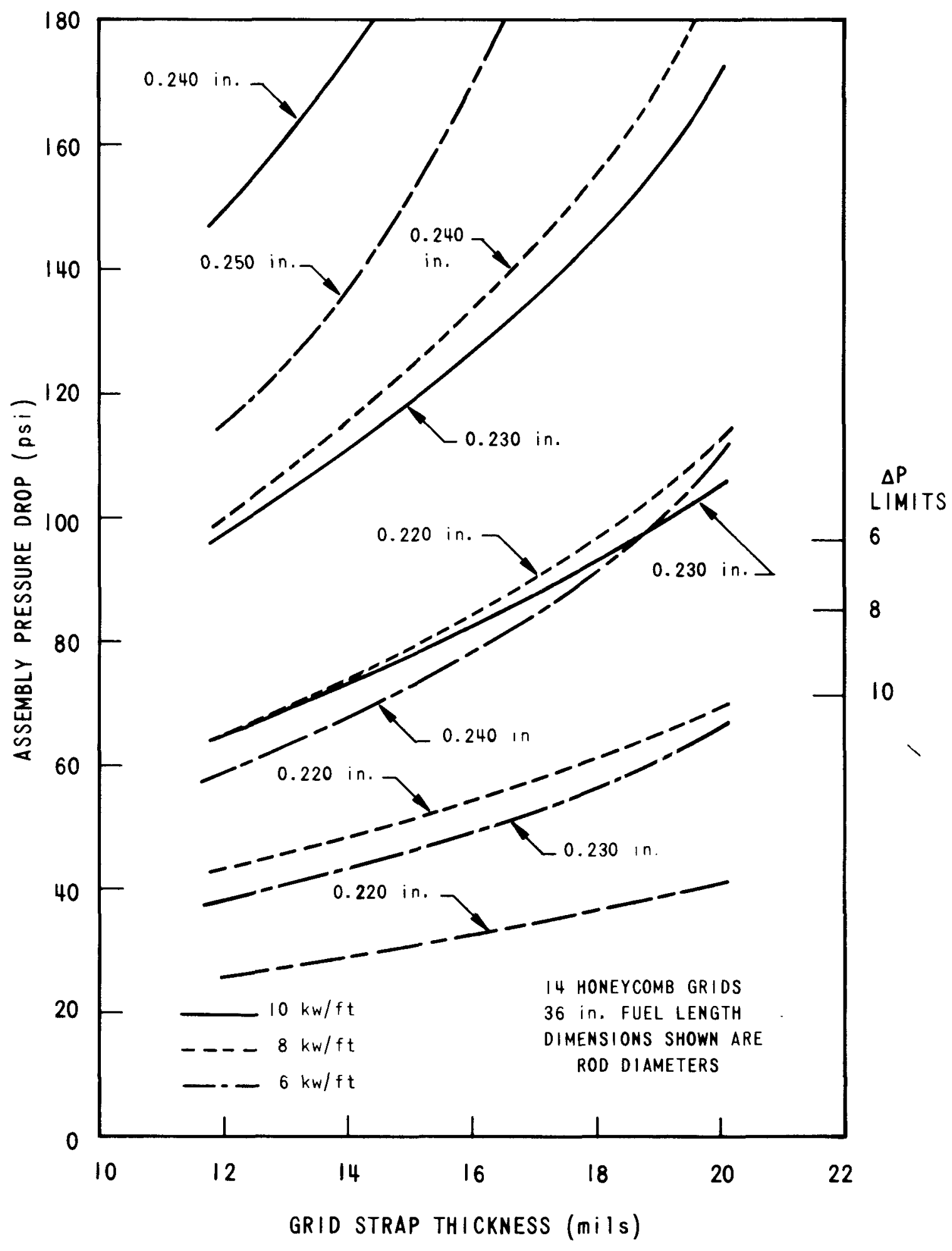

Figure 7-14. Effect of Grid Strap Thickness on Assembly Pressure Drop ( $950^{\circ} \mathrm{F}$ outlet temperature)

$3679-50$ 


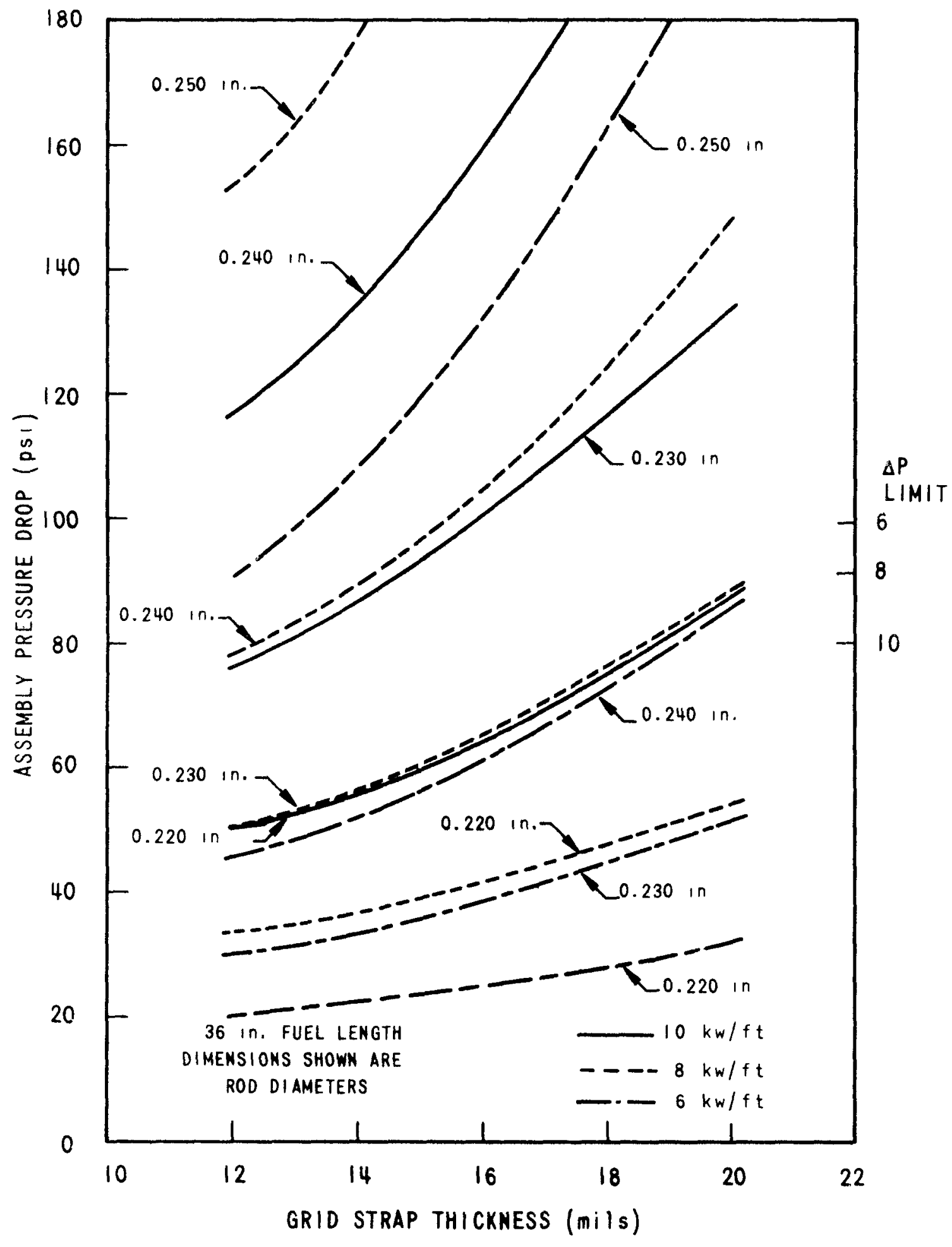

Figure 7-15. Effect of Grid Strap Thickuess on Pressute Diop ( $1000^{\circ} \mathrm{F}$ outlet temperature. 14 Honeycomb giris) 


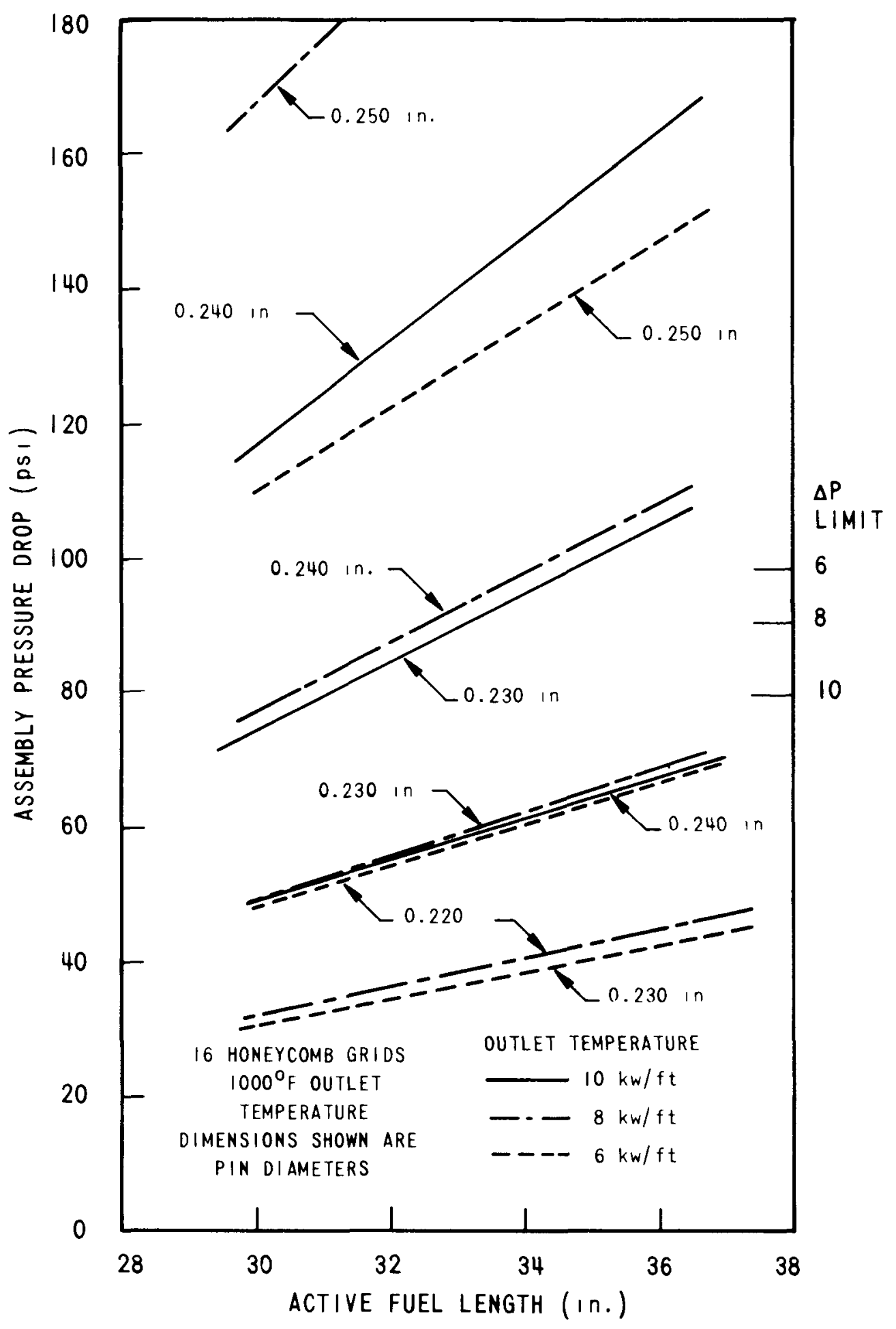

Figuid 7-16. Effeet of Active Fuel Length on $\Delta P$ 


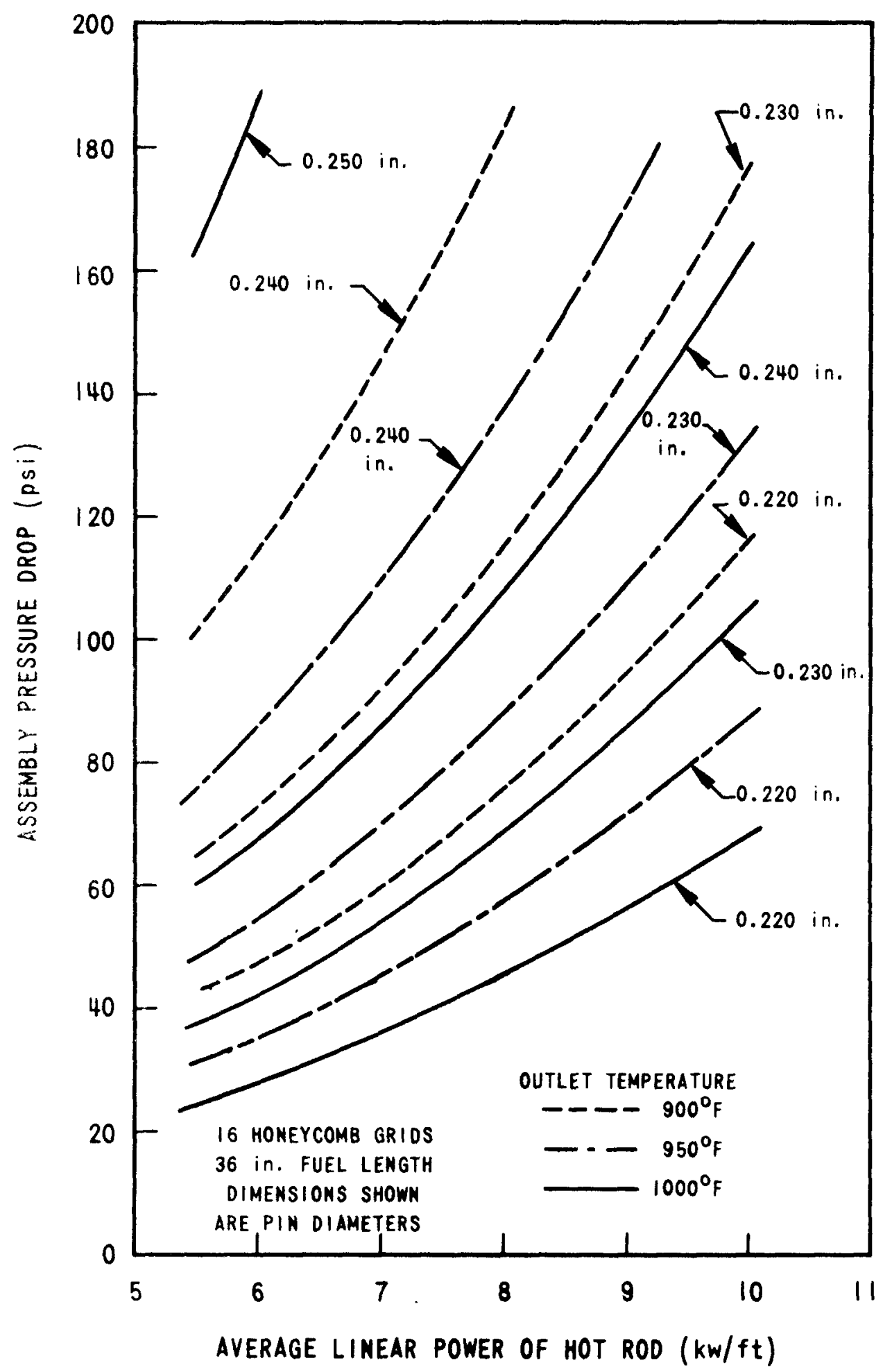

Figure 7-17. Effect of Linear Power on Pressure Drop $.3679-53$ 
strap thickness was constant at 16 mils. Figures 7-18 through 7-22 show the results for $6 \mathrm{kw} / \mathrm{ft}$ to $10 \mathrm{kw} / \mathrm{ft}$ linear power.

\section{Fission Gas Pressure}

A preliminary study of the effect of burnup on internal fuel rod pressure was made for the two cases of $100 \%$ fission gas release and on fission gas release rates dependent on burnup as shown by recent test data. An FFTF fuel rod was assumed with a 0.230-inch diameter, a 42-inch fission gas plenum length, and an initial fill of 14.7-psia helium. The effects of moisture, gas contamination, and dimensional changes due to thermal expansion and swelling were included as rough estimates. Figure 7-23 shows that at an estimated mean gas space temperature of $1160^{\circ} \mathrm{F}$, the internal pressure at 8 a/0 maximum burnup and $100 \%$ fission gas release is 740 psi. It also shows that at 11 percent maximum burnup and partial release, the internal pressure is 660 psia.

\section{Discussion}

Operating conditions were examined for the grid-type 217-pin assembly for two open loop locations; one peripheral with $8 \mathrm{kw} / \mathrm{ft}$ average linear power output, the other nearly central with $10 \mathrm{kw} / \mathrm{ft}$. Two types of grids were studied, the "1ine-of-sight" grid and the "honeycomb" grid. The lineof-sight grid geometry is fixed by the pin clearance. A basic question, not yet resolved, is whether the pins are sufficiently cooled at the narrow grid passages. The line-of-sight grid has a somewhat lower pressure drop than a honeycomb grid of the same strap thickness, because there are no double straps and no projections. This allows operation with lower outlet temperature (higher flow rates) for pin diameters of 0.230 inch or more. However, at pin sizes larger than approximately 0.233 inch, the grid straps become too thin for positive pin restraint and location. The honeycomb grid strap can be dimensioned to suit the strength requirements. Therefore a wider range of fuel pin sizes can be accommodated than with the line-ofsight grids. However, pressure drop and flow velocity requirements limit the pin diameter at $8 \mathrm{kw} / \mathrm{ft}$ to about 0.240 inch, at $9 \mathrm{kw} / \mathrm{ft}$ to about 0.235 inch, and at $10 \mathrm{kw} / \mathrm{ft}$ to about 0.230 inch for the nominal design parameters of $1000^{\circ} \mathrm{F}$ outlet temperature, grid strap thickness of $14 \mathrm{mils}, 14 \mathrm{grids}$, and an active fuel length of 36 inches. Trade-off of one or the other parameter can be made to extend the ranges of application or size using Figures 7-9 through 7-22. However, the curves are based on preliminary design choices and may shift considerably if more detailed examination of the design so requires. It is impossible, however, to obtain a satisfactory design with the demonstration plant pin diameter of 0.250 inch. Therefore, it is desirable to use the same pin diameter of 0.230 inch as in the 37-pin grid-type subassembly being built for installation in EBR-II. If an outlet temperature near $900^{\circ} \mathrm{F}$ should become imperative, the fuel length will have to be reduced to about 30 inches. W1th the preliminary assumptions of cladding and fuel composition and properties, there was no difficulty in staying below the center melting and cladding temperature criteria. A considerable change in enrichment or in hot channel factors, however, could reduce the current margin. This thermal margin is naturally large for installation in one of the open loop locations at the periphery of the core. The larger flux gradient will produce higher mechanical loading here than at the more central open loop location. 


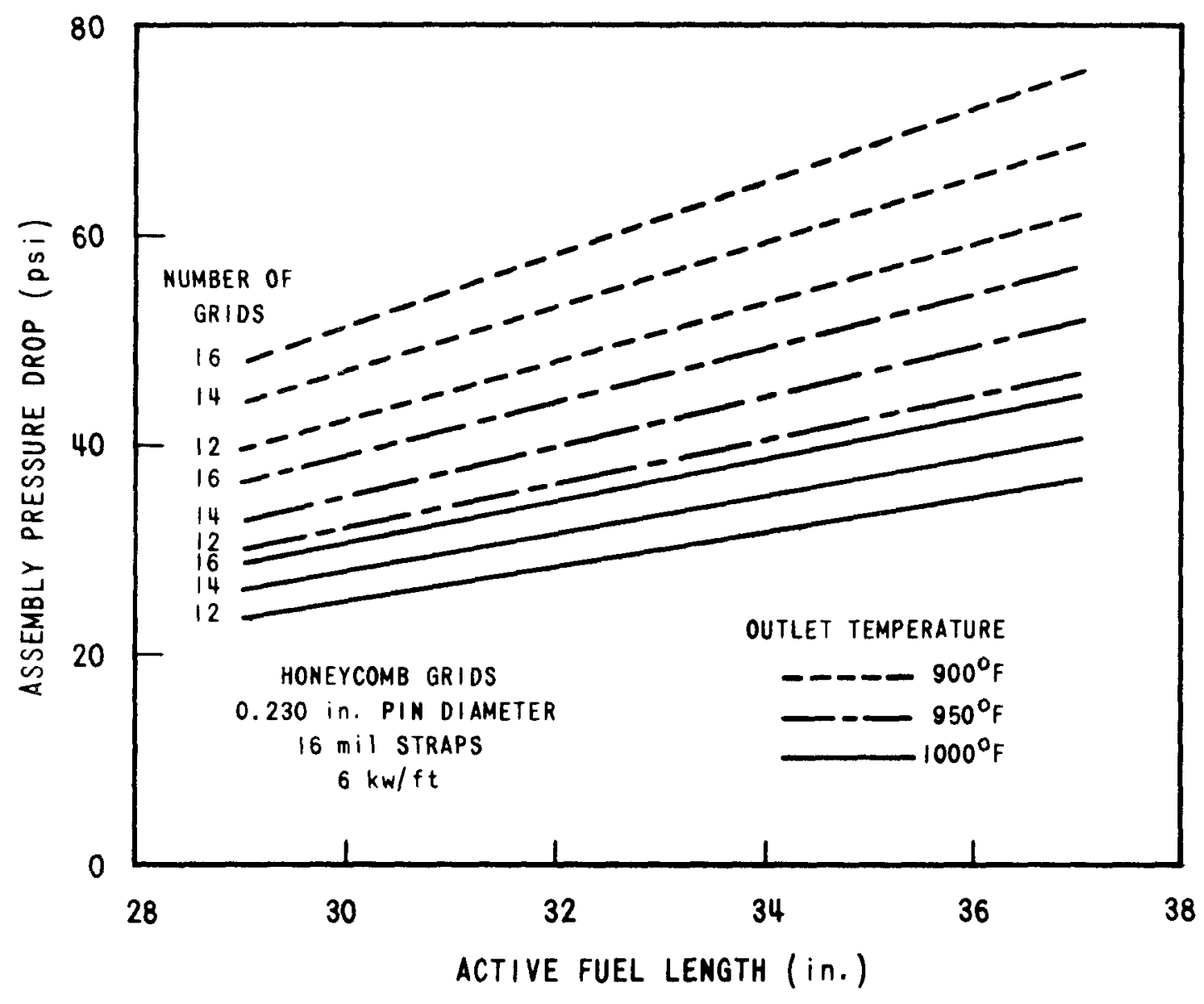

Figure 7-18. Effect of Fuel Length, Outlet Temperature and Number of Grids on Pressure Drop (6 kw/ft)

$3679-54$ 


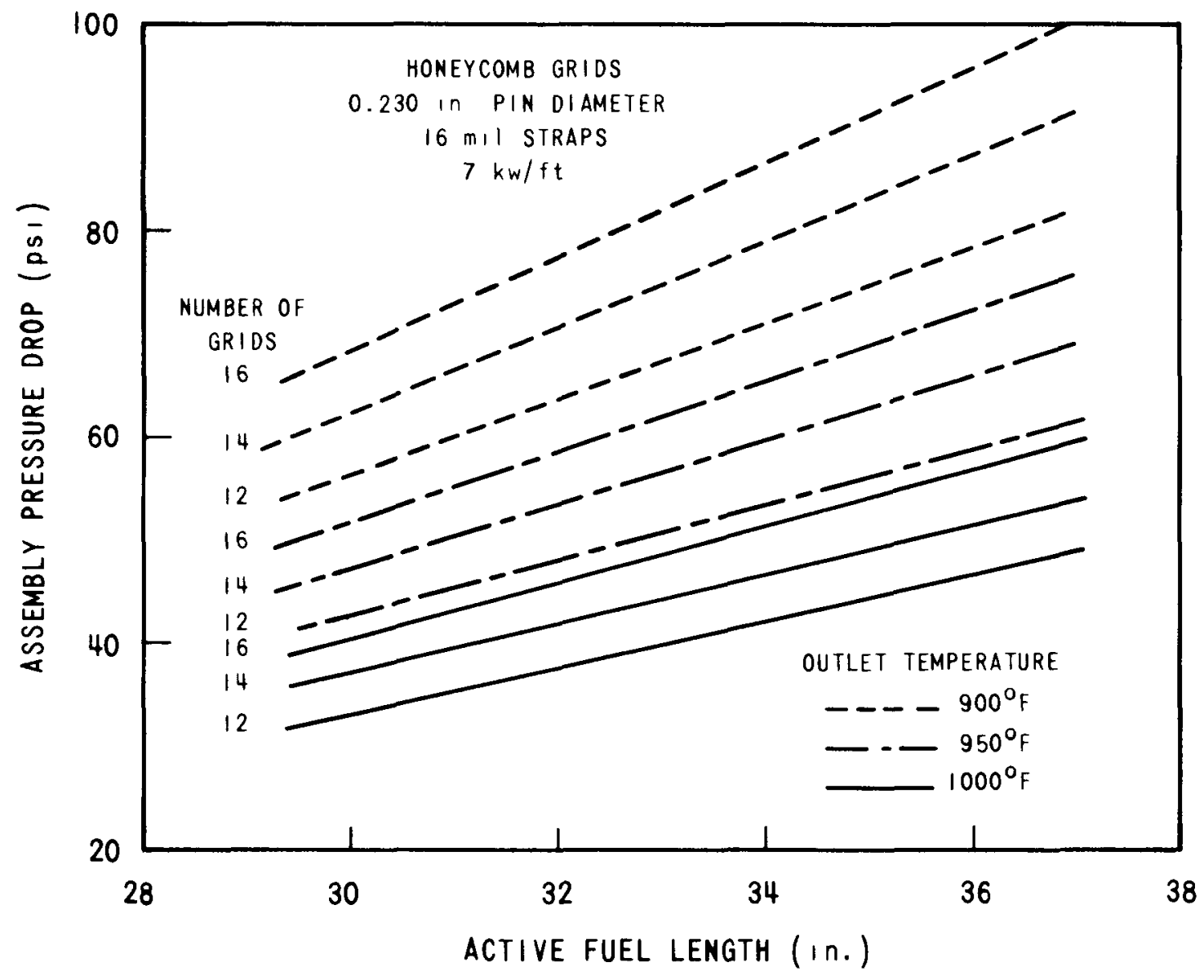

Figure 7-19. Effect of Fuel Length Outlet Temperature and Gide Number on Pressuic Diop $(7 \mathrm{kw} / \mathrm{tt})$

$3679-55$ 


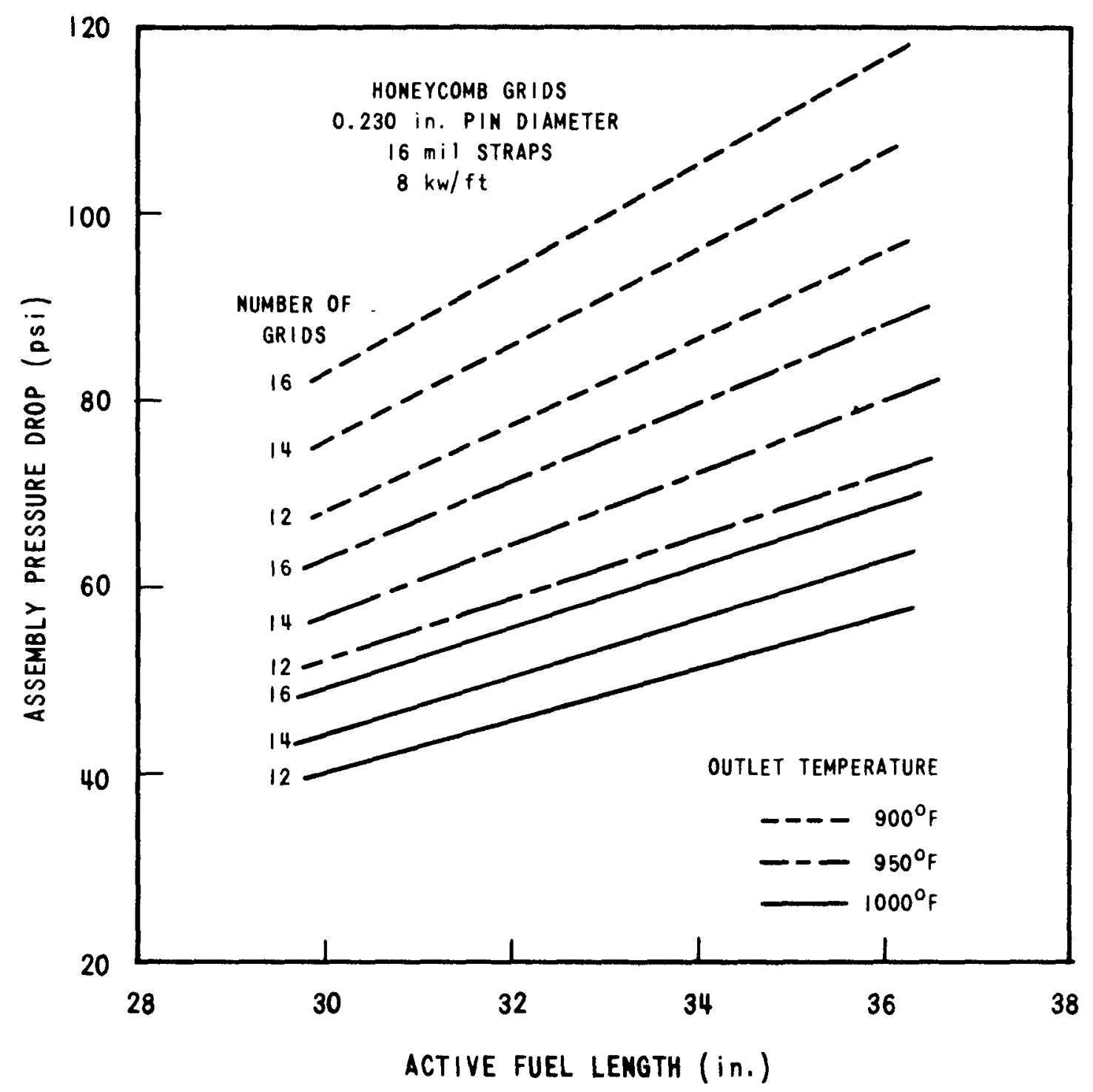

Figure 7-20. Effect of Fuel Length, Outlet Temperature and Number of Grids on Pressure Drop $(8 \mathrm{kw} / \mathrm{ft})$

$3679-56$ 


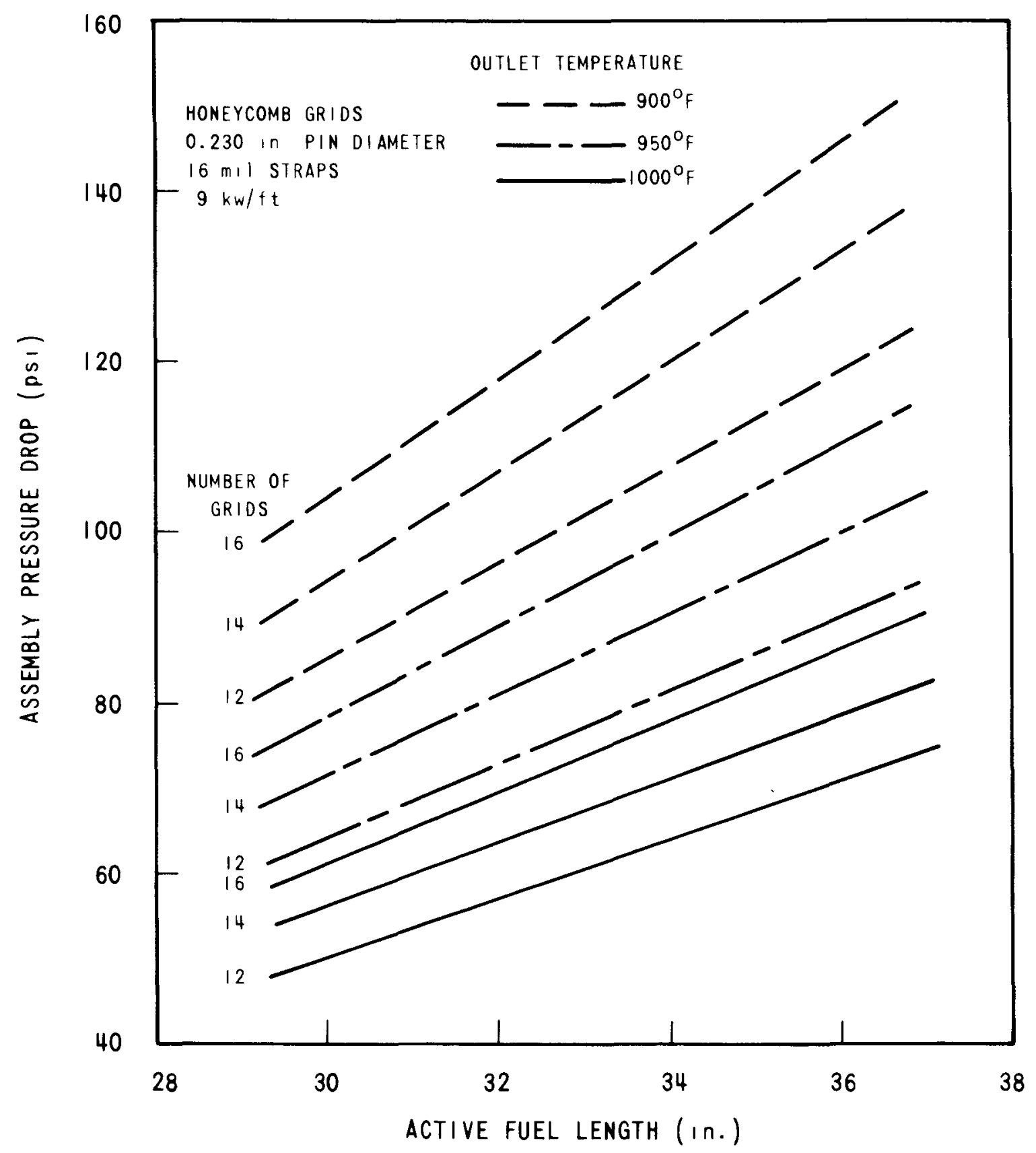

Figure 7-21. Etfect of Fuel Length Outlet Temperature and Number of Giads On Prosure Diop $(9 \mathrm{kw} / \mathrm{tt})$

$3679-57$ 


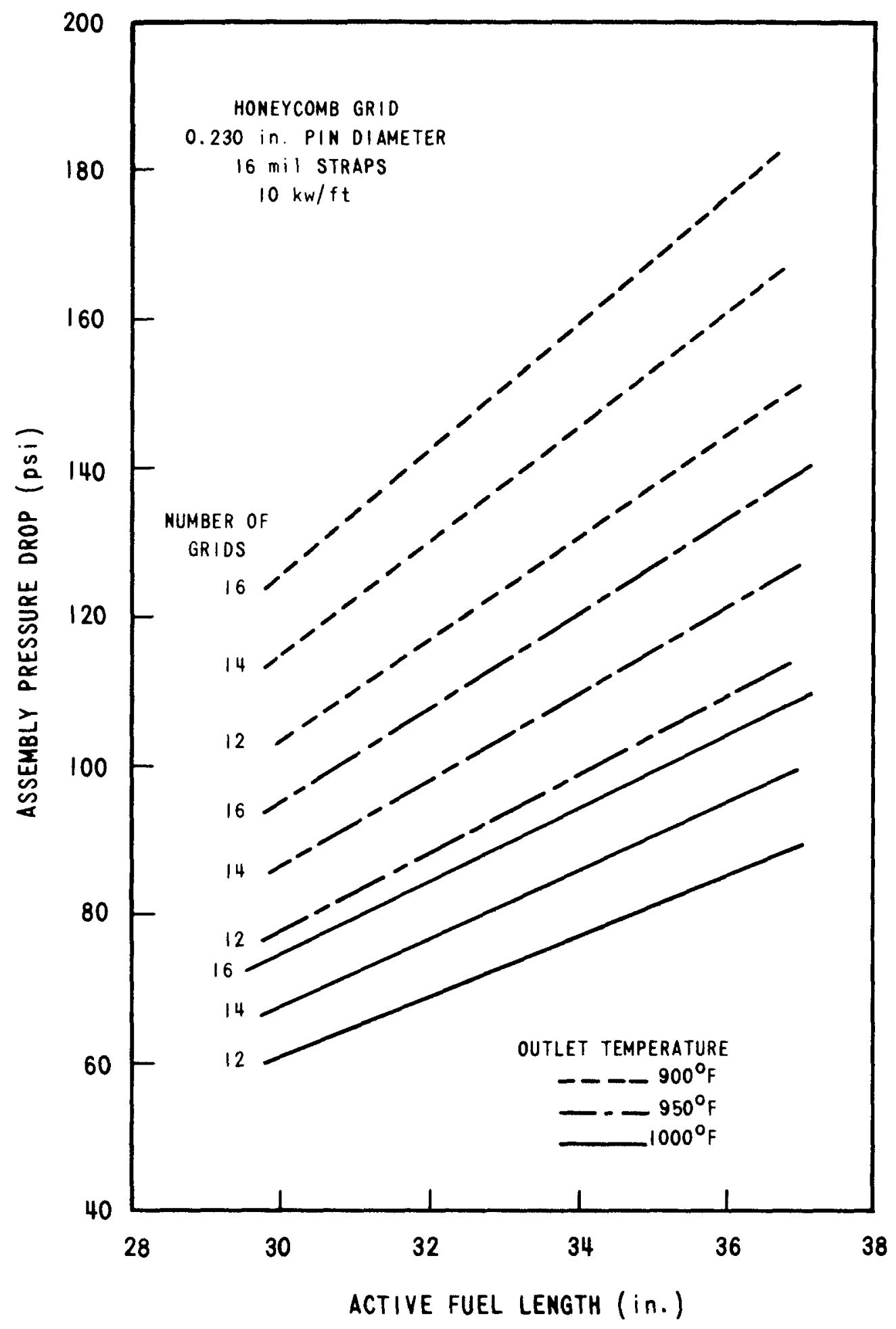

Figure 7-22. Effect of Fuel Length, Outlet Temperature and Grid Number on Pressure Drop $(10 \mathrm{kw} / \mathrm{ft})$

$3679-58$ 


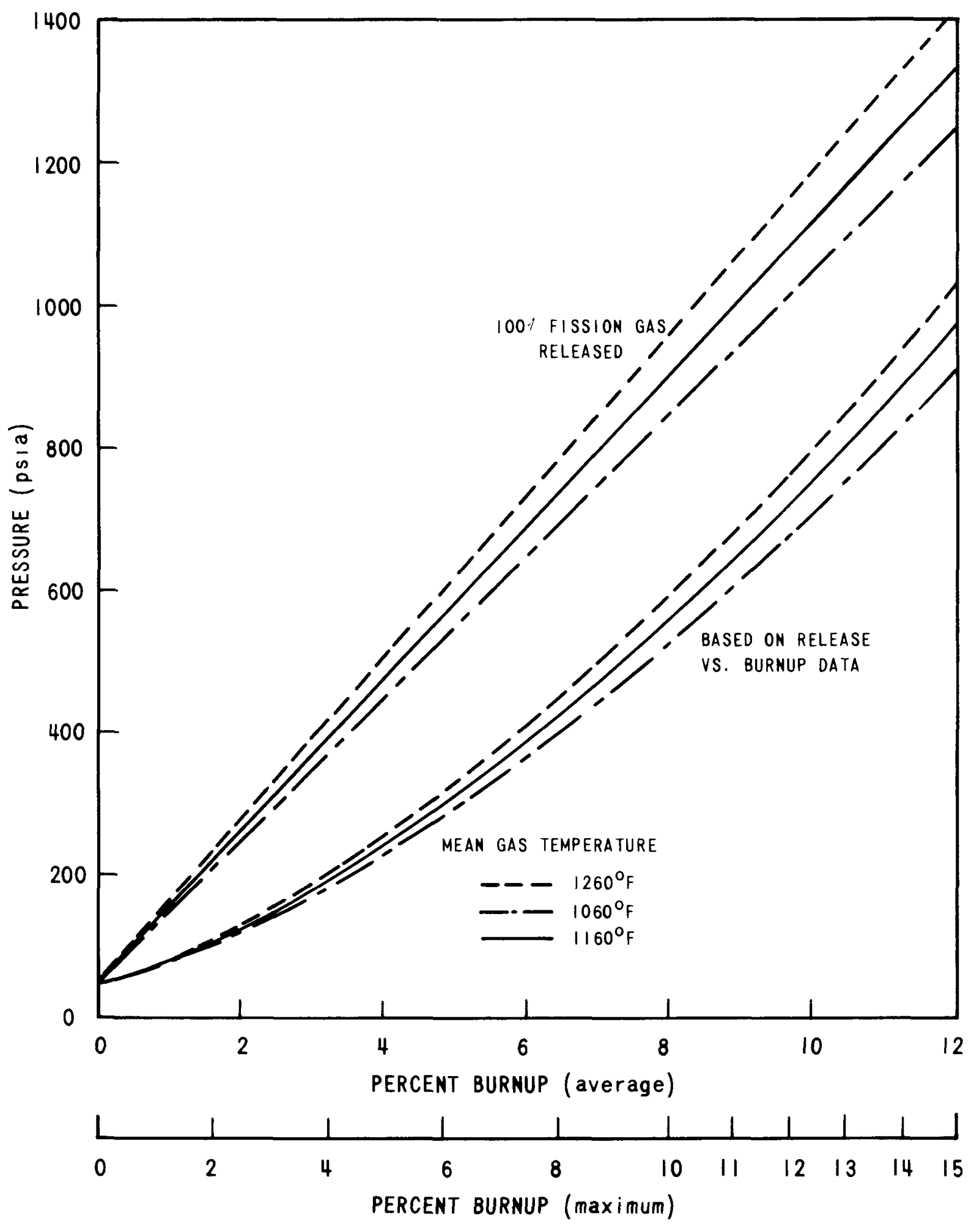

Figure 7-23. Maximum Internal Fuel Rod Pressure vs. Burnup for $90.9 \%$ Theoretical Density Fuel 14.7 psia Helium Fill (sımplified calculation) 
OFBA-313 FABRICATION, DEVELOPMENT, AND TESTING OF LMFBR FUEL ASSEMBLIES

A. Krebs, S. A. Shiels, G. A. Whitlow, and W. L. Wilson

SUBTASK 1. HEXAGONAL GRID-FUEL ROD FRETTING AND WEAR TEST

\section{OBJECTIVES}

The objectives of this program are to evaluate the wear damage caused by those grid-pin interactions, Induced in a fuel pin assembly typical of WSA-3 design, when operating in dynamic sodium, (WSA-3 will be the first 37-pin grid-type subassembly to be inserted in EBR-II) and to similarly evaluate a 37-pin subassembly which will utilize the final grid design proposed for the first 217-pin subassembly designed for irradiation in FFTF.

PRIOR WORK

A program plan was written and submitted in the FY-1970 work program, "Fabrication Development and Testing of LMFBR Fuel Assemblies." This program covered the testing of four 37-p1n subassemblles, two with the PFR-type grid design and two with 217-pin grid designs. The modifications required to the WSA-3, 37-pin subassembly and to the DFAT loop to be used in these evaluations were identified and design work for the modifled rig initiated.

\section{CURRENT PROGRESS}

The drawings for the subassembly and for this test capsule were completed and detalled. Quotes were recelved for the tungsten carbide pellets and for the fuel pin end plugs.

Early in this reporting period, the DFAT $\mathrm{rig}$ was operated, and it was discovered that the cooler which cools the bypass sodium flow from $1200^{\circ} \mathrm{F}$ to the required $600-700^{\circ} \mathrm{F}$ temperature was not performing to specifications. Since this cooler is required for the Sub-Assembly Fretting Test (SAFT), it was realized that a new heat exchanger would have to be designed and built.

Work was then temporarily suspended, while the test program was reorganized on a reduced scale. As a result of this redefinition, only two tests are now scheduled. The first test will be on the WSA-3 subassembly design and the second will be on a 37-pin assembly utilizing the final 217-pin grid design.

At the end of the reporting perlod, funding was made avallable for the procurement of materials and work was relnitlated. Current scheduling requires that the SAFT fac1lity w11l be ready to run early in the first quarter of fiscal 1971. 


\section{OBJECTIVES}

The purpose of this task is to provide quantitative sodium corrosion data from welded and brazed foints exposed under conditions simulating actual LMFBR service. The program has been designed to examine the corrosion behavior of welded and brazed fuel pin spacer grid foints and simulated end closure welds principally by weight change and metallography.

PRIOR WORK

Not Charged to this Contract

Operating experience with sodium cooled reactors indicated that weldment corrosion should not be more severe than base metal corrosion. However, only very limited quantitative data[6,7] are available on sodium corrosion of welds at $1200^{\circ} \mathrm{F}$.

The selection of brazing alloys for service In sodium has been studied at ORNL, [8] AI, [9] UKAEA, [10] and CEN-EURATOM. [11]

A literature survey indicated that several fuel rod support grid brazing alloys, including Nicrobraz 50, were potentially the most suitable for further sodium corrosion evaluation, prior to a selection being made for a Westinghouse LMFBR design application. Accordingly, a sodium test 1oop, WBTL-1, was constructed and operated for 3500 hours over the temperature range $900-1230^{\circ} \mathrm{F}$ to evaluate Inconel 718 fuel rod support grid joints brazed with Nicrobraz 50. Further detalls and preliminary results from this work will be reported in Task NCAA-300 on Contract AT(30-1)-4173. This loop system has since been rebuilt and is being used in this present subtask.

\section{Charged to this Contract}

A program involving the evaluation of the effects of exposure to sodium on several types of Type 316 stainless steel fuel-system jointures was designed. Spot welded grid type samples, brazed foints, and simulated end closure weld samples are being tested.

The behavior of welds in both annealed and cold-worked stainless steel after exposure is being examined. Unwelded samples are included for comparison purposes. A limited number of end closure welds containing a known defect are also being tested. One test section contains brazed grid samples, for some of which a post brazing homogenfzation treatment has been included prior to exposure to sodium.

An existing sodium corrosion testing loop was redesigned and rebuilt for operation under this task. The loop system, WBTL-2, is a modification of the Materials Testing Loops (MTL) which have operated successfully at WARD during the last few years. 
This loop was designed with five test section locations; two operate at $900^{\circ} \mathrm{F}$ and the remalning three at $1200-1230^{\circ} \mathrm{F}$. Within any one of the three test sections containing the grid type samples, three velocity regions $(2.5,6.5$, and $9.5 \mathrm{fps})$ have been arranged by varlation of the sample size and sodium flow area. In the two test sections containing the end closure welds, the sodium velocity is constant at 9.5 fps. It is intended that the system will operate for approximately 3000 hours at temperature, and at the end of the previous period, 340 hours at reference sodium conditions had been accumulated.

\section{CURRENT PROGRESS}

During this reporting perfod several alarm signals indicating posstble operational troubles with the sodium loop system were experfenced. With the exception of one due to a heater fallure, all were traced to instrumentation problems. Some operational time has been lost, and only $\sim 900$ hours were logged during this period.

After the loop system, WBTL-2, had accumulated approximately 1250 hours at reference operating conditions, the system temperature was reduced and a sodium sample taken. Mercury amalgamation analysis indicated an oxygen value of $18 \mathrm{ppm}$ but the sodium sample was observed to contain volds indicative of a poor sample. Consequently, the system was cold trapped again and a further sodium sample indicating $<10 \mathrm{ppm}$ was obtalned. The loop system has since been returned to reference temperatures.

Progress on future work (FY-1971) in the area of sodium corrosion of weldments and brazements is reported under Task NCAA-300 of Contract AT(30-1)-4173. 


\title{
SECTION 9
}

\section{OFBA-410 FABRICATION DEVELOPMENT OF EBR-II GRID-TYPE SUBASSEMBLIES}

\author{
E. C. Bishop, D. N. Elliott, T. A. Galloto, W. E. Ray, and W. L. Wilson
}

\section{OBJECTIVES}

The objective of this task is to develop fabrication procedures and produce 37-pin EBR-II subassemblies, based on the PFR honeycomb grid design. The scope will be limited to grids, cans, and end fittings with fuel pins being prepared under OFBA-510 to 513. Furthermore, all tooling and fixture design, fabrication, and procurement will be funded under OFBA-411. The subassembly fabrication effort covered by this task will include the following:

1. Establish optimum welding parameters for grid fabrication

2. Determine the optimum welding procedures for fabrication of can welds and can-to-grid joints

3. Determine fabrication and assembly procedures for attaching any fittings required to support and locate the subassemblies in EBR-II

4. Prepare simulative samples of all joints and evaluate the effects of fabrication and heat treatment operations on the mechanical properties of the joints.

5. Identify suitable inspection criteria for assessing subassembly components

6. Fabricate the simulative models for design verification testing

7. Provide mechanical test data and component characterization

8. Fabricate subassemblies for insertion in EBR-II

9. Provide input to hazards reports on component reliability

PRIOR WORK

Grid strap material from Hamilton Precision Metals was rejected because of out-of-specification chemistry, and most of the inner and outer cans from Carpenter Technology were rejected because of tolerance outages. Neither rejection caused delay in the program schedule. A purchase order was placed with Carpenter Technology for liners with delivery scheduled for late February 1970. Grid fabrication development continued as grid straps became available and TIG welding parameter studies for grid to can joints were completed. A visit was made to EBR-II site to observe subassembly fabrication and Inspection procedures and to discuss the design, fabrication, and inspection of WSA-3. 


\section{CURRENT PROGRESS}

Equipment (Procurement not funded under this contract)

Al1 major inspection and quality control equipment has been received with the exception of the 30-inch comparator which will be installed at WARD in early April. Layout tables for the subassembly fabrication facility have been recelved and installed.

\section{Materials}

Hamilton Precision Metals slipped their early January shipping date for grid strap materials, because the wrong heat of material was used for the order. WARD Purchasing Department expedited shipment of replacement material by direct contact with Hamilton management and via the Department of Commerce. A visit was made to Hamilton on February 12-13 to expedite final inspection of acceptable grid materials, and the bulk of the order was hand carried back to WARD. The remaining outstanding item on the order was 2.1 pounds of support strap material which was delivered in March. By accepting partial shipments of material with out-of-specification carbon and nitrogen, the tooling development program was not delayed. The acceptable heat of material did not show any significantly different forming characteristics than the out-of-specification material. WARD now has enough acceptable grid strap material on site for the program requirements in the calendar year.

\section{Liner Procurement}

Liners were due to be shipped from Carpenter Technology on February 16 and scheduled for arrival at WARD by the end of February. Status reports on the liners were encouraging until February 10, at which time it was determined that Carpenter was having difficulties in holding final dimensions. The liner tooling was reworked five times in attempts to produce acceptable components without any success. A WARD engineer visited the Carpenter plant February 23-26 to expedite delivery of acceptable liners. At this time bulging of the liners during the flanging operation was the principal remaining problem. This bulging was corrected by making a hand roller to correct the bow on individual'sides of the liners. This process is extremely tedious but appears to be the only practical way to hold the close tolerances on the across flats dimension ( $1.755 \pm 0.002$ inch) without making major tooling modifications. Twenty acceptable liners were brought back to WARD on February 26, 1970 so that no delay was incurred in the program schedule. The balance of the liners were made during March, and final inspection was witnessed by a WARD engineer. Another ten liners were hand carried back to WARD from this inspection trip, and the balance have been shipped from Carpenter.

\section{Inner and Outer Can Procurement}

Inner and outer cans refected for tolerance outages were re-worked or replaced by Carpenter during this period, and final inspection was witnessed 
at the Carpenter plant at the same time as the liners were inspected. These cans are also being delivered to WARD.

\section{Grid Fabrication}

Grid strap tooling is being modified, under OFBA-411, to produce correct dimple sizes. Formed straps from the tooling development runs have been used to make a total of fifteen inner grid assemblies by resistance spot welding. These grids have been inspected to characterize weld fixture performance and to develop rapid inspection techniques. A simple computer program has been written to provide grid cell pitch measurements using optical comparator readings of cell center coordinates. This inspection has been performed on a 14-inch optical comparator at WARD pending delivery of a 30-inch comparator which will be installed at WARD in early April.

The first grids made had oversize dimple circle diameters and erratic cellto-cell pitches. The oversize dimple circle diameters were partly due to two of the dimples in each cell being undersize, and, in addition, one dimple was interfering with the fixture locating pins. This interference was a result of the dimple being approximately 0.002 inch oversize and the locating pin pitch being 0.001 inch undersize. The dimple was consequently flattened, and the dimple circle diameter therefore increased. A photograph of the grid welding fixture is shown in Figure 9-1. Variations in pitch and dimple circle diameter were also caused by the dimples on the $60^{\circ}$ faces of the strap being unequal in size. This source of variation was subsequently removed by ensuring that the grid straps were all assembled with the biggest dimple to one side. The resultant grid should have the correct dimple circle diameter and pitches, but the cell positions are slightly eccentric with respect to the overall profile of the grid.

Another source of pitch variation was experienced when the dimples on the $60^{\circ}$ faces were undersize, because this condition allowed the straps to move laterally on the locating pins, which are machined to position straps with the nominal dimple size.

Superimposed on all of the above variations was the pitch variation due to the welding fixture. It was noted that the same row of cells was outof-position on all of the grids that were made with the unequal $60^{\circ}$ face dimples located in the same position on each strap. The welding fixture was consequently dismantled and locating pin sizes and holes were dimensionally checked. Both the pin diameters and hole diameters were satisfactory and the hole pitches were within 0.001 inch of the nominal 0.285 -inch pitch. In the vertical direction the hole pitches were consistently 0.001 inch undersize, but it was not considered worthwhile to have a new fixture plate to attempt correction of such a small difference. Because of the tight fit of the grids on the pins, the straps had to be hammered on and forced off with a screwdriver, which frequently resulted in several of the pins being pulled out at the same time. Due to this severe treatment many of the pins were burred, and this may have also caused location problems. The pins were deburred and remachined to compensate for the 0.001 inch difference between the nominal and acutal pin pitch. 


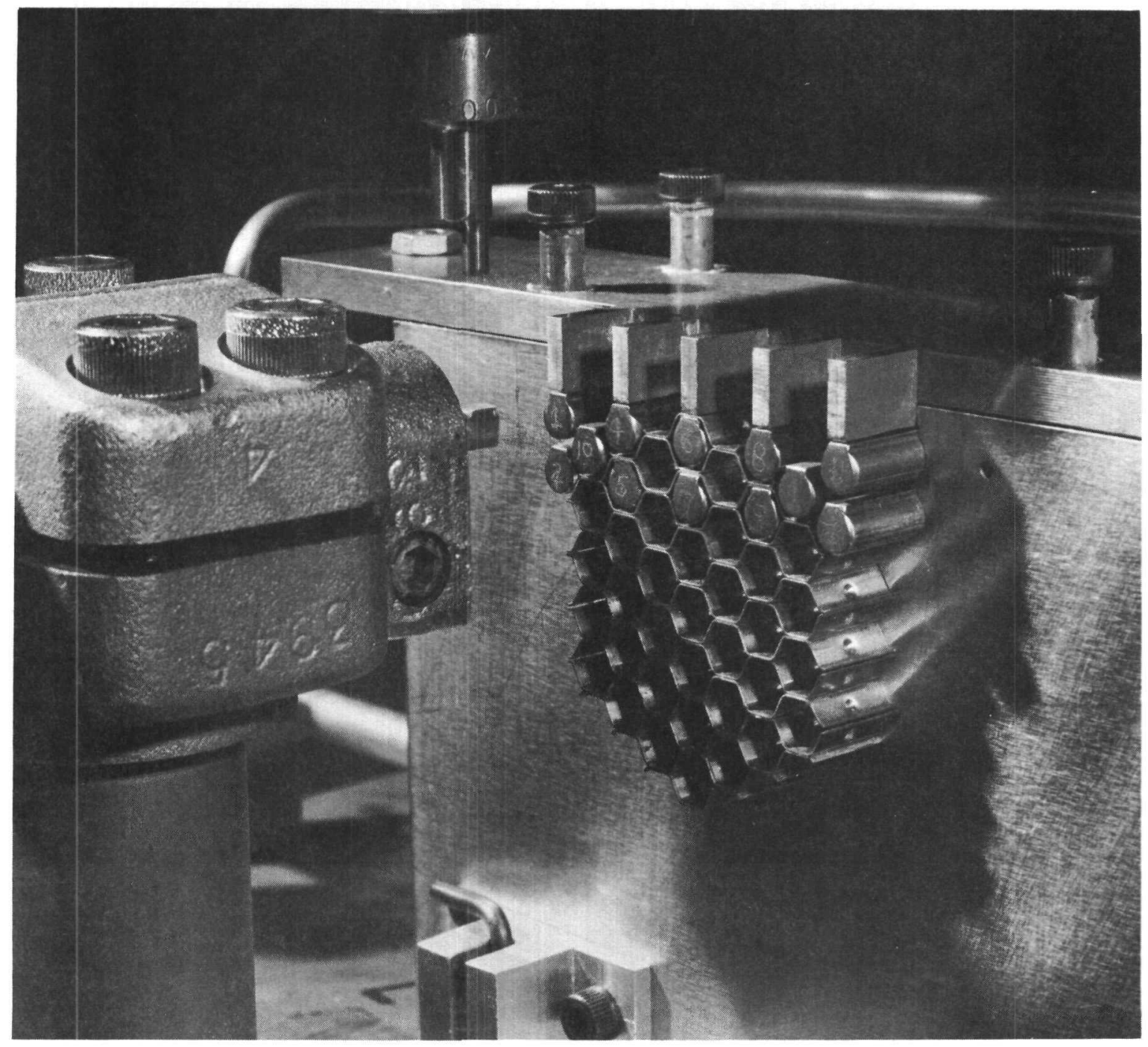

Figure 9-1. Grid Welding Fixture $3679-60$ 
Welding sequence was also varied, because it appeared that the pitch variation on the grid was associated with the last joint to be welded on each pair of straps. It was found that welding sequence did not have a significant effect on the pitch variations.

Techniques for positioning the straps on the welding fixture pins have been studied. Having the straps longer than the finished sizes improves positioning of the first straps welded. This is particularly important, because an error at this stage may become magnified as more straps are added to the assembly.

Only one of the grids made to date held acceptable dimensional tolerances on dimple circle diameter and pitch. The dimple circle diameters were $0.232 \pm 0.001$ and pitches were $0.285 \pm 0.002$ in all cells except eight at the periphery, that are not welded until they are positioned in the support strap assembly. However, even this grid had one row of cells that was consistently out of position. The two subsequent grids also had the same row out of position even though welding procedure was varied. On the next grid this problem was corrected, apparently by more careful deburring and using longer straps for better positioning of the first three straps. However, on this grid the dimples were oversize, and the grid is not acceptable for WSA-3, because the dimple circle diameters are undersize. Another two grids have been made since then and are now being inspected.

One of the grids was heated at $1100^{\circ} \mathrm{F}$ for two days to determine its dimensional stability at elevated temperatures. The dimensional changes observed $(<0.001$ inch) were not clearly resolved on the 14-inch comparator. This test will be repeated when the 30-inch comparator is available.

Before making each grid, three qualification tests are made to check fixture alignment and welder performance. Three spare straps are welded together to check that the electrodes and fixture are correctly aligned. This three strap weldment is then used for metallographic examination or kept for future reference. Metallographic examination of these weldments has revealed some thinning of the strap at the dimples, and the Reactor Engineering group are aware of this dimple feature. Two strips from the same heat of material that the grid is made from are also welded together to simulate a grid joint. This test piece is then pulled in shear and the breaking load recorded. Another two strips are welded together in six positions and then peeled apart to check for nugget pull-out and consistency. Information obtained from these qualification samples is recorded as part of the fabrication history on each grid.

A studio photograph of the inner grid assembly is shown in Figure 9-2, along with samples of liners, inner and outer cans, and a grid assembly having the support strap assembly in posttion.

A total of five support strap assemblies have been made during the current period. Fixture problems have been identifled and are being modifled. Electro-discharge machining electrodes have been made for cutting slots in these assemblies and shaping the peripherial flow tabs. Both electrodes appear to be satisfactory, but positioning procedures are still being modified to improve slot and tab position tolerances. 


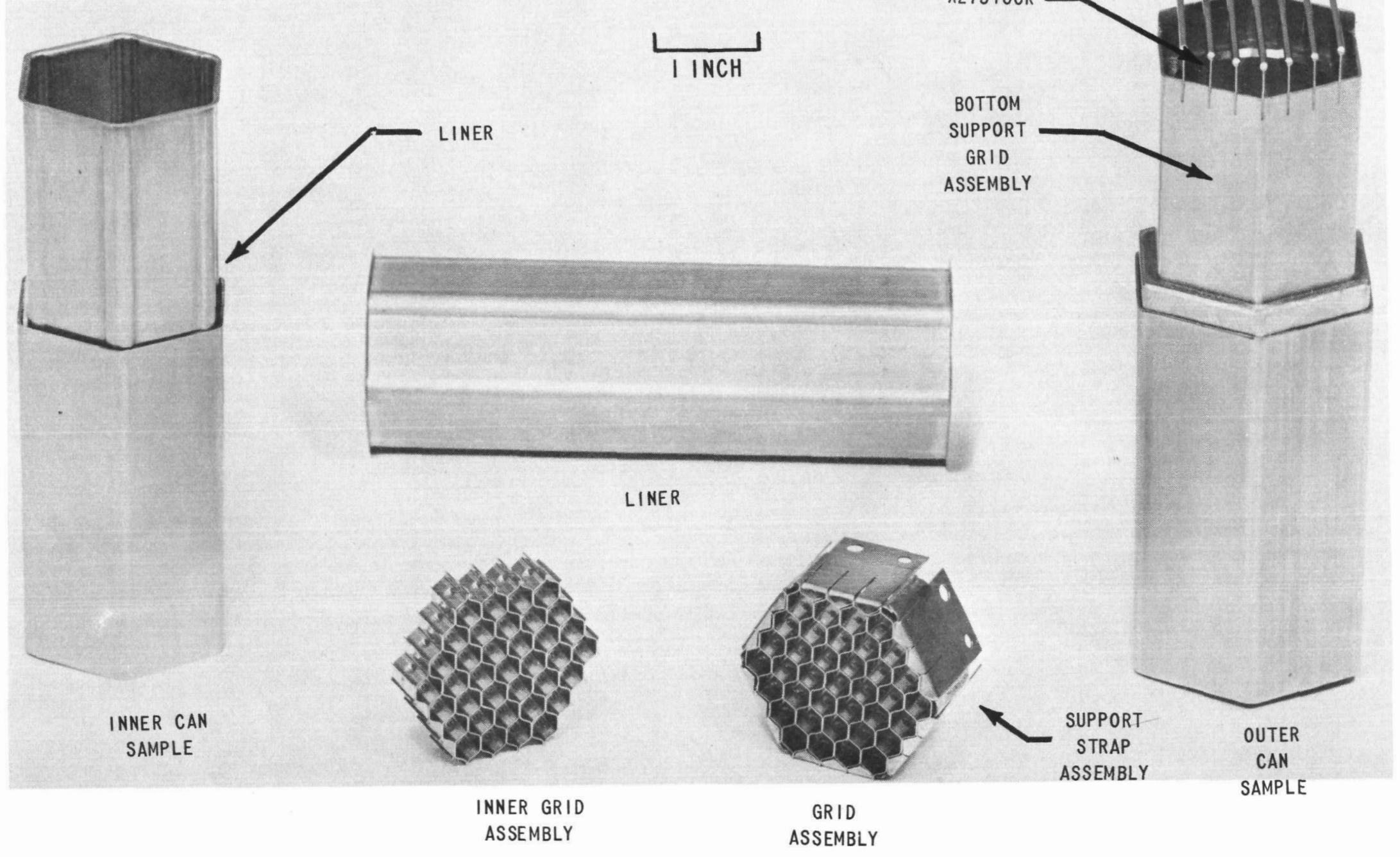


Several attempts were made to TIG weld spacers to the liners using a variety of procedures, fixturing, and chills. Regardless of the technique used, the liner distorted in the region of the 0.625 -inch diameter spacer to result in a minimum of 0.005 -inch reduction across flats. Distortion of this magnitude is not acceptable, and an alternate spacing system has been evaluated. The new spacer is rectangular instead of circular and can be resistance spot welded in two places to attach it to the liner. Simulative welding trials with this design were successful. Distortion was restricted to a region of 0.125 -inch diameter, and the individual welds showed lap shear strengths in excess of 580 pounds at room temperature. Spacers to the new design are being machined.

A purchase order was placed with Excel Mold \& Die for electro-discharge machining liner flanges to size. One end of each liner must fit into a grid assembly, and the other end must fit the inner can. The clearance in both cases should be 0.001-0.009 1nch. The first attempt at this machining produced a slightly eccentric flange, and the indexing system to position the electrode has been modified. A liner machined with the modified system is being inspected, but further machining is temporarily delayed because machining of support strap assemblies has a higher priority.

\section{Inner Can Fabrication}

Two inner cans have been machined to length, drilled, slotted, and the ends chamfered. A studio photograph of one of these cans is shown in Figure 9-3 which also shows the positions occupied by the bottom grid, liners, and grids when the inner can assembly is fabricated. Only two liners and one grid assembly are shown in this photograph, but the actual assembly will have 11 grid assemblies and 10 liners.

Manual TIG welding trials on inner can spacer joints were made using a specially designed expanding copper mandrel. Regardless of welding sequence or parameters, a satisfactory weld could not be made without producing excessive distortion in the across flats dimensions of the can. Bulges in the region of the 0.625-inch diameter spacer were 0.005-0.008 inch high and would cause problems in loading the grids and liners. A TIG spot welding technique has been developed to circumvent the distortion problem using a rectangular spacer with two welds holding each spacer on the can.

\section{Bottom Grid Fabrication}

A total of three bottom grid hexagonals have been machined to date. One of these components had the key slots machined by milling, but dimensions on these slots were not within tolerance. The other two components will have the key slots electro-discharge machined. An electrode has been made for machining these slots and was tried out on a sample of inner can so that problems could be resolved prior to machining the actual bottom grids. Slot widths and pitch were not satisfactory in all cases, and the electrode is being modified. Keystock for the bottom grid was received from ANL 
Central Shops, and one set of keys has been machined and inspected. This set of keys has been fitted into the bottom grid with the milled slots, as shown in Figure 9-3, and will be used to optimize welding procedures for bottom grid fabrication. Preliminary weld trials will be performed without fixturing until a fixture being designed under OFBA-411 is completed.

\section{End Fittings}

One bottom end fitting and two top end fittings have been received from ANL for use in fabrication of the flow test subassembly and the fretting test subassembly. The latter subassembly is funded under OFBA-313.

\section{Subassembly Assembly}

Several design changes have been made to the WSA-3 subassembly to provide a capability for interim examination. The princlpal hardware change is in the inner can length and the bottom grid design. These design changes did not affect the fabrication schedule.

A new orifice design has been made, reflecting the subassembly position change from Row 5 to Row 6 position. Two orifice plates to the new design have been made and will be welded in place on the bottom grid assembly.

Modified assembly-disassembly procedures have been prepared for WSA-3 and will be forwarded to the EBR-II Project. The modified procedures include interim examination and the use of a pin holding device to factlitate loading in the EBR-II vertical Mark Assembly fixture.

A studio photograph simulating a cross section through the subassembly without the fuel pins is shown in Figure 9-4. 


\section{$\bullet$}

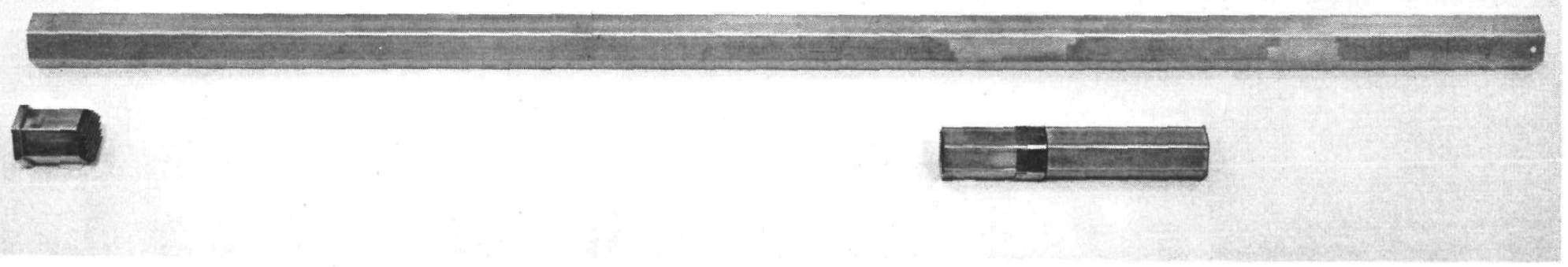

Figure 9-3. Inner Can: Showing Bottom Grid, Liner and Grid Positions $3679-62$ 


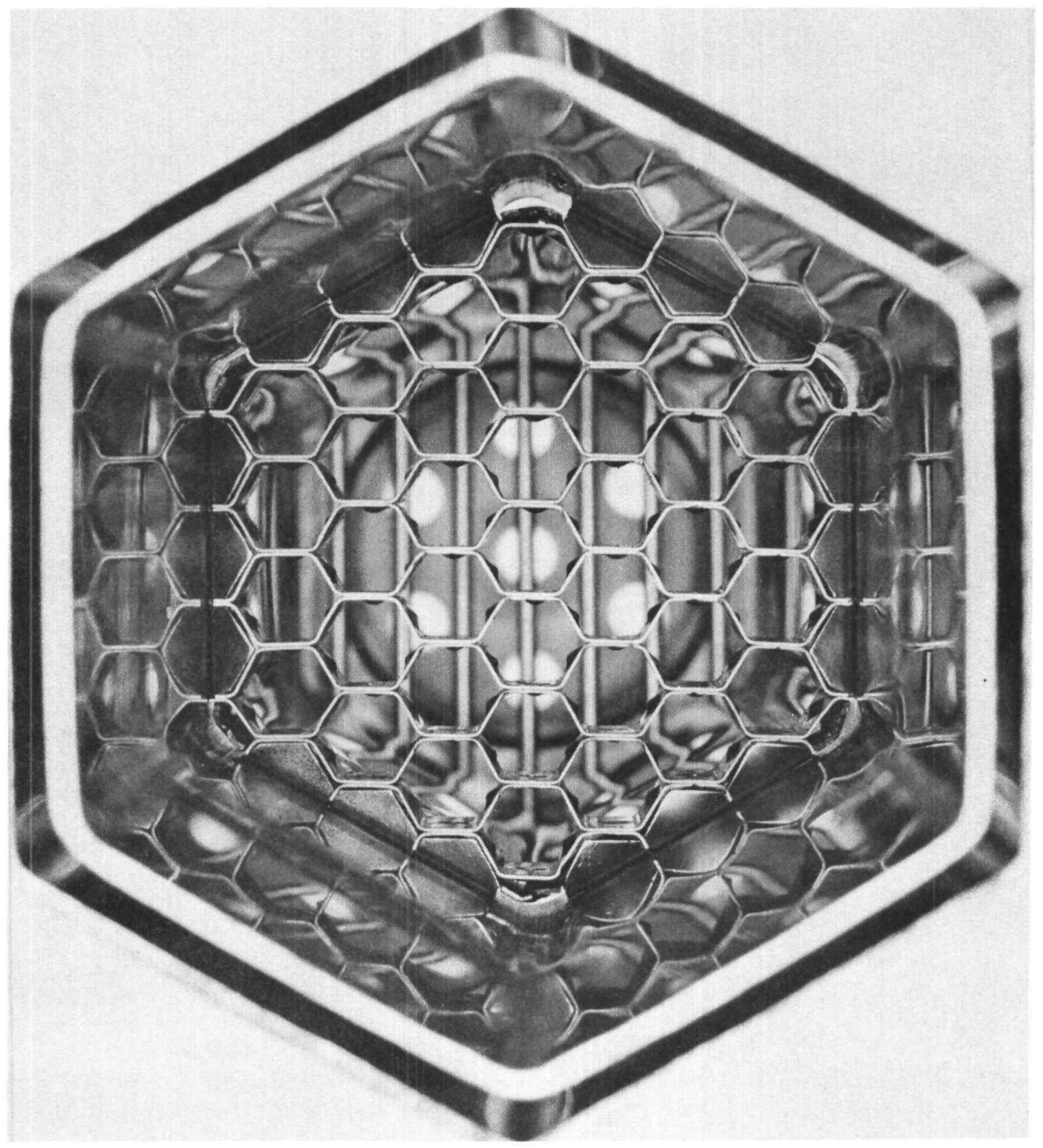

Figure 9-4. Subassembly Cross Section Without Fuel Pins. 3x Magn $3679-63$ 


\section{SECTION 10 \\ OFBA-411 SUBASSEMBLY DESIGN AND HARDWARE}

R. Borst, F. C. Engel, R. A. Markley, and J. F. Patterson

SUBTASK 1. SUBASSEMBLY HARDWARE

\section{OBJECTIVES}

The objective of this subtask is to design and fabricate tooling necessary for forming grid and subassembly components. Mechanical design of subassembly hardware, consistent with the design analysis of OFBA-311, is also included in this subtask.

\section{PRIOR WORK}

Mechanical design of the stainless steel grids was completed. All subassembly components including liners, fuel pins, inner can, and outer cans have been designed. Design of tooling and weld fixtures was undertaken and completed. The manufacture and procurement of tooling and fixtures was proceeding during the previous quarter.

\section{CURRENT PROGRESS}

During this quarter the grid strap forming tool was modified several times in order to improve the quality of the manufactured grid straps. At the present time, the grid strap forming tool is producing corrugated straps which are essentially at required length and angle tolerances. These grid straps are suitable for welding into inner grid assemblies. The center to center distances of the cells of a typical welded inner grid assembly are ranging from 0.283 to 0.286 inch. Perpendicular to the corrugated strap the tolerances are significantly tighter - ranging from 0.2848 to 0.2858 inch. It is anticipated that minor adjustments will continue to be made in an effort to bring the grid strap weldments even closer to nominal dimensions. These touchup operations can be performed at any time but will be delayed until inner grids are welded into support strap weldments and more physically meaningful inspection data are available.

The dimple punches have required some modification in order to bring the inscribed dimple circle diameter closer to the specifled $0.232 \pm 0.001$ inch. One dimple formed by the tool is about 0.024 inch deep instead of the required depth of 0.022 inch. To correct this situation, a 0.002 inch hard chrome layer has been plated in the appropriate region of the dimpling tool.

The grid support strap forming tooling has been setup and modified during this quarter. The Urethane pads have been supplemented with a male metal forming die because the destred angle of $90^{\circ}$ between the support strap and 
flow tab could not be obtained with the Urethane forming technique by itself. Grid support straps have now been formed and successfully welded into support strap outer assemblies which appear satisfactory. Electron discharge machining of the flow tabs and the slots in the support straps which hold the grid straps has been started. Adjustments to the various fixtures have been undertaken in order to produce nominal dimensions and acceptable tolerances from this procedure.

Al1 tooling is now available except for the grid and liner inserting fixtures for which a purchase order has been placed and the grid strap $60^{\circ}$ cutoff tool which is being held until the final configuration of the forming tool is established. The inserting fixture is due to be received April 30 .

The fuel pin top end plug design has been modified to facilitate loading, and the bottom support grid location has been changed to facilitate examination. To facilitate drainage from the subassembly, liner holes near the bottom flange have been proposed. The effect of these holes on bypass flow will be evaluated under OFBA-311.

\section{SUBTASK 2. FLOW TESTING}

\section{OBJECTIVES}

The objectives of this subtask are to plan, conduct, and evaluate out-ofpile flow tests intended to characterize hydraulic parameters of 37-pin subassemblies.

\section{PRIOR WORK}

A schedule for designing and conducting the flow tests was established. The flow test duct design and instrumentation requirements were established and drawings started.

\section{CURRENT PROGRESS}

A brass housing as shown in Figure 10-1 has been designed to accommodate the 37-pin subassembly for flow testing in water. The housing will be joined to the 120-gpm hydraulic loop in the Thermofluids Laboratory. It will be instrumented to measure pressure drops across the rod bundle, across the inlet orifice, and across one grid. Total head probes and static pressure taps will be installed near the outlet in order to measure the ratios of flow rates inside to central and corner to central channels. Detailed construction drawings were issued to the WARD model shop. Manufacture and installation should be complete by the end of Apri1 1970 . 


\section{Genera1}

The funding required to design hardware, tooling, and weld fixtures and conduct flow tests for 37-pin subassemblies planned for fiscal years 1971 and 1972 has been estimated. These estimates include the purchase costs of all tooling and fixtures but not subassembly hardware for either the flow or irradiation tests.

1. HOUSING

2. STRAIGHTENING VANES

3. SEAT AND SEAL

4. HOLDDOWN SCREW

5 ORIFICE

6. PRESSURE TAP

7. FUEL PIN ASSEMBLY

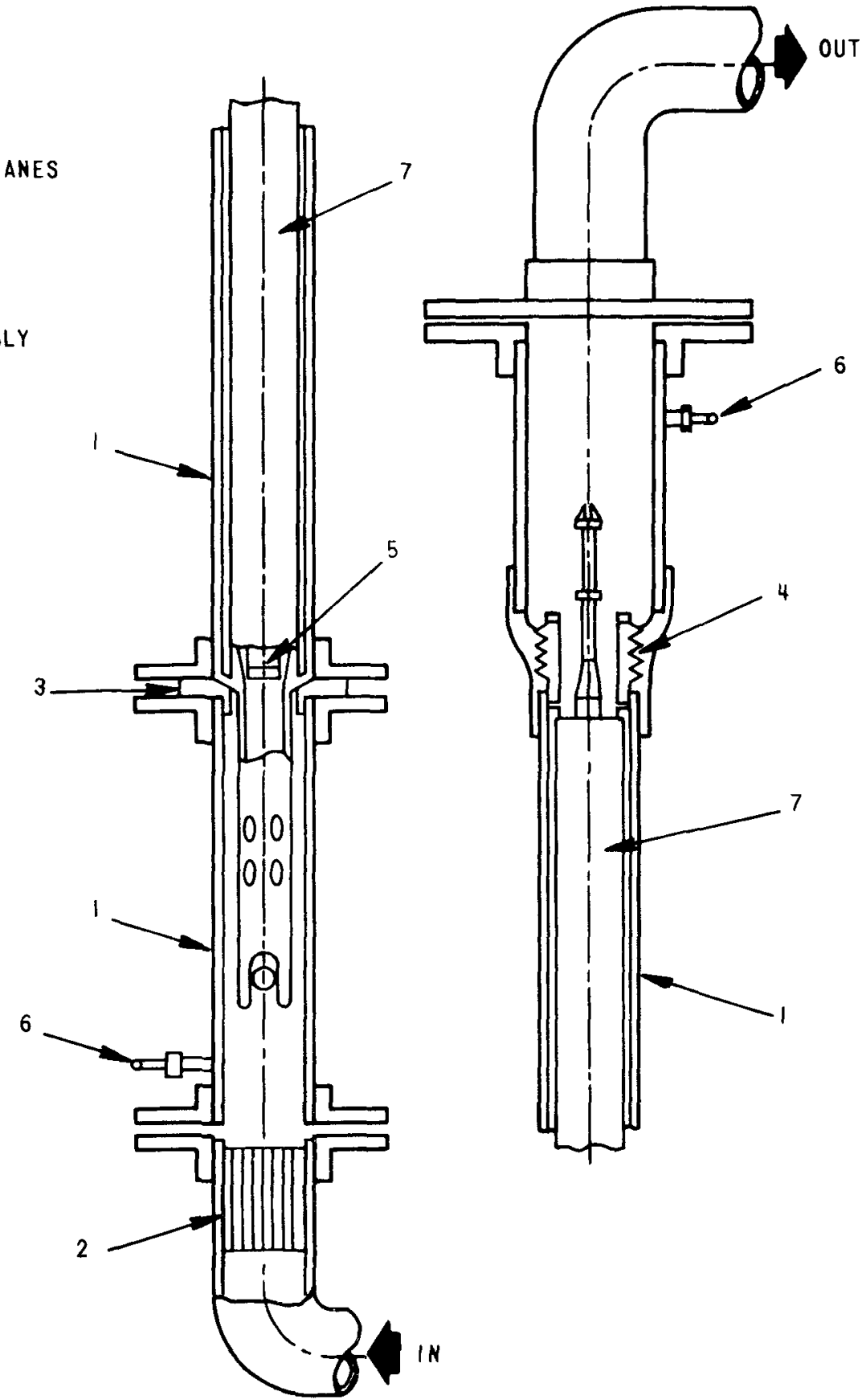

Figure 10-1. Flow Test Housing Diagram 


\section{SECTION 11 \\ OFBA-510 PELLET FABRICATION}

M. G. Bale, B. Riley, T. W. Wallace, and N. G. Wolcott, Jr.

\section{OBJECTIVES}

The objectives of this task are to demonstrate a process capable of producing mixed uranium-plutonium dioxide fuel of the required isotopic, physical, and chemical form to meet all aspects of OFBA-310 and -311 ; to demonstrate the capability for all necessary and pertinent support analytical determinations in the control of process varlables and requirements defined by fuel specifications; and to fabricate mixed uranium-plutonium dioxide fuel for all phases of the contract and irradiation program.

\section{PRIOR WORK}

\section{Work Charged to Contract}

During the last quarter, investigations began on mixed oxides to determine the effects of various processing parameters. The following effects were noted.

1. Drying of the powders prior to milling may be necessary to provide adequately mixed batches.

2. The pressing pressure can be used to control the shrinkage without any adverse effect on fired density (no effect noted with data available at that time). Pellet capping occurred when pressures above 20 ts 1 were used with unslugged powders, and above 30 ts 1 with powders preslugged at 8 tsi.

3. Acceptable $O / M$ and carbon values were obtained on the fired pellets using a $5 \%$ hydrogen-argon gas mixture during sintering.

In addition, fabrication of all depleted $\mathrm{UO}_{2}$ insulator pellets for the WSA $-1,-2$, and -3 experiments was completed.

\section{Related Work Not Charged to Contract}

A11 the necessary Operation Procedures were written and approved, a license to operate was received, and mixed oxides were introduced into the box line. All pleces of equipment were checked out for operation under active conditions with the exception of the automatic press. 


\section{Investigation of Process Variables}

Work performed in the previous quarter Indicated that additional investigations would be required to meet homogeneity and high density (95\% TD) pellet specifications. A 16-hour milling with $\mathrm{Al}_{2} \mathrm{O}_{3}$ balls resulted in improved mixing but unacceptably high Al content ( $1000 \mathrm{ppm}$ ). This was presumably due to a combination of damp powder $\left(\sim 0.2 \% \mathrm{H}_{2} \mathrm{O}\right)$, packing of the powder on the mill sides, and eventual self-attrition of the grinding media.

To investigate these and other problems, a series of experiments were devised, those typical of the milling operations being shown in Table 11-1. It was anticipated from these trials that sufficient information would be generated to provide a convenient means for solving any future difficulties due to batch-to-batch variation, variations in process variables, etc.

\section{$\underline{\text { Sleving }}$}

Three, $20 \mathrm{~g}$ mixed oxide lots were passed through 20-, 100-, and 140-mesh sieves, respectively. Each lot was sleved three times and pellets prepared from each lot were examined autoradiographically. A marked improvement in homogeneity was noted when the finer screens were used, although homogeneity specification limits were not achieved in any of these cases.

Under the prevalling conditions (room-air atmosphere glove boxes), however, long times ( $\sim 3$ hours) were required to pass the $20 \mathrm{~g}$ lots through the $100-$ and 140-mesh sieves, and it appeared impractical to use this method for 1 $\mathrm{Kg}$ size batches.

Further work was thus directed toward decreasing the screening times if at all possible by the use of dry atmospheres, dried powders, or different sieving techniques. As an example, a batch of $\mathrm{UO}_{2}$ sieved normally for up to six hours on a vibrator and under an argon atmosphere was found to have particles retained on the 140- and 325-mesh screens (see also OFBA-511). It was possible to pass $200 \mathrm{~g}$ of similar material through both screens in one hour, however, when copper shot was placed on the screens (this latter analysis confirms the Vendor's analysis that all particles were nominally $<44$ micron). A similar conclusion was also reached when a wet sieving technique using a 270-mesh sieve indicated negligible material with size $>60 \mu$.

Qualitative conclusions to date are as follows:

1. The as-recelved $\mathrm{UO}_{2}$ powder will not readily pass the finer screens whether sieving aids (copper shot, $\mathrm{ZrO}_{2}$ cylinders, etc.) are used or not.

2. Mechanical working of the powder (e.g., milling) apparently increases sieving difficulty although not in direct proportion to the milling time. 


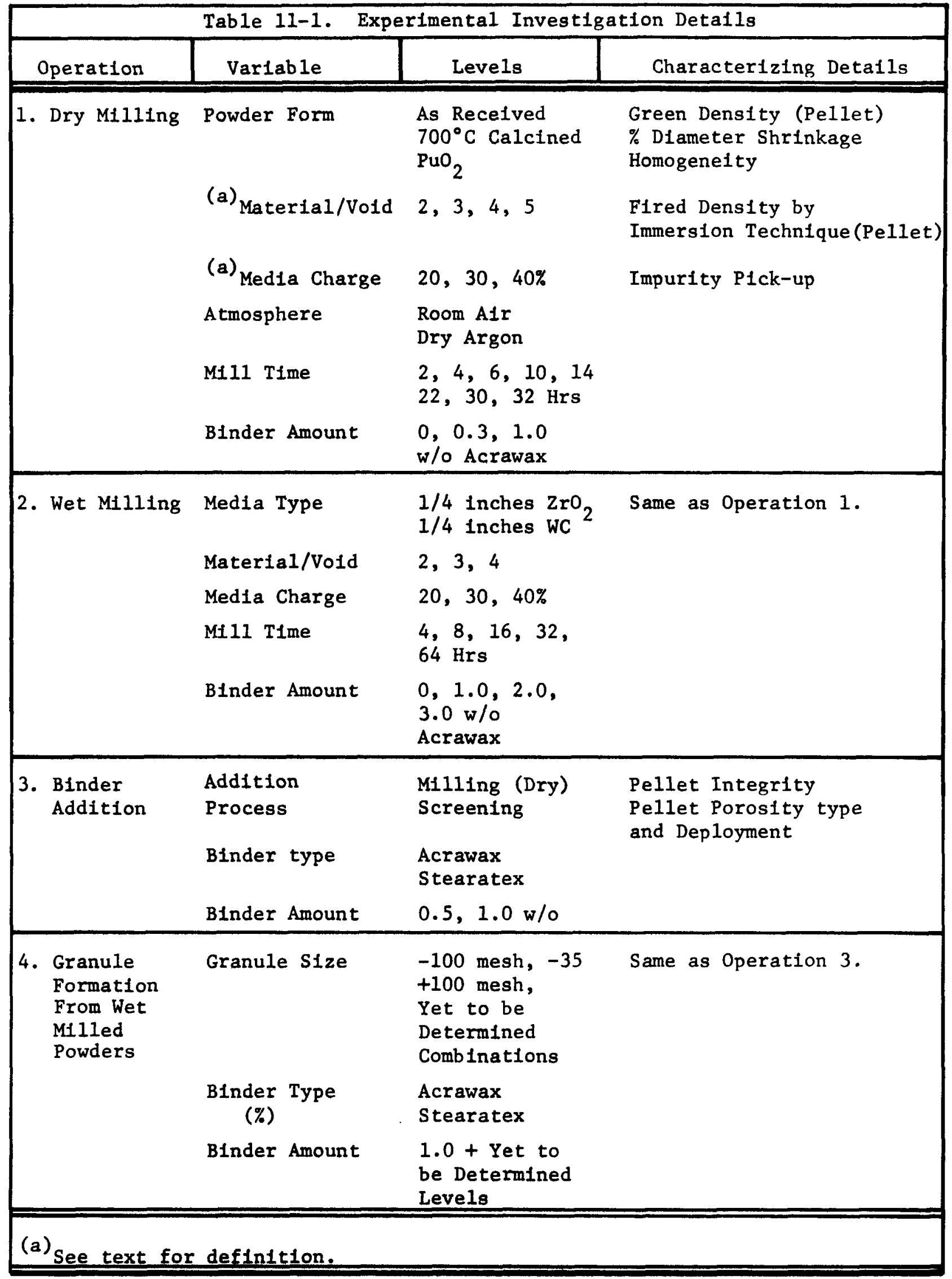


3. Drying of the as-received powder decreases sieving difficulties.

The as-received $\mathrm{PuO}_{2}$ will eastly pass a 140 -mesh screen in the room-air atmosphere glove box and a 325-mesh screen under dry argon conditions. These findings are somewhat surprising when it is considered that the $\mathrm{PuO}_{2}$ is more hygroscopic than the $\mathrm{UO}_{2}$; drying of the $\mathrm{UO}_{2}$ and $\mathrm{PuO}_{2}$ powders followed by exposure to room air has shown that the $\mathrm{PuO}_{2}$ gains welght at a much faster rate than the $\mathrm{UO}_{2}$ and equilibrates at a higher percentage increase.

With the above mentioned sieving variabilities and time factors involved, 20- and 50-mesh sieves have been employed in the majority of the initial screening operations to break up any large agglomerates and provide semiblended powders for the ball mill.

\section{V-blending}

In every case this operation has been performed in the room-air atmosphere glove boxes. With the preliminary batches it was noted that the mixing action of the equipment tended to agglomerate powders and subsequent autoradiographic results showed that an increase in V-blending time did not materially improve pellet homogenelty. It is probable that an intensifier bar is required to make this piece of apparatus efficient; as of this date the $\mathrm{V}$-blender is not used as part of the powder preparation process.

\section{Dry and Wet Milling}

As noted above, the initial dry mixing trials led to considerable caking of the powder during milling. After a discussion with the ball-mill manufacturer, (a) it was suggested that 0.75 -1nch $\mathrm{ZrO} 2$ radius-end cylinders be used, and two batches were run using $12 \%$ and $8 \%$ charges. From this work it was tentatively noted that:

1. The homogeneity increased as a function of increased charge and milling time.

2. Caking of the powder during milling was eliminated.

3. The fired pellet density was not affected by a change in either mill charge or milling time.

Since only one sample of each condition was analyzed autoradiographically, (1) above is inconclusive, but time restrictions did not permit additional investigations.

\footnotetext{
(a) Paul 0. Abbe Co. -- Private Communication.
} 
Concurrent with this work, detalled dry milling trlals were conducted to determine the effects of three milling variables: media charge,(a) material void ratio $(M / V),(b)$ and milling time. Other variables such as mill $\mathrm{far}$ size, mill speed, and material preparation were held constant. For this work, factorial and randomized block experiments were conducted. Table 11-2 contains specific detalls of the designs employed. Material flow for the batches of Design 1 is given in Figure 11-1. From statistical analysis of the data, it was evident that the $M / V$ ratio and the interaction between the $M / V$ ratio and the milling time produced significant effects on fuel density whereas the milling time did not. The following conclusions have been made from these studies.

1. The mill time has had a significant effect only when the $M / V=2$.

2. The highest densities were achieved using an $M / V=4$.

\begin{tabular}{|c|c|c|c|c|c|}
\hline $\begin{array}{c}\text { Design } \\
\text { No. } \\
\end{array}$ & Type & S1ze & Operation & Variables & Levels \\
\hline 1 & Factorial & $3 \times 3$ & Dry M1111ng & $\begin{array}{l}\text { Material/Void } \\
\text { Ratio } \\
\text { Mill Time }\end{array}$ & $\begin{array}{l}2,3,4 \\
4,10,22 \mathrm{Hrs}\end{array}$ \\
\hline 2 & Factorlal & $3 \times 3$ & Dry Milling & $\begin{array}{l}\text { Media Charge } \\
\text { M11l Time }\end{array}$ & $\begin{array}{l}20,30,40 \% \\
2,6,22 \mathrm{Hrs}\end{array}$ \\
\hline 3 & Block & & Dry Milling & Powder Type & $\begin{array}{l}\text { As received } \\
\text { calc. } \mathrm{PuO}_{2}\end{array}$ \\
\hline 4 & Block & & Dry Milling & Atmosphere & $\begin{array}{l}\text { Room Air } \\
\text { Dry Argon }\end{array}$ \\
\hline 5 & Factorial & $2 \times 5$ & Wet Milling & $\begin{array}{l}\text { Material/Void } \\
\text { Ratio } \\
\text { M111 Time }\end{array}$ & $\begin{array}{l}2,3 \\
4,8,16,32,64 \mathrm{Hrs}\end{array}$ \\
\hline 6 & Block & & Dry Milling & Media Type & $\begin{array}{l}\mathrm{WC} \\
\mathrm{ZrO}_{2}\end{array}$ \\
\hline 7 & Block & & & Milling Type & $\begin{array}{l}\text { Wet } \\
\text { Dry }\end{array}$ \\
\hline 8 & Factorial & $3 \times 2$ & Dry Milling & $\begin{array}{l}\text { Binder Amount } \\
\text { Material/Void } \\
\text { Ratio }\end{array}$ & $\begin{array}{l}0,1 \% \\
2,3,4\end{array}$ \\
\hline 9 & Factorial & $3 \times 2$ & Dry Milling & $\begin{array}{l}\text { Binder Amount } \\
\text { Media Charge }\end{array}$ & $\begin{array}{l}0,1 \% \\
20,30,40 \%\end{array}$ \\
\hline
\end{tabular}

(a) The ratio of bulk volume of balls to total volume of mlll far expressed as a percentage.

(b) The amount of material in a mill can be expressed conveniently as the ratto of its volume to that of the volds in the ball charge. If the solid material fust $f 111$ s the ball volds, the $M / V$ ratio is one, for example. 
(CONDUCTED IN ROOM AIR

ATMOSPHERE GLOVE BOX)

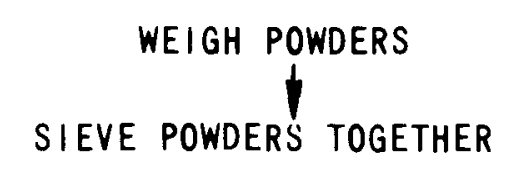

THROUGH 20 MESH SCREEN, 3 TIMES

V-BLEND 10 MINUTES

MILL

SIIEVE THROUGH 20 MESH SCREEN

Figure 11-1. Material Flou for Design 1

$3679-65$ 
A suggested explanation for the significance of the $M / V$ ratio relates to the higher material charge assoclated with the increased $M / V$ ratio. Since some caking of materlal against the far wall occurs, it would appear that the larger quantities permit simultaneous caking and attrition of agglomerates leading to a more efficient milling operation. Additional work is being directed to optimizing the relationship between the mill time and mill charge variables.

Figure 12-3 (see Section 12, page 12-25) shows some of the autoradiographic results of single pellets taken from batches produced in the above study. Qualitatively, improvements in homogenelty follow the general trends observed with increase in the immersion density data.

Concurrent with this work, a batch was dry milled under dry argon conditions, and pellets pressed from this material were examined autoradiographically. It was noted that the dry argon atmosphere yielded a more homogeneous material (tentatively within specifications) although complete density data is not presently avallable for additional comparison with material processed in the room-alr atmosphere glove boxes. This work has led to the mixing of two batches of material for the fuel irradiation program (see "Mixed Oxide Fuel Fabrication," page 11-11).

Programs similar to the dry milling investigations have also been conducted for wet milling. The material flow for these programs is given in Figure 11-2. The inftial autoradlographic results indicate that this method has produced the best homogeneity (also see OFBA-511, Section 12). Immersion density results indicate that higher densities are achieved by this method than by dry milling. It appears that wet milling will be required to produce high ( $95 \%$ of theoretical) density fuel.

Throughout this work, material has been sampled for total metallic impurities to check for possible contamination from milling media, vial, etc. Using $\mathrm{ZrO}_{2}$ mill balls, both wet and dry milling have produced $<200 \mathrm{ppm} \mathrm{Zr}$ to date.

\section{$\underline{\text { Pressing }}$}

Pelletization trials reported in the last Quarterly Report indicated little effect on the pellet sintered density when material was pressed between 5 and 20 tsi. To provide a comparative basis for much of the powder preparation work, a fixed pressure, 15 tsi, has been used throughout the current work. For such trials, a Carver hand press has been used and this has also been employed for producing a preslugged feed for the Komage automatic press.

Work on the latter plece of equipment has proceeded satisfactorily with green pellet densities between 42 and $52 \%$ TD belng obtained. Preslugged powder containing $1 \mathrm{w} / 0$ binder (Acrawax or Stearatex) has been found to feed well, with consistent pellets being produced when welghts in excess of $50 \mathrm{~g}$ are present $1 \mathrm{n}$ the feed shoe. With this provision, no detectable pellet-to-pellet varlation has so far been noted. 
(CONDUCTED IN ROOM AIR

ATMOSPHERE GLOVE BOXES)

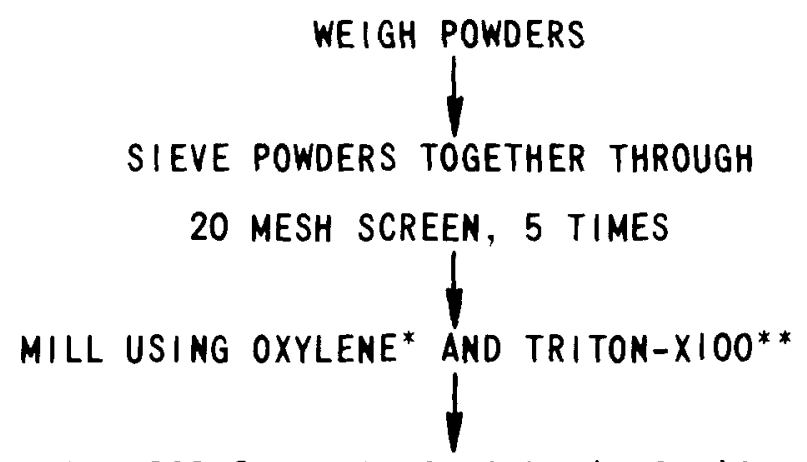

DRY FOR 2 HOURS USING DYMAMIC VACUUM

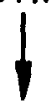

SIEVE THROUGH 20 MESH SCREEN

ADD BINDER/LUBR I CANT

SIEVE BINDER/LUBRICANT

THROUGH 20 MESH SCREEN

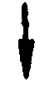

V-BLEND FOR 15 MINUTES
BINDER ADDITIONS

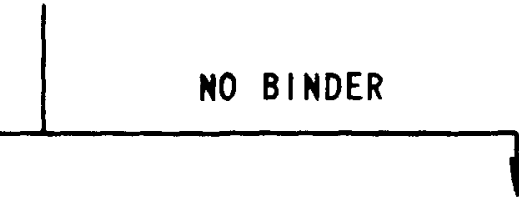

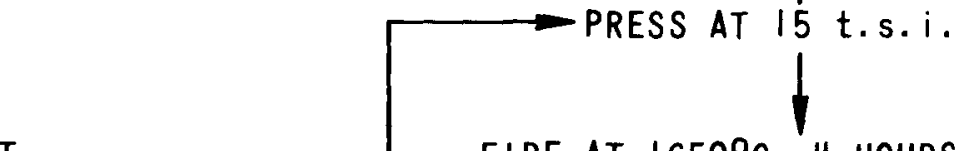

FIRE AT $1650^{\circ} \mathrm{C}, 4$ HOURS

$\mathrm{N}_{2}, 5 \% \mathrm{H}_{2}$ ATMOSPHERE

* nOn-flammable solvent

** WETTINg agent USED IN SMALL AMOUNT

Figure 11-2. Material Flow for Wet Milling Trials $3679-66$ 


\section{Sintering}

As with pressing, a standard sintering schedule has been established to permit comparisons of various mixing/milling operations. This schedule, nine hours from room temperature to $1650^{\circ} \mathrm{C}$ with four hours at temperature, has on occasion been shortened by use of a faster heating rate. No apparent effect on pellet density or integrity has been observed. In a number of other cases, however, a marked density decrease has been observed when $1 \%$ binder has been added to powders, in particular to those that sinter to 95$97 \%$ TD when no binder is added. Variations in the ultimate hold temperature also affect the final pellet density, and these variables, together with green density values, will be used to control the final pellet size and density. Investigations on these aspects will be pursued concurrent with fuel fabrication.

\section{Miscellaneous - Pellet Inclusions}

Inclusions of various compositions have been noted in most of the nonhomogeneous pellets produced by the milling investigations (see OFBA-511, Section 12). The slze of these inclusions appears to diminish as the homogeneity improves.

\section{Summary}

The experimental work has led to the following conclusions relevant to the fabrication of fuel for the irradiation program:

1. The inftial batches intended for low density ( $90 \%$ of theoretical) fuel will be made by dry milling in the dry argon glove box line.

2. Wet milling will be required for production of the high density fuel ( $95 \%$ of theoretical).

3. Perfodic screening of the batches during milling is used to break up any agglomerates which have formed due to powder caking against the walls of the mill vials.

4. Binder (type and \%) and preslugging and pressing pressure will have to be Investigated for each production batch to produce pellets of acceptable and uniform density and integrity.

\section{Mixed-Oxide Fuel Fabrication}

Based on the above results, two batches of mixed oxide are currently being processed to nominally satisfy requirements for most of the low density (90\% TD) fuel pellets (WSA-3). These batches have been milled for 30 hours under dry-argon conditions with intermediate screening through a 20-mesh 
screen to break up agglomerates that may tend to form. Preliminary autoradiographic results indicate that homogeneity is within specification. 


\section{SECTION 12}

\section{OFBA-511 FUEL CHARACTERIZATION}

J. Y. Chang, P. M. French, W. R. Jacoby, and P. D. Shalek

\section{OBJECTIVES}

The principal obfectives of this task are to develop characterization techniques and to characterize and evaluate the uranium dioxide and mixed uranium-plutonium dioxide (powders and pellets) developed and fabricated under Task OFBA-510. Product characterization is required for control and performance evaluation objectives.

A secondary objective is to determine the various physical and mechanical properties; e.g., thermal conductivity, expansion, etc., of these materlals at each compositional change. These are necessary to complement the fabrication process (OFBA-510) and the irradiation programs (OFBA-310 and -311). This task will require some National Laboratory support.

\section{PRIOR WORK}

Sampling procedures and tentative specifications were established for the vartous materials to be characterized in the mixed oxide fuel program. Uranlum-plutonfum dioxide fuel pellets for the two 19-pin 1rradiation tests described under Task OFBA-310 were manufactured for WARD by United Nuclear Corporation (UNC) and recelved at Cheswick. Characterization of pellets having three separate uranium enrichments and densities was well advanced. $O / M$ values determined by WARD were generally in good agreement with those reported by UNC for this material.

Metallographic evaluation of the above fuel batches was completed. Composite porosity photographs revealed different pore structures for the various fuel batches.

The $\mathrm{PuO}_{2}$ and enriched $\mathrm{UO}_{2}$ powders to be used in fabricating fuel pellets at WARD for the 37-pin 1rradiation tests were recelved and sampled. Analytical chemlstry, metallography, and homogenelty studles were undertaken on the first trial batch of $(\mathrm{U}, \mathrm{Pu})_{2}$ pellets produced from these starting materfals.

\section{CURRENT PROGRESS}

\section{Analyt1cal Chemlstry}

A11 analytical chemistry work on the (U, $\mathrm{Pu}) \mathrm{O}_{2}$ pellet batches for use in the WSA-1 and -2 subassemblies has been completed with the exception of total gas releane. There 18 very good agreement between WARD and UNC data on the varlous batches except for certain values for $O / M$ and molsture. It has previously been reported [12] that there were gignificant differences in the 
$0 / M$ values obtained at the two laboratorles on the $43 \%$ enriched $(\mathrm{U}, \mathrm{Pu}) \mathrm{O}_{2}$ fuel. Consequently, the $\mathrm{O} / \mathrm{M}$ determinations on this material were repeated at WARD. No significant change was observed in the second set of WARD values compared to the first.

Nitrogen determinations using the KJeldahl method were undertaken on (U,Pu) $\mathrm{O}_{2}$ pellets from all batches. Details are given in Table 12-1. All batches are acceptable since the specification for this element in this experiment is 75 ppm maximum.

\begin{tabular}{|c|c|c|c|}
\hline \multirow{2}{*}{$\begin{array}{c}\text { Table } 12-1 . \\
\text { for Witrogen Contents (ppm) of }(\mathrm{U}, \mathrm{Pu}) \mathrm{O}_{2} \text { Pellet Batches } \\
\end{array}$} & \multicolumn{4}{|c|}{$\%$ Theoretical Density } \\
\cline { 2 - 5 } $\begin{array}{c}\text { Enrichment } \\
(\%)\end{array}$ & $\begin{array}{c}95 \\
(\mathrm{ppm})\end{array}$ & $\begin{array}{c}91 \\
(\mathrm{ppm})\end{array}$ & $\begin{array}{c}89 \\
(\mathrm{ppm})\end{array}$ \\
\hline \hline 93 & 21 & 30 & 25 \\
65 & 14 & 14 & 22 \\
43 & - & $<10$ & $<10$ \\
\hline
\end{tabular}

Initial moisture values obtained for three of the eight batches of (U, $\mathrm{Pu}) \mathrm{O}_{2}$ pellets manufactured by UNC for WSA-1 and WSA-2 were found to be above the $50 \mathrm{ppm}$ average specification limit set for these particular subassemblies. A drying procedure was, therefore, developed to bring these pellets to within specification. The various trials are summarized in Table 12-2.

The as-received $89 \% \mathrm{TD}, 65 \%$ enriched $\mathrm{U}_{0} .75^{\mathrm{Pu}} 0.25_{2} \mathrm{O}_{2}$ pellets showed an average $99 \mathrm{ppm}$ moisture content when run in the CEC Sollds Moisture Analyzer $\left(700^{\circ} \mathrm{C}\right.$ analysis temperature, $\mathrm{N}_{2}$ carrier gas). Trials 2 and 3 , at low temperature removed only a small amount of physically held and possibly hydrate moisture. Drying at $300-600^{\circ} \mathrm{C}$ in $\mathrm{N}_{2}$ or Ar eliminated increasing amounts of moisture (trials 4, 8, and 9), but $700^{\circ} \mathrm{C}$ in $\mathrm{N}_{2}$ (Trial 5) was found to be the first treatment to essentially eliminate moisture. $\mathrm{Ar}-5 \% \mathrm{H}_{2}$ was then used for batch-scale drying at $700^{\circ} \mathrm{C}$ ( Trail 6), since it was readily available, but the moisture content $(\sim 80 \mathrm{ppm})$ was unaffected by this treatment. Further drying in $\mathrm{Ar}$ at $800^{\circ} \mathrm{C}$ (Trial 7), did, however, lower the moisture content to a satisfactory level ( $\sim 3 \mathrm{ppm})$. A temperature of $700^{\circ} \mathrm{C}$ with flowing argon was later found to be adequate (Trials 10 and 11 ).

It was thus conclusively demonstrated that $\mathrm{H}_{2}$ is chemisorbed onto pellets cooled in $\mathrm{Ar}-5 \% \mathrm{H}_{2}$, and that this $\mathrm{H}_{2}$ manifests itself as a moisture indication during analysis. Other facilities have observed and investigated this same phenomenon. [13,14] The amount of this absorption is directly related to open porosity, since it depends on total avallable surface area.

The true meaning of such moisture values has not yet been definitely established. Plucinski, [13] for example, has found that molsture values for identical pellets containing adsorbed $\mathrm{H}_{2}$ can be made to vary from 10 to $100 \mathrm{ppm}$ depending on the heating rate used during analysis. The two most 


\begin{tabular}{|c|c|c|c|}
\hline \multirow{2}{*}{$\begin{array}{c}\text { Trial } \\
\text { No. }\end{array}$} & \multicolumn{2}{|c|}{ Treatment (Chronological Order) } & \multirow{2}{*}{$\begin{array}{c}\text { Moisture Values After Trial } \\
(\mathrm{ppm})\end{array}$} \\
\hline & Previous (Trial Nos.) & This Trial & \\
\hline 1 & (a) & As received & Avg. $=99(98,97,100,100,100)$ \\
\hline 2 & 1 & $210^{\circ} \mathrm{C}, 8 \mathrm{hrs}, 10 \mathrm{cfh} \mathrm{Ar}$ & Avg. $=84(70,67,109,86,87,87)$ \\
\hline 3 & 1,2 & $150^{\circ} \mathrm{C}, 15 \mathrm{hrs}, 30 \mathrm{in}$. vac. & Avg. $=77(106,75,67,65,67,80)$ \\
\hline 4 & $1,2,3$ & $300^{\circ} \mathrm{C}, 10 \mathrm{~min} .$, flowing $\mathrm{N}_{2}$ & 68 \\
\hline 5 & $1,2,3,4$ & $700^{\circ} \mathrm{C}, 10$ min., flowing $\mathrm{N}_{2}$ & 5 \\
\hline 6 & $1,2,3$ & $700^{\circ} \mathrm{C}, 1 \mathrm{hr}, 6 \mathrm{cfh}\left(\mathrm{Ar}-5 \% \mathrm{H}_{2}\right)$ & Avg. $=77(62,82,88)$ \\
\hline 7 & $1,2,3,6$ & $800^{\circ} \mathrm{C}, 2 \mathrm{hrs}, 6 \mathrm{cfh} \mathrm{Ar}$ & Avg. $=4(4,7,3,4,2)$ \\
\hline 8 & $1,2,3,6$ & $425^{\circ} \mathrm{C}, 2 \mathrm{hrs}, 6 \mathrm{cfh} \mathrm{Ar}$ & Avg. $=42(44,39)$ \\
\hline 9 & $1,2,3,6$ & $600^{\circ} \mathrm{C}, 2 \mathrm{hrs}, 6 \mathrm{cfh} \mathrm{Ar}$ & Avg. $=48(34,62)$ \\
\hline 10 & (b) & As received & Avg. $=70(73,49,81,81,65)$ \\
\hline 11 & 10 & $700^{\circ} \mathrm{C}$, no hold, $6 \mathrm{cfh} \mathrm{Ar}$ & Avg. $=<3$ \\
\hline
\end{tabular}


likely places for the chemisorbed $\mathrm{H}_{2}$ to combine with $\mathrm{O}_{2}$ are:

1. Within the $(\mathrm{U}, \mathrm{Pu}) \mathrm{O}_{2}$ structure Itself

2. Within the electrolytic cell of the analyzer after leaving the pellet as $\mathrm{H}_{2}$

If the latter is the case, this adsorbed $\mathrm{H}_{2}$ can also contribute to the TGR value since it will pass through the moisture trap in this apparatus.

The implication of this work is that porous pellets cooled in Ar-, He-, or $\mathrm{N}_{2}-5 \% \mathrm{H}_{2}$ atmospheres may adsorb enough $\mathrm{H}_{2}$ to give both excessive moisture and TGR readings. Such adsorption can be most easily prevented by switching the furnace atmosphere to inert gas at $700-800^{\circ} \mathrm{C}$ during the cooling portion of the firing cycle.

Tests were run to determine the extent of moisture pickup at room temperature by the above porous $65 \%$ enriched fuel pellets. Pellets, which had been dried to about $4 \mathrm{ppm} \mathrm{H}_{2} \mathrm{O}$, attained what appears an equilibrium moisture content of about $30 \mathrm{ppm}$ both when exposed to "dry" argon for two weeks and to humid air for two hours to two weeks. It is felt that this moisture is physically held and can be driven off at a lower temperature. Work is in progress to confirm this. It does appear that pellets having high open porosity will require special handling.

\section{Powder Characterization}

The particle size distribution of the natural and enriched $\mathrm{UO}_{2}$ powders was determined by the Andreason pipette technique. Data obtained from duplicate runs on each powder have been plotted in Figure 12-1. The size distribution curve obtained for the natural $\mathrm{UO}_{2}$ powder is typical of Eldorado materia1, [15] while that for the enriched is reasonably consistent with the average particle diameter of $0.57 \mu$ previously reported.[12] Displacement of a curve to the right, as in Figure 12-1, indicates a less sinterable powder. This has been confirmed by the fact that natural $\mathrm{UO}_{2}$ pellets sintered to a lower density than enriched $\mathrm{UO}_{2}$ pellets under similar fabrication conditions.

Samples of the $\mathrm{PuO}_{2}$ and enriched $\mathrm{UO}_{2}$ starting powders were sieved on a vibrator in a dry argon atmosphere. All the $\mathrm{PuO}_{2}$ powder had passed through a $37 \mu$ sieve after 40 minutes. However, after $6-1 / 2$ hours sieving, $6.6 \mathrm{w} / \mathrm{o}$ of the enriched $\mathrm{UO}_{2}$ powder had been retalned on a $105 \mu$ screen (see also OFBA-510, Section 11). This behavior is somewhat surprising, since the average particle size of the $\mathrm{PuO}_{2}$ powder was previously found to be $1.31 \mu$ and that of the $\mathrm{UO}_{2}, 0.57 \mu .{ }^{[12]} \mathrm{A}$ small quantity of this coarse fraction of $\mathrm{UO}_{2}$ powder was mounted, carefully ground and then examined microscopically. It appeared to consist of individual particles (Figure 12-2). However, these particles could be crushed with moderate effort between two glass slides into smaller particles. 


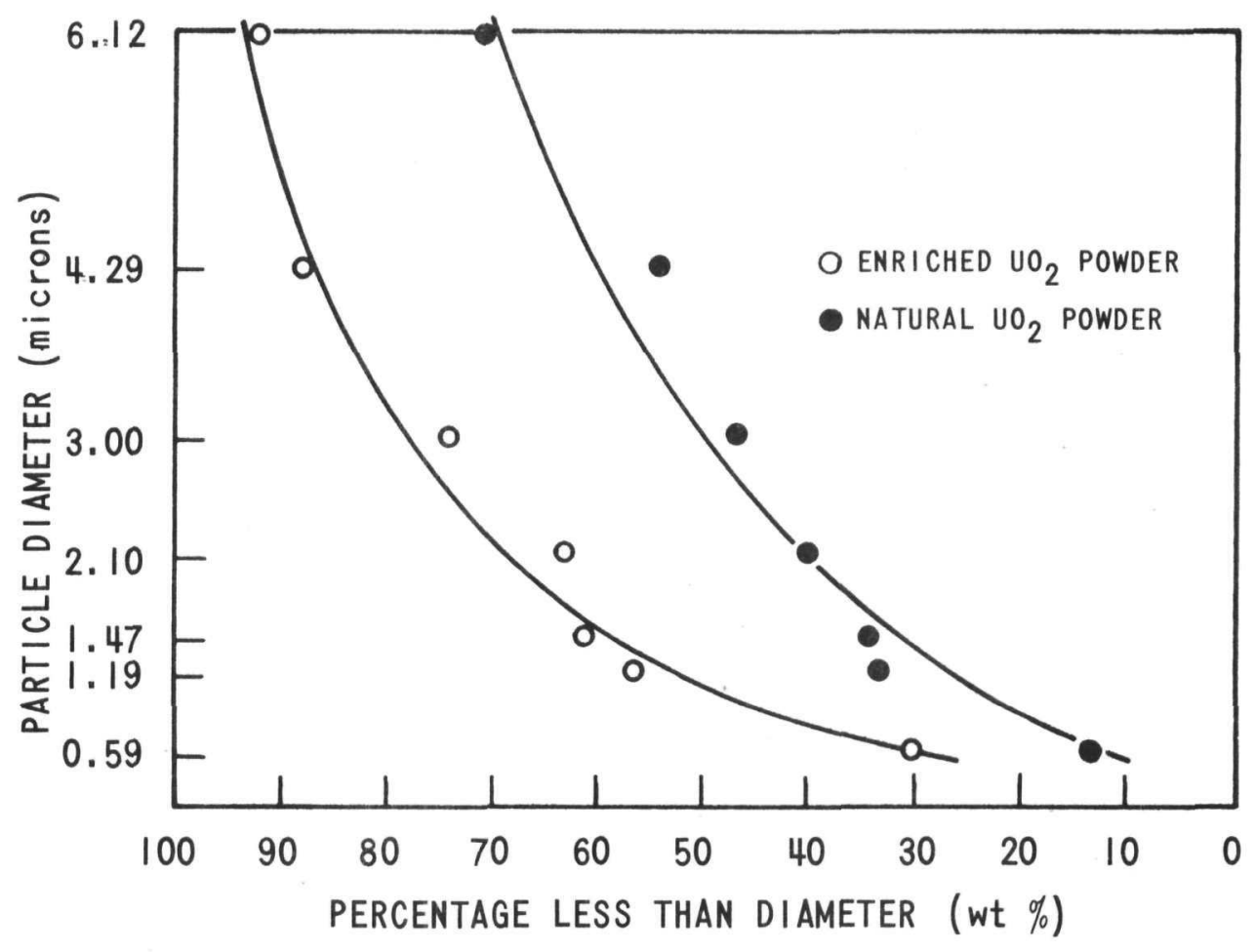

Figure 12-1. The Particle Size Distribution for Natural and $3679-67$ Enriched $\mathrm{UO}_{2}$ Powders

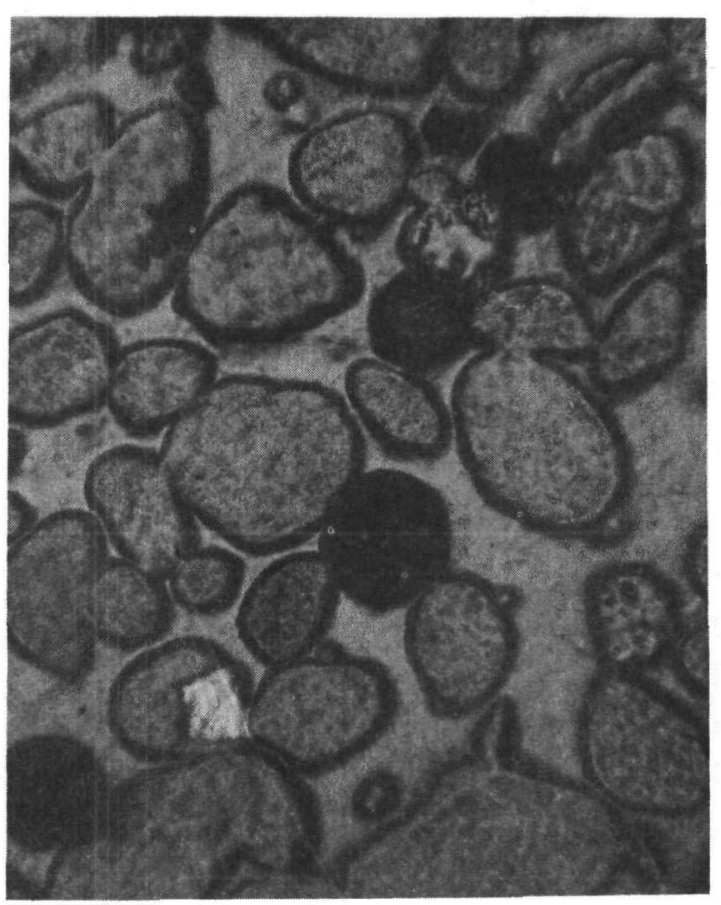

Figure 12-2. $\mathrm{UO}_{2}$ Particles Retained on 105 $\mu$ Sieve. As Polished $3679-68$

(Mag. 75X) 
Chemical analysis (TMI) was also undertaken on this coarse fraction of $\mathrm{UO}_{2}$ powder. It was found to be slightly enriched in $\mathrm{Al}, \mathrm{Cr}$, and $\mathrm{Si}$ when compared with the powder as a whole, as shown in Table 12-3.

\begin{tabular}{|l|c|c|c|}
\hline \multicolumn{4}{|c|}{$\begin{array}{l}\text { Table 12-3. Comparison of Certain Impurity Contents in the Overal1 } \\
\mathrm{UO}_{2} \text { Powder Versus Those in the Coarse Fraction }\end{array}$} \\
\hline & $\begin{array}{c}\mathrm{A} 1 \\
(\mathrm{ppm})\end{array}$ & $\begin{array}{c}\mathrm{Cr} \\
(\mathrm{ppm})\end{array}$ & $\begin{array}{c}\mathrm{Si} \\
(\mathrm{ppm})\end{array}$ \\
\hline \hline & $<14$ & 12 & $<20$ \\
Average for Powder Batch & 50 & 50 & 175 \\
\hline
\end{tabular}

\section{Metallography and Autoradiography}

$(\mathrm{U}, \mathrm{Pu})_{2}$ Material for Experiments WSA-1 and WSA-2

Metallographic and homogeneity evaluation of all fuel batches for experiments WSA-1 and WSA-2 have now been completed. Examination of the porosity distribution in the $43 \%$ enriched material indicated that the nominally $95 \%$ dense pellets have an appreciable amount of interconnected porosity. Although this material is "poorly" sintered by comparison to the equivalent pellets at the 65 and $93 \%$ enrichment, its homogeneity, as revealed by autoradiography, is superior. There is no particle in the $43 \%$ enriched $95 \%$ dense material corresponding to an area of high $\mathrm{Pu}$ concentration greater than $40 \mu$ in diameter. With the $43 \%$ enriched, $91 \%$ dense material, the maximum Pu-containing particle diameter is $60 \mu$. Examination of autoradiographs (Figures $12-3$ and $12-4$ ) of the $43 \%$ enriched (U, $\mathrm{Pu}) \mathrm{O}_{2}$ fuel indicates that the homogeneity of the two different density batches is acceptable. Table 12-4 lists the maximum particle diameters of high $\mathrm{Pu}-$ containing areas found in all fuel batches for experiments WSA-1 and WSA-2, along with characterization data previously reported. With one exception, as the maximum Pu-rich particle size increases within a particular enrichment, so do the values for open porosity and average pore size. One would not expect to see a correlation from one enrichment to another, as the different amounts of depleted uranium added to the material would affect the sintering characteristics of the pellets.

WARD Test Batches of $(\mathrm{U}, \mathrm{Pu}) \mathrm{O}_{2}$ Pellets

The majority of work undertaken during this period has been concerned with investigating the effects of the various processing variables described in OFBA-510 upon sintered fuel homogeneity. When fabrication processing was undertaken in a room-air atmosphere, the following observations were made regarding pellet homogeneity: 


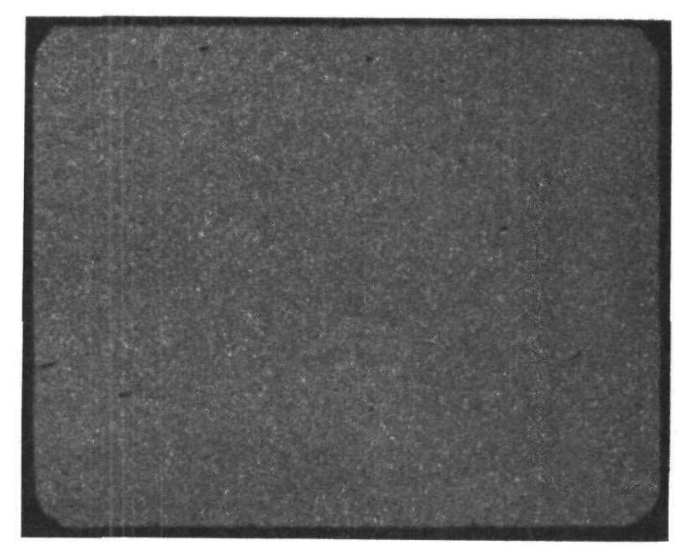

Figure 12-3. Autoradiograph of a 95\% Dense, $43 \%$ Enriched (U,Pu) $\mathrm{O}_{2}$ Pellet (Mag.10X)

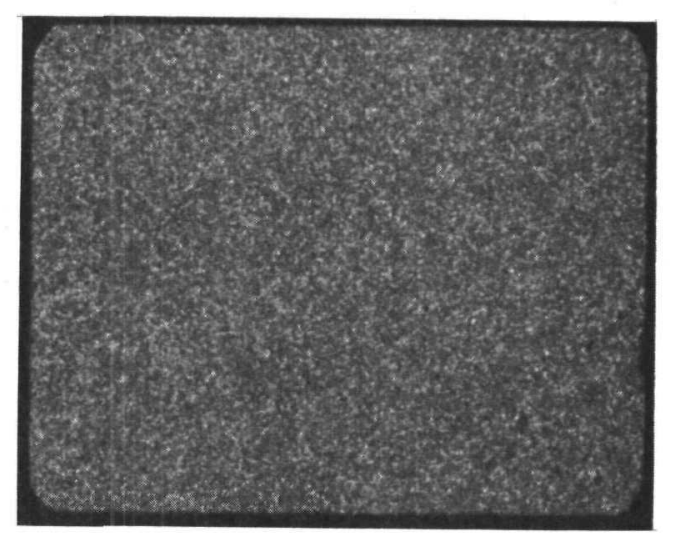

Figure 12-4. Autoradiograph of a 91\% Dense, $43 \%$ Enriched $3679-69$ $(\mathrm{U}, \mathrm{Pu}) \mathrm{O}_{2}$ Pellet (Mag.10X) 
1. No pellet of acceptable homogeneity was produced, although depending upon processing conditions, autoradiographs showed some pellets having close to acceptable plutonium homogeneity.

2. Autoradiography revealed that pellets have roughly the same degree of uranium and plutonium heterogeneity. It is considered essential that pellets should meet the same conditions for uranium homogeneity as those for plutonium to be acceptable for use in WSA-3 subassemb1y. [16]

3. V-blending the powders prior to milling did not improve pellet homogeneity.

4. Milling the powders for periods greater than 14 hours improved pellet homogeneity.

5. The material/void ratio employed during milling is a significant factor when all other variables are kept constant. This is illustrated in Figures $12-5 \mathrm{a}$ and $\mathrm{b}$, the former corresponding to a material/void ratio during milling of $2: 1$, and the latter to a ratio of $4: 1$. It can be seen that there is a significant improvement in homogeneity in the latter case, particularly from the standpoint of plutonium.

6. In addition to the normal uranium and plutonium in homogeneity, inclusions have been observed in virtually all pellet sections seen to date. Correlation of metallographic and autoradiographic observations suggests there are three types of inclusions: plutoniumrich, uranium-rich, and nonfissile. However, with improvement in pellet homogeneity, the size of the two fissile types of inclusions is greatly reduced and they become uniformly distributed throughout the pellet.

\begin{tabular}{|c|c|c|c|c|}
\hline \multicolumn{5}{|c|}{$\begin{array}{l}\text { Table 12-4. Physical Characterization Data on Various } \\
(\mathrm{U}, \mathrm{Pu}) \mathrm{O}_{2} \text { Pellet Batches }\end{array}$} \\
\hline $\begin{array}{c}\text { U-235 } \\
\text { Enrichment } \\
(\%) \\
\end{array}$ & $\begin{array}{c}\text { Nominal } \\
\text { Density } \\
(\%) \\
\end{array}$ & $\begin{array}{r}\text { Maximum Pu } \\
\text { Particle Size } \\
(\mu)\end{array}$ & $\begin{array}{l}\text { Open } \\
\text { Porosity } \\
(\%)\end{array}$ & $\begin{array}{c}\text { Average Pore } \\
\text { Size } \\
(\mu) \\
\end{array}$ \\
\hline 93 & $\begin{array}{l}95 \\
91 \\
89\end{array}$ & $\begin{array}{l}60 \\
70 \\
80\end{array}$ & $\begin{array}{l}0.5 \\
4.2 \\
4.7\end{array}$ & $\begin{array}{r}6 \\
15 \\
20\end{array}$ \\
\hline 65 & $\begin{array}{l}95 \\
91 \\
89\end{array}$ & $\begin{array}{r}70 \\
100 \\
80\end{array}$ & $\begin{array}{l}0.5 \\
2.5 \\
6.3\end{array}$ & $\begin{array}{c}3 \\
25 \\
\text { (b) }\end{array}$ \\
\hline 45 & $\begin{array}{l}95 \\
91\end{array}$ & $\begin{array}{l}40 \\
80\end{array}$ & $\begin{array}{l}2.7 \\
3.3\end{array}$ & $\begin{array}{r}6 \\
35\end{array}$ \\
\hline $\begin{array}{l}\text { (a) Obtained frol } \\
\text { (b) Impossible } t\end{array}$ & $\begin{array}{l}\text { Immers } \\
\text { obtain }\end{array}$ & $\begin{array}{l}\text { Density Meas } \\
\text { eliable valu }\end{array}$ & nts & ty type \\
\hline
\end{tabular}




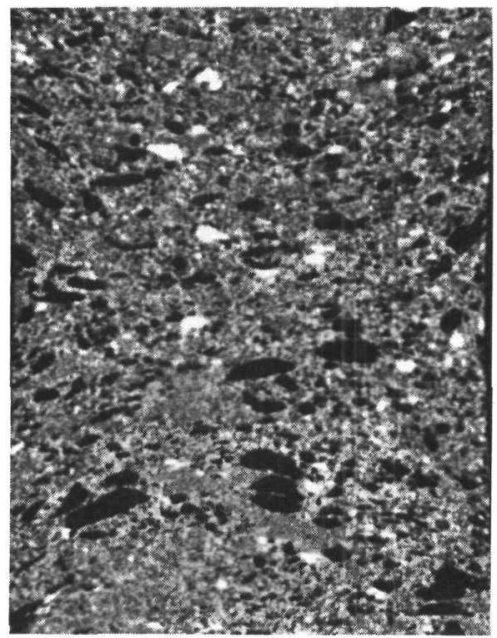

(a) MATERIAL: VOID $=2: 1$

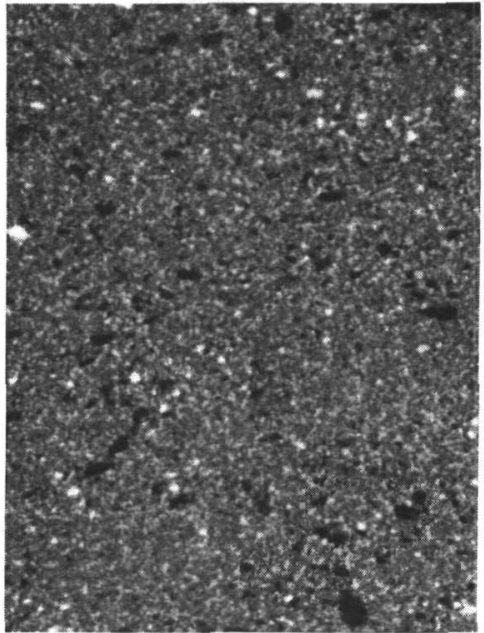

(b) MATERIAL: VOID $=4: 1$

Figure 12-5. Autoradiographs of Sintered (U, Pu) $0_{2}$ Pellets, Illustrating the Effects of Different Material/Void Ratios Em$3679-70$ ployed During Powder Milling (Mag.10X)

Some effort has been spent in an attempt to determine the nature and source of these inclusions. Figure 12-6a is an autoradiograph and Figure 12-6b a photomicrograph of the same green pellet surface. The corresponding bright spots in both figures are considered to be agglomerates of $\mathrm{PuO}_{2}$ formed during the milling operation. Similarly, the corresponding dark spots are probably agglomerates of $\mathrm{UO}_{2}$. Similar correlations have been observed in sintered pellets as shown in Figures 12-7a (autoradiograph) and Figure 12-7b (photomicrograph). In this instance the corresponding white spots are considered to be of the type $\mathrm{PuO}_{2-x}$, formed during sintering by the reduction of the $\mathrm{PuO}_{2}$ agglomerates previously seen in the green pellet. This conclusion is based in part on thermodynamic considerations [17] and also from the observation that the $0 / \mathrm{M}$ of a $\mathrm{PuO}_{2}$ ellet, sintered under identical conditions to the $(\mathrm{U}, \mathrm{Pu}) \mathrm{O}_{2}$ pellets, was 1.935. Using a similar argument, the corresponding dark spots are considered to be $\mathrm{UO}_{2}$. We have also observed very bright spots in the photomicrograph as shown in Figure 12-7. Since these spots appear dark on an autoradiograph, they do not contain plutonium. These are, therefore, classified as a third type of inclusion which may be nonfissile material. Recent experiments, with improved powder preparation techniques (e.g., wet milling or milling in a dry inert atmosphere) indicate significant progress in the elimination of these fissile inclusions.

(a) The cracking in this pellet is not typical of that presently being produced by WARD. This particular photomicrograph was included solely as the best example of the different types of inclusions. 


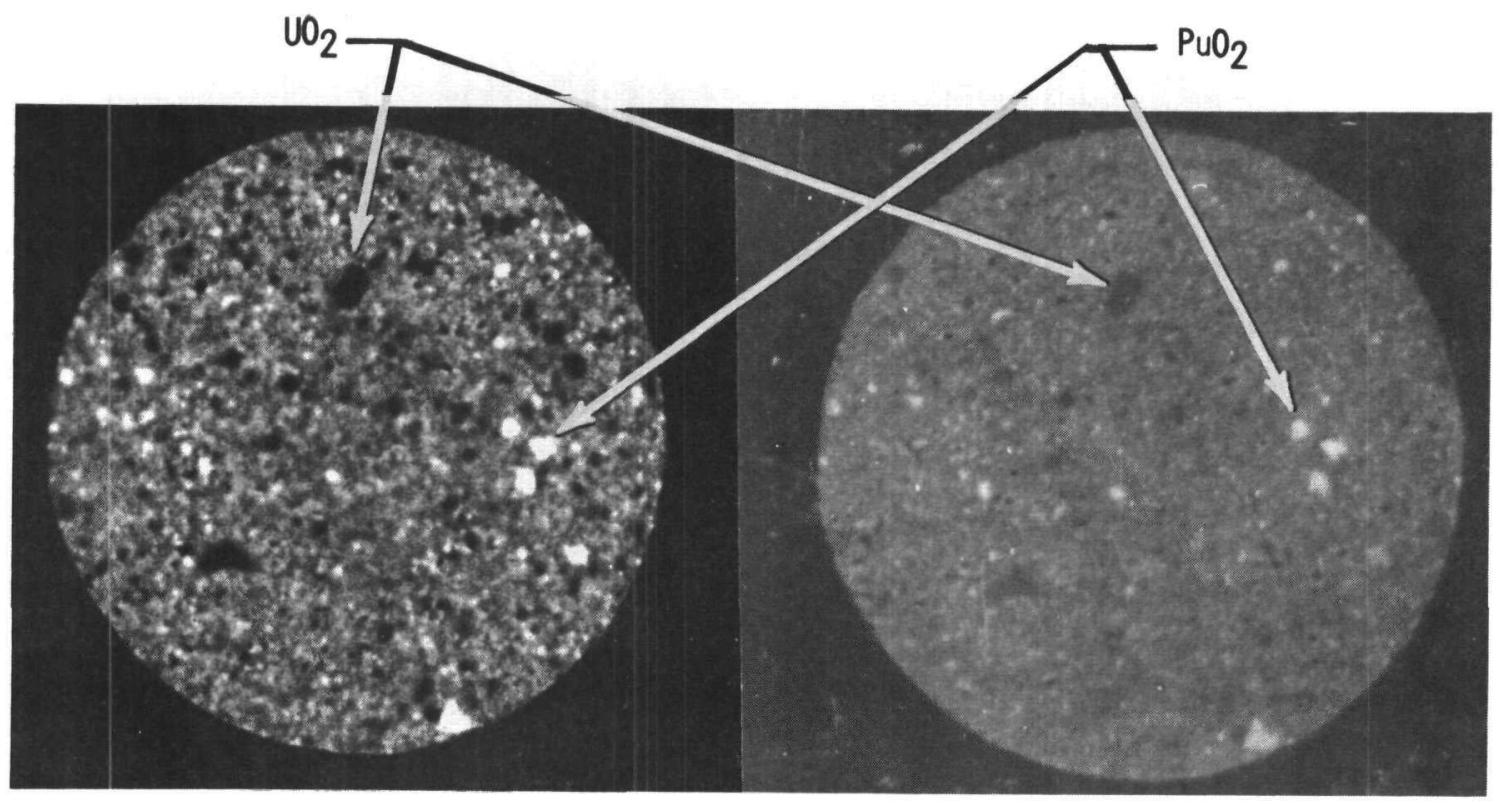

(a)

(b)

Figure 12-6. (a) is an Autoradiograph, and (b) is a Photomicrograph of $3679-71$ the Same Green (U,Pu)O $\mathrm{O}_{2}$ Pellet Surface (Mag.10X)

In the case of the nonfissile inclusions, it is believed that their source is impurities in the starting $\mathrm{UO}_{2}$ and $\mathrm{PuO}_{2}$ powders. This is based on the following observations:

1. Such inclusions occur in green and sintered pellets.

2. This type of inclusion occurs in both sintered $\mathrm{UO}_{2}$ and $\mathrm{PuO}_{2}$ pellets produced directly from the starting powders; i.e., no powder preparation stage was used.

Work is continuing in this area in an attempt to eliminate the various inclusions that occur in sintered $(\mathrm{U}, \mathrm{Pu}) \mathrm{O}_{2}$ pellets.

An autoradiography technique, which has been developed by Westinghouse PFDL and uses cellulose nitrate film, has been evaluated and compared to that currently employed by NUMEC. As a result of the diffuseness of the autoradiographs produced by the Westinghouse PFDL process, it is impossible to measure the particle size of the enriched plutonium areas. Furthermore, particles less than approximately $100 \mu$ in size cannot be resolved, depending upon the intensity of the $\alpha$-emitter. Consequently the Westinghouse PFDL technique can currently only be used as a rough screening process. 
Using this latter technique, autoradiography has been undertaken on $(\mathrm{U}, \mathrm{Pu}) \mathrm{O}_{2}$ pellets representing the numerous processing trials by WARD. These autoradiographs indicated that milling of powders, either in a dry, inert atmosphere or by wet milling, yields sintered pellets having probably the best homogeneity seen to date. The homogeneity of these pellets will be rechecked using the NUMEC autoradiography technique before deciding if the processes are acceptable.

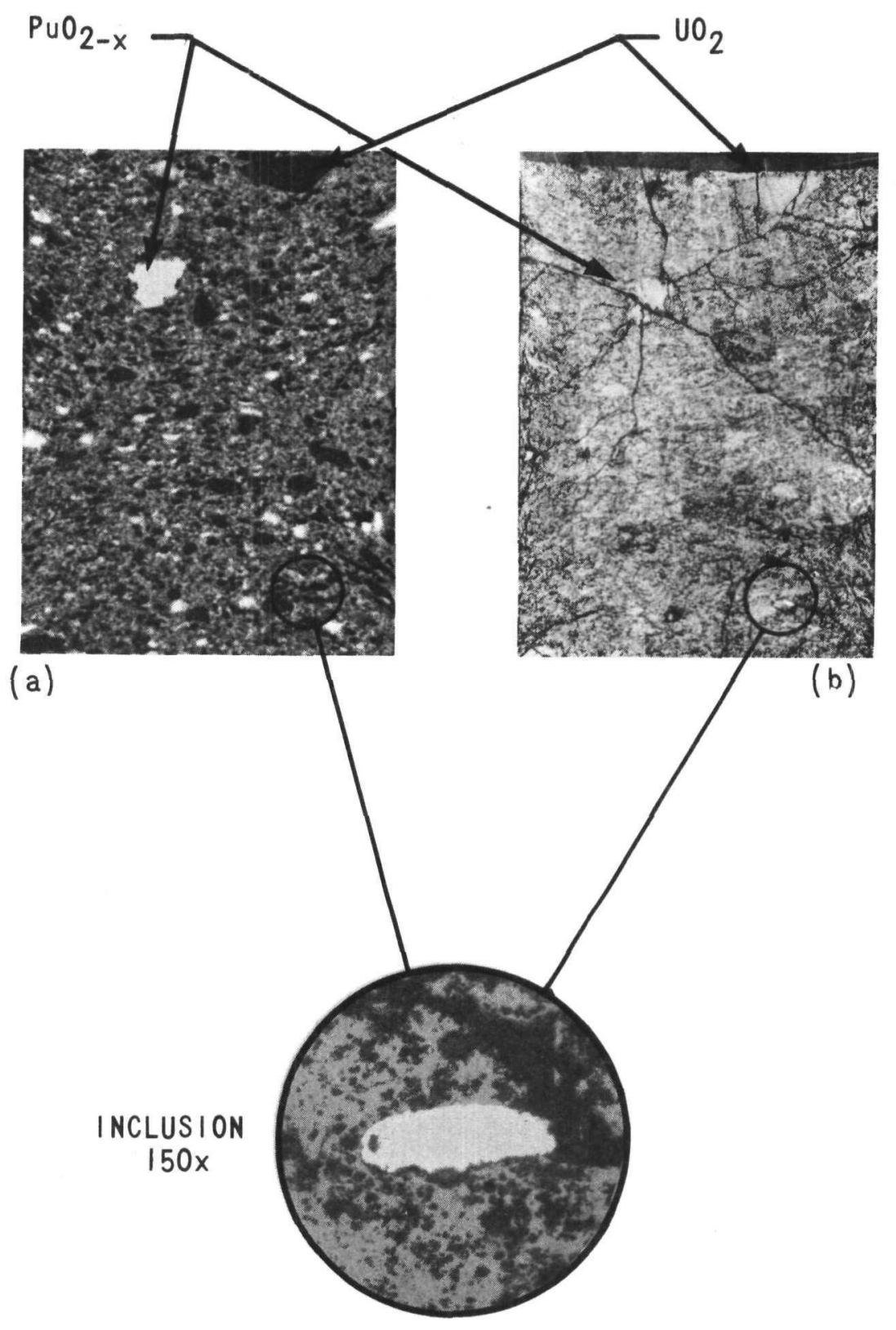

Figure 12-7. (a) is an Autoradiograph and (b) is a Photomicrograph of the Same Sintered $(\mathrm{U}, \mathrm{Pu}) \mathrm{O}_{2}$ Pellet Surface (Mag 10X)

$3679-72$ 
SECIION 13

UFBA-512. FUEL ELEMEHT PABRICATTON

R, C Deklever, W. R, Sacoby, K, K, MoGeary, and D. P. 3hapland

\section{OB.JECTIVES}

The princlpal objectives of this task are to:

1. Fabricate and haracterize the required fue: ins and capsules needed for two 19-pin assemblies for irradidelon sesting.

2. Complete the fuel pins for a $37-p 1 n$ fuel assembly for irradiation testing.

3. Froduce and "akinte pins containing axial fuel motion restrictors. These restidctors will be rlgidly flxed to the cladding by crimping the cindis $s$ into a circumferential groove in the restrictor discs which axe located within the cladding and serve to compartmentalize the fuel pellets.

4. Adapt methous for xenon tagging of oxide $z^{j}$ is and to fabricate pins Cortaflini the xemu gas.

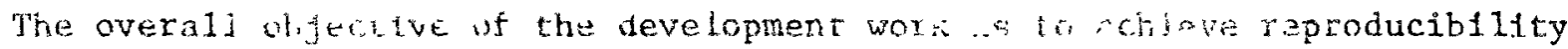
and reliability of operations required to fabrefer. ond shacterize irradiacion rest fise] pins.

PRIOR WORK

Fabrication of the 19-pin subassembly fuel rodo (djA-2) was fin progress. Al1 plenum and end welds were completed in preparation ror the final connector weld. The profilometer for pin characterization was constructed. Adaptations to the glove box was made for crimping axial spactexs in fuel rods.

CURRENT PROGRESS

Vo1. Deployne Et Irrad! at1 on Assemb11es (WSA-1, WSA-2)

\section{Process}

All developwent work on the three-foot long fuel pins with center connector plugs has been completed. The connector plug was the cause of considerable difficulty durling fabrication as a result of distortion during welding. Siace distortion or loss of pin straightress could not be 
prevented, it was necessary to develop techniques for straightening the pins within specification. Welding procedures were qualified, which now produce a high probability of adequate fuel pin closure welds. Characterization, quality control, and working procedures were formalized and used in the actual fabrication and acceptance of WSA-2 capsules. The 19 WSA-2 encapsulated pins were shipped to EBR-II in February 1970 and are currently in the reactor (see OFBA-310, Section 6).

The process steps used in the fabrication of these capsules are outlined in Figure 13-1. The individual operations for fabricating the finished product, are shown in Table 13-1. Construction of the fission gas plenum chambers is a separate clean operation; the complete pin is produced by a single circumferential weld conducted in a weld box joining the active fuel pin to the plenum chamber.

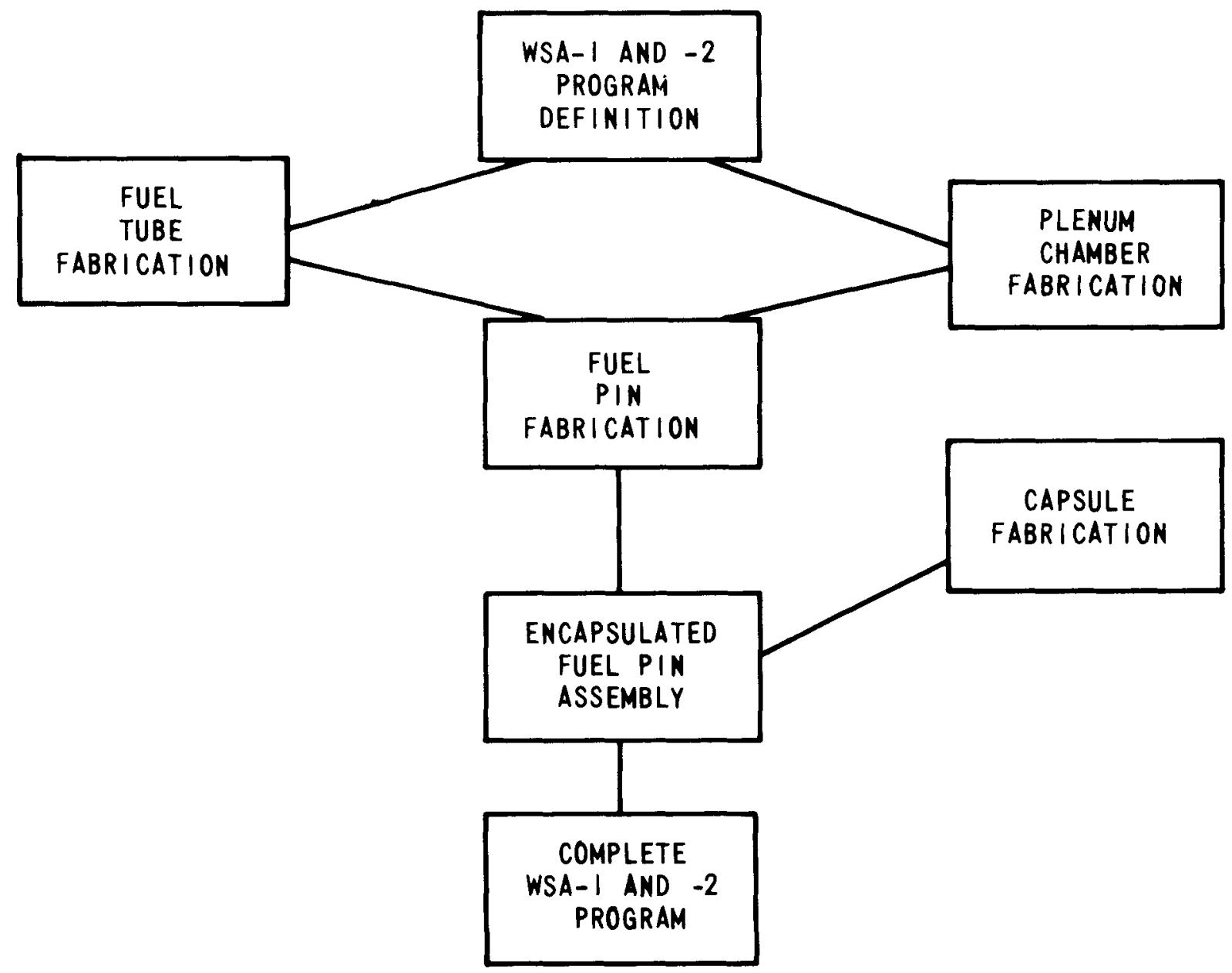

Figuid 13-1. Overal1 Progiam Process Flow Diagram for WSA-1 AND WSA-2 $3679-73$ 
Table 13-1. Fabrication Process Steps for WSA-2

\section{Fuel Tube Fabrication}
a. Machine and inspect tubing length
b. Fiducial mark and inspect tube
c. Receive weld plugs, inspect
d. Clean components
e. Weld bottom end plug to fuel tube
f. Radiograph, leak test, dye check weld
g. Dimensional inspect and upgrade
h. Receive fuel and insulator pellets
i. Weigh and dimensional inspect pellets
$j$. Computer sorting of pellet data
$k$. Select fuel and insulator pellets
1. Load fuel and insulator pellets
m. Decontaminate fuel pin
n. Upgrade and store

II. Plenum Chamber Fabrication
a. Machine and inspect tubing length
b. Receive top and connector plugs inspect
c. Clean components
d. Weld top plug to plenum tube
e. Radiograph, leak test, dye check welds
f. Dimensional inspect and upgrade
g. Weld connector plug to plenum tube
h. Radiograph, leak test, dye check welds
i. Straighten, and dimensionally inspect
j. Upgrade and store

\section{Fuel Pin Assembly}

a. Receive upgraded components

b. Selectively match plenum tube assembly to fuel tube assembly

c. Load spring and spacer disk, press assemblies

d. Weld plenum tube assembly to fuel tube assembly in Helium

e. Radiograph, leak test, dve check welds

f. Straighten and simensionally inspect

g. Profilometry of fuel tube

h. Final dimensional inspection

i. Final cleaning

j. Upgrade

$k$. Store for encapsulation

IV. Encapsulation

a. Receive tubing and end plugs from ANL

b. Machine tubing and bottom end plugs to length

c. Inspect, upgrade, clean components

d. Weld bottom end plug to capsule tube

e. Radiograph, leak test, dye check welds

f. Load sodium, seat fuel pin

g. Weld top plug to capsule tube

h. Radiograph, leak test, dve check welds

i. Sodium bond fuel pin to capsule

j. Eddy current test sodium bond

k. Fu1l length radiograph

1. Final inspection

m. Final polish and cleaning

n. Certify for shipment to F.BR II site o. Load and ship 


\section{Spacer Disc Crimping}

A final modification of the spacer disc configuration, shown in Figure 13-2 required further 1sostatic crimping trials. Initial tests were run using 0.198-inch OD discs in 0.200-inch ID $x$ 0.0125-1nch wal1, Type 316 stainless steel solution annealed tubing. These trials were to determine a satisfactory crimping pressure. Isostatic pressure was applied by a hydraulic ram using urethane as a force transmitting medium.

In Figure 13-3 the amount of intimate contact between deformed cladding tube and disc at various crimping pressures is estimated. Clearances were measured from radiographs. Any clearance at any point on the cylindrical disc lands that was less than 0.0015 -inch was considered by definition to be a "heat transfer surface." On the V-groove, areas with clearances less than 0.0010 inch were considered available for heat transfer. Adding the two contributions and subtracting from the total disc-to-tube surface area gives the percentage of available heat transfer surface plotted.

Metallographic and radlographic measurements of the center hole were used to measure the deformation of the disc caused by high crimping pressures. Thus, a practical upper crimping pressure limit was determined. The two curves plotted in Figure 13-3 were used to determine the optimum crimping stress of 33,000 psi, which appears to be fust in excess of the yield point of the tubing metal, but below the stress that would cause deformation of the discs.

To test the strength of the crimps, push-out tests were run on $0.200-$ inch ID $\mathrm{x} 0.0125$-inch wall, and 0.223-inch ID x 0.0125-inch wall 316 stainless steel solution annealed tubing with discs crimped in place. Figure 13-4 shows an average of three profiles of the axial stress at room temperature required to dislodge the discs. A test was also run at $600^{\circ} \mathrm{F}$, but the unsupported tube buckled under load so that test results were ambiguous.

Fuel pins WSA-1-16S, $-17 \mathrm{~S},-18 \mathrm{~S},-19 \mathrm{~S}$, have been fabricated using equipment shown in Figure 13-5. The tube extension of the udder bag is attached to the fuel tube. The fuel is loaded from the box through the udder bag into the fuel tube. The spacer discs are inserted from the box into the fuel tube using a special tool which accurately positions the disc in the fuel tube. The fuel tube is then inserted into the crimping fixtures and positioned such that the crimping action will occur over the spacer disc.

Figure 13-6 shows the bottom half of the crimping die. The slot in the center of the die contains the urethane force transmitting medium.

\section{Welding Qualification Results}

Prior to fabrication of WSA-1 and WSA-2 void deployment fuel pins, a welding qualification program was performed for welds deslgnated as (1), (2), (3), and (4) as shown in Figure 13-7. In addition to the fuel pin weld qualifications, the top end fitting for the capsule was of a new design and required development of welding techniques. The capsule top end fitting has a weld joint design originated by EBR-II personnel. 


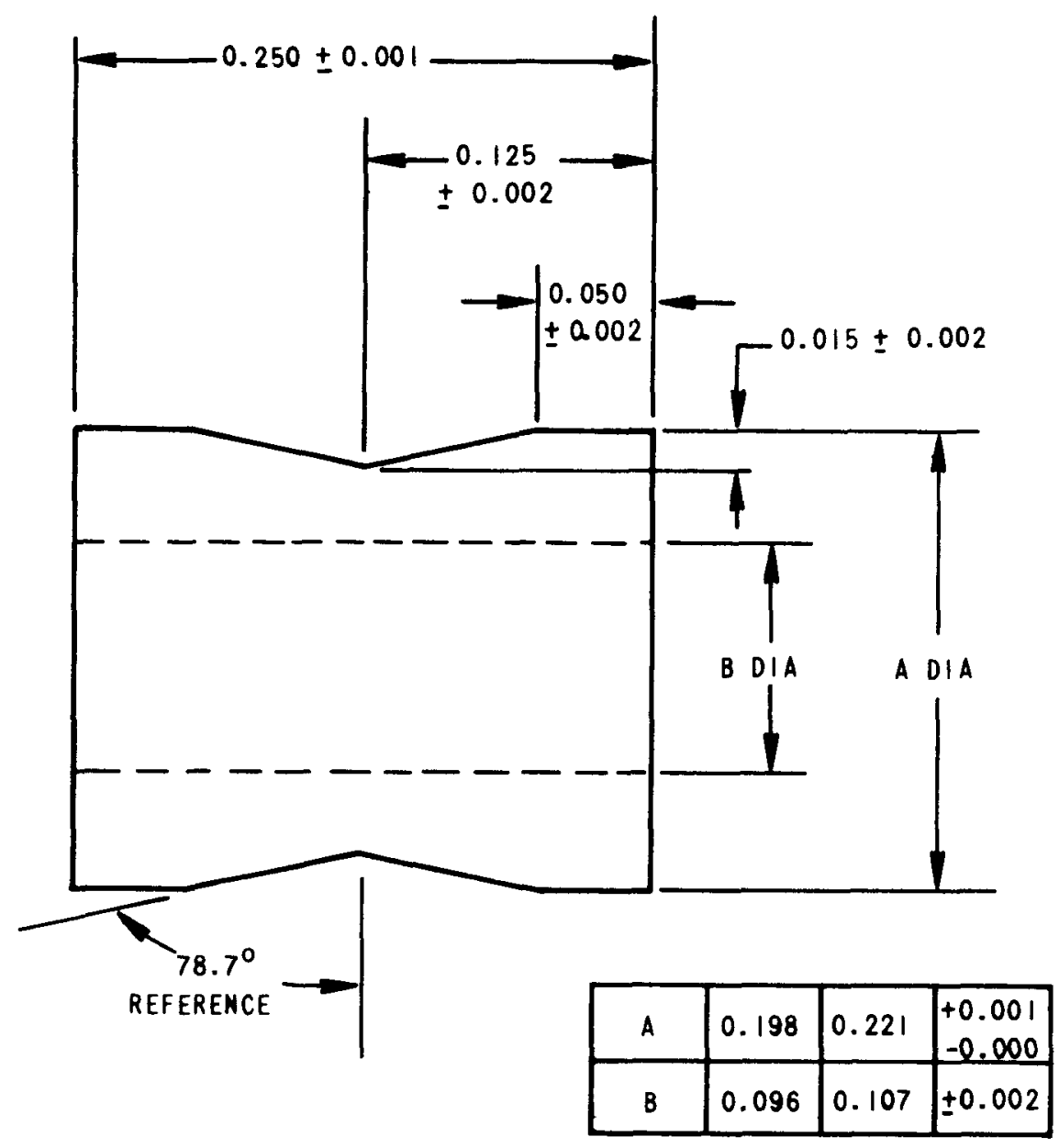

MATERIAL: TYPE 304 STAINLESS STEEL

Figure 13-2. Final Fuel-motion Restrictor Dise Configuration $3679-74$ 


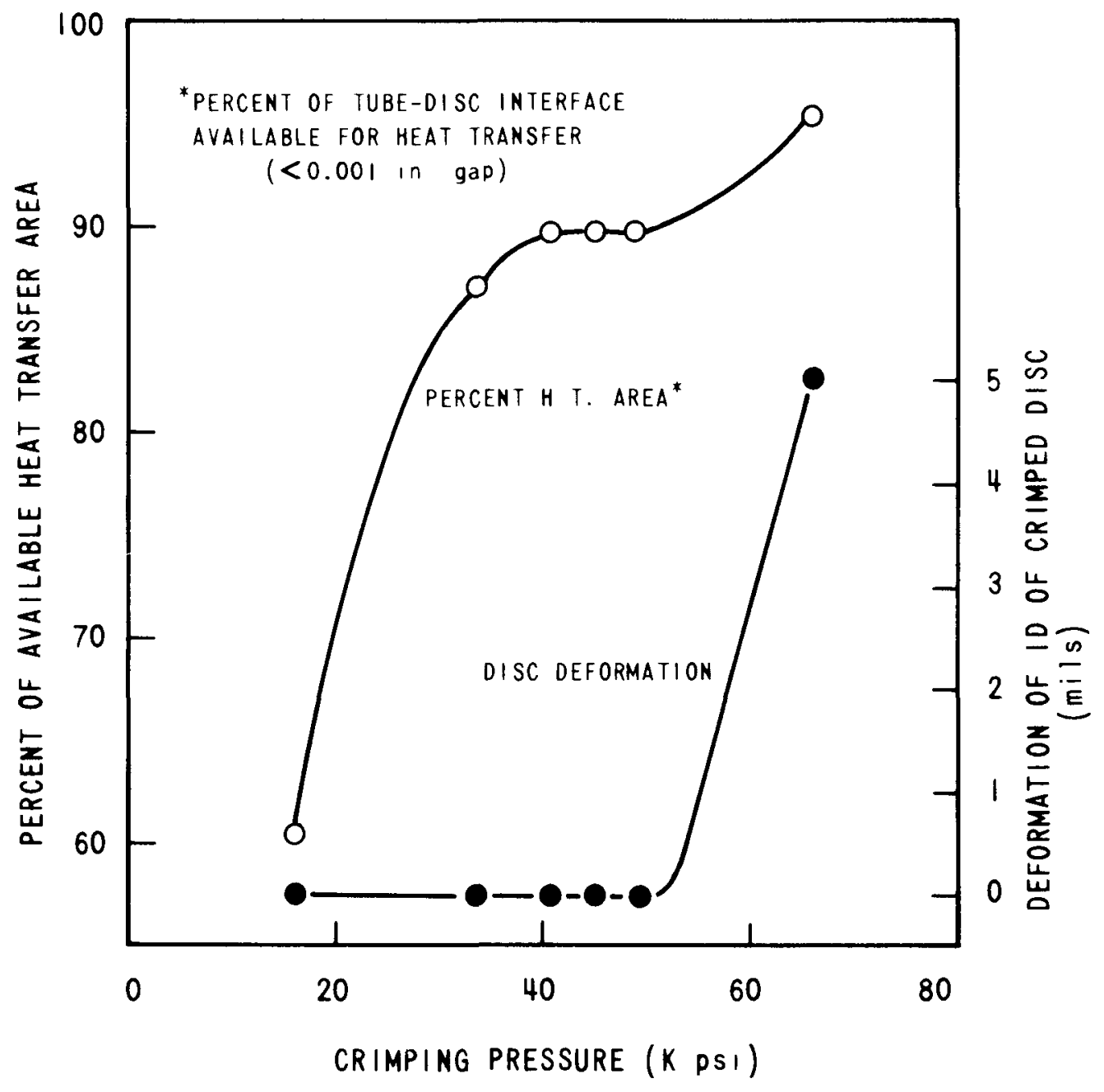

Figure 13-3. Peicent Avalable Heat Transfer Area* and Centerholc Deformat 1 on Obtained at Varrous Crimping Pressures

$3679-75$ 


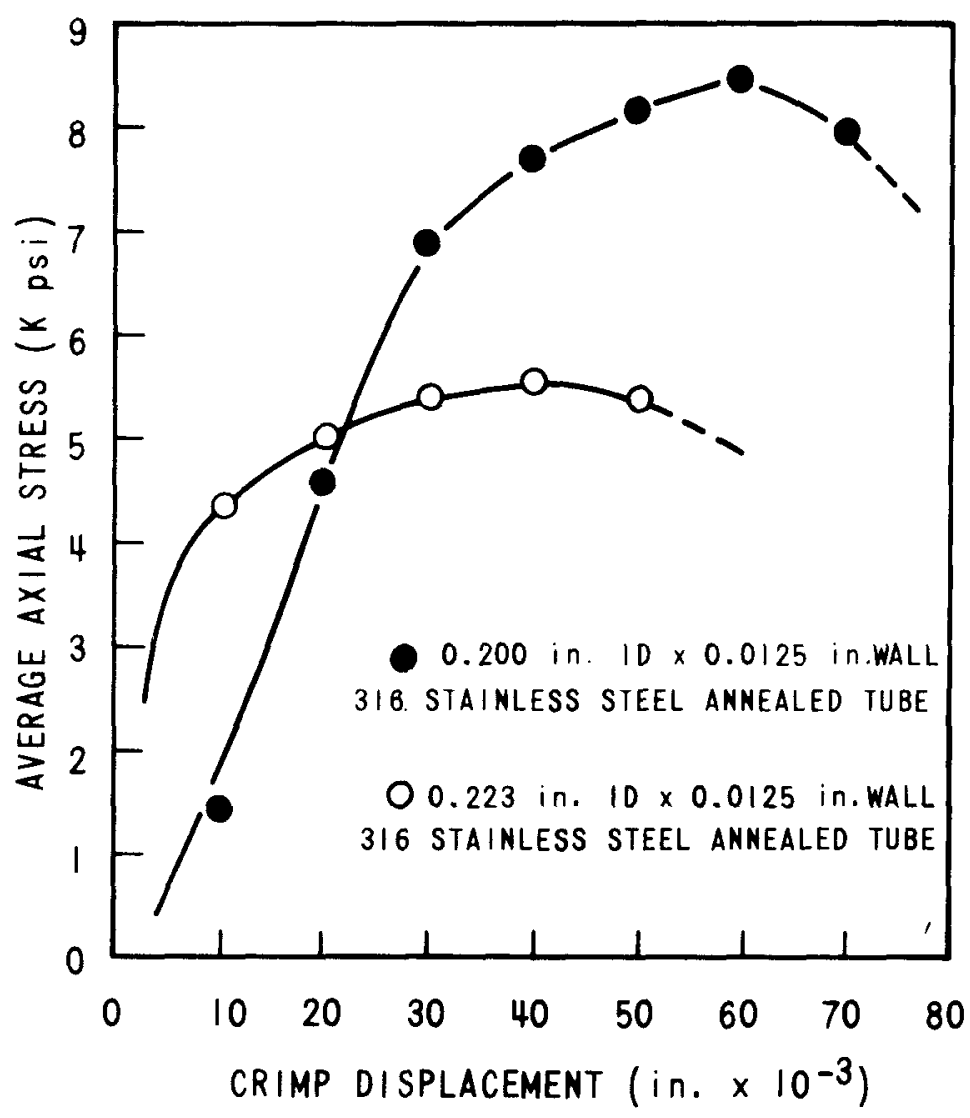

Figure 13-4. Average Applied Axial Stress to Cause Crimp Displacement

$3679-76$

A practical welding evaluation program was applied to each significantly different weld joint on the fuel pin. All circumferential welds were performed in a welding chamber backfilled with Grade A helium. The Merrick Model TCR-300 DC power supply with a high capacitance energy discharge arc starter was used. Welding current and voltage were traced with a model S602R dual channel Esterline Angus recorder. A fixed electrode-towork distance ( 0.013 inch) was used for all fuel pin welds utilizing a seasoned 0.040-inch diameter, two-percent thoriated tungsten electrode.

Figure 13-8 illustrates the weld joint design used for weld (1) and the four distinct welding current profiles evaluated. Radiographic results of the resulting welds indicated some localized $\left(\sim 30-60^{\circ}\right.$ of the circumference) internal solidification voids occurring in samples welded using Mode A. All welds using Modes $B, C$, and $D$ revealed acceptable radiographic results. Although Mode A induced internal weld defects, the resulting physical characteristics such as relative deflection (T.I.R.) between tube and end fitting and average diameterfcal weld metal build-up were the best. Mode $B$ was selected for welding fuel tube end plugs. Although the parameters qualified were proven suitable for 0.0125 -inch and 0.015 -inch wall tubing, only 0.010 -inch wal1, 20-percent cold worked Type 316 stainless steel 


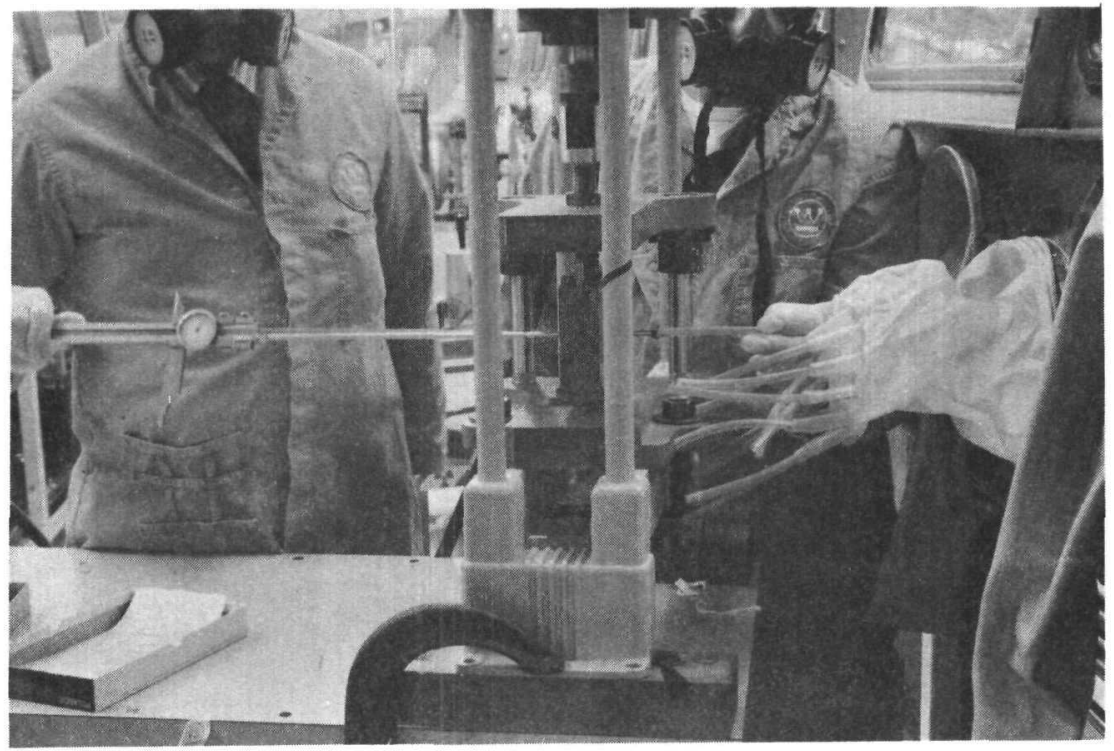

Figure 13-5. Crimping Press with Fuel Tube Connected to Loading-Tube Extension of Udder Bag

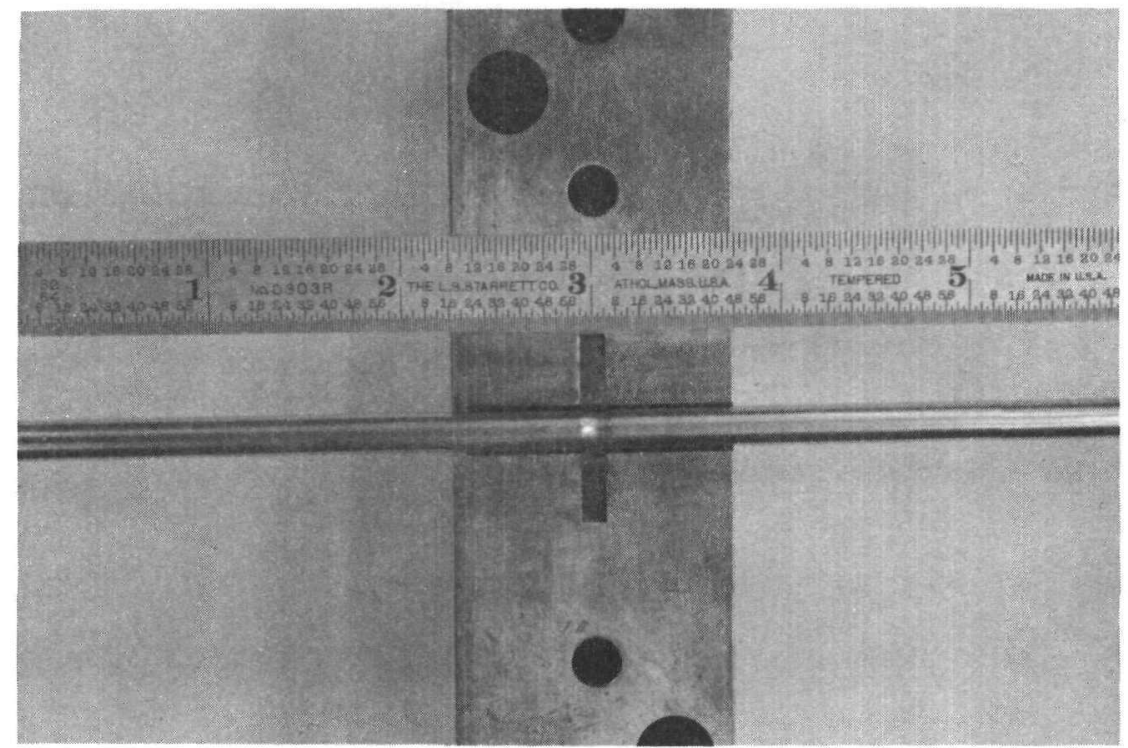

Figure 13-6. Bottom Half of Crimping Die Block Showing Slot Filled with Urethane Compression Medium and with $3679-77$ a Crimped Tube in Position 
1. $\mathrm{UO}_{2}-\mathrm{PuO}_{2}$ FUEL PELLETS

2. 316 SS CLADDING

3316 SS TOP END PLUG

4. 316 SS BOTTOM END PLUG

5. $\mathrm{UO}_{2}$ INSULATOR PELLETS

6. 304 SS HOLD DOWN DISC

7. INCONEL $X 750$ SPRING

8. 316 SS CONMECTING PLUG

9. 316 SS PLENUM TUBE
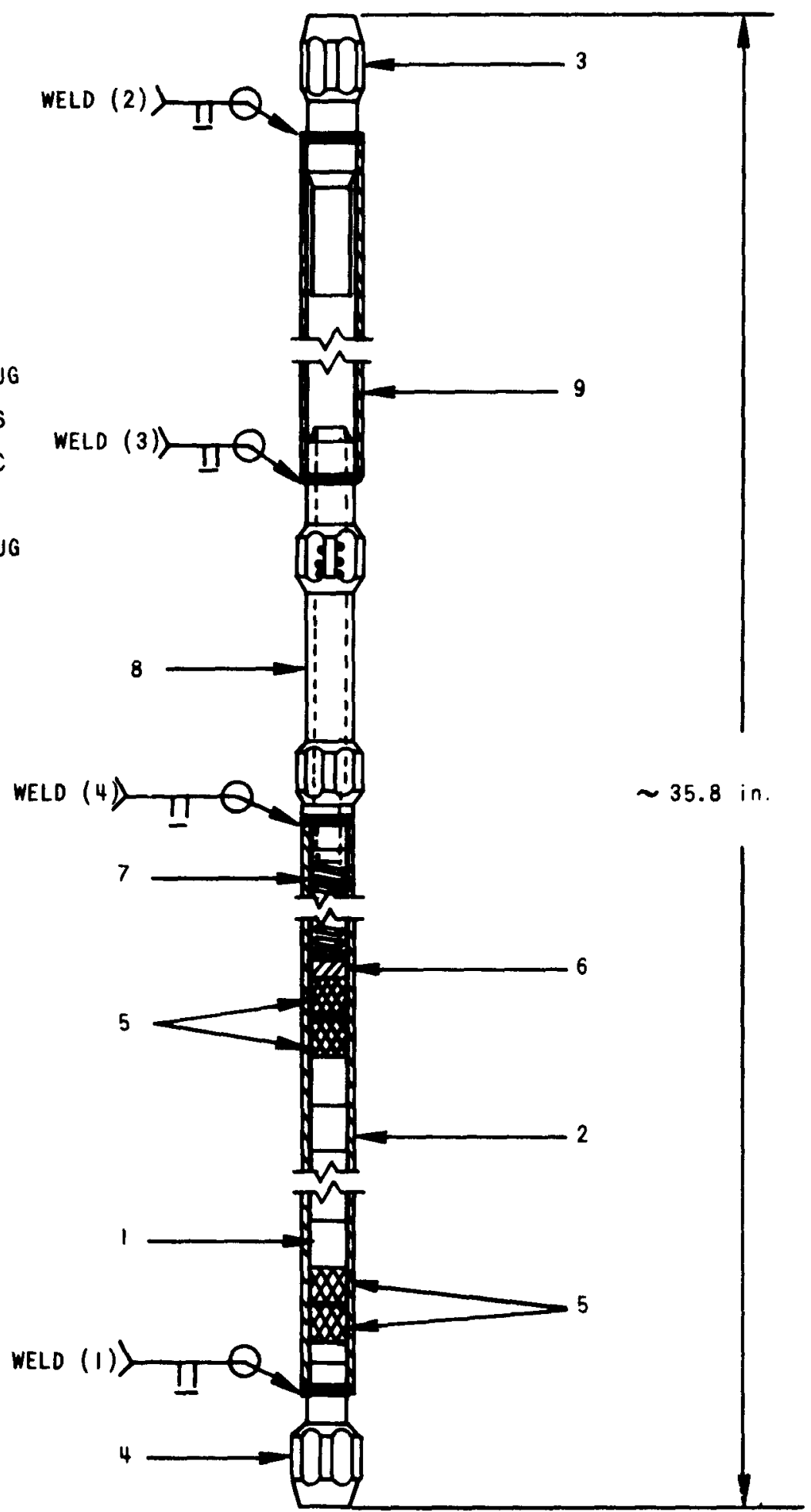

Figure 13-7. Void Deployment Irradiation Test Fuel Pin 

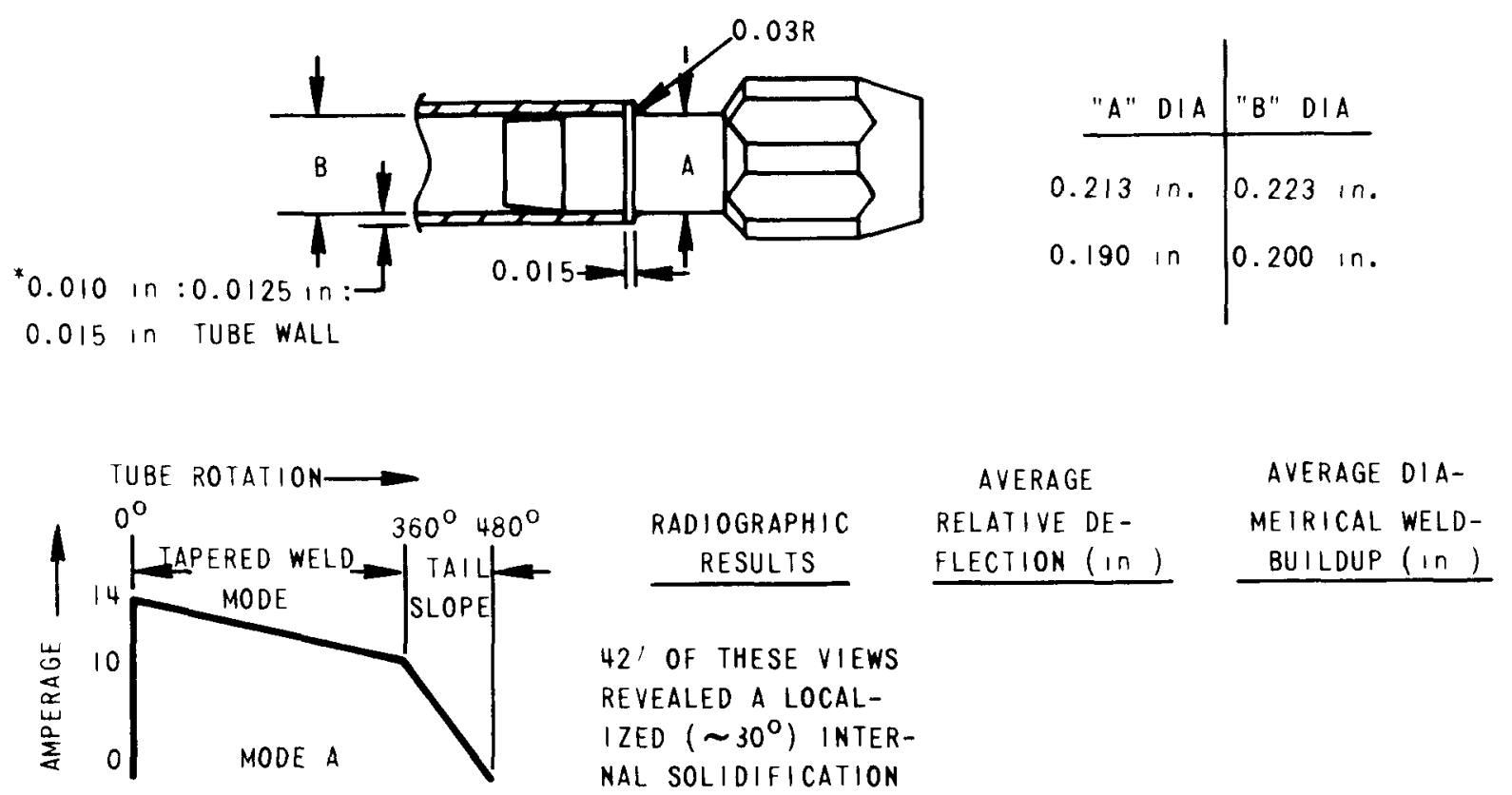

42' OF THESE VIEWS

REVEALED A LOCAL-

IZED $\left(\sim 30^{\circ}\right)$ INTER-

NAL SOLIDIFICATION

$\begin{array}{lll}\text { VOID } & 0.002 & 0.003\end{array}$
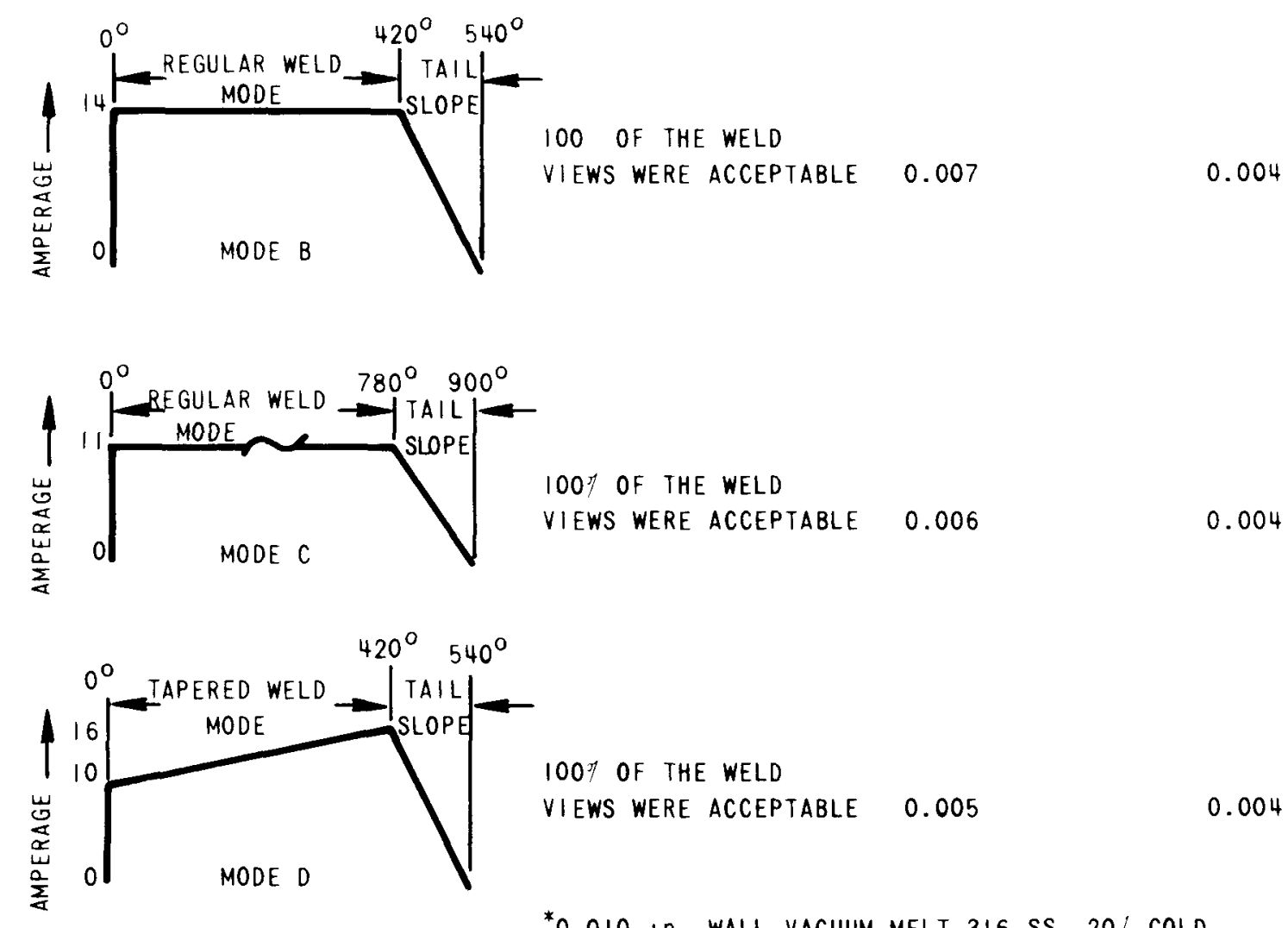

100\% OF THE WELD
VIEWS WERE ACCEPTABLE 0.005

$\begin{array}{ll} & * 0.010 \text { in WALL VACUUM MELT } 316 \text { SS. } 20 / \text { COLD } \\ \text { WELDING CURRENT PROFILE } & \text { WORKED TUBING USED FOR WELD QUALIFICATIONS }\end{array}$

Figuir 13-8. Summaty of Wolding Study Performed on Bottom End Plug to Fuel Tube (1)

$3679-79$ 

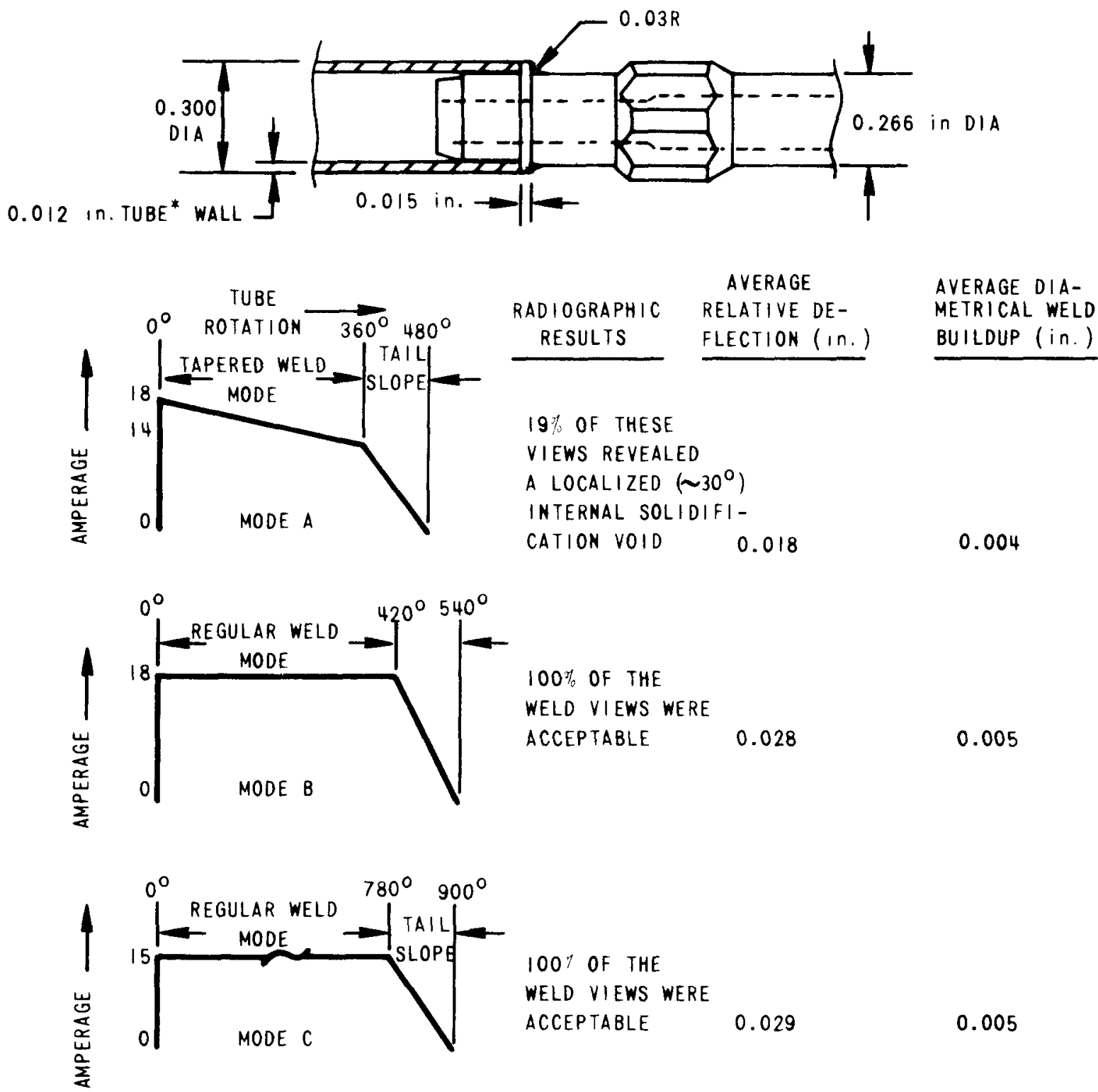

$19 \%$ OF THESE

VIEWS REVEALED

A LOCALIZED $\left(\sim 30^{\circ}\right)$

INTERNAL SOLIDIFI-

CATION VOID

0.018

0.004

WELD VIEWS WERE

CCEPTABLE

ACCEPTABLE $\quad 0.029$

0.005

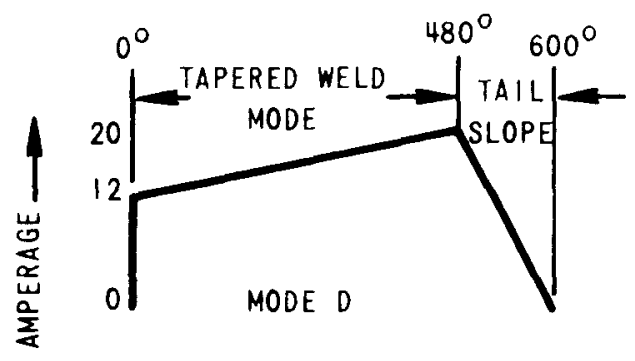

WELDING CURRENT PROFILE
100\% OF THE

WELD VIEWS WERE

ACCEPTABLE

0.019

0.004 *air melt 316 ss solution

ANNEALED TUBING

Figure 13-9. Summary of Welding Study Performed on Top End Plug (2) and Connector Plug (3) to Plenum Tube

$3679-80$ 


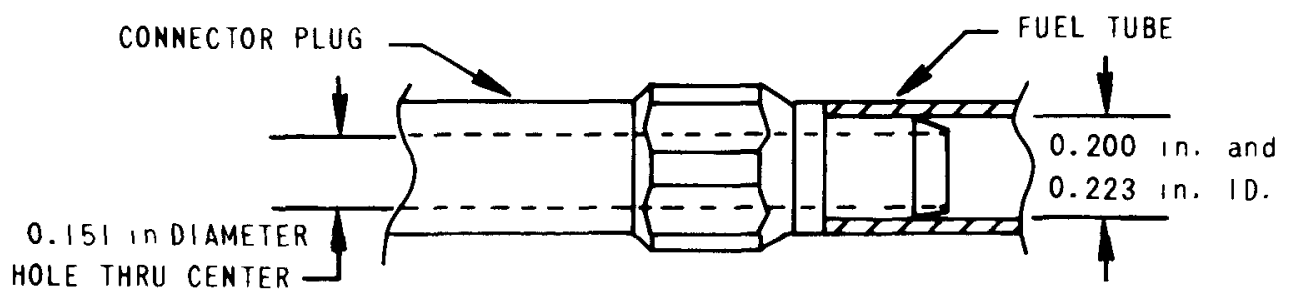

OF CONNECTOR PLUG
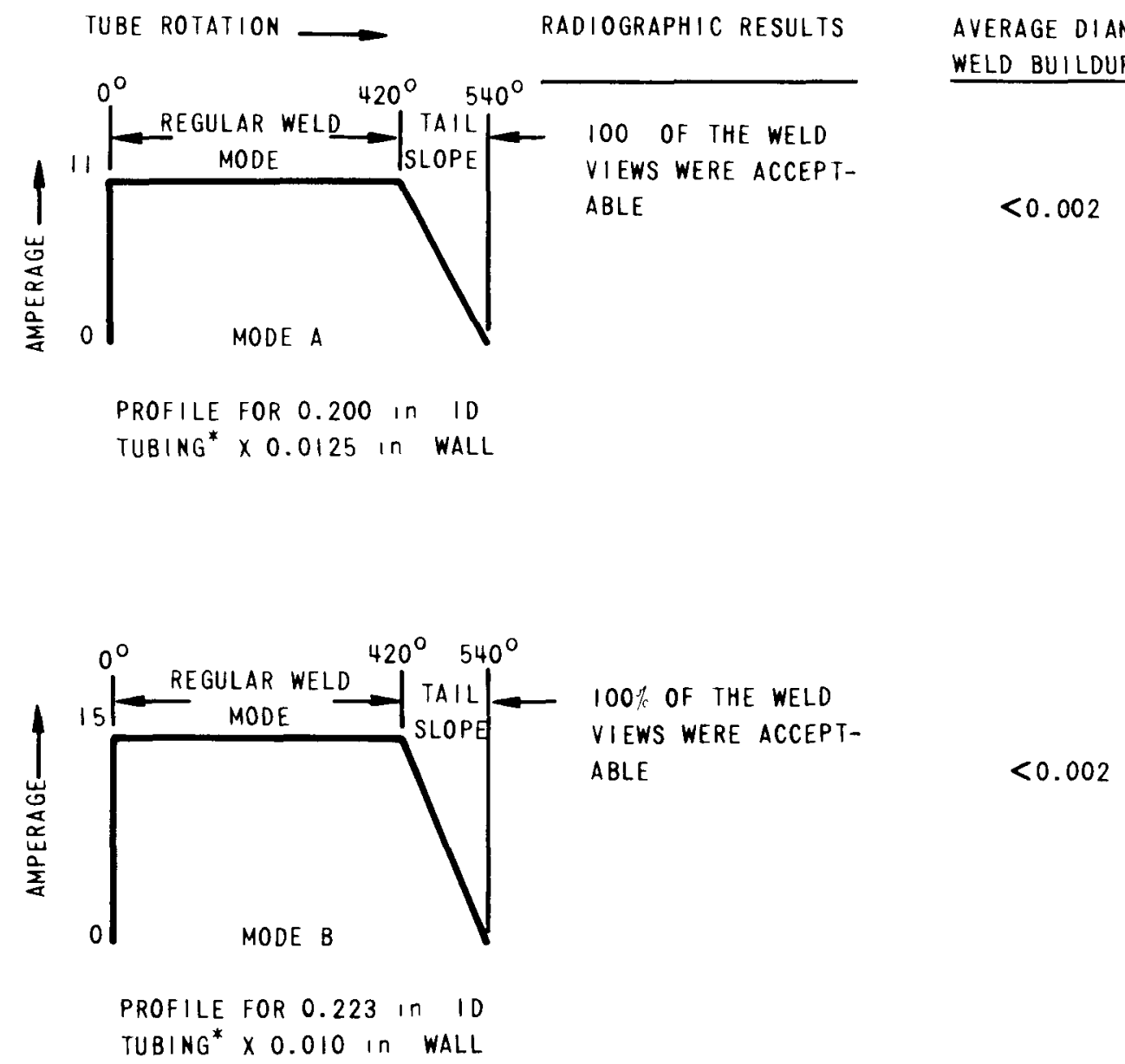

WELDING CURRENT PROFILE "VACUUM MELT 316 SS, $20 \%$ COLD WORKED TUBING

Figure 13-10. Summary of Welding Study Peitormed on Fuel Tube to Connector Plug (4)

$3679-81$ 
tubing was used for all qualification welds, since the thin wall tubing is more susceptible to internal solidification voids.

Figure 13-9 illustrates the same basic approach as above except for a change in welding current. This study was applied to welds (2) and (3) shown in Figure 13-7. Radiographic examination, relative "as welded" distortion, and diametrical weld buildup results all revealed similar trends relative to weld (1). Again, Mode B was selected for use in welding the plenum chambers.

Figure 13-10 illustrates results from the final weld closure, joining the plenum chamber to the fuel tube. Previous experience using the tapered weld mode revealed some localized internal weld defects; therefore, the regular weld mode was qualified and used for the final fuel pin closure weld.

Samples processed through metallography all revealed acceptable weld penetration. In some cases mixing within the "as cast" weld metal was delineated sharply by a difference in the heterogeneous nucleation of a second phase within the dendritic structure. Differences in the size of dendrites appearing in the "as cast" structure of the tubing material could be detected. The plenum tubing was air melted material while the fuel tubing came from double vacuum melted stock. Figure 13-11 is a photomicrograph of

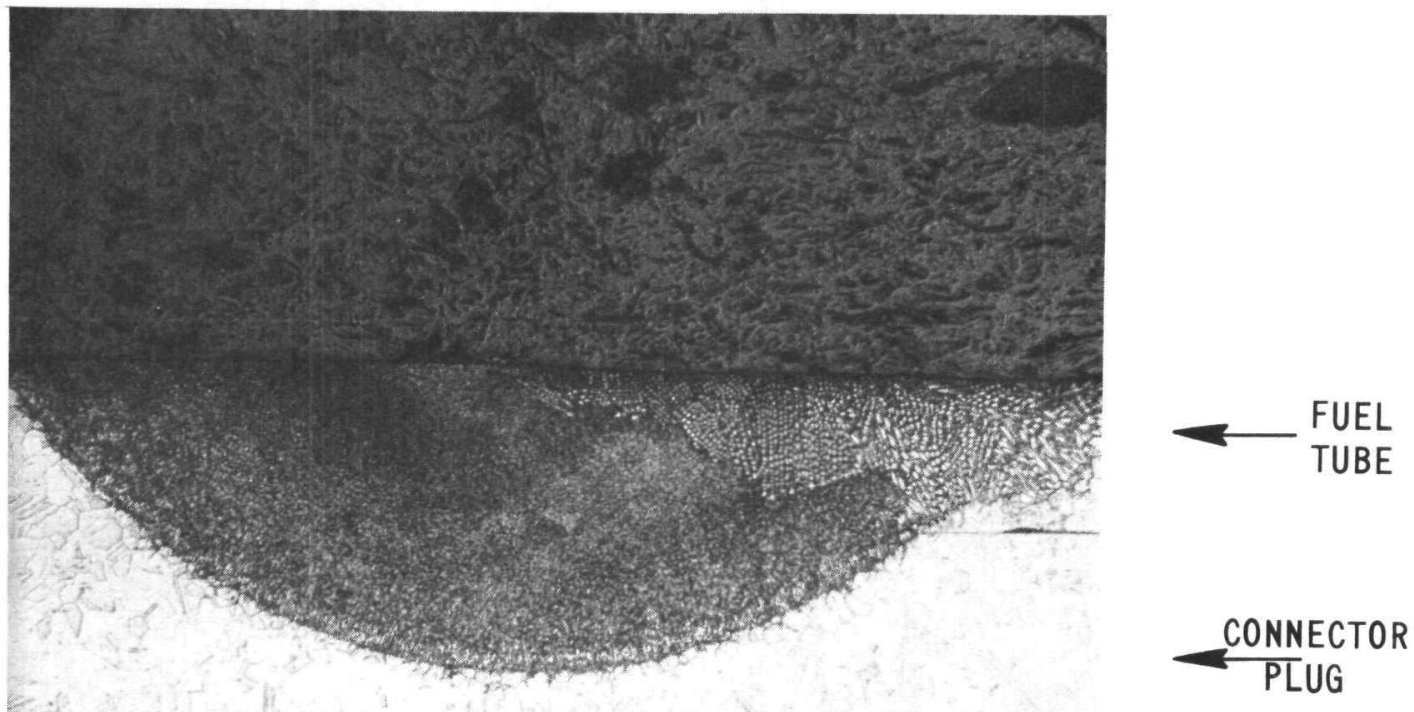

Figure 13-11. Final Closure Weld Nugget (4) Illustrating Mixing of 3679-83 Austenite and Austenite + Delta Ferrite Phases (Mag.65X) 
a weld nugget joining a 0.010-inch wall, 20-percent cold worked fuel tube to a connector plug which is from air melted bar stock. The demarcation between the single-phase austenite and two-phase austenite plus delta ferrite region is evident.

\section{Fuel Pin Welding}

Upon completion of the welding qualification program, the parameters discussed above were applied to the four circumferential welds required for fabrication of the fuel pin. Minor problems encountered during fabrication were straightening the plenum chamber assembly before and after making the final fuel pin closure weld (4) and small blow holes and electrode pickup in the weld puddle due to short electrode to work distances. These factors affecting weld quality were influenced primarily by excessive eccentric rotation during welding and upward deflection of components caused by weld metal solidification and subsequent shrinkage during the weld pass. Straightening of "as welded" deflection between plenum and fuel tube sections was made within the reduced diameter region of the connection plug.

\section{Capsule End Fitting Welding}

The top and bottom capsule end fitting welds were qualified by acceptable nondestructive and destructive inspection results which complied with requirements in the Guide for Irradiation Experiments in EBR-II. The top end fitting consisted of the latest EBR-II weld joint design which has a reduced groove depth ( 0.003 inch - 0.005 inch) relative to the previous design which had a nominal groove depth of 0.020 inch. No problems were encountered during welding with this new joint design. The welding qualification procedure and welding procedure for the capsule end fitting welds were submitted, along with radiographic and metallographic results of the qualification welds. Four representative sample welds--two each of the top and bottom end fittings with 12 inches of capsule tubing attached--were submitted to EBR-II.

WSA-3 Assemb 1y

Fabrication of 37 pins approximately five feet long for use in a grid assembly for EBR-II irradiation testing is scheduled to start about May 1 , 1970. Development work is now under way, particularly in the areas of xenon tagging and new equipment organization and checkout. The major new equipment item is a weld box in the WARD Plutonium Oxide Laboratory. This box has recently become operational and work is under way to evaluate its capabilities.

\section{Xenon Tagging}

A review and evaluation of existing xenon tagging procedures used at BNW and ANL has resulted in the decision to use an evacuate-backfil1 concept. This technique will be used to introduce a predictable amount of a unique 
isotopic mixture of xenon tag gas to the hellum bond gas in unencapsulated irradiation test fuel pins for testing in EBR-II. Based on the vold volume avallable within the fuel pin, a mixture of 11.3 volume percent xenon in helium will be required for a nominal addition of $1 \mathrm{ml}$. of xenon tag gas to each fuel pin. The xenon tagging apparatus is presently being fabricated according to the general design illustrated in Figure 13-12. A basic premise considered in the design of this system was to minimize total internal volume, thus minimizing gas losses at the end of processing each batch of fuel pins. Several cylinders of 11.3 volume percent xenon in helfum are presently on order. Work planned for the next quarter will be to develop tagging procedures by running mockup fuel pins through welding and subsequent quantitative analysis of xenon by mass spectrometry. Section IX entitled "Xenon Tagging Procedures and Requirements" in the Guide for Irradiation Experiments in EBR-II will be used as a guide for developing acceptable tagging procedures. 


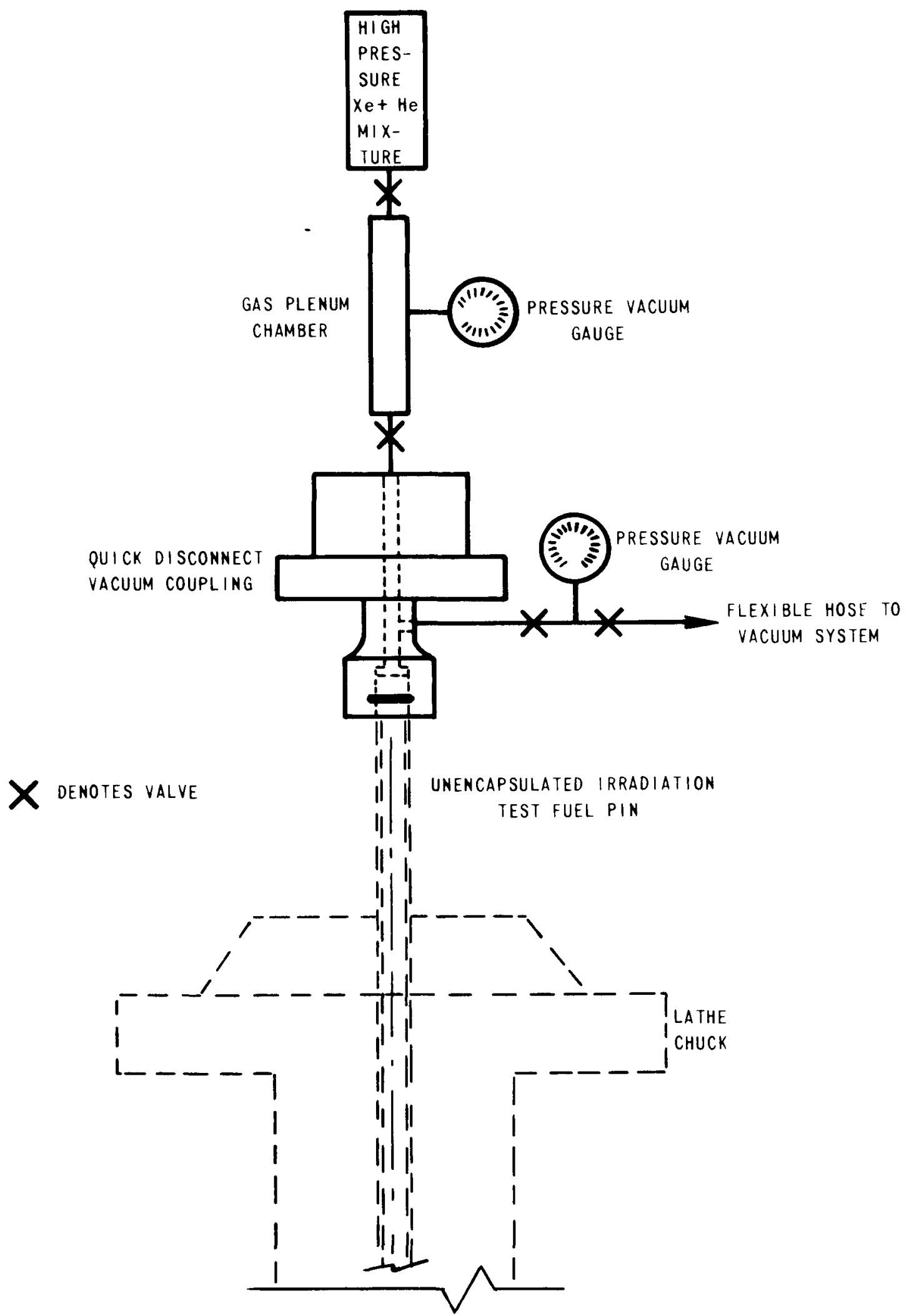

Figure 13-12. Apparatus tor Xenon Tagging Unencapsulated Irradiation Tost Fuel Pins $3679-82$ 


\section{SECTION 14}

\section{OFBA-513 PRODUCT CONTROL AND DOCUMENTATION}

W. B. Bargerstock, W. R. Jacoby, and R. K. McGeary

\section{OBJECTIVES}

The objective is to provide quality control for the entire program from raw material acceptance to final product verification. Included is responsibility for documentation of all data and information needed for final records from all phases of fabrication and material handling.

During FY-1970 at least 79-irradiation pins are required: two 19-pin encapsulated assemblies and the first 37-pin assembly. In addition, detailed records will be required for prototype pins, test pins, encapsulated samples, and library samples. Data for more than 3,000 pellets will be keypunched and processed.

\section{PRIOR WORK}

The computer control handling of accountability, record storage, and pellet computations was developed. Product control and documentation for the WSA-2 assembly was initiated.

\section{CURRENT PROGRESS}

The computer program for pellet data handling was used to classify 3443 pellets according to diameter, length, weight, pellet density, and smear density, to establish standard deviations and to sort and list these parameters in various appropriate ways. Three uranium enrichments (93, 65, and $43 \%$ ), five diameters, and three densities were handled.

Forms and procedures for product control have been established and were used satisfactorily during fabrication of the WSA-2 assembly and presently for the WSA-1 assembly.

A complete data package was complled for the WSA-2 assembly and this was submitted to the Fuel Irradiation Project Group. Information was in such form that pertinent data could be extracted by this group and sent to EBR-II personnel for experiment approval. These functions are continuing in a routine manner for the WSA-1 and WSA-3 assemblies. 
1. T. D. Gulden and J. L. Kaae, "On the Driving Forces for Pore Growth and Swelling Irradiation," Journal of Nuclear Materlals 32, pp. 168-170 (1969).

2. "Guide for Irradiation Experiments in EBR-II," Revision 3, July 1969, EBR-II Project, Argonne National Laboratory, Argonne, Illinols.

3. H. C. Paxton, J. T. Thomas, Dixon Callihan, and E. B. Johnson, "Critica1 Dimensions of Systems Containing $\mathrm{U}^{235}, \mathrm{Pu}^{239}$, and $\mathrm{U}^{233}, "$ TID-7028, June 1964.

4. "Oxide Fuel Element Development Quarterly Progress Report for the Period Ending December 31, 1969," WARD-4135-4, February 1970.

5. "Evaluation of Compliant Grid-Type Fuel Rod Spacers for FTR Fuel Assembly," WARD-3684-5, November 1968.

6. "Reactor Development Program, Progress Report, January 1968," ANL-7419, February 1968.

7. G. A. Ratz and K. G. Brickner, "Effect of Liquid Sodium on Welded AISI Type 304 Stainless-Stee1 Pipe," Nuclear Applications, V. 4, March 1968, Pp. 154-158.

8. E. E. Hoffman, et a1., "An Evaluation of the Corrosion and Oxidation Resistance of High-Temperature Brazing Alloys, July 1954-September 1955," ORNL-1934, November 1956.

9. S. K. Lee, "An Investigation of Nickel-Base Brazing Alloys and Brazed Joints," NAA-Sr-11325, December 1965.

10. A. W. Thorley and C. Tyzack, "The Corrosion Behavior of Iron and NickelBase Alloys in High-Temperature Sodium" Alkali Metal Coolants Symposium, Vienna, 1966.

11. M. Soenen, "Compatibility of Different Brazing Alloys During Long TimeExposure in Sodium Loop," in "Proceedings of the Symposium on Alkal1 Metal Coolant, International Atomic Energy Agency, Vienna, November 28December 2, 1966," Paper SM-85/2, pp. 391-414.

12. "Oxide Fuel Element Development Quarterly Progress Report for the Perlod Ending December 31, 1969," WARD-4135-4, February 1970.

13. C. E. Plucinsk1, Battelle-Northwest Laboratorles, personal communication.

14. W. H. Pech1n, "Analytical Chemistry In Fuels and Materials Development Program," ORNL-4520, Quarterly Progress Report for the Perlod Ending December 31, 1969. 
15. W. M. McNeill, Westinghouse Nuclear Fuels Division, personal communication.

16. A. Biancheria, Westinghouse Advanced Reactors Division, personal communication.

17. B. Riley, "High Temperature Oxygen Equilibrium in the Plutonium-Oxygen System," a paper presented at the International Conference on Science of Ceramics, Ronneby Brunn, Sweden, April 20-23, 1969. 


\section{U. S. ATOMIC ENERGY COMMISSION}

Division of Reactor Development and Technology

Washington, D. C. 20545

Assistant Director, Engineering Standards

Assistant D1rector, Nuclear Safety

Assistant Director, Plant Engineering

Assistant Director, Program Analysis

Assistant Director, Project Management (2)

Assistant Director, Reactor Englneering (2)

Assistant Director, Reactor Technology

Chief, Coolant Chemistry Branch

Chief, Fuels and Materials Branch (3)

Chief, Fuel Engineering Branch

Chief, Reactor Vessels Branch

Division of Naval Reactors

Chief, Nuclear Materials Branch

United States Atomic Energy Commission

Washington, D. C. 20545

New York Operations Office

Manager (2)

U. S. Atomic Energy Commission

376 Hudson Street

New York, New York 10014

Division of Technical Information Extension (3)* (50)**

United States Atomic Energy Commission

P. 0. Box 62

Oak Ridge, Tennessee 37831

Office of Assistant General Council for Patents

U. S. Atomic Energy Commission

Washington, D. C. 20545

Assistant Director Pacific Northwest Laboratory

U. S. Atomic Energy Commission

P. O. Box 550

Richland, Washington 99352

* Submitted with transmittal form AEC-426

**

Submitted for transmittal to reciplent under URAEA/USAEC and EURATOM/

USAEC Fast Breeder Reactor Information Exchange Arrangements 
RDT Site Office

U. S. Atomic Energy Commission Argonne National Laboratory Bullding 2

Argonne, Illinols 60439

RDT Site Office

U. S. Atomic Energy Commission Argonne National Laboratory

P. 0. Box 2108

Idaho Falls, Idaho 83401

RDT Site office

U. S. Atomic Energy Commission Atomics International

P. 0. Box 1446

Canoga Park, California 91304

RDT Site office

U. S. Atomic Energy Commission

General Electric Company

310 DeGuigne Drive

Sunnyvale, California 94086

RDT Site Office

U. S. Atomic Energy Commission

Gulf - General Atomic

P. 0. Box 2325

San Diego, California 92112

RDT Site Office

U. S. Atomic Energy Commission Oak Ridge National Laboratory

P. 0. Box X

Oak Ridge, Tennessee 37830

RDT Site office

U. S. Atomic Energy Commission

Pacific Northwest Laboratory

P. O. Box 550

Richland, Washington 99352

RDT Site office

U. S. Atomic Energy Commission

Westinghouse Electric Corporation (2)

Advanced Reactors Division

P. 0. Box 154

Madison, Pennsylvania 15663 


\section{LABORATORIES}

Director, LMFBR Program Office (2)

Argonne National Laboratory

9700 South Cass Avenue

Argonne, Illinots 60439

Director, Metaliurgy Division (2)

Argonne National Laboratory

9700 South Cass Avenue

Argonne, Illinots 60439

Manager, FFTF Project (2)

Pacif1c Northwest Laboratory

P. O. Box 999

Richland, Washington 99352

FFTF Fuels Department (2)

Pacific Northwest Laboratory

P. O. Box 999

Richland, Washington 99352

Manager, Chemistry and Metallurgy Division

Pacific Northwest Laboratory

P. O. Box 999

Richland, Washington 99352

Division Leader, Chemistry and Metallurgy Division (CMB)

Los Alamos Scientific Laboratory

P. O. Box 1663

Los Alamos, New Mexico 87544

Director, Metallurgy and Materials Sclence Division

Brookhaven National Laboratory

Upton, New York 11973

Director, Metals and Ceramics Division (2)

Oak Ridge National Laboratory

P. 0. Box X

Oak Ridge, Tennessee 37830

Division Chief, $M \& S$ Division

NASA - Lewis Research Center

21000 Brookpark Road

Cleveland, Ohio 44135

Director

Liquid Metal Engineering Center

P. O. Box 1449

Canoga Park, Calıfornia 91304 
Division Leader, Inorganic Materials

Chemistry Department

Lawrence Radiation Laboratory

P. O. Box 808

Livermore, California 94551

Manager, Advanced Development Activity

General Electric Company

Knolls Atomic Power Laboratory

P. 0. Box 1072

Schenectady, New York 12301

General Manager, Westinghouse Electric Corporation

Bettis Atomic Power Laboratory

P. 0. Box 79

West Mifflin, Pennsylvania 15122

\section{CONTRACTORS}

Director, LMFBR Technology Program

Atomics International

P. O. Box 1449

Canoga Park, California 91304

Associate Manager, Materials Engineering Department

Battelle Memorial Institute

Columbus Laboratories

505 King Avenue

Columbus, Ohio 43201

Director, Nuclear Development Center

The Babcock and Wilcox Company

Atomic Energy Division

Lynchburg, Virginia 24501

Manager, Nuclear Laboratories

Combustion Engineering, Inc.

Nuclear Division

Prospect Hill Road

Windsor, Connecticut 06095

Laboratory Assistant Director

Gulf-General Atomic

P. 0. Box 608

San Diego, California 92112

Manager, Plutonium Chemistry and Ceramics Fuels Development P1utonium Laboratory

Nuclear Materials and Equipment Corporation

Leechburg, Pennsylvania 15656 


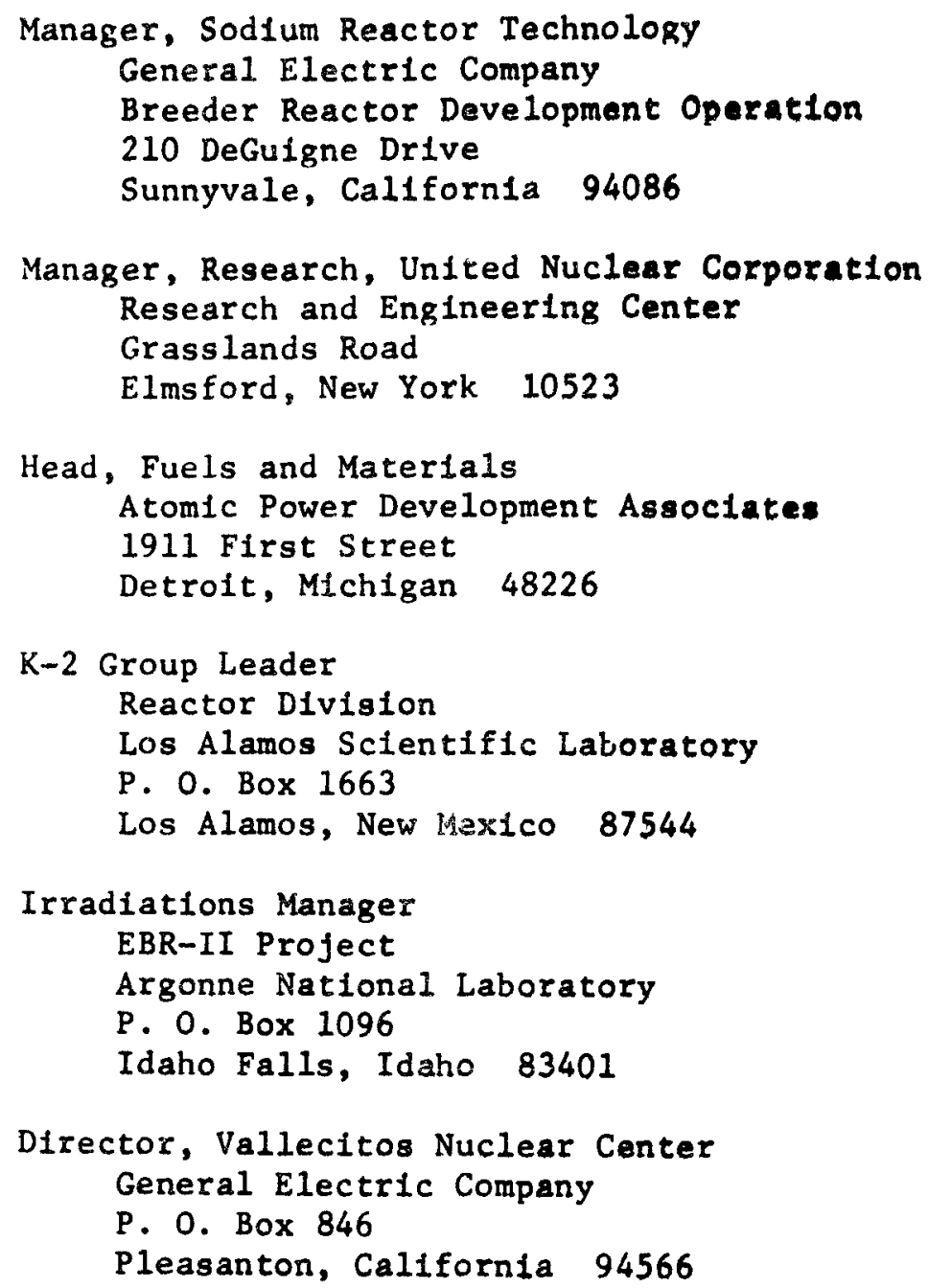

